University of Louisville

ThinkIR: The University of Louisville's Institutional Repository

Electronic Theses and Dissertations

8-2013

\title{
Mitigation of bicycle-motor vehicle conflicts research at intersections in Louisville, Kentucky.
}

Ying Zhang 1980-

University of Louisville

Follow this and additional works at: https://ir.library.louisville.edu/etd

\section{Recommended Citation}

Zhang, Ying 1980-, "Mitigation of bicycle-motor vehicle conflicts research at intersections in Louisville, Kentucky." (2013). Electronic Theses and Dissertations. Paper 1641.

https://doi.org/10.18297/etd/1641

This Doctoral Dissertation is brought to you for free and open access by ThinkIR: The University of Louisville's Institutional Repository. It has been accepted for inclusion in Electronic Theses and Dissertations by an authorized administrator of ThinkIR: The University of Louisville's Institutional Repository. This title appears here courtesy of the author, who has retained all other copyrights. For more information, please contact thinkir@louisville.edu. 


\title{
MITIGATION OF BICYCLE-MOTOR VEHICLE CONFLICTS RESEARCH AT INTERSECTIONS IN LOUISVILLE, KENTUCKY
}

\author{
By \\ Ying Zhang \\ B.A., Beijing Jiaotong University, 2003 \\ M.S., Research Institute of Highway, 2007

\begin{abstract}
A Dissertation
Submitted to the Faculty of the

Speed School of Engineering of the University of Louisville

In Partial Fulfillment of the Requirements for the Degree of
\end{abstract}

Doctor of Philosophy

Department of Civil \& Environmental Engineering

University of Louisville

Louisville, Kentucky

August 2013 
Copyright 2013 by Ying Zhang

All rights reserved 



\title{
MITIGATION OF BICYCLE-MOTOR VEHICLE CONFLICTS RESEARCH AT INTERSECTIONS IN LOUISVILLE, KENTUCKY
}

\author{
By \\ Ying Zhang \\ B.A., Beijing Jiaotong University, 2003 \\ M.S., Research Institute of Highway, 2007
}

A Dissertation Approved on

July 08,2013

By the following Dissertation Committee

\begin{tabular}{c}
\hline $\begin{array}{c}\text { Roswell A. Harris } \\
\text { Dissertation Director }\end{array}$ \\
\hline Mark French \\
\hline Tom Rockaway \\
\hline Zhihui Sun \\
\hline Christopher M. Richards
\end{tabular}




\section{DEDICATION}

This dissertation is dedicated to my parents and family

Mr. Jinsheng Zhang and Mrs. Lihua Zhao

$\&$

Mei Cao and Emma Zhang

who have been my constant sources of inspiration. They have given me the drive and discipline to tackle any task with enthusiasm and determination. Without their love and support this dissertation would not have been made possible. 


\section{ACKNOWLEDGEMENTS}

First and foremost, my utmost gratitude goes to my academic advisor Dr.

Roswell A. Harris whose sincerity and encouragement I will never forget. Dr. Harris has been my inspiration as I hurdle all the obstacles in the completion of this research work.

In addition, I would like to express my deepest appreciation to Mr. Dirk Gowin, Executive Administrator of Bike Louisville office in the Louisville Metro Department of Public Works \& Assets, for his academic guidance and kindness throughout my research work. I would also like to thank Dr. Mark French, Dr. Rockaway, T. D and Dr. Zhihui Sun for their guidance and support in my academic study and research. I would like to give my special thanks to Dr. J.P. Mohsen, and the Department of Civil \& Environmental Engineering at the University of Louisville, for their financial and academic support. I also want to give my sincere thanks to people who helped me during my studying at the University of Louisville and writing my dissertation.

Finally, I would like to give my deepest thanks to my parents, my brother and his family for their infinite support. I am further appreciative of my wife, Mei Cao and my daughter, Emma Zhang. Without all their unlimited patience, support and understanding, this dissertation would not have been finished successfully. 


\section{ABSTRACT \\ MITIGATION OF BICYCLE-MOTOR VEHICLE CONFLICTS RESEARCH AT INTERSECTIONS IN LOUISVILLE, KENTUCKY}

Ying Zhang

July 08,2013

The main purpose of this research was to find out the characteristics of bicycle-related crashes and improve safety and comfort for bicyclists around signalized intersections in Louisville, KY. At first, the benefits of bicycling for accessibility, health, environment and traffic were discussed. Plans made by a number of states, regions and local governments for encouraging people to use bicycles as an alternative to motor-vehicles were introduced. Emphases were put on the introduction of the Louisville Metro Bike Master Plan, which aimed to increase bicycling activity throughout all parts of Louisville by making it a fun, comfortable and accessible mode of travel, and to simultaneously reduce the number of cyclists killed and injured in crashes with motor vehicles.

Second, an elaborative literature interview was made to look for the reasons which caused crashes between bicyclists and drivers. The conclusion was that a large percentage of bicyclists-related crashes happened at intersections. The 
most important reason for bicyclists-related crashes was drivers' failing to yield when they were entering turning movements.

Third, research for possible solutions which were used to improve safety for bicyclists was made. Studies which evaluated the effectiveness of those solutions were discussed.

Fourth, in order to determine the characteristics of bicyclists-related crashes in Louisville, crash data of 10 years (from 2003 to 2012) was collected from the Kentucky Collision Analysis for the Public. Bicycle-related crashes in Louisville were most prevalent in the summer months, on weekdays and in the afternoon peak period in clear weather conditions. Turning-right was one of three highest possible pre-crash maneuvers in all bicycle-related crashes in Louisville The most important factor causing bicyclists-related crashes was motorists' inattentiveness, or failing to yield the right-of-way to bicyclists. Bicyclists' inattentiveness or failing to yield the right-of-way was also important for bicyclists-related crashes.

Fifth, surveys were made four times to evaluate the effectiveness of a newlydeveloped countermeasure for bicyclists' safety. The conclusion was that this countermeasure for bicyclists' safety couldn't influence the distance from the curb where motor-vehicle crossed the stop bar. Most drivers preferred 4-6 feet away from the curb when they crossed the stop bar. This countermeasure for bicyclists' safety could attract about $40 \%$ of drivers to cross the boundary between the bicycle lane and the traffic lane and to enter the right-of-way of the bicycle lane. More than $50 \%$ of drivers needed $60-100$ feet to finish the process of entering the 
right-of-way of the bicycle lane from the adjacent traffic lane. In short this newlydeveloped countermeasure for bicyclists' safety could greatly improve bicyclists' safety at intersections by changing drivers' right-turning movements. At last, some possible improvements for this new countermeasure were discussed to better this countermeasure in the future. 
TABLE OF CONTENTS

PAGE

ACKNOWLEDGMENTS ................................................................................

ABSTRCT

LIST OF TABLES

LIST OF FIGURES ............................................................................................

CHAPTER

I.INTRODUCTION

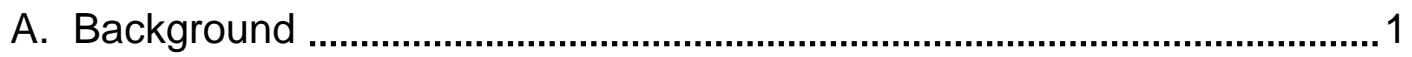

B. Dissertation Organization ..........................................................................12

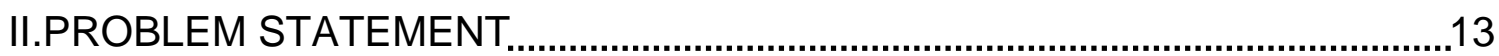

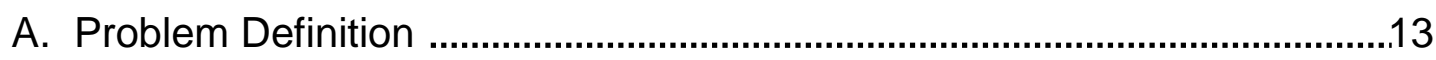

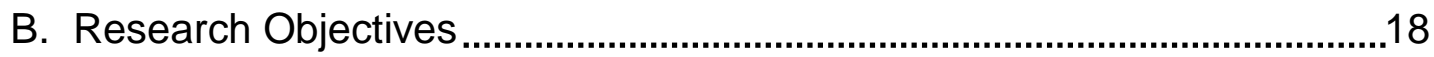

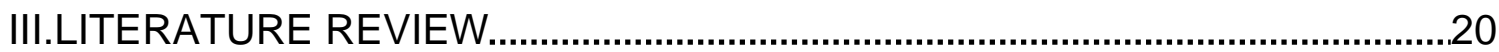

A. Reports and Studies from Federal Government ........................................20

B. Reports and Studies from U.S. State and Local Governments ................. 35

C. Studies of Bicycle-related Crashes ............................................................. 47

D. Kentucky Laws Related to Bicycle Operations ..........................................52

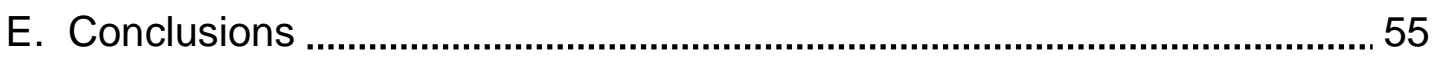




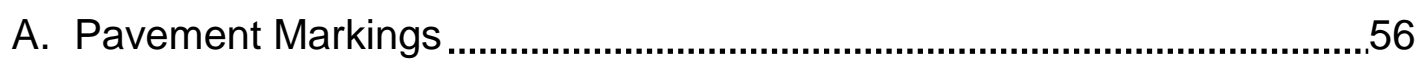

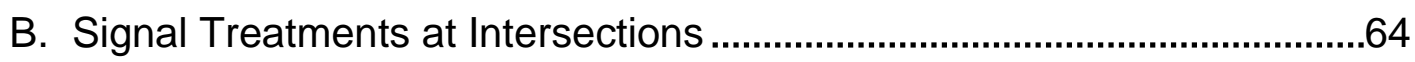

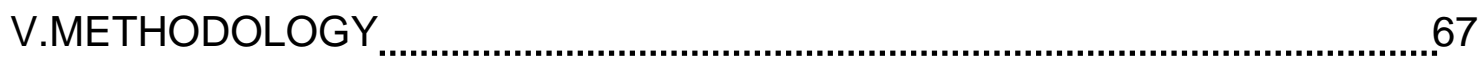

A. Methodology for Bicycle-related Crashes Data Analysis..........................67

B. Methodology for a New Kind of Countermeasure for Bicycle Safety at

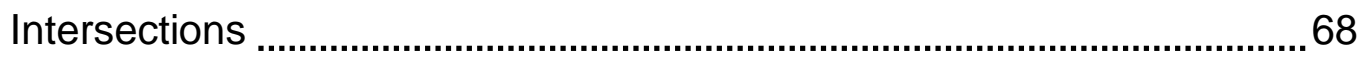

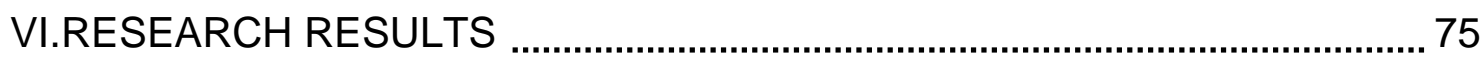

A. Research Results for Bicycle-related Crashes Data in Louisville, KY...... 75

B. Research Results for the Newly-Developed Countermeasure for Bicyclist

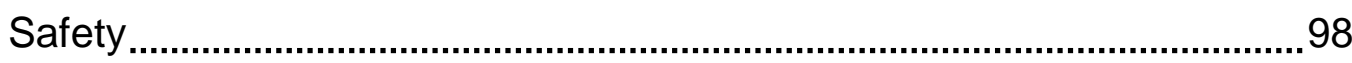

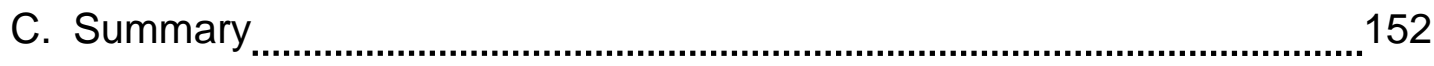

VII.CONCLUSTIONS AND RECOMMENDATIONS .......................................154

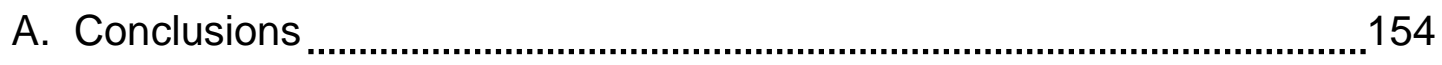

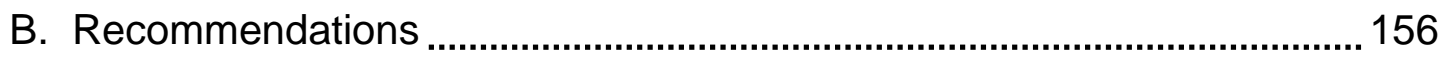

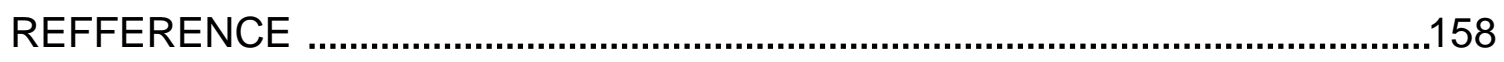

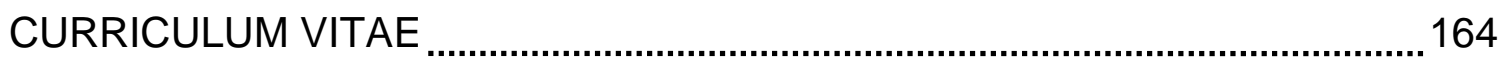




\section{LIST OF TABLES}

TABLE

PAGE

1. Total Fatalities and Bicyclists Fatalities in Traffic Crashes, 2001-2010..

2. Percentage of Bicyclist Fatalities in Relation to Land Use, Non-Motorist Location and Time of Day 22

3. Percentage of Bicyclist Fatalities by Age from 2001 to 2010 in U.S. 23

4. Federal Transportation Policy Chronology 25

5. Development of the Manual on Uniform Traffic Control Devices (MUTCD)....31

6. Bicycle-related Crashes Happened in Louisville from 2003 to 2012 by Year

7. Bicycle-related Crashes Happened in Louisville from 2003 to 2012 by Month

8. Bicycle-related Crashes Happened in Louisville from 2003 to 2012 by Day of Week 78

9. Bicycle-related Crashes Happened in Louisville from 2003 to 2012 by Time of Day 80 
10. Bicycle-related Crashes Happened in Louisville from 2003 to 2012 by Weather Type

11. Bicycle-related Crashes Happened in Louisville from 2003 to 2012 by Road Surface Condition 83

12. Bicycle-related Crashes Happened in Louisville from 2003 to 2012 by Motorvehicle Type 85

13. Bicycle-related Crashes Happened in Louisville from 2003 to 2012 by Bicyclists Age 87

14. Bicycle-related Crashes Happened in Louisville from 2003 to 2012 by Bicyclists' Condition 89

15. Bicycle-related Crashes Happened in Louisville from 2003 to 2012 by Drivers' Condition 91

16. Bicycle-related Crashes Happened in Louisville from 2003 to 2012 by Drivers' Pre-crash Maneuver 94

17. Bicycle-related Crashes Happened in Louisville from 2003 to 2012 by Manner of Crash 96

18. Survey Results for the First Survey-Distance from Curb. 102

19. Survey Results for the First Survey-Turning Position 105

20. Survey Results for the Second Survey-Distance from Curb 111 
21. Survey Result for the Second Survey-Crossing the Virtual Line Position

22. Survey Results for the Third Survey-Distance from Curb 119

23. Survey Result for the Third Survey-Crossing the Extension Line Position

24. Survey Results for the Fourth Survey-Distance from Curb 127

25. Survey Results for the Fourth Survey-Crossing the Trace Line Position ....129

26. Survey Results for the Fourth Survey-Turning Position 132

27. Survey Results for the Fourth Survey- Side Driving Distance. 134

28. Analysis of the Distance from Curb for the Four Surveys .137

29. Distribution Analysis of the Distance from Curb for the Four Surveys 138

30. Analysis of the Turning Position for the First and Four Surveys 141

31. Distribution Analysis of the Turning Position for the First and Four Surveys-

Percentages

32. Statistical Analysis of the Crossing the Line Position for the Second to the Four Surveys 144

33. Distribution Analysis of the Crossing the line Position for the Second to the

Four Surveys-Percentage

34. Distribution Analysis of the Crossing the line Position for the Second to the Four Surveys- Accumulation Percentage 146

35. Accumulation Percentage Analysis for the Side Driving Distance of the Fourth Survey 150 
36. Turing Position Analysis for the Side Driving Distance of the Fourth Survey 


\section{LIST OF FIGURES}

FIGURE

PAGE

1. Percent of Obsess in U.S. Adults ..............................................................

2. Time series For VMT/LD (1985-2007) and adult Obesity rate (1995-2007) with a six-year lag applied to the obesity rate trend …..........................................

3. Louisville Bike Master Plan-Current Bike Facilities ............................................11

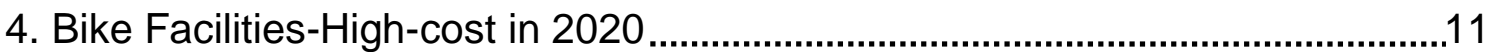

5. Conflict Points at a Typical Four-leg Signalized Intersection ...........................14

6. Pavement Markings for Bicycle Lanes on a Two-Way Street ............................16

7. Typical Bicycle and Motor Vehicle Movements at Intersections of Multilane Streets without Right-Turn-Only Lanes …....................................................17

8. AASHTO Guide for the Development of Bicycle Facilities ................................ 26

9. ASHTO Guide for the Development of Bicycle Facilities, $4^{\text {th }}$ Edition ..............22

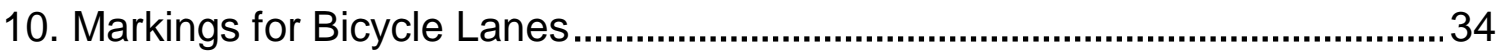

11. Bicycle-Related and Pedestrian-Related Roadway Crashes ........................36

12. Michigan Fatal and Serious Injury Bicycle Crashes by Driver Action.............40

13. Bicycle Crashes by Bicycle Action ................................................................ 41

14. Understanding Bicyclist-Motorist Crashes in Minneapolis, Minnesota ...........45

15. Colored Bicycle Lane Marking through Intersection ..........................................58

16. Colored Bicycle Crossings at Intersection Approach .......................................59 
17. Example of Bike Box Design Treatment

18. Intersection with New Designed Countermeasures for Bicyclist Safety ........69

19. Base Line for the New Designed Countermeasure Evaluation. .70

20. The Second Survey Environment for the Chosen Intersection with Marked

Point as a Virtual Line 71

21. The Third Survey Environment for the Chosen Intersection with a New Striped Line 72

22. The Fourth Survey Environment for the Chosen Intersection . .73

23. The Measurement of the Distance from Curb . .74

24. Bicycle-related Crashes Happened in Louisville from 2003 to 2012 by Month . .78

25. Bicycle-related Crashes Happened in Louisville from 2003 to 2012 by Day of Week 79

26. Bicycle-related Crashes Happened in Louisville from 2003 to 2012 by Time of Day 81

27. Bicycle-related Crashes Happened in Louisville from 2003 to 2012 by Weather Type 83

28. Bicycle-related Crashes Happened in Louisville from 2003 to 2012 by Road Surface Condition 84

29. Bicycle-related Crashes Happened in Louisville from 2003 to 2012 by Motorvehicle Type 86

30. Bicycle-related Crashes Happened in Louisville from 2003 to 2012 by Bicyclists Age 88 
31. Bicycle-related Crashes Happened in Louisville from 2003 to 2012 by Bicyclists' Condition .90

32. Bicycle-related Crashes Happened in Louisville from 2003 to 2012 by Drivers' Condition 93

33. Bicycle-related Crashes Happened in Louisville from 2003 to 2012 by Drivers' Pre-crash Maneuver 95

34. Bicycle-related Crashes Happened in Louisville from 2003 to 2012 by Manner of Crash. 97

35. Method for the First Survey of the Newly-Developed Countermeasure for Bicyclists Safety-Turning Position 100

36. Method for the First Survey of the Newly-Developed Countermeasure for Bicyclists Safety-Turning Position 101

37. Method for the First Survey of the Newly-Developed Countermeasure for Bicyclists Safety-Distance from Curb 101

38. Survey Results for the First Survey-Distance from Curb (feet) 104

39. Survey Results for the First Survey-Distance from Curb Accumulation Percentage 104

40. Survey Results for the First Survey-Turning Position (feet) 106

41. Survey Results for the First Survey-Turning Position Accumulation

Percentage 107

42. The Virtual Line of the Second Survey of the Newly-Developed

Countermeasure for Bicyclists Safety-Part 1 108

43. Virtual Line of the Second Survey of the Newly-Developed Countermeasure 
for Bicyclists Safety-Part 2 109

44. Marks for Distance from Curb for the Second Survey ................................ 109

45. An Example of a Motor-vehicle Crossing the Stop Bar................................110

46. Survey Results for the Second Survey-Distance from Curb (feet)..............112

47. Survey Results for the Second Survey-Distance from Curb Accumulation

Percentage

48. Survey Results for the Second Survey-Crossing the Virtual Line Position (feet)

49. Survey Result for the Second Survey-Crossing the Virtual Line Position Accumulation Percentage 115

50. The Extension Line of the Third Survey of the Newly-Developed Countermeasure for Bicyclist Safety-Part 1

51. The Extension Line of the Third Survey of the Newly-Developed

Countermeasure for Bicyclists Safety-Part 2

52. Marks for Distance from Curb for the Third Survey

53. Survey Results for the Third Survey-Distance from Curb (feet)

54. Survey Results for the Third Survey-Distance from Curb Accumulation

Percentage

55. Survey Results for the Third Survey-Crossing the Extension Line Position (feet) 123

56. Survey Result for the Third Survey-Crossing the Extension Line Position Accumulation Percentage 123

57. The Trace Line of the Fourth Survey of the Newly-Developed 
Countermeasure for Bicyclists Safety-Part 1

58. The Trace Line of the Fourth Survey of the Newly-Developed

Countermeasure for Bicyclists Safety-Part 2 125

59. Marks for Distance from Curb for the Fourth Survey ....................................126

60. Survey Results for the Fourth Survey-Distance from Curb (feet) 128

61. Survey Results for the Fourth Survey-Distance from Curb Accumulation

Percentage

62. Survey Results for the Fourth Survey-Crossing the Trace Line Position (feet)

63. Survey Result for the Fourth Survey-Crossing the Trace Line Position

Accumulation Percentage

64. Survey Results for the Fourth Survey-Turning Position (feet) 133

65. Survey Result for the Fourth Survey-Turning Position Accumulation

Percentage

66. Survey Results for the Fourth Survey- Side Driving Distance (feet). 136

67. Survey Result for the Fourth Survey- Side Driving Distance Accumulation

Percentage 136

68. Frequency Distribution Analysis of Distance from Curb for the Four Surveys

69. Distribution Analysis of the Turning Position for the First and Four Surveys 143

70. Distribution Analysis of the Crossing the line Position for the Second to the Four Surveys- Percentage 


\section{CHAPTER I}

\section{INTRODUCTION}

\section{A. Background}

\section{Benefits of Bicycling}

Bicycling is a low-cost and practical means of transportation that is pollutionfree, energy-efficient, versatile, healthy, and fun. Bicycling is a viable means of transportation that promotes vibrant communities and helps to improve individual health and fitness. Bicycling is a notable quality of life factor which brings many significant benefits for accessibility, health, environment and congestion. In recent years, many communities throughout the United States have been working to create a more friendly environment for bicyclists.

Accessibility- Bicycling is the most efficient and accessible form of transportation and recreation, requiring no fare, fuel, or license. For those who cannot use other modes of transportation, the ability to bicycle safely is essential. For young people, bicycling affords a sense of independence, and for seniors, bicycling is an effective means to stay active both physically and socially.

Health- Bicycling can greatly improve people's health. Overweight is defined 
as a body mass index (BMI) of 25.0 or greater and obesity is defined as a BMI of 30.0 or greater. Kentucky is the fourth most obese state in the country. Its obesity rate is 31.3 percent in 2010 (Centers for Disease Control and Prevention of U.S.A, 2010).

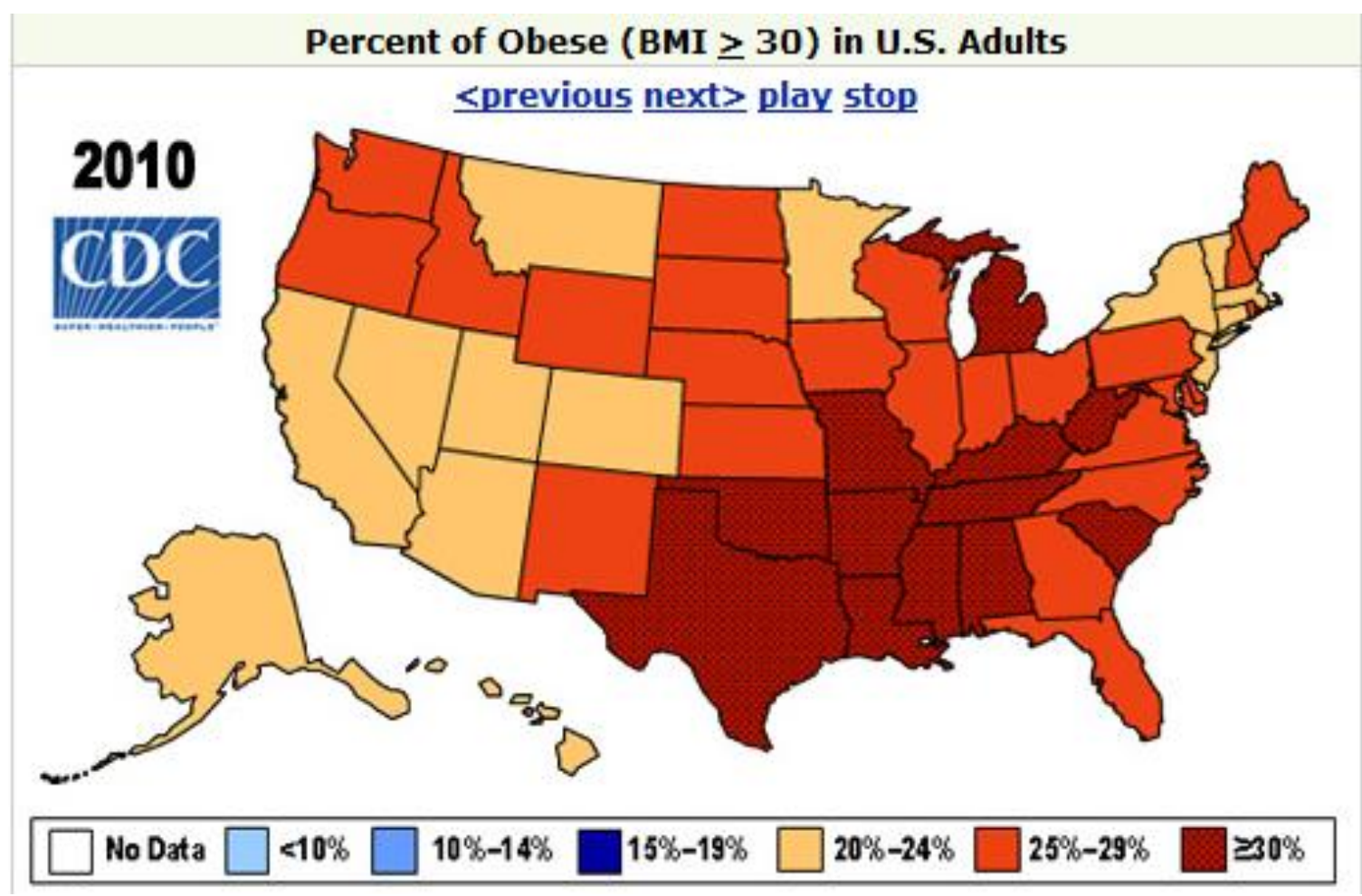

Figure 1. Obesity Rate in U.S. Adults (Centers for Disease Control and Prevention of U.S.A, 2010).

Obesity is currently costing Kentucky tax payers $\$ 1.1$ billion annually. Moreover, obesity spending in Kentucky makes up 6.2 percent of adult medical spending and 11.4 percent of Medicaid costs (Kentucky Department for Public Health, The Kentucky Obesity Epidemic, 2004). According to Dr. Jacobson, et al's research "A Note on the Relationship between Obesity and Driving", which 
was published on Transport Policy in 2011, increasing vehicle driving by one mile per day has been associated with a 2.16 percent increase in the adult obesity rate six years later. Figure 2 depicts the Vehicle Mile Traveled (VMT) divided by Licensed Drivers (LD) trend along with an obesity trend that has been lagged by six years.

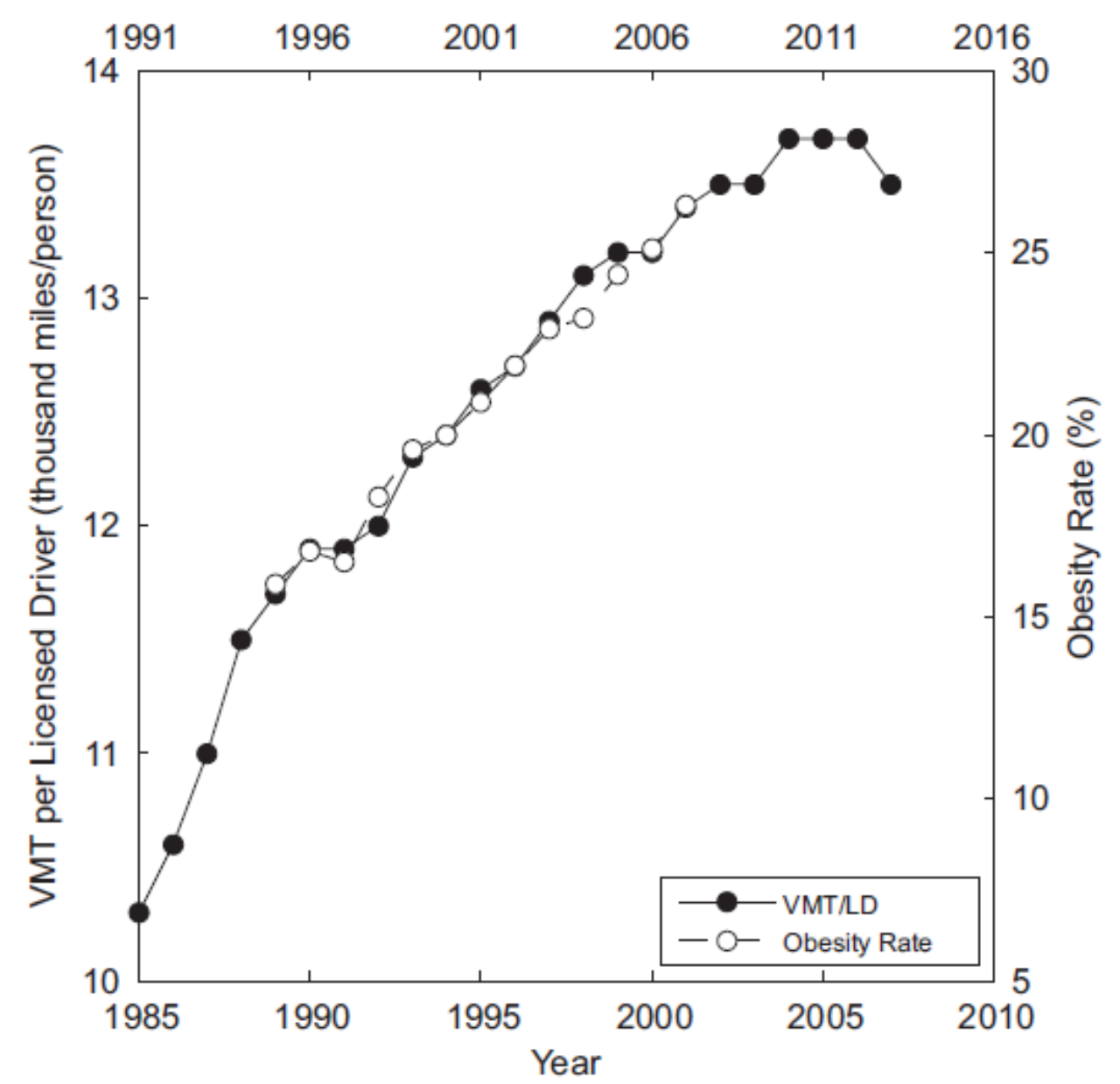

Figure 2: Time series for VMT/LD (1985-2007) and adult Obesity rate (1995-2007) with a six-year lag applied to the obesity rate trend (Jacobson, et al, "A Note on the Relationship between Obesity and Driving", Transport Policy, 2011) 
Obesity is a gateway disease which can lead to a number of different illnesses such as: diabetes, heart disease, liver disease, pulmonary problems and reproductive problems (Centers for Disease Control and Prevention, Obesity-Halting the Epidemic by making Health Easier at a Glance 2011). A common way to manage weight is through physical activity. Physical activity is defined by any body movement which results in energy expenditure. Examples other than sports include cycling, walking, yard work and climbing stairs. Walking 30-60 minutes a day at a moderate pace can help prevent health risks. Therefore, ensuring that adequate bicycling facilities are provided in Louisville, KY can help keep residents and visitors healthy.

Environment- Bicycling can help control air pollution and benefit people's health. According to the Environmental Protection Agency in "Transportation and Air Pollution", motor vehicles have been identified as the largest contributor to air pollution in the United States. The dangerous emissions made by automobiles include carbon monoxide, ground level ozone, PM10 and PM2.5, oxides of nitrogen and so on. There are several facts about air pollution in the United States coming from the Pedestrian and Bicycle Information Center, which are shown below:

a. Motor vehicle emissions represent 31 percent of total carbon dioxide, 81 percent of carbon monoxide, and 49 percent of nitrogen oxides released in the U.S.

b. 60 percent of the pollution created by automobile emissions happens in 
the first few minutes of operation, before pollution control devices can work effectively. Since "cold starts" create high levels of emissions, shorter car trips are more polluting on a per-mile basis than longer trips.

c. A short, four-mile round trip by bicycle keeps about 15 pounds of pollutants out of the air we breathe.

Emissions caused by motor vehicles can greatly influence people's health. Take ground level ozone as an example. According to a report from WHO ("Health Effects of Transport-related Air Pollution"), ground level ozone can cause coughing, breathing difficulties, aggravation of asthma and permanent lung damages. The problem of ground level ozone pollution in Louisville is also very serious. According to Louisville Metro Government, an ozone air quality alert was issued on Oct $6^{\text {th }}, 2012$, which was the $21^{\text {st }}$ air quality alert in 2012 . This alert warned that high ozone levels may make it hard for people who are young, elderly, and those with heart or lung problems. Compared to driving, bicycling doesn't burn any gas and brings no air pollution to the environment. So, it is totally green. Using a bicycle to replace driving can help control air pollution and benefit everyone in Louisville, especially for short trips.

Congestion-Converting motor vehicle trips into bicycling trips (or bicycling /transit trips) can reduce the use of the personal automobile and reduce congestion, while simultaneously improving climate and population health. For 
example, according to the 2000 U.S. Census, 11 percent of Louisville's residents walked or used public transportation to commute to work. According to the National Household Travel Survey, (2001) in the US, 41 percent of all trips made in 2001 were less than 2 miles and 28 percent were less than 1 mile. However, Americans used automobiles for about 74 percent of trips less than 2 miles and 66 percent of trips less than 1 mile. Even though most trips are less than 2 miles or 10-20 minutes, cycling still only makes up less than 1 percent of these trips. Bicycling requires significantly less space per traveler than driving. If more people use bicycles as alternatives to motor vehicles for their short distance trips, less congestion can be imagined.

\section{Bicycle Master Plan}

Because of those benefits brought by bicycling, a lot of states, regions and local governments have made plans to encourage people using bicycles as their alternatives for motor vehicles. According to the Pedestrian and Bicycle Information Center (U.S. Department of Transportation Federal Highway Administration, www.bicyclinginfo.org), there are such states, regions and local governments who have their bicycle development plans:

\section{Statewide Plans:}

a. Arizona Statewide Bicycle and Pedestrian Plan 
This is a guide for making pedestrian-related transportation decisions at the State and local level. The plan provides a long-term agenda for implementing a system of pedestrian facilities on the Arizona Department of Transportation (ADOT) State Highway System and seeks to coordinate the relationship between ADOT and smaller jurisdictions.

b. California Pedestrian and Bicycle Facilities: Technical Report

Caltrans's Technical Reference Report is intended to help accommodate pedestrian transportation throughout the State of California. It is intended as a resource for professionals, agency staff, and citizens.

c. Florida Bicycle Facilities Planning and Design Handbook

This is a detailed manual on bicycle facility planning and development, which covers planning factors, design detail and more. This handbook is intended as an aid to engineers, planners, architects, landscape architects, and citizens concerned with the planning and design of bicycle facilities.

\section{d. New Jersey Statewide Bicycle and Pedestrian Master Plan}

This plan presents a good example of how to use GIS analysis to prioritize the improvement of bicycle and pedestrian facilities around New Jersey. It used demand forecasting (showing pedestrian trips by census tract and roadway cross ability) and suitability forecasting (calculating the suitability of making capital investments) to identify and prioritize project locations. Summarized in a matrix 
form, the implementation section includes several strategies and assigns responsibility to various agencies and organizations.

e. North Carolina Bicycling and Walking: A Long Range Transportation Plan

Developed by the Office of Bicycle and Pedestrian Transportation of the North Carolina Department of Transportation (NCDOT), this bicycle and pedestrian plan builds upon the North Carolina long-range transportation plan, elaborating on the goals, focus areas, and programming specific to bicycling and walking.

\section{f. Oregon Bicycle and Pedestrian Plan}

A statewide planning and design guide for both bicycle and pedestrian modes; contains useful graphics and information about many innovative approaches to accommodating bicycling and walking.

\section{Regional Plans}

a. Anne Arundel County Maryland: Bicycle and Pedestrian Master Plan

b. Forsyth County Bicycle and Pedestrian Plan

c. Knoxville Regional Bicycle Plan

d. Madison/Dane County Bicycle Transportation Plan

e. Maricopa County Bicycle Transportation System Plan 
f. MTC Regional Bicycle Plan

g. Puget Sound Regional Bicycle and Pedestrian Implementation Strategy

\section{Local Plans}

a. Brunswick Bicycle and Pedestrian Improvements Plan

b. Bellevue, Washington Pedestrian and Bicycle Plan Update

c. Austin Bicycle Plan

d. Chapel Hill, North Carolina: Bicycle and Pedestrian Action Plan

e. Davis Bike Plan

f. Denver Bicycle Master Plan Update

g. Long Beach Bicycle Master Plan

h. Los Angeles Bicycle Plan

i. Marina Pedestrian and Bicycle Master Plan

j. New York City Bicycle Master Plan

k. Portland Bicycle Master Plan

I. Seattle Bicycle Master Plan

m. Bike 2015 Plan: The Pedestrian and Bicycle Plan for Chicago Area Transportation 


\section{Louisville Metro Bike Master Plan}

This research will focus on bicycle-related crashes that happened in Louisville from 2003 to 2012. Thus, the Louisville Metro Bike Master Plan will be introduced in detail. The Louisville Metro Bike Master Plan is a long-term action plan to help Louisville reclaim its heritage as a center for bicycling. The plan was based on the Bicycle Summit in February 2005 and the 2009 Bicycle Summit II (“Louisville Metro Bike Master Plan-Overview, 2010”). The Bicycle Summits outlined the policies, programs, design criteria, and projects that would further enhance bicycle safety, comfort, and access in all of Louisville's neighborhoods (“Louisville Metro Bike Master Plan-Overview, 2010”).

There are two goals in this plan: (1) To increase bicycling activity throughout all parts of Louisville by making it a fun, comfortable and accessible mode of travel between 2010 and 2030; (2) To simultaneously reduce the number of cyclists killed and injured in crashes with motor vehicles ("Louisville Metro Bike Master Plan-Chapter 1-Introduction, Goal, 2010"). Through the Louisville Metro Bike Master Plan, Louisville will expand the bicycle system to over 550 miles at a total cost of $\$ 50$ million or an average of $\$ 2.5$ million per year ("Louisville Metro Bike Master Plan-Chapter 3-Recommendations, 2010"). This action will make its transportation system more environmentally, economically, and socially sustainable. Figure 3 shows the current bike facilities of Louisville. Figure 4 shows possible future bike facilities if the Louisville Metro Bike Master Plan is 
finished.

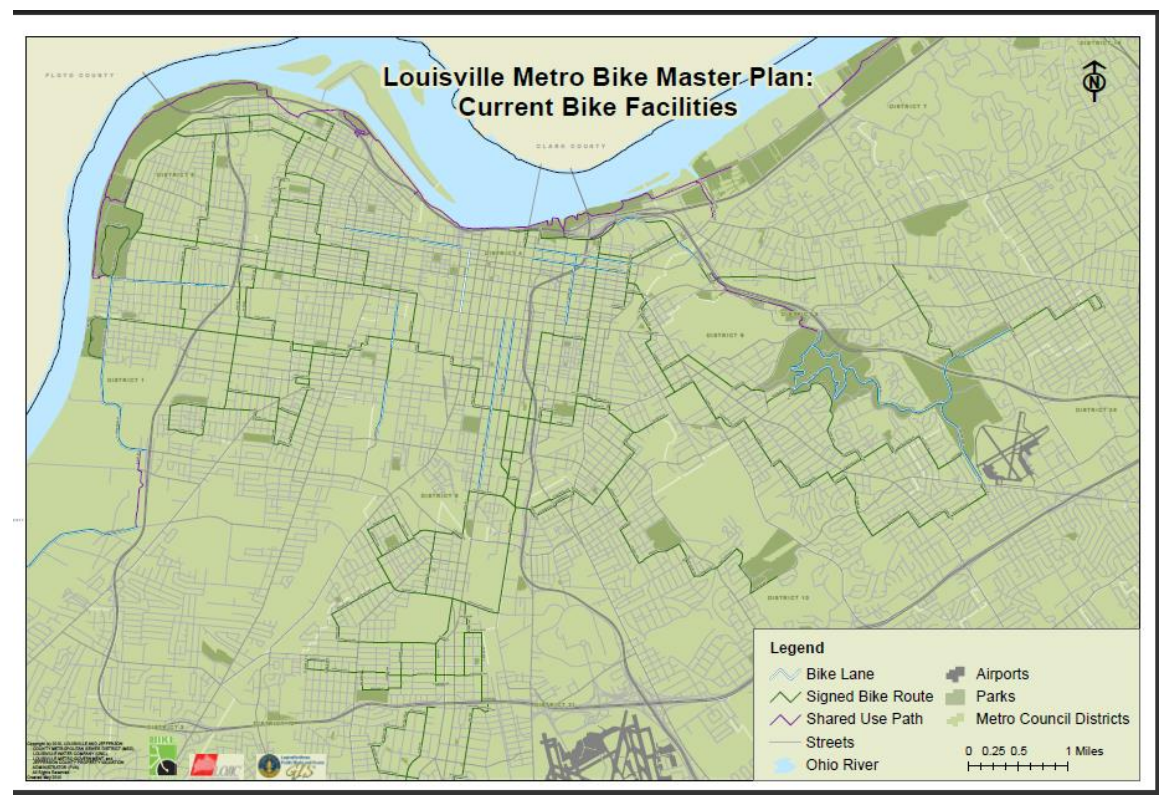

Figure 3: Louisville Bike Master Plan-Current Bike Facilities (Source: Louisville Metro Bike Master Plan, 2010)

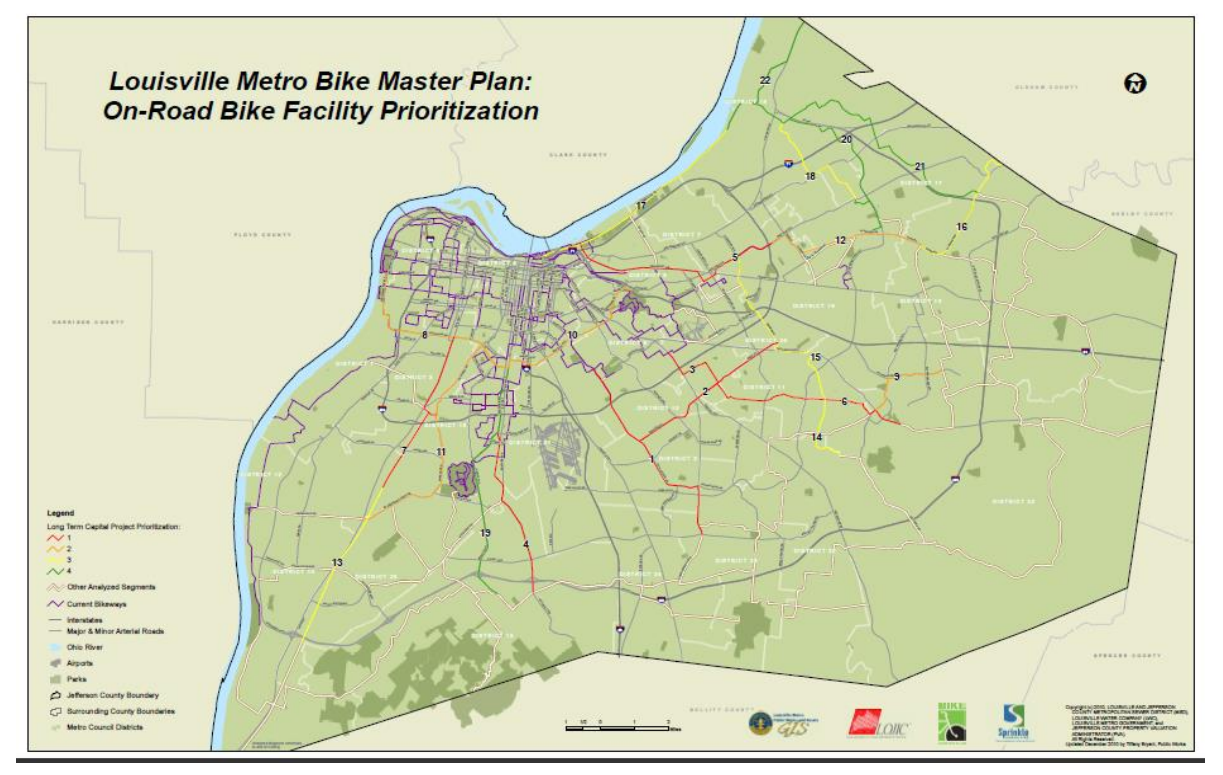

Figure 4: Bike Facilities-High-cost in 2020 (Source: Louisville Metro Bike Master

Plan, 2010) 


\section{B. Dissertation Organization}

Chapter I.INTRODUCTION

Chapter II.PROBLEM STATEMENT

Chapter III.LITERATURE REVIEW

Chapter IIII.POTENTIONAL SOLUTIONS

Chapter IV.METHODOLOGY

Chapter V.RESEARCH RESULTS

Chapter VI.CONCLUSTIONS AND RECOMMENDATIONS

REFFERENCE

APPENDIXES 


\section{CHAPTER II}

\section{PROBLEM STATEMENT}

\section{A. Problem Definition}

Conflicts between bicycles and motor vehicles around intersections in urban areas are serious problems, which can cause delay, injury, and even death. Traditionally, there are already many conflict points around intersections just for motor vehicles. The number of conflict points change depending on many factors, such as the type of intersections, the number of intersection legs, the number of traffic lanes, traffic rules, and so on. Figure 5 shows the number of motor vehicle conflict points of a typical four-leg intersection in urban areas, which can be divided into three categories: diverging, merging, and crossing. The sum of these conflicts points is 32 . 


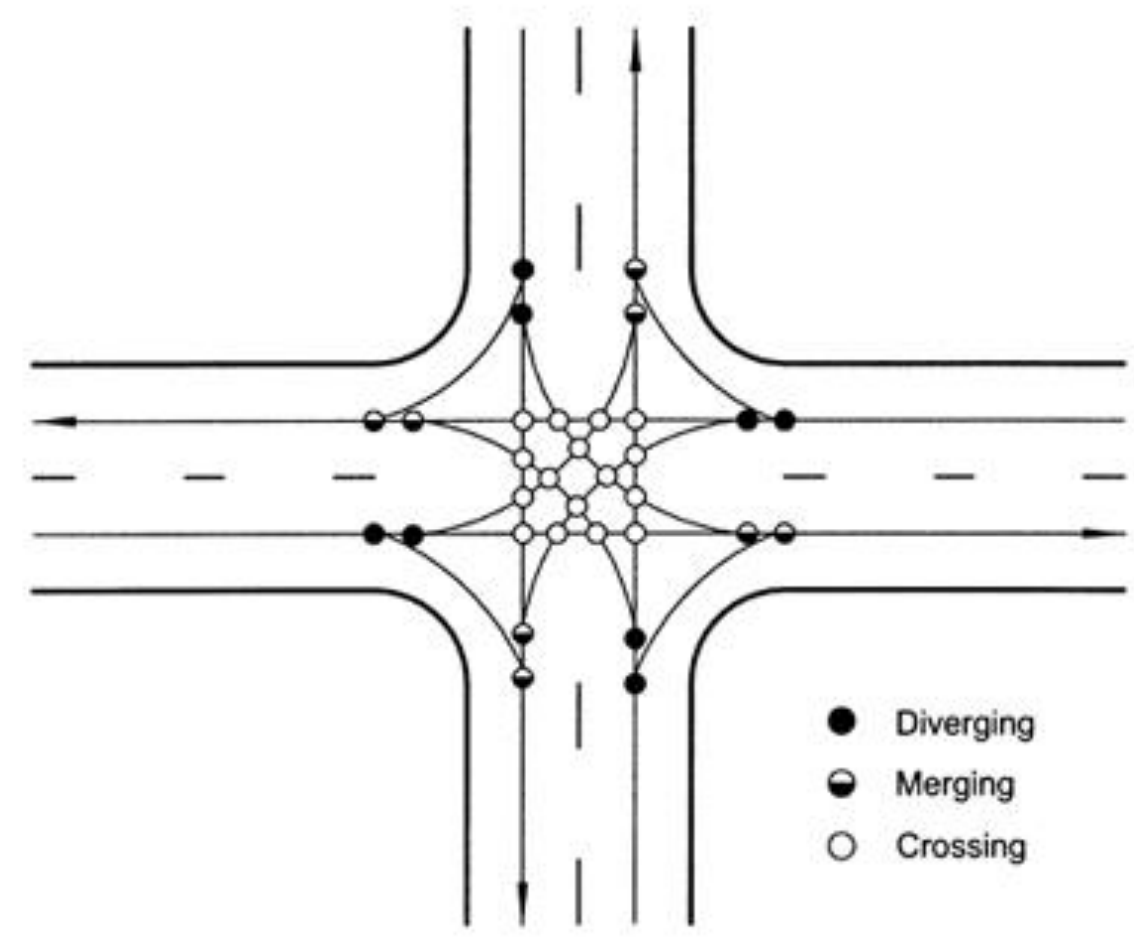

Figure 5: Conflict Points at a Typical Four-leg Signalized Intersection (Source: Signalized Intersections: Informational Guide, Page45, The Federal Highway Administration of U.S. Department of Transportation, August, 2004)

According to the Guide for the Development of Bicycle Facilities, published by the American Association of State Highway and Transportation Officials (AASHTO), there are four main on-road facilities for the use of bicyclists:

(1) Bicycle lane- A portion of a roadway which has been designated by striping, signing and pavement markings for the preferential or exclusive use of bicyclists. 
(2) Bicycle path (which is equal to shared use path) - A bikeway physically separated from motorized vehicular traffic by an open space or barrier and either within the highway right-of-way or within an independent right-ofway. Shared use paths may also be used by pedestrians, skaters, wheelchair users, joggers, and other non-motorized users.

(3) Bikeway- A generic term for any road, street, path or way which in some manner is specifically designated for bicycle travel, regardless of whether such facilities are designated for the exclusive use of bicycles or are to be shared with other transportation modes.

(4) Signed bike route- A shared roadway which has been designated by signing as a preferred route for bicycle use.

In May, 2012, the Federal Highway Administration (FHWA) of the U.S. Department of Transportation published the revised Manual on Uniform Traffic Control Devices (MUTCD). Figure 6 shows a typical signalized and nonsignalized intersection with bicycle lanes which are very common in the downtown area of Louisville, KY. 


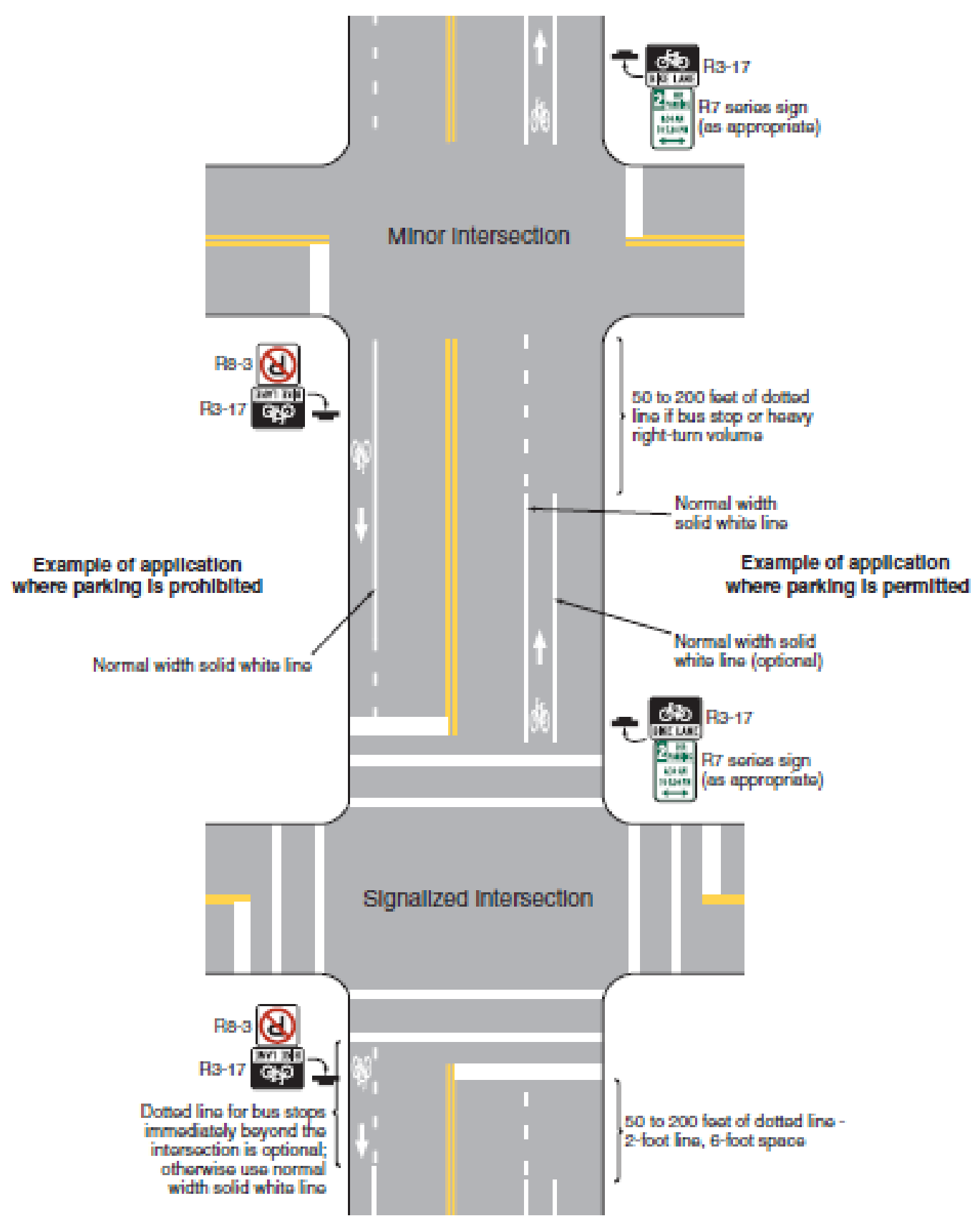

Figure 6: Pavement Markings for Bicycle Lanes on a Two-Way Street (Source: Uniform Traffic Control Devices 2009 Revisions (MUTCD)-Part 9 Traffic Control for Bicycle Facilities, Page 813, May, 2012) 


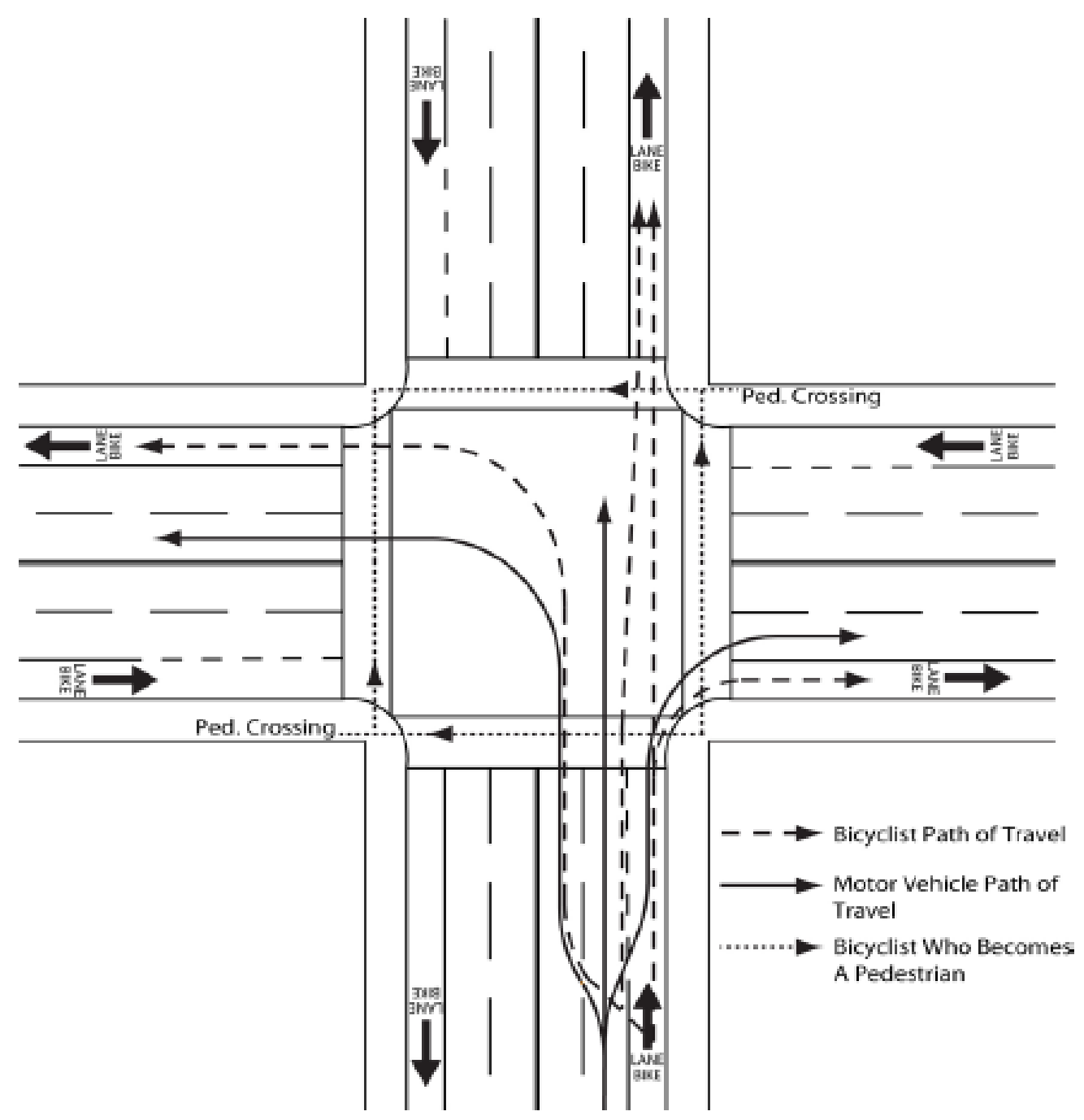

Figure 7: Typical Bicycle and Motor Vehicle Movements at Intersections of Multilane Streets without Right-Turn-Only Lanes (Source: ASSHTO, Highway Design Manual, May 7, 2012, 400-7)

Figure 7 illustrates a typical at-grade intersection of multilane streets without right-turn-only lanes. Bike lanes or shoulders are included on all approaches. Some common movements of motor vehicles and bicycles are shown. A prevalent crash type is between straight-through bicyclists and right-turning 
motorists, who do not yield to through bicyclists. When bicyclists are going through signalized intersections in bicycle lanes, they will face right-turn motor vehicles. Usually, drivers pay attention to their left to make sure they are safe to turn right and pay less attention to their right. There are already several methods to improve the conflicts between go-through bicyclists and right-turn motor vehicles. This research will analyze the bicycle-related crash data of Louisville, including the general characteristics of accident data, such as date, time and age distribution, road surface and weather condition. Efforts will focus on the bicycle and motor vehicle contribution factors and their maneuvers before crashes to find

out the reasons causing bicycle-related crashes. A totally new kind of countermeasure which is not included in the Manual on Uniform Traffic Control Devices will be evaluated. Behaviors of drivers and bicyclists where these new methods are used will be observed and analyzed.

\section{B. Research Objectives}

The goal of this research is to look for the characteristics of bicycle-related crashes and improve safety and comfort for bicyclists around signalized intersections in the downtown area of Louisville, KY.

The main objectives include:

(1) To find out the characteristics of bicycle-related crashes. 
(2) To understand the reasons which cause crashes between bicycles and motor vehicles at signalized intersections.

(3) To reduce conflicts between bicycles and motor vehicles at signalized intersections.

(4) To observe and analyze the behaviors of drivers when they turn right with bicycle lanes on their right.

(5) To evaluate the effectiveness of a newly-developed countermeasure, which can improve the drivers' awareness of bicyclists on their right.

(6) To improve safety for bicyclists. 


\section{CHAPTER III}

\section{LITERATURE REVIEW}

\section{A. Reports and Studies from Federal Government}

\section{Traffic Safety Facts 2010 by National Highway Traffic Safety Administration, U.S.}

Conflicts between bicycles and motor vehicles in urban areas are serious problems with a long history. According to the Traffic Safety Facts published by National Highway Traffic Safety Administration in 2012, the first automobile crash in the United States occurred in New York City in 1896, when a motor vehicle collided with a bicycle rider. About 53,000 bicyclists have died in traffic crashes in the United States since 1932. In 2010, 618 lives were lost in bicycle/motor vehicle crashes in the U.S. and over 52,000 injured, which is shown in Table 1. Bicycle deaths accounted for 2 percent of all motor vehicle traffic fatalities, and made up 2 percent of all the people injured in traffic crashes during the year. There are several other facts in the Traffic Safety Facts 2010, which are very important for this research and shown below: 


\section{Table1}

Total Fatalities and Bicyclists Fatalities in Traffic Crashes, 2001-2010

\begin{tabular}{|c|c|c|c|}
\hline Year & Total Fatalities & Fatalities & Fatalities \\
\hline 2001 & 42,196 & 732 & $1.7 \%$ \\
\hline 2002 & 43,005 & 665 & $1.5 \%$ \\
\hline 2003 & 42,884 & 629 & $1.5 \%$ \\
\hline 2004 & 42,836 & 727 & $1.7 \%$ \\
\hline 2005 & 43,510 & 786 & $1.8 \%$ \\
\hline 2006 & 42,708 & 772 & $1.8 \%$ \\
\hline 2007 & 41,259 & 701 & $1.7 \%$ \\
\hline 2008 & 37,423 & 718 & $1.9 \%$ \\
\hline 2009 & 33,883 & 628 & $1.9 \%$ \\
\hline 2010 & 32,885 & 618 & $1.9 \%$ \\
\hline
\end{tabular}

(Source: Traffic Safety Facts, National Highway Traffic Safety Administration, Department of Transportation, U.S., June 2012, DOT HS 811,624).

\section{(1) Time and Position}

As shown in Table 2, Bicyclists fatalities in 2010 occurred more frequently in urban areas (69 percent), at non-intersection locations (67 percent) in the U.S. The majority of bicyclist fatalities, 174 (28 percent), occurred between the hours of 4 p.m. and 7:59 p.m. The second highest number of fatalities, 152 (25 percent), 
occurred between the hours of 8 p.m. and 11:59 p.m. The fewest bicyclist fatalities occurred between the hours of midnight and 3:59 a.m.

\section{Table2}

Percentage of Bicyclist Fatalities in Relation to Land Use, Non-Motorist Location and Time of Day

\begin{tabular}{|c|c|c|}
\hline Bicyclists Killed & $\mathbf{2 0 0 9}$ & $\mathbf{2 0 1 0}$ \\
\hline Rural & $30 \%$ & $28 \%$ \\
\hline Urban & $70 \%$ & $72 \%$ \\
\hline Intersection & $33 \%$ & $33 \%$ \\
\hline Non-Intersection & $67 \%$ & $67 \%$ \\
\hline Midnight-3:59 a.m. & $8 \%$ & $7 \%$ \\
\hline 4 a.m.-7:59 a.m. & $12 \%$ & $11 \%$ \\
\hline 8 a.m.-11:59 a.m. & $14 \%$ & $17 \%$ \\
\hline Noon-3:59 p.m. & $17 \%$ & $28 \%$ \\
\hline 4 p.m.-7:59 p.m. & $29 \%$ & $25 \%$ \\
\hline 8 p.m.-11:59 p.m. & $19 \%$ & \\
\hline
\end{tabular}

(Source: Traffic Safety Facts, National Highway Traffic Safety Administration, Department of Transportation, U.S., June 2012, DOT HS 811,624).

\section{(2) Age}

In 2010, the average age of bicyclists killed in traffic crashes was 42. During 
the past 10 years, there has been a steady increase in the average age of both bicyclists killed and injured (Table 3). Bicyclists under age 16 accounted for 11 percent of all bicyclists killed and 21 percent of all those injured in traffic crashes in 2010. By comparison, bicyclists under age 16 accounted for 21 percent of all those killed and 38 percent of those injured in 2001. Bicyclists ages 25 to 64 have made up an increasing proportion of all bicyclists deaths since 2001. The proportion of bicyclist fatalities among those ages 25 to 63 was 16 percent higher in 2010 as in 2001 ( 65 percent and 56 percent respectively).

\section{Table 3}

Bicyclist Fatalities by Age from 2001 to 2010 in U.S

\begin{tabular}{|c|c|c|}
\hline Year & Bicyclists Killed Average Age & Bicyclists Injured Average Age \\
\hline 2001 & 36 & 26 \\
\hline 2002 & 36 & 28 \\
\hline 2003 & 36 & 29 \\
\hline 2004 & 39 & 29 \\
\hline 2005 & 39 & 30 \\
\hline 2006 & 41 & 30 \\
\hline 2007 & 40 & 31 \\
\hline 2008 & 41 & 31 \\
\hline 2009 & 41 & 31 \\
\hline 2010 & 42 & \\
\hline
\end{tabular}




\begin{tabular}{|l|c|c|}
\hline Average & 39 & 29 \\
\hline
\end{tabular}

(Source: Traffic Safety Facts, National Highway Traffic Safety Administration, Department of Transportation, U.S., June 2012, DOT HS 811,624).

(3) Gender

Most of the Bicyclists killed or injured in 2008 were males (87 percent and 79 percent, respectively), and most were between the ages of 5 and 44 (48 percent and 77 percent, respectively). In 2008, the bicyclist fatality rate per capita was eight times higher for males than for females, and the injury rate per capita was more than four times higher for males.

\section{Guide to Promoting Bicycling on Federal Lands}

In 1990, the FHWA Administrator described bicycling and walking as "the forgotten modes" of transportation (Federal Highway Administration, U.S. Department of Transportation, GUIDE TO PROMOTING BICYCLINGON FEDERAL LANDS, FHWA-CFL/TD-08-007, 09, 2008). Since then, federal support for bicycling as an alternative to automobile travel has steadily increased. The following chronology shows continuing support for bicycling facilities and programs through three Federal transportation bills: the Intermodal Surface Transportation Efficiency Act (ISTEA), the Transportation Equity Act for the 21st Century (TEA-21) and the Safe, Accountable, Flexible and Efficient Transportation Equity Act: A Legacy for Users (SAFETEA-LU) (Federal Highway 
Administration, U.S. Department of Transportation, GUIDE TO PROMOTING BICYCLINGON FEDERAL LANDS, FHWA-CFL/TD-08-007, 09, 2008).

\section{Table 4}

Federal Transportation Policy Chronology

\begin{tabular}{|c|c|}
\hline Year & Event \\
\hline 1973 & Federal Aid Highway funds first used for bicycle facilities \\
\hline 1990 & $\begin{array}{l}\text { USDOT policy created to mainstream bicycling into transportation } \\
\text { network }\end{array}$ \\
\hline 1991 & ISTEA greatly increases funding for bicycle facilities and programs \\
\hline 1994 & $\begin{array}{l}\text { National Bicycling and Walking Study sets goals to increase bicycle } \\
\text { travel }\end{array}$ \\
\hline 1998 & TEA 21 increases bicycle facility and program funding \\
\hline 2005 & SAFETEA-LU significantly expands support for bicycling programs \\
\hline
\end{tabular}

(Federal Highway Administration, U.S. Department of Transportation, GUIDE TO

PROMOTING BICYCLINGON FEDERAL LANDS, FHWA-CFL/TD-08-007, September, 2008).

In 1997, a key Memorandum of Understanding (MOU) between the Department of the Interior (DOI) and the USDOT established joint actions to promote alternative transportation in national parks. This MOU called for integrating transportation planning into normal NPS activities, including bicycle 
and pedestrian safety initiatives. In 1998, a comprehensive study of alternative transportation needs in national parks and public lands was initiated by Congress as part of Section 3039 of TEA-21.

In the Guide to Promoting Bicycling on Federal Lands, published by the Federal Highway Administration, U.S. Department of Transportation (USDOT) in September 2008, the USDOT adopted a new national transportation policy that sought to mainstream bicycling and pedestrian needs into the transportation system (Federal Highway Administration, U.S. Department of Transportation, GUIDE TO PROMOTING BICYCLINGON FEDERAL LANDS, FHWA-CFL/TD08-007, September 2008). Nationwide goals were set as:

- Double the percentage of total trips made by bicycling and walking in the United States from 7.9 percent to 15.8 percent of all travel trips; and

- Simultaneously reduce by 10 percent the number of bicyclists and pedestrians killed or injured in traffic crashes.

The Guide to Promoting Bicycling on Federal Lands provides guidance to Federal land managers on how to promote bicycling. Bicycling facilities are important transportation and recreation links to connect gateway communities, visitor centers, campgrounds, trailheads, and other attractions on Federal lands. The Guide to Promoting Bicycling on Federal Lands presents benefits of bicycling, successful bicycling programs, policies that support bicycling, issues and challenges faced by land managers, and useful resources available to help 
meet these challenges. Bicycle transportation networks have significant positive impacts for the environment, health and visitor experience on Federal lands. Federal land managers have the opportunity to serve as positive national role models by mainstreaming bicycling to create sustainable transportation networks.

This guide explores bicycling issues on lands managed by these agencies and offers ideas for designing appropriate and sustainable programs to promote the use of bicycles in these public places (Federal Highway Administration, U.S. Department of Transportation, Guide to Promoting Bicycling on Federal Lands, FHWA-CFL/TD-08-007, September 2008). This guide can be seen as:

- A tool to raise awareness of the benefits of active transportation and the nationwide movement to incorporate bicyclists and pedestrians into our transportation network.

- A compendium of selected bike-friendly projects and programs on Federal lands; the first comprehensive study of bicycling policies and issues on Federal lands.

- A reference for bike-friendly resources to assist in the planning and design, promotion and management of bicycle transportation programs.

- A discussion of the challenges of changing the way people move around in an automobile-dominated culture.

- A challenge to Federal land managers to shift priorities and reallocate transportation resources to promote one of the oldest and simplest forms of transportation. 


\section{Guide for the Development of Bicycle Facilities}

The AASHTO Guide for the Development of Bicycle Facilities is a key resource for transportation professionals in designing, building, modernizing, and preserving safe and efficient bicycle facilities.

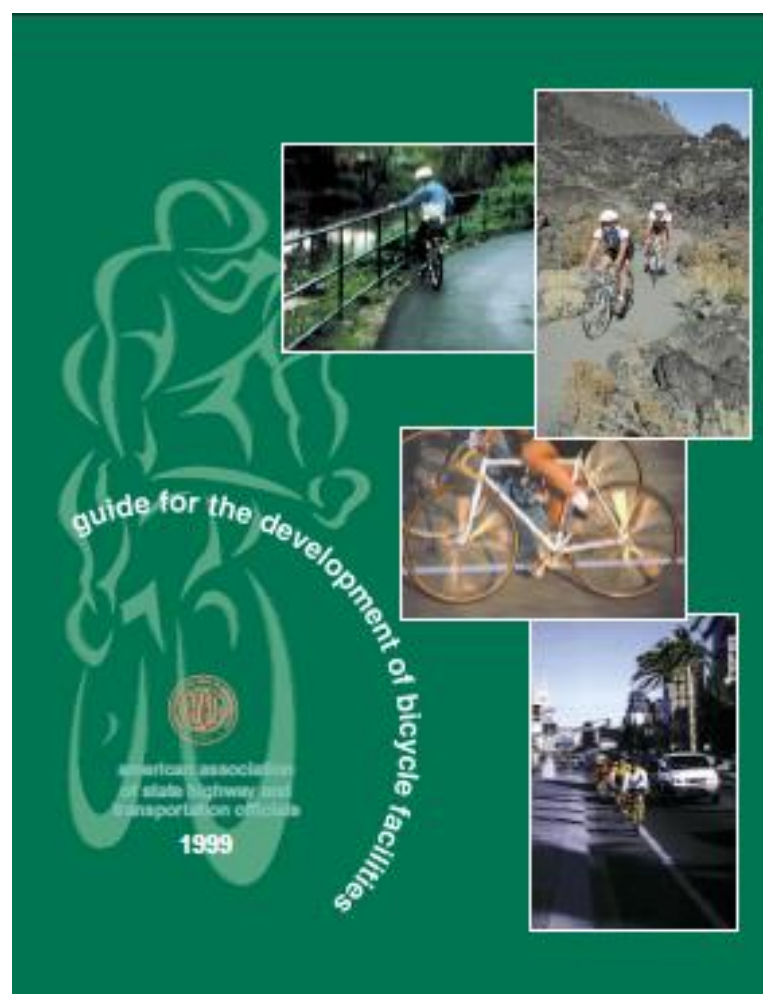

Figure 8: AASHTO Guide for the Development of Bicycle Facilities (Source: American Association of State Highway Transportation Officials (AASHTO), www.aashto.org, 1999)

AASHTO released the updated Guide for the Development of Bicycle Facilities 4th edition in 2012. The updated version was greatly expanded from the 1999 release. The planning and design sections included much more information. 
The design section had been split into two sections in the new version, "Design of On-Road Facilities" and "Design of Shared Use Paths". Added to the new version are sections on "bicycle operation and safety" and "Maintenance and operations". The "Bicycle Operation and Safety" section was a significant addition to the new version. It highlighted contributing causes of bicycle related crashes and offers recommended countermeasures.

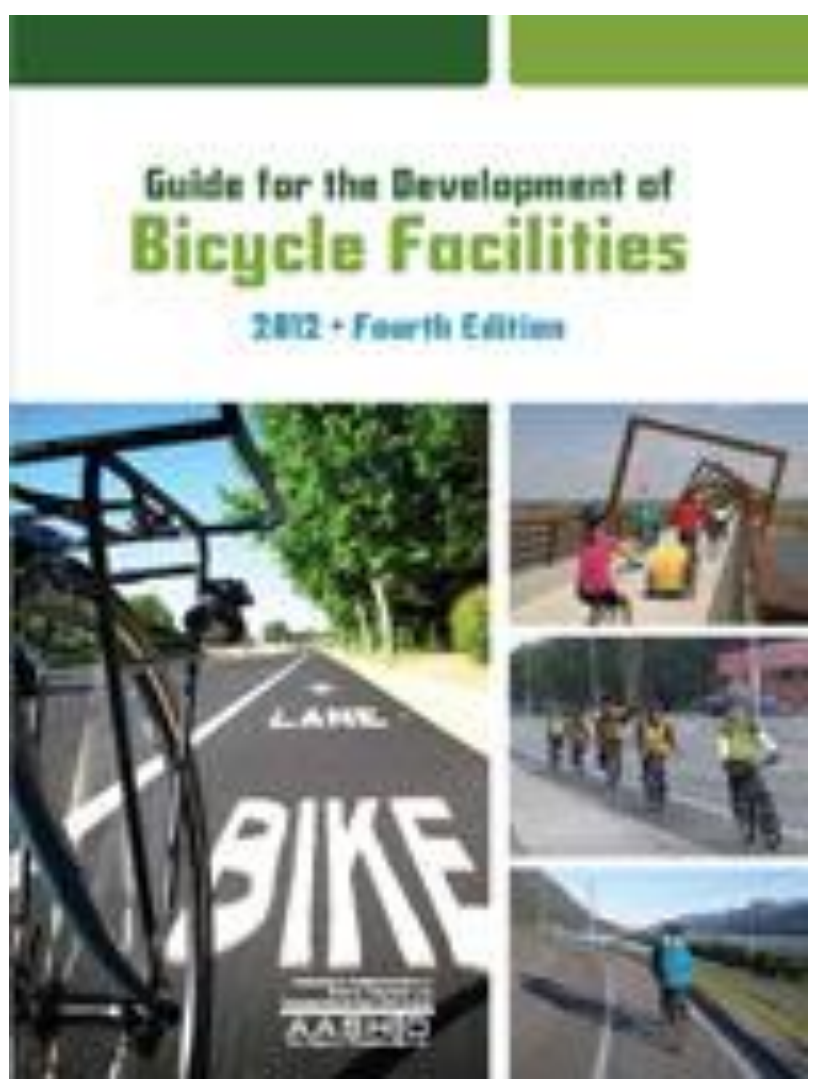

Figure 9: AASHTO Guide for the Development of Bicycle Facilities, $4^{\text {th }}$ Edition (Source: American Association of State Highway Transportation Officials, www.aashto.org, 2012) 


\section{The Manual on Uniform Traffic Control Devices (MUTCD), 2009 Edition}

Anyone who wants to become a traffic engineer professional must not ignore the Manual on Uniform Traffic Control Devices (MUTCD), 2009 Edition, published by AASHTO. In this manual, it says:

The traffic control devices (TCD) are very critical for the safe and efficient transportation of people and goods. The MUTCD, by setting minimum standards and providing guidance, ensures uniformity of traffic control devices across the nation. The use of uniform TCDs (messages, location, size, shapes, and colors) helps reduce crashes and congestion, and improves the efficiency of the surface transportation system. Uniformity also helps reduce the cost of TCDs through standardization. The information contained in the MUTCD is the result of eight years of practical experience, research, and/or the MUTCD experimentation process. This effort ensures that TCDs are visible, recognizable, understandable, and necessary. The MUTCD is a dynamic document that changes with time to address contemporary safety and operational issues. (Manual on Uniform Traffic Control Devices (MUTCD), Federal Highway Administration, U.S. Department of Transportation, 2009, Overview)

The development of the MUTCD has a very long history. The American Association of State Highway Officials (AASHO), which is the predecessor of 
AASHTO, published a manual for rural highways in 1927, and the National Conference on Street and Highway Safety (NCSHS) published a manual for urban streets in 1930. In the early years, the necessity for unification of the standards applicable to the different classes of road and street systems was obvious. To meet this need, a joint committee of AASHO and NCSHS developed and published the original edition of this MUTCD in 1935. That committee, now called the National Committee on Uniform Traffic Control Devices (NCUTCD), though changed from time to time in name, organization, and personnel, has been in continuous existence and has contributed to periodic revisions of this Manual. The FHWA has administered the MUTCD since the 1971 edition. The FHWA and its predecessor organizations have participated in the development and publishing of the previous editions. There were nine previous editions of the MUTCD, and several of those editions were revised one or more times. Table 5 traces the evolution of the MUTCD, including the two manuals developed by AASHO and NCSHS.

\section{Table 5}

Development of the Manual on Uniform Traffic Control Devices (MUTCD)

\begin{tabular}{|c|l|c|}
\hline Year & \multicolumn{1}{|c|}{ Name } & $\begin{array}{c}\text { Month / Year } \\
\text { Revised }\end{array}$ \\
\hline 1927 & Manual and Specifications for the & $4 / 29,12 / 31$ \\
\hline
\end{tabular}




\begin{tabular}{|c|c|c|}
\hline & $\begin{array}{l}\text { Manufacture, Display, and Erection of } \\
\text { U.S. Standard Road Markers and Signs } \\
\text { (for rural roads) }\end{array}$ & \\
\hline 1930 & $\begin{array}{l}\text { Manual on Street Traffic Signs, Signals, } \\
\text { and Markings (for urban streets) }\end{array}$ & No revisions \\
\hline 1935 & $\begin{array}{l}\text { Manual on Uniform Traffic Control } \\
\text { Devices } \\
\text { for Streets and Highways (MUTCD) }\end{array}$ & $2 / 39$ \\
\hline 1942 & $\begin{array}{l}\text { Manual on Uniform Traffic Control } \\
\text { Devices } \\
\text { for Streets and Highways - War } \\
\text { Emergency Edition }\end{array}$ & No revisions \\
\hline 1948 & $\begin{array}{l}\text { Manual on Uniform Traffic Control } \\
\text { Devices } \\
\text { for Streets and Highways }\end{array}$ & $9 / 54$ \\
\hline 1961 & $\begin{array}{l}\text { Manual on Uniform Traffic Control } \\
\text { Devices } \\
\text { for Streets and Highways }\end{array}$ & No revisions \\
\hline 1971 & $\begin{array}{l}\text { Manual on Uniform Traffic Control } \\
\text { Devices } \\
\text { for Streets and Highways }\end{array}$ & $\begin{array}{l}11 / 71,4 / 72,3 / 73 \\
10 / 73, \\
6 / 74,6 / 75,9 / 76 \\
12 / 77\end{array}$ \\
\hline
\end{tabular}




\begin{tabular}{|c|c|c|}
\hline 1978 & $\begin{array}{l}\text { Manual on Uniform Traffic Control } \\
\text { Devices } \\
\text { for Streets and Highways }\end{array}$ & $\begin{array}{l}12 / 79,12 / 83,9 / 84 \\
3 / 86\end{array}$ \\
\hline 1988 & $\begin{array}{l}\text { Manual on Uniform Traffic Control } \\
\text { Devices } \\
\text { for Streets and Highways }\end{array}$ & $\begin{array}{l}\text { 1/90, 3/92, 9/93, } \\
11 / 94, \\
12 / 96,6 / 98,1 / 00\end{array}$ \\
\hline 2000 & $\begin{array}{l}\text { Manual on Uniform Traffic Control } \\
\text { Devices } \\
\text { for Streets and Highways - Millennium } \\
\text { Edition }\end{array}$ & 7/02 \\
\hline 2003 & $\begin{array}{l}\text { Manual on Uniform Traffic Control } \\
\text { Devices } \\
\text { for Streets and Highways }\end{array}$ & $11 / 04,12 / 07$ \\
\hline 2009 & $\begin{array}{l}\text { Manual on Uniform Traffic Control } \\
\text { Devices } \\
\text { for Streets and Highways }\end{array}$ & \\
\hline
\end{tabular}

(Source: Manual on Uniform Traffic Control Devices (MUTCD), Federal Highway Administration, U.S. Department of Transportation, 2009)

The most importation part of the MUTCD concerned with this research is Part 9-Traffic Control for Bicycle Facilities. This part covers signs, pavement markings, and highway traffic signals specifically related to bicycle operation on 
both roadways and shared-use paths.

In the Chapter 9C-Markings of the MUTCD 2009, the stated functions of Markings is that "Markings indicate the separation of the lanes for road users, assist the bicyclist by indicating assigned travel paths, indicate correct position for traffic control signal actuation, and provide advance information for turning and crossing maneuvers" (Manual on Uniform Traffic Control Devices, Federal Highway Administration, U.S. Department of Transportation, 2009).

The Section 9C.04- Markings for Bicycle Lanes provides an example bicycle lane with bicycle lane word, symbol, and/or arrow markings and their specific dimensions, which is shown in Figure 10.
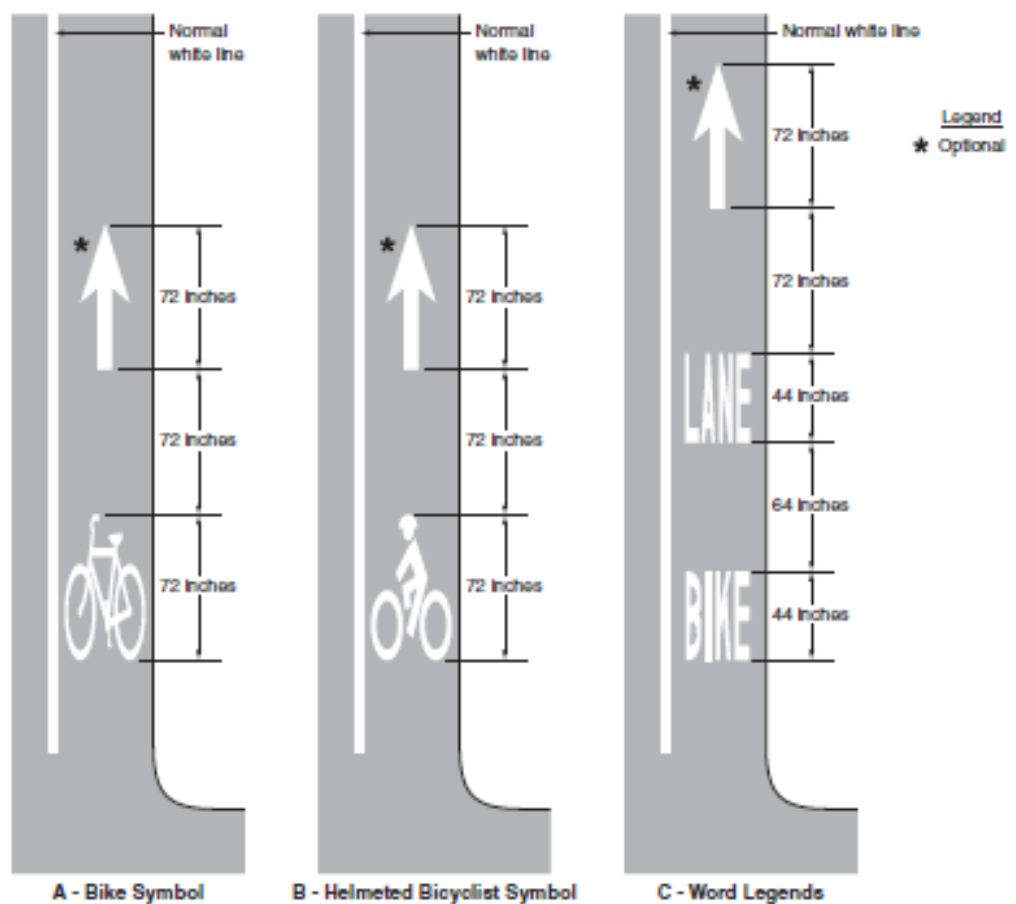
Figure 10: Markings for Bicycle Lanes (Source: Manual on Uniform Traffic Control Devices (MUTVD), Federal Highway Administration, U.S. Department of Transportation, 2009, Page 809)

\section{B. Reports and Studies from U.S. State and Local Governments}

There are many studies and reports made by U.S. state governments. Several important studies made by U.S. state governments are introduced in this research.

\section{Colorado Department of Transportation}

Analysis of Bicycle-Related and Pedestrian-Related Roadway Crashes was published by Colorado Department of Transportation in 2007. This report conducted a corridor-specific study along state highways within local and/or county jurisdictional boundaries to identify potential trends based on patterns in crash types and causes. Besides analysis of pedestrian-related crashes, this study analyzed bicycle-related crashes involving a motorist overtaking a bicyclist, a motorist turning or merging into the path of a bicyclist, or a bicyclist turning or merging into the path of a motorist. By identifying common causal factors of these crashes, this study can help planning and design efforts to provide safer intersections and corridors for use by bicyclists. The study developed recommendations to improve statewide, county and local data recording of 
bicycle crash factors (Colorado Department of Transportation, Analysis of Bicycle-Related and Pedestrian-Related Roadway Crashes, June, 2007).

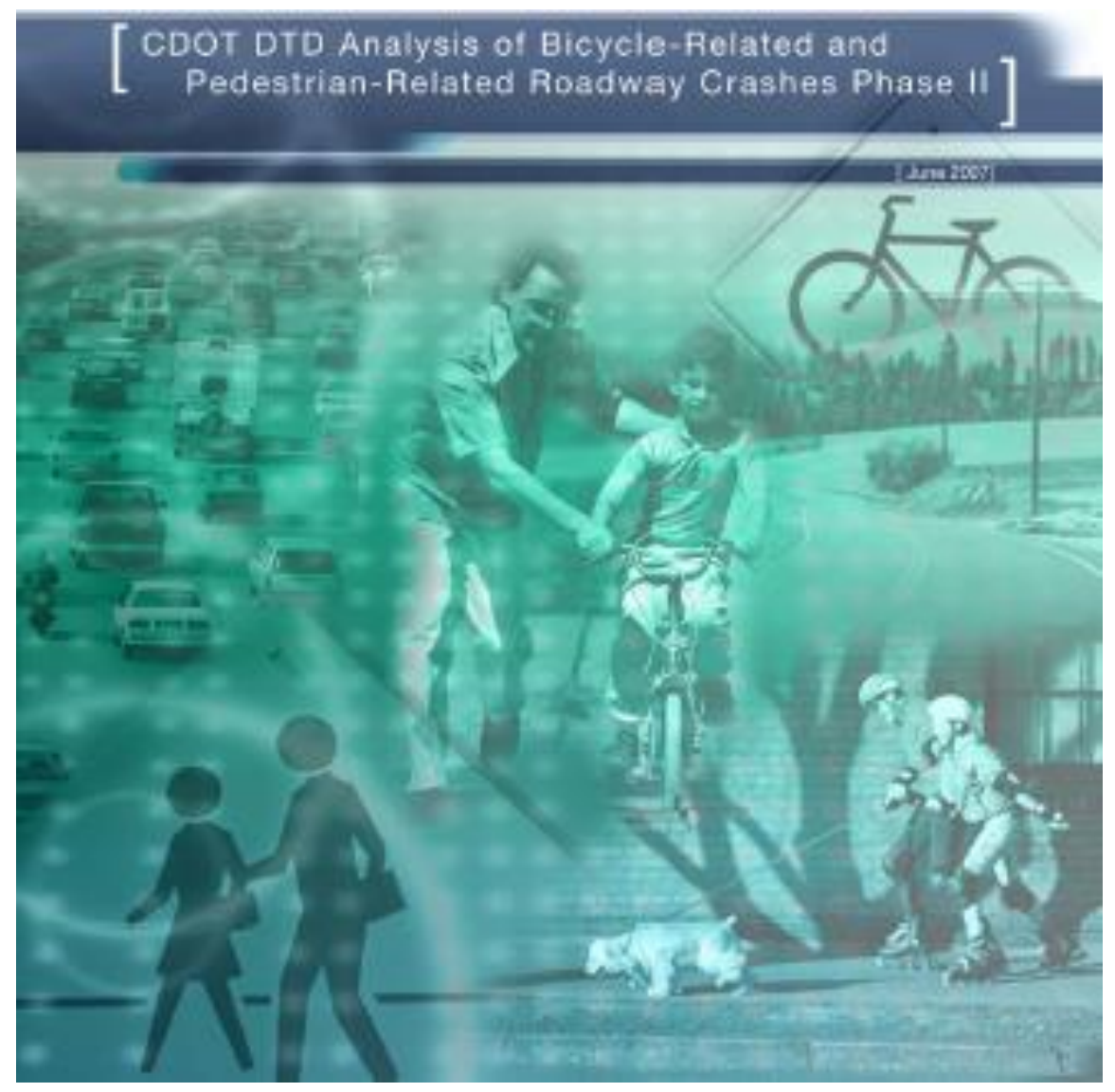

Figure 11: Bicycle-Related and Pedestrian-Related Roadway Crashes (Colorado Department of Transportation, Analysis of Bicycle-Related and PedestrianRelated Roadway Crashes, June, 2007)

\section{California Department of Transportation}

Strategies for Reducing Pedestrian and Bicyclist Injury at the Corridor Level was published by the California Department of Transportation (Caltrans) in July 
2011. The purpose of this study was to develop methods for identifying sites where there is potential for significant reductions in pedestrian and bicyclist injury. Data from 1998-2007 from a 16.5-mile section of San Pablo Avenue in the San Francisco East Bay was used as a study area. Several approaches for identifying sites with high potential for reducing pedestrian and bicyclist injury were evaluated and compared, a framework was developed for conducting benefitcost analyses, and a prototype was developed for a training protocol for conducting analyses of pedestrian and bicyclist safety in a corridor or network. The basic principle followed is that sites with the most potential for reducing injury are those sites where the most injuries can be prevented per dollar spent. Everything else being equal, these sites are the ones with the highest expected number of injuries if nothing is done. Prior history is typically used to make this estimate, but this may not be sufficient, especially if the underlying rates are low. Several approaches to developing statistically stable estimates are explained and compared: (1) extend the number of years for both the baseline and follow-up periods, (2) expand the size of the target sites considered, and (3) apply Bayesian methods to include a modeled estimate of risk in the calculation. Strengths and weaknesses of each of these approaches are discussed with illustrations from the study area (California Department of Transportation Strategies for Reducing Pedestrian and Bicyclist Injury at the Corridor Level, July, 2011). 


\section{Michigan Department of Transportation}

Sharing the Road: Optimizing Pedestrian and Bicycle Safety and Vehicle Mobility was published by Michigan Department of Transportation (MDOT) on April 30, 2012. This research initiative combines the results of five reports to provide recommendations for improving the multimodal aspects of the MDOT transportation network through the use of practices, guidelines, and policies that MDOT engineers use to design and construct pedestrian, bicycle, and automobile facilities (Michigan Department of Transportation (MDOT), Sharing the Road: Optimizing Pedestrian and Bicycle Safety and Vehicle Mobility, 04/30, 2012). Recommendations of this research were based on information collected and analyzed in the following reports:

- An analysis of crashes involving pedestrians and bicyclists in Michigan

- A review and summary of current roadway improvements summarized by the FHWA and their impacts on reducing crashes and their potential impact on mobility for all users

- A case study analysis at five roadway improvement projects in Michigan and crash impacts at each location

- A review of emerging design innovations provided by the National Association of City Transportation Officials (NACTO)

$\checkmark$ A summary report of the best design practices for pedestrian, bicycle, and automobile improvements in Michigan 
The last part of this research presented improvements that were found to have the greatest utility in Michigan with respect to pedestrian and bicyclist safety and vehicle mobility. Created as a standalone document, Best Design Practices for Walking and Bicycling in Michigan was organized as a toolbox for planners and designers of pedestrian and bicycle facilities.

In addition, as part of the final report, a review was conducted of existing MDOT manuals, guidelines, and other publications that guided the planning and design of pedestrian and bicycle facilities in Michigan. Recommendations were provided to facilitate the inclusion of these best practices in various MDOT roadway design documents.

Key findings for bicycles in this research included the determinations that approximately 20 percent of fatal bicycle crashes occurred on roadways with posted speeds between 25 and $30 \mathrm{mph}$. Bicycle crashes in Michigan occurred most often between the hours of 3 and $6 \mathrm{pm}$. Bike lanes can reduce bicycle crashes by 50 percent. 49 percent of all bicycle crashes happened at intersections and 51 percent occurred at non-intersections. 48 percent of all fatal and serious injuries happened at intersections and 52 percent happened at nonintersections. According to Figure 12, through vehicles (34 percent), right turning vehicles (25 percent) and left turning vehicles (13 percent) were involved in most bicycle crashes at intersections. Slowing or stopping in the roadway were 
associated with the next highest category (10 percent). However, though the role of turning vehicles was well understood, it was not clear what percentage of through vehicle crashes involved right angle crashes.

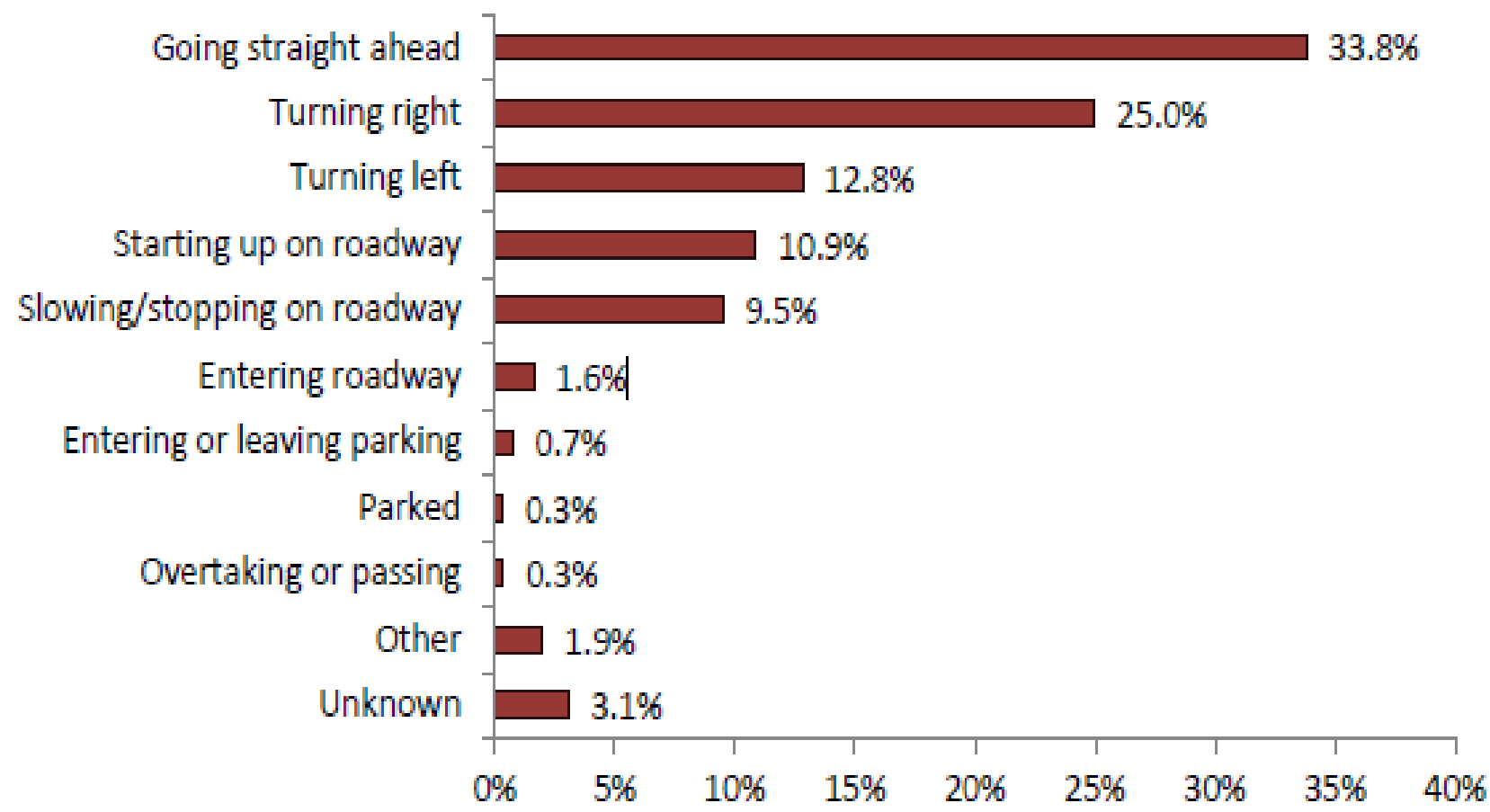

Figure 12: Michigan Fatal and Serious Injury Bicycle Crashes by Driver Action (Michigan Department of Transportation (MDOT), Sharing the Road: Optimizing Pedestrian and Bicycle Safety and Vehicle Mobility, 04/30, 2012)

Figure13 shows bicycle crashes by bicyclist action at intersections and nonintersections for the top four actions. The most common action was a bicyclist straight ahead. For intersection crashes, bicyclists going straight or crossing at an intersection accounted for over 75 percent of all crashes. Bicyclists turning left or right accounted for less than 4 percent of all crashes in both intersections and 
non-intersections.

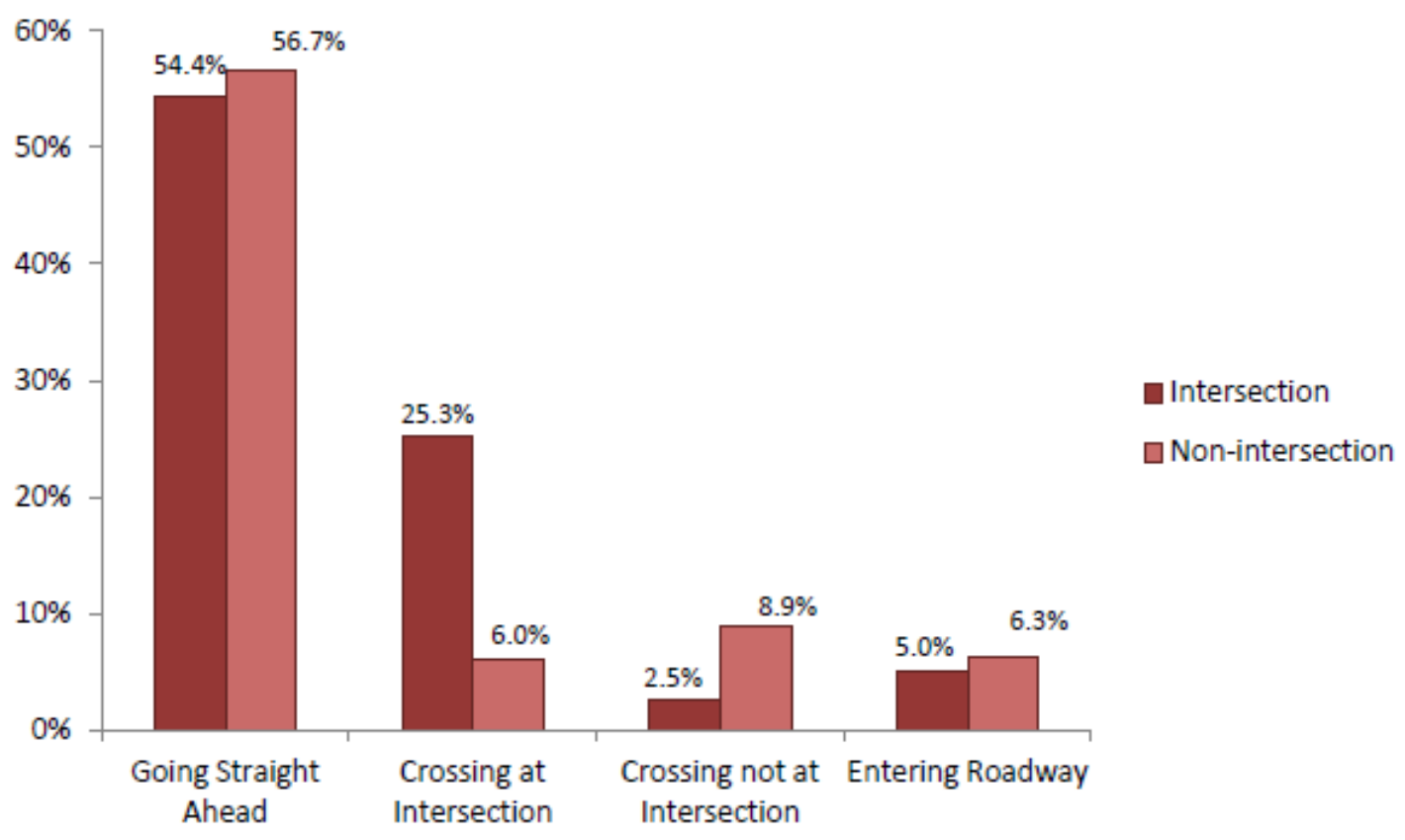

Figure 13: Bicycle Crashes by Bicycle Action (Michigan Department of Transportation (MDOT), Sharing the Road: Optimizing Pedestrian and Bicycle Safety and Vehicle Mobility, 04/30, 2012)

\section{Understanding Bicyclist-Motorist Crashes in Minneapolis, Minnesota}

Understanding Bicyclist-Motorist Crashes in Minneapolis, Minnesota: A Comprehensive Look at Crash Data from 2000-2010 and Solutions for Improved Bicyclist Safety was published by the City of Minneapolis Public Works Department on January 15,2013 . The aim of this research was to better understand what was causing bicycle-motor vehicle crashes. 2,973 bicyclistmotorist crash records from 2000-2010 were examined. Specific crash attributes 
were extracted from the Minnesota Department of Public Safety accident reports, analyzed and mapped. The findings in this report can be used to inform and influence the design of new bicycle facilities, the redesign of existing roadways, the development of education programs for bicyclists and motorists, enforcement campaigns, and the creation of bicycle-related policy in Minneapolis (Public Works Department, City of Minneapolis Understanding Bicyclist-Motorist Crashes in Minneapolis, Minnesota: A comprehensive look at crash data from 2000-2010 and solutions for improved bicyclist safety, January 15, 2013). Key findings from this research are shown below:

\section{When crashes occur:}

D Average of 270 bicyclist-motorist crashes occurred annually in Minneapolis. This was down from an average of 320 from 1993-1999.

D Crashes were most prevalent from April-October (88.3 percent), on weekdays (79.3 percent) and during the afternoon peak period from 3:006:00 p.m. (28.5 percent).

Crashes mostly occurred on clear or cloudy days (93.5 percent), when the road surface is dry (89.1 percent) and during daylight hours (72.7 percent).

\section{Who is involved:}


Most (93.5 percent) crashes involved bicycles and automobiles. Large trucks, buses, taxis and other vehicles made up the remaining vehicle types.

Bicyclist age was tracked for 2009-2010 data. The age group 18-24 was the most prevalent -21.9 percent of all crashes.

$>$ Crashes involving known drug use or drinking were limited. Bicyclists were impaired in 5.9 percent of crashes and motorists in 1.2 percent of crashes.

Approximately one out of five crashes was hit-and-runs, with the motorist fleeing the scene 93.3 percent of the time. Motorist condition was unknown in these cases.

\section{Injuries and fatalities:}

Bicyclists sustained an injury in 87.0 percent of crashes. It was estimated that motorists sustained an injury in no crashes.

> There were 12 bicyclist fatalities from 2000-2010. All cases involved at least one of the three following attributes: rain or wet pavement, aggressive or impaired motorist, or a large motor vehicle.

\section{Causes of crashes:}

Assigning fault was a difficult and inexact task. However, it appeared that bicyclists and motorists were equally contributing to the causes of 
crashes. Bicyclists were estimated to have contributing factors in 59.0 percent of crashes and motorists in 63.9 percent of crashes. The totals exceeded 100 percent as both parties had contributing factors.

The most common contributing factors for bicyclists were failure to yield right-of-way (13.3 percent), disregarding a traffic control device (12.6 percent) and improper lane use (9.2 percent).

The most common contributing factors for motorists were failure to yield right-of-way (31.8 percent), driver inattentive or distracted (8.5 percent) and improper lane use (5.2 percent).

$>$ The most common pre-crash maneuvers for bicyclists were bicyclist riding across roadway (46.0 percent), bicyclist riding with traffic (29.8 percent) and bicyclist riding against traffic (15.4 percent).

$>$ The most common pre-crash maneuvers for motorists were vehicle following roadway (42.2 percent), vehicle making left turn (18.7 percent) and vehicle making right turn (16.4 percent).

\section{Where crashes are occurring:}

41 percent of crashes occurred at intersections and another 40 percent occurred within 50 feet of intersections.

Crashes occurred in all areas of Minneapolis, although there was a clear concentration along major arterials with high volumes of motor vehicles. 


\section{Safety in Numbers:}

There was a clear correlation between the number of bicyclists and the crash rate. Minneapolis had seen these phenomena occurred across both time and space.

As the number of bicyclists had increased over the past decade, the crash rate had decreased.

On streets and corridors with higher volumes of bicycle traffic, the crash rate tended to be lower than on streets with lower volumes of bicycle traffic.

\section{Understanding Bicyclist-Motorist Crashes in Minneapolis, Minnesota}

A comprehensive look at crash data from 2000-2010 and recommendations for improved bicyclist safety
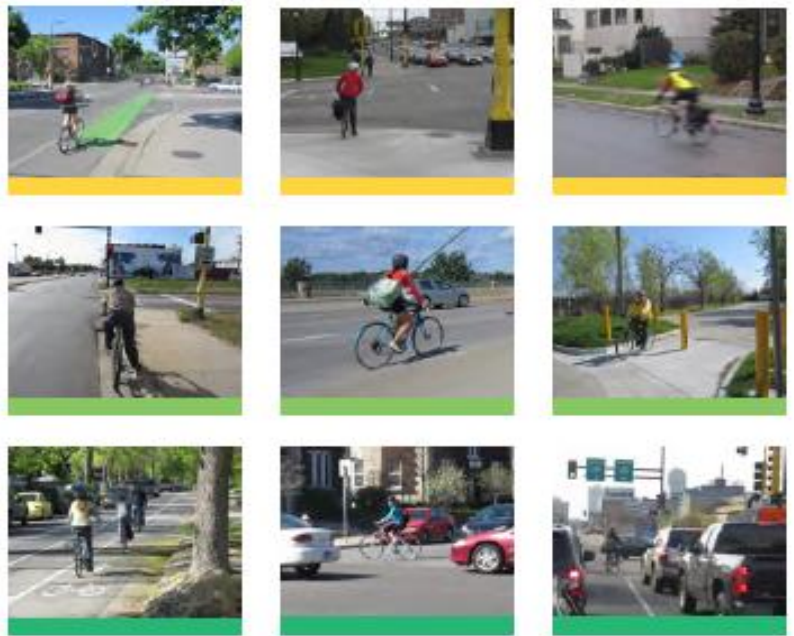

Bicycle and Pedestrian Section

Public Works Department City of Minneapolis January 15, 2013 
Figure 14: Understanding Bicyclist-Motorist Crashes in Minneapolis, Minnesota: A comprehensive look at crash data from 2000-2010 and solutions for improved bicyclist safety, Public Works Department, City of Minneapolis, January 15, 2013

In a word, after the analysis of the 2,973 bicyclist-motorist crashes, three primary conclusions emerge from the data which are shown in this research.

- Most crashes are occurring at intersections along major arterials.

- Motorists are not seeing or yielding to bicyclists.

- Bicyclists are not riding in a predictable manner.

At last, there were some recommendations provided in this research which aimed to reduce perceived fears of "interested but concerned" bicyclists and were presented within the framework of the "Six E's of Bicycling": Equity, Engineering, Enforcement, Education, Encouragement and Evaluation (Public Works Department, City of Minneapolis Understanding Bicyclist-Motorist Crashes in Minneapolis, Minnesota: A comprehensive look at crash data from 2000-2010 and solutions for improved bicyclist safety, January 15, 2013).

\section{Equity}

Develop a bicycle traffic safety work group

Ensure that safety talking points equally address motorists and bicyclists

\section{Engineering}


Guide and protect bicyclists at intersections and on busy streets

Highlight areas where bicyclists and motorists cross paths

Provide designated and comfortable places for bicyclists to ride

\section{Enforcement}

Expand a relationship with the Memphis Police Department (MPD)

Ensure bicyclists and motorists are treated equally under the law

Use enforcement as an educational tool

\section{Education}

$>$ Educate professional drivers

$>$ Use media to reach a wide audience

$>$ Continue rides and classes

\section{Encouragement}

Design infrastructure that is perceived to be safe

Publish data and document results

\section{Evaluation}

Publish a regular safety bicyclist report

$>$ Increase understanding of crashes

\section{Studies of Bicycle-related Crashes}

There have been a number of studies on conflicts between bicycles which have been done on crashes between bicycles and motor vehicles. According to the research studied by Räsänen and Summala (1998) and Preusser et al. (1982), the most frequent type of bicycle-motor vehicle accidents were related to 
a driver turning right and a bicycle coming from the drivers' right. When drivers turn right, they pay much more attention to their left. They may ignore the existence of the bicyclists on their right

Pedestrian and Bicycle Crash Types of the Early 1990s was published by Federal Highway Administration (FHWA) in June, 1996. The purpose of this research was to apply the basic pedestrian and bicyclist typologies to a sample of recent crashes and to refine and update the crash type distributions with particular attention to roadway and locational factors. Five thousand pedestrianand 3,000 bicycle-motor vehicle crashes were coded in a population-based sample drawn from the States of California, Florida, Maryland, Minnesota, North Carolina, and Utah. Nearly a third of the pedestrians were struck at or near (within $16 \mathrm{~m}(50 \mathrm{ft})$ ) of an intersection. Midblock events were the second major pedestrian crash type grouping, representing over a fourth (26 percent) of all crashes. The bicycle-motor vehicle crash types distributed as: (1) parallel paths: 36 percent, (2) crossing paths: 57 percent, and (3) specific circumstances: 6 percent. Most frequent parallel path crashes were motorist turn/merge into bicyclist's path (34.4 percent) of all parallel path crashes, motorist over-taking (24.2 percent), and bicyclist turn/merge into motorist's path (20.6 percent). Most frequent crossing path crashes were motorists failed to yield (37.7 percent of crossing path crashes), bicyclists failed to yield at an intersection (29.1 percent), and bicyclists failed to yield midblock (20.5 percent). 
In a study by Thom and Clayton (1992), the most frequent contributing factor to bicyclist-motorist accident risk for both bicyclists and drivers was the failure to yield right-of-way. Based on discussions with police and field observations, it was reported that the main causes of bicycle-traffic accidents in San Juan, Puerto Rico (Fernandez de Cieza et al., 1999), were an excessive vehicle speed, lack of proper illumination during the afternoon peak period and at night, and poor roadway design.

Gårder (1994) analyzed the causal factors for bicycle accidents with data collected from 1986 to 1991 in Maine. He found that about 57 percent of intersection bicycles and motor vehicles collisions involved turning movements of motor vehicles.

Yinhai Wang and Nancy L. Nihan (2004) estimated the risk of collisions between bicycles and motor vehicles at signalized intersections. They divided bicycle-motor vehicle (BMV) accidents into three categories:

(1)BMV-1: BMV accident type 1.Collisions between bicycles and through motor vehicles.

(2)BMV-2: BMV accident type 2.Collisions between bicycles and left-turning motor vehicles.

(3)BMV-3: BMV accident type 3.Collisions between bicycles and right-turning motor vehicles. 
A methodology for estimating these BMV accident risks was developed based on probability theory. The methodology was demonstrated using a 4-year (1992-1995) data set collected from 115 signalized intersections in the Tokyo Metropolitan area. This data set contains BMV accident data, bicycle flow data, motor vehicle flow data, traffic control data, and geometric data for each intersection approach. For each BMV risk model, an independent explanatory variable set was chosen according to the characteristics of the accident type. Three negative binomial regression models (one corresponding to each BMV accident type) were estimated using the maximum likelihood method. The coefficient value and its significance level were estimated for each selected variable. All in all, this research estimated the accidents of bicycles and turning motor vehicles by building a statistical model. The disadvantage of this model is that it is not clear if this model is fit for the United States because the data of this model came from Japan in the 1990s.

Joon-Ki Kima et al published Bicyclist Injury Severities in Bicycle-Motor Vehicle Accidents in 2007. This research explored the factors contributing to the injury severity of bicyclists in bicycle-motor vehicle accidents using a multinomial logit model. The model predicted the probability of four injury severity outcomes: fatal, incapacitating, non-incapacitating, and possible or no injury. The analysis was based on police-reported accident data between 1997 and 2002 from North Carolina, USA. The results showed several factors which more than doubled the probability of a bicyclist suffering a fatal injury in an accident, all other things 
being kept constant. These factors included inclement weather, darkness with no streetlights, head-on collision, speeding-involved, vehicle speed above $48.3 \mathrm{~km} / \mathrm{h}$ (30 mph), truck involved, intoxicated driver, bicyclist age 55 or over, and intoxicated bicyclist. The largest effect was caused by vehicle speed being greater than $80.5 \mathrm{~km} / \mathrm{h}$ (50 mph), where the probability of fatal injury increased more than 16-fold. Speed also showed a threshold effect at $32.2 \mathrm{~km} / \mathrm{h}(20 \mathrm{mph})$, which supported the commonly used $30 \mathrm{~km} / \mathrm{h}$ (15 mph) speed limit in residential neighborhoods.

Twisk A M, in his paper "Understanding Right-Turn Car-Cycle Conflicts at Intersections: Findings from Site-Based and In-Car Observations" published in May of 2012, indicated that the intersection layout limited the driver's perception of the possible presence of a cyclist more when the car was stopped than when the car was not stopped. Vehicle drivers adapted to this limitation by putting more effort into detecting the presence of cyclists in a timely way. Car-cyclist conflicts were less frequent and less severe when the car had stopped than when the car had not stopped, because of the lower speed of approach and because the bicyclist had a head start in time and in distance. This study revealed an intricate relationship among intersection design, traffic light phasing, and driver-bicyclist interactions and allowed the interactions to be explored. 


\section{Kentucky Laws Related to Bicycle Operations}

The operation of a bicycle in the City of Louisville is governed by several state and local regulations: the Kentucky Revised Statutes (KRS), the Kentucky Administrative Regulations (KAR) of the Transportation Cabinet, and the Ordinances of Louisville-Jefferson County Metro Government. All of following regulations and rules comes from the Website of Louisville government.

\section{State Regulations:}

The Kentucky Revised Statues give the Transportation Cabinet the right to promulgate bicycle safety regulations and standards. These regulations are defined in the Kentucky Administrative Regulations.

- Bicyclists must use a front light when riding at night or whenever it is darker than usual.

- Bicyclists must use a red rear reflector or light on yourself or your bicycle whenever riding on a highway or shoulder.

- At night or when overcast, bicyclists must use a steady or flashing red rear light.

- Bicyclists must shout or sound a bell or horn when approaching a pedestrian or other bicycle.

- It is illegal to carry more passengers than the bicycle was designed to accommodate. 
- Bicyclists may not carry a package which prevents you from keeping at least one hand on the handlebars.

- Bicycles shall be operated the same as a motor vehicle except for the following:

- A bicycle may be operated on the shoulder of a highway.

- If a bicycle lane is provided, it must be used whenever feasible.

- Not more than two bicycles may ride side-by-side in a single highway lane.

\section{Local Regulations:}

No person over 11 years old shall operate a bicycle on any sidewalk in Louisville Metro, and nobody of any age shall ride on the sidewalk downtown.

- No person shall operate a motorized vehicle on a designated bike path or bike lane.

- Bicyclists must wear a helmet if they are under 18 years old and they are riding in any Metro Park.

In all other ways, bicycles are considered "vehicles" by the Kentucky and Local regulations and are subject to all rights and regulations of other vehicles. These include:

- Bicyclists must stop at all stop signs and red lights as must other vehicles.

- Bicyclists must pass on the left and make turns from the appropriate lane. 
- Bicyclists must signal, using your hands, lamps, or mechanical devices. The signal must be given intermittently for the last fifty feet before the turn.

- All slow moving vehicles must bear as far right in their lane as is safe and practical, including bicycles.

- If there is on-road parking, a particularly narrow street, debris, or other hazards, Bicyclists are allowed to claim as much of the lane as necessary to ride safely.

Rules for Motorists Concerning Bicycles

Since motor vehicles and bicycles are both considered "vehicles" under the eyes of the law, there are rules which apply to motorists as well as to bicyclists regarding their behavior on the road.

\section{Motorists must:}

Share the road with bicyclists.

- Before passing a bicyclist:

- Look to see if there is something in the right lane (debris, parked cars, drainage grates, etc.) that might cause the bicyclists to divert their course to the left.

- Pass only when you can allow at least three feet between yourself (as measured from the extent of your rear-view mirrors) and the bicyclist.

- Return to your lane only when completely clear of the bicyclist. 
- If you turn right after passing a bicyclist, only do so if you leave enough room that his forward path is not obstructed.

- When opening your car door, look for bicyclists in your rear-view mirror.

\section{E. Conclusions}

As bicycling is taking a more important role as an alternative for driving in many states and regions of U.S.A in the last thirty years, crashes between bicyclists and drivers are becoming more frequent. Even though bicyclist's fatalities only made up less than 2 percent of total fatalities every year from 2001 to 2010 according to the data of Traffic Safety Facts, 2010, about 600 to 700 bicyclists were killed in the same period. Each life is precious and unique, especially for their families. In order to decrease bicycle-related crashes, federal governments paid much attention on formulating all kinds of design criteria, guides and specifications. Several state governments did careful research on bicycle-related crashes to help build a bicycle-friendly environment within their own states. Studies were also preceded by some researchers to look for the reasons causing bicycle-related crashes.

Even though that work was done by federal government, state governments, and researchers, there is no specific research for the bicycle-related crashes happening in Louisville, KY. Characteristics of bicycle-related crashes of Louisville are unknown. The effect of countermeasures used in Louisville for bicycle-related crashes has not been evaluated. This research will deal with these unknown questions in the next several chapters. 


\section{CHAPTER IV \\ POTENTIAL SOLUTIONS}

Intersection treatments designed to improve bicycle access and safety can generally be grouped into two categories: signal treatments and pavement markings (Lynn Weigand, 2008). Within these categories there are several variations on design and application. This chapter describes each of the treatments by category and reviews the relevant research on their effectiveness.

\section{A. Pavement Markings}

Pavement markings are generally used on the approach or through an intersection to delineate the path of travel and waiting spaces for bicyclists. The intent is to make the cyclists more visible to drivers and indicate the area where the bicyclist will travel through the intersection. Most pavement markings tend to focus on the approach to position cyclists in a safe and visible place before they enter the intersection. However, some designs include pavement markings that continue through the intersection to designate the bicycle path.

\section{Colored Bicycle Lane Markings through Intersections}

Colored bicycle crossings provide a lane marking in a highly visible color for bicyclists through an intersection to warn drivers of potential conflicts and provide 
bicyclists with a designated route through the intersection (see Figure 15). They are one of the few treatments that focus on the intersection rather than the approach. A study of this treatment at 65 signalized intersections in Copenhagen found that marking a bicycle lane through the intersection in a single direction reduced the number of crashes by 10 percent. They found that marking two or more bike lanes across the intersection in any direction increased the number of crashes (Jensen, 2007). The authors speculated that two or more marked bicycle crossings may have been confusing to motorists and perhaps were disregarded, while one lane marking was clear and legible. However, they also cautioned that the safety benefits of the colored crossing through the intersection also depended on other factors, such as intersection size, traffic volume, and number of legs entering the intersection (Lynn Weigand, Intersection Treatments to Improve Bicycle Access and Safety, Portland State University, Center for Urban Studies, 2008). 


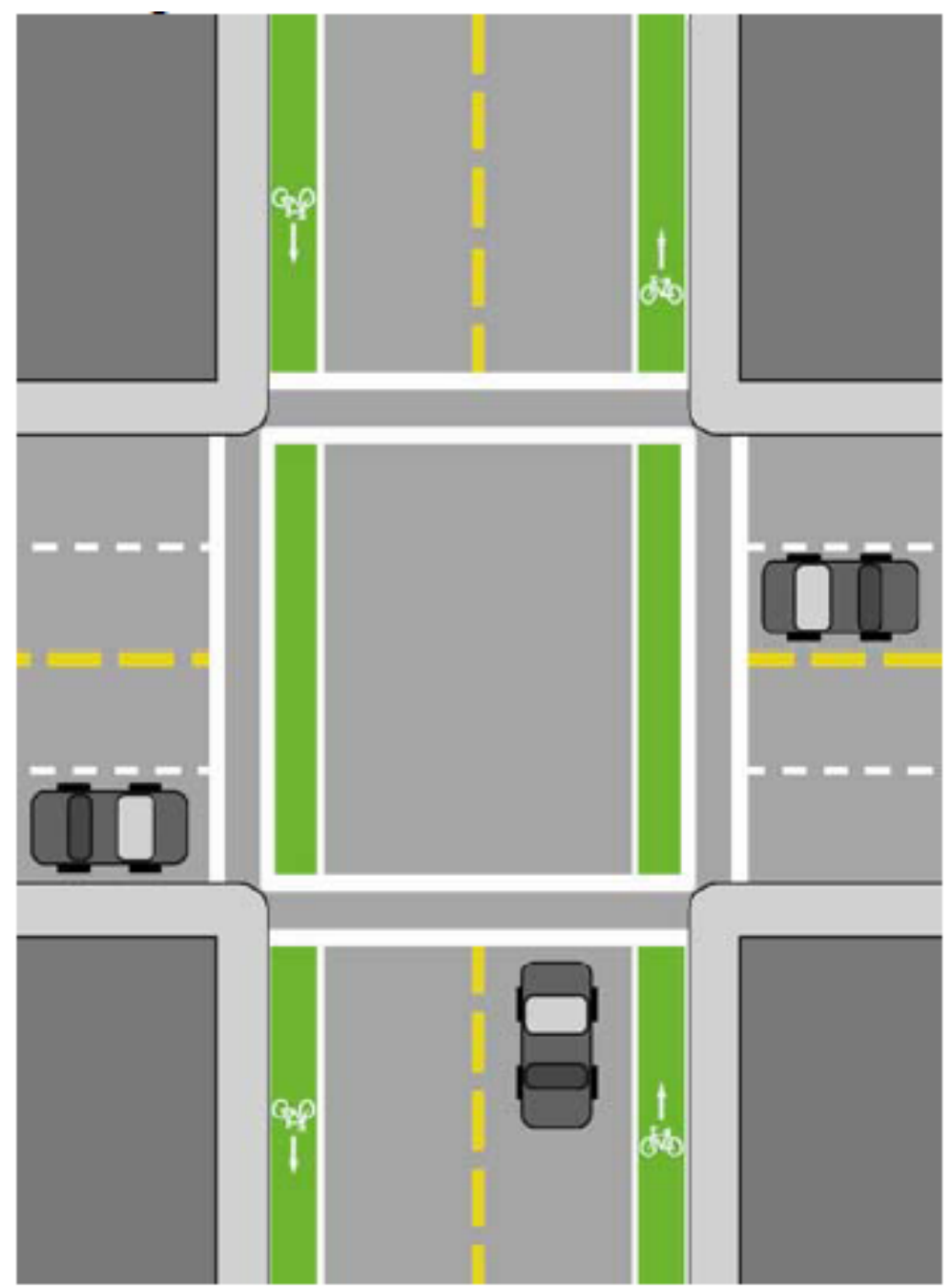

Figure15: Colored Bicycle Lane Marking through Intersection (Source: AASHTO Guide for the Development of Bicycle Facilities, $4^{\text {th }}$ Edition www.aashto.org)

\section{Colored Bicycle Crossings at Intersection Approach}

Motor vehicle right-turning movements are a common source of conflict between bicycles and motor vehicles at intersections where bike lanes are striped on the right side of the roadway approaching the intersection (Gårder, 1994). A colored bicycle crossing delineates the path where the bike lane 
crosses a motor vehicle lane to position the cyclist on the left side of a vehicle right-turn lane to avoid the potential for right-hook conflicts during the green phase of the signal. These crossings are typically accompanied by signage indicating the designated path for both motor vehicles and bicycles (Lynn Weigand, Intersection Treatments to Improve Bicycle Access and Safety, Portland State University, Center for Urban Studies, 2008).

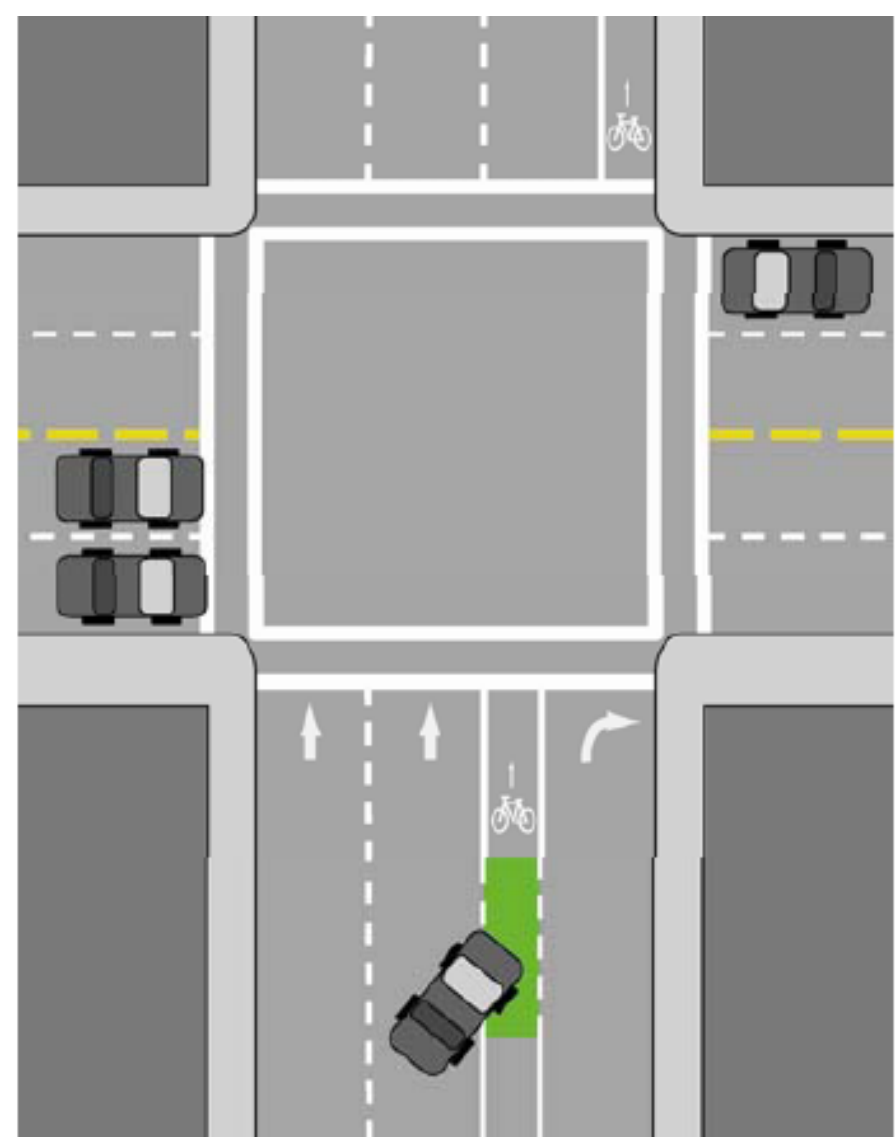

Figure 16: Colored Bicycle Crossings at Intersection Approach (Source: AASHTO Guide for the Development of Bicycle Facilities, $4^{\text {th }}$ Edition www.aashto.org)

European and Canadian cities have used the colored markings and found 
that they help improve bicyclist safety and reduce conflicts with motor vehicles (City of Portland Office of Transportation, 1999). However, until recently, it was untested in American cities. Portland, Oregon was the first to install and evaluate colored bicycle crossings. Hunter (2000) conducted a pre- and post-evaluation of the safety effects of colored bicycle crossings at ten intersections in Portland, Oregon. They concluded that the crossings enhanced cyclist safety by making both motorists and bicyclists aware of the conflict area and found a reduction in conflicts after the lanes were installed. Specifically, they found that significantly more motorists yielded to bicyclists after the pavement markings were installed. However, they also found that cyclists were less likely to use hand signals or turn their heads before crossing the lane, potentially indicating a false sense of security provided by the lane markings (Lynn Weigand, Intersection Treatments to Improve Bicycle Access and Safety, Portland State University, Center for Urban Studies, CUS-CTS-08-02, 2008).

\section{Bike Boxes, or Advanced Stop Line (ASL)}

The bike box, also known as the advanced stop line, is a treatment that allows bicyclists to move in front of vehicles when stopped at signalized intersections (Seattle Department of Transportation, Bicycle Program: Bike Boxes). It consists of a marked or colored waiting area that spans the width of the vehicle travel lane (see Figure 17). The intent is to reduce the risk of conflict between bicyclists and drivers, primarily when bicyclists are attempting to proceed straight through the intersection and drivers are attempting to turn right 
across the bicyclist's path, also known as a right-hook conflict. Advanced stop lines have been adopted primarily in Europe with few applications in the U.S. (Lynn Weigand, Intersection Treatments to Improve Bicycle Access and Safety, Portland State University, Center for Urban Studies, 2008).

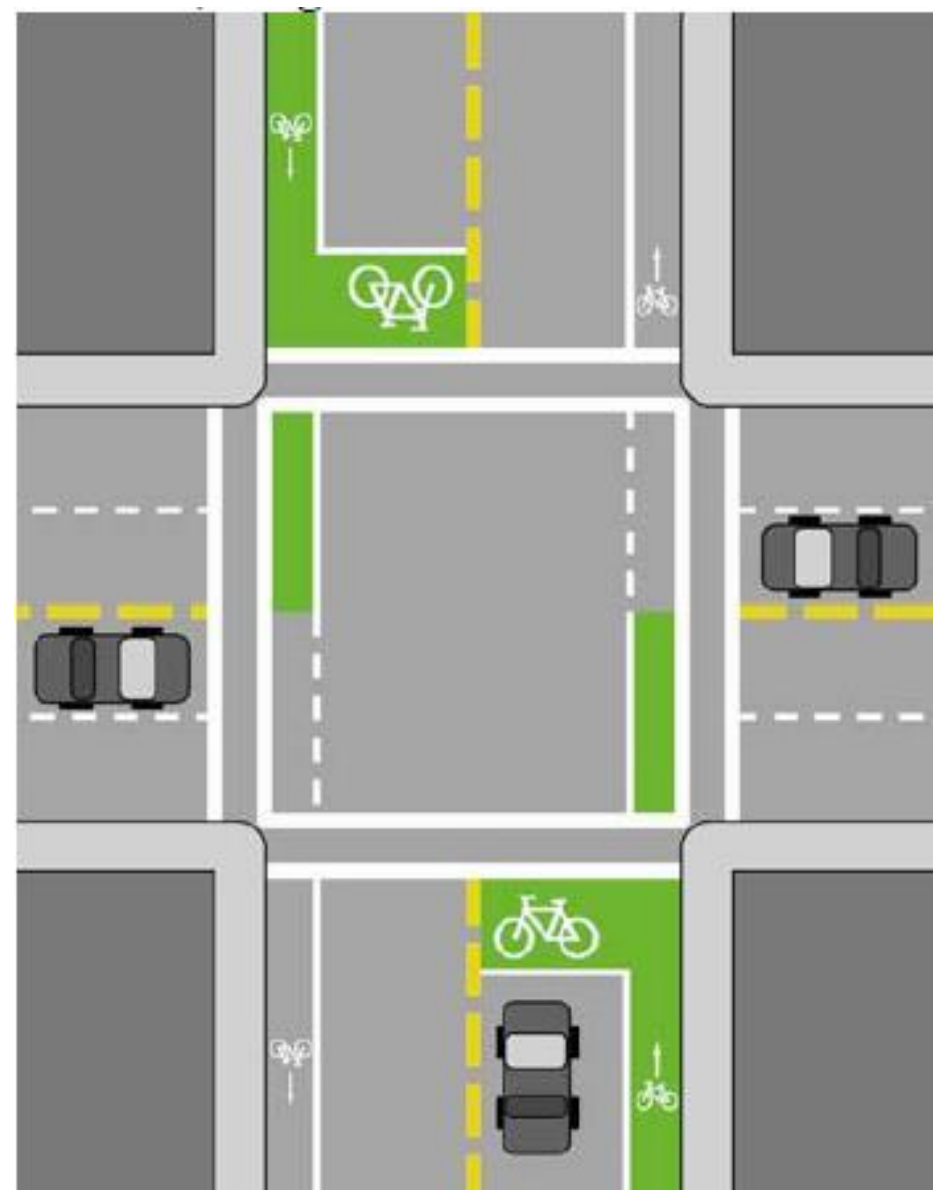

Figure 17: Example of Bike Box Design Treatment (Source: AASHTO Guide for the Development of Bicycle Facilities, $4^{\text {th }}$ Edition www.aashto.org)

Three studies of advanced stop lines have been conducted in the UK (Wheeler 1995; Wall, Davies et al. 2003; Allen, Bygrave et al. 2005). Allen et al. examined 12 sites receiving the ASL treatment and two control sites in the 
greater London area, using video to record bicyclist and driver behaviors and level of conflict at the sites. This study did not record behaviors before the design treatments were installed. Wheeler (1995) conducted an earlier study of four advanced stop lines in Bristol, Cambridge and Manchester. This study also used video to record driver and bicyclist behaviors at the sites, and included a preinstallation study at one site. Wall et al. (2003) used before and after video surveillance and bicyclist questionnaires at four sites in Surrey in the U.K. The papers do not indicate if signage was present at the sites to indicate proper usage of the design treatment (Lynn Weigand, Intersection Treatments to Improve Bicycle Access and Safety, Portland State University, Center for Urban Studies, 2008).

All three studies found that bicyclists were able to access the bike box and position themselves in front of the vehicles when waiting for the signal. Allen et al. and Wall et al. concluded that this position reduced the potential for conflicts with vehicle turning movements on green signals. Allen et al. (2005) found an added benefit for pedestrians by providing a buffer zone between waiting motor vehicles and the pedestrians crossing that discouraged vehicles from blocking the crossing. The bicyclist surveys conducted by Wall et al. found that bicyclists thought the advanced stop lanes were safer and easier to use because they allocated more road space for the bicyclists and made them more visible to drivers. However, the survey found bicyclists had concern about drivers who did not comply with the layout and drove into the cycle lane or box (Lynn Weigand, 
Intersection Treatments to Improve Bicycle Access and Safety, Portland State University, Center for Urban Studies, 2008).

All three studies found problems with motor vehicle encroachment. Allen et al. found that 36 percent of the bicyclists across all the study sites experienced some level of vehicle encroachment into the ASL. All of the studies concluded that drivers need to be encouraged to comply with the bike box markings through signs, education and enforcement, and it is important to maintain the visibility of the markings. Wall et al. (2003) found no evidence that the drivers were delayed by bicyclists queuing in front of the vehicles, and that proportion of motor vehicles going straight or turning remained similar. Other impacts of the Wall et al. study were difficult to assess because design changes, such as motor vehicle lane removal and bicycle lane additions, were made at the same time the advanced stop lines were installed (Lynn Weigand, Intersection Treatments to Improve Bicycle Access and Safety, Portland State University, Center for Urban Studies, 2008).

Studies of bike boxes in the U.S. are limited. Hunter (2000) made an evaluation of a bike box which was installed at a Eugene, Oregon intersection and found that the rate of bicycle-vehicle conflicts changed little before and after the bike box was installed, and no conflicts took place when the bike box was used as intended. The study did find problems with motor vehicle encroachment into the box, leading the authors to recommend bold demarcation and education 
for both drivers and bicyclists with installation of this treatment. However, the treatment design in this study was unique because the bike lane shifted from one side of the street to the other through the intersection, limiting the ability to generalize from these results (Lynn Weigand, Intersection Treatments to Improve Bicycle Access and Safety, Portland State University, Center for Urban Studies, 2008).

\section{B. Signal Treatments at Intersections}

Signal treatments at intersections to enhance bicyclist safety include both bicycle scramble signals and bicycle-only signal phasing (Metropolitan Transportation Commission of San Francisco Bay Area, Safety Toolbox: Engineering). On the surface, the two appear quite similar. The common feature is that all vehicular traffic is stopped at the same time to permit safe bicycle movement through the intersection. However, the bicycle-only signal phase permits bicyclists to proceed through the intersection in designated directions, similar to vehicular traffic. With the bicycle scramble, bicyclists can move through the intersection in any direction on the green signal.

\section{Bike Scramble}

A student project conducted by Wolfe et al. (2006) in Portland, Oregon evaluated a bicycle scramble treatment installed at an intersection in North Portland. The scramble signal was installed by the City of Portland to improve traffic conditions and safety for bicyclists by allowing a protected movement for 
bicyclists. When activated, the signal indicates that all motor vehicle traffic should stop, allowing bicyclists to cross the intersection in any direction to access one of several bike ways, including a riverfront trail connection. The data was collected through observation before and after the signal was installed in 2004. The results indicated that the volume of bicyclists using the intersection increased and the amount of illegal crossings (defined as crossing against a signal indication) significantly decreased after the scramble signal was installed. Specifically, 78.1 percent of all bicyclists passing the intersection before the signal change did so illegally (against the signal) while after the signal was installed, only 4.2 percent of bicyclists made an illegal crossing. The study also found a small amount of illegal right turns (3.3 percent in 895 signal counts) made by motor vehicles when the scramble signal was active (Lynn Weigand, Intersection Treatments to Improve Bicycle Access and Safety, Portland State University, Center for Urban Studies, 2008).

\section{Bicycle-Only Signal Phase}

Many European cities provide separate signal phases for bicyclists to allow them to cross the intersection without the potential for conflict with vehicle turning movements (Godefrooij 1997). Korve and Niemeier (2002) claim that incorporating a new bicycle-only signal phase at an existing intersection in the U.S. had never been analyzed before their study. They examined the effects of a bicycle-only signal phase at a high-volume intersection for both bicyclists and vehicles in Davis, California and found increased bicycle safety due to a lower 
number of bicycle-vehicle conflicts. Applying a cost-benefit analysis to both vehicle delay and emissions, they found that the benefits outweigh the costs and disadvantages (Lynn Weigand, Intersection Treatments to Improve Bicycle Access and Safety, Portland State University, Center for Urban Studies, 2008). 


\section{CHAPTER V \\ METHODOLOGY}

\section{A. Methodology for Bicycle-related Crashes Data Analysis}

At first, to yield patterns of statistical and spatial significance, an appropriate sample size of bicyclist-motorist crash records should be determined. When evaluating safety projects, three-year before and after periods are often used. This is a logical approach, as a substantial number of motor vehicle crashes occur each year in even small communities. In Louisville, $\mathrm{KY}$, there is only an average of 154 bicycle related crashes annually. Due to the relatively small number of crashes, a longer time period was desired for this analysis. On the other hand, the records for bicycle-related crashes are limited. Although it is noted that five years is long enough, an example period of 10 years from 2003 to 2012 is selected to gain a broader understanding of bicycle-related crashes.

According to the records coming from Kentucky Collision Analysis for the Public, the primary attributes available for each crash are:

\section{Context, Environment and Injury Severity}

$>$ Date

$>$ Time 
$>$ Weather

$>$ Road Surface Condition

\section{Bicyclist Information}

$>$ Bicyclist Contributing Factor

\section{Motorist Information}

$>$ Motorist Contributing Factor

$>$ Motorist Pre-Crash Maneuver

> Motorist Vehicle Type

\section{Manner of Collisions}

By carefully studying each crash related to bicycles, the reasons which cause those crashes will be found out. Much attention will be put on items, such as Bicyclist Contributing Factor, Motorist Contributing Factor, Motorist Pre-Crash Maneuver and Manner of Collisions.

\section{B. Methodology for a New Kind of Countermeasure for Bicyclist Safety at Intersections}

Since the goal of this research is to improve bicycle safety in Louisville, $\mathrm{KY}$, the author worked closely with Mr. Dirk Gowin, PE, PLS from the Louisville Metro Public Works and Assets Department. The approach chosen to reduce potential conflicts between bicyclists and right turning motor vehicles has not been attempted in any other location, and is described in the following paragraphs. 
The Louisville Metro Public Works and Assets Department applied the modified striping used in this study. Figure 18 shows the location of the study intersection.

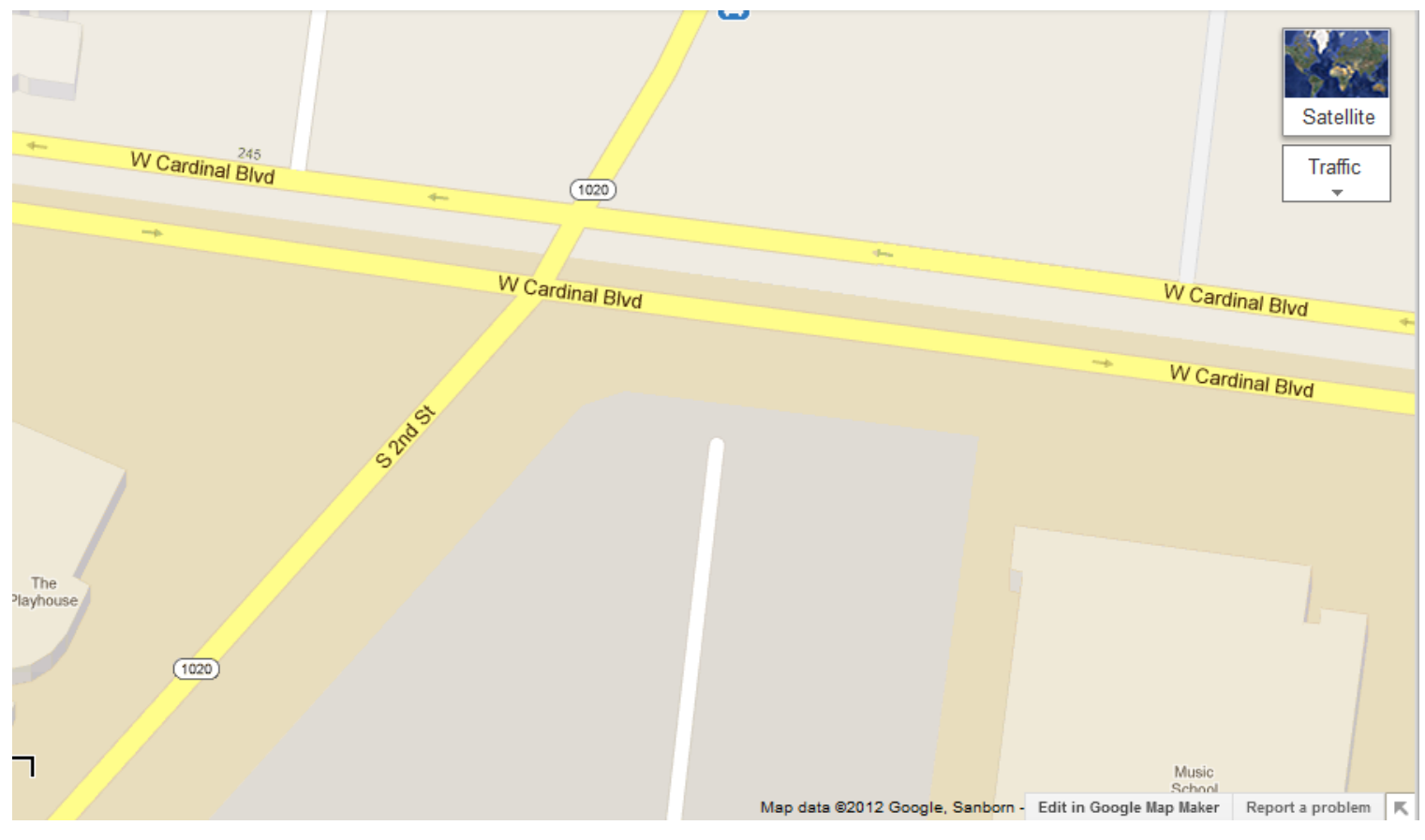

Figure 18: Intersection with New Designed Countermeasures for Bicyclist Safety (Source: Google map, https://maps.google.com)

Figure 19 shows the circumstance of the first survey, which is different from the traditional bicycle lane shown in Figure 6. This will be considered as the base line of this evaluation for this kind of new design countermeasure for bicyclist safety. An oblique striped line has been drawn at the end of the bicycle lane, which is near the chosen intersection. This new countermeasure aims to decrease the conflicts between through bicycles with right-turning motor vehicles. This new countermeasure can attract drivers to turn right earlier than their old 
driving habits in order to let motor vehicles take up the space of the bicycle lane so through bicycles join in line behind motor vehicles.

Four surveys were made to observe drivers' behavior. The main purpose of the first survey is to observe the position in which right-turning motor vehicles begin to turn right. This survey also can be considered as a base line for this research.

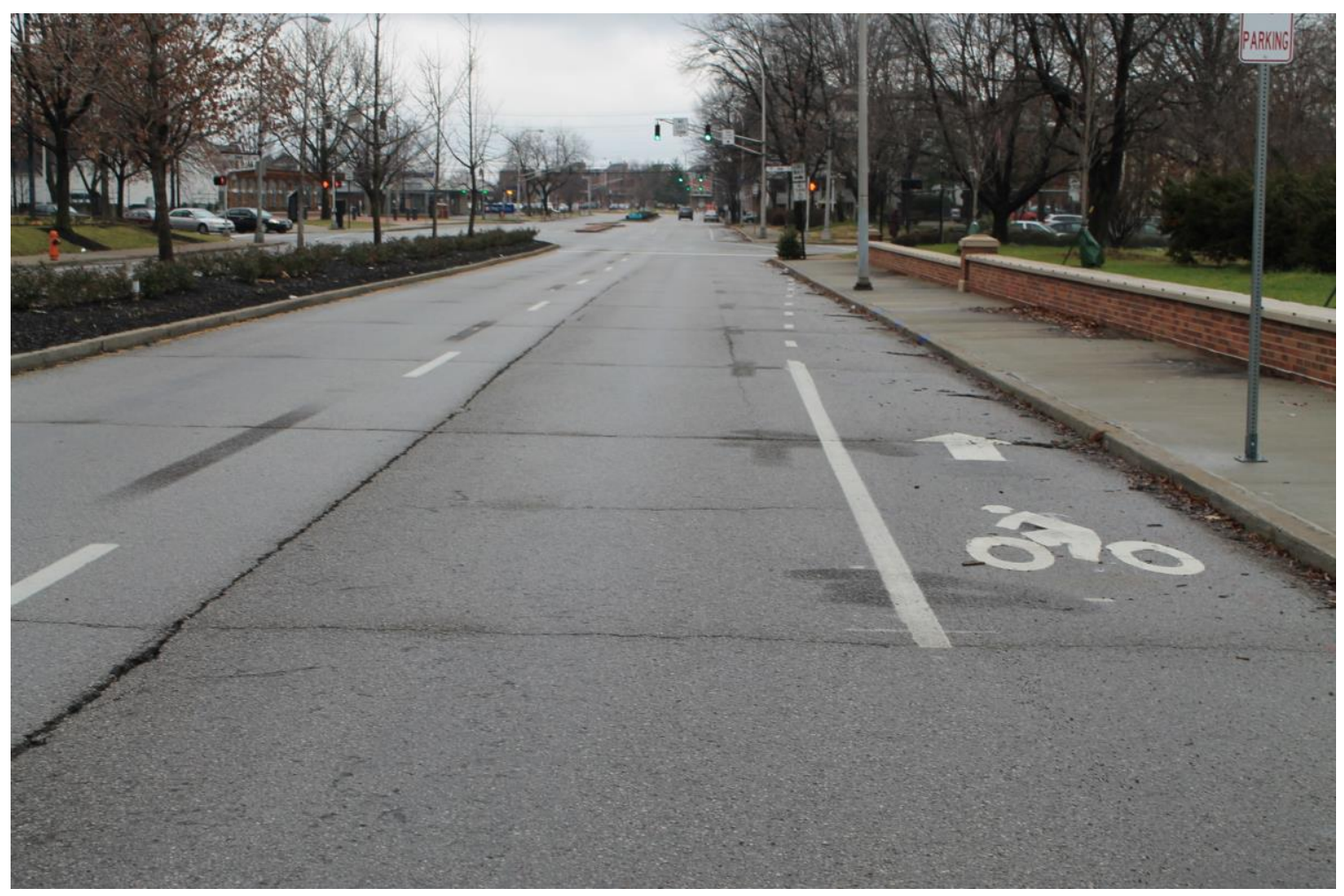

Figure 19: Base Line for the New Designed Countermeasure Evaluation 


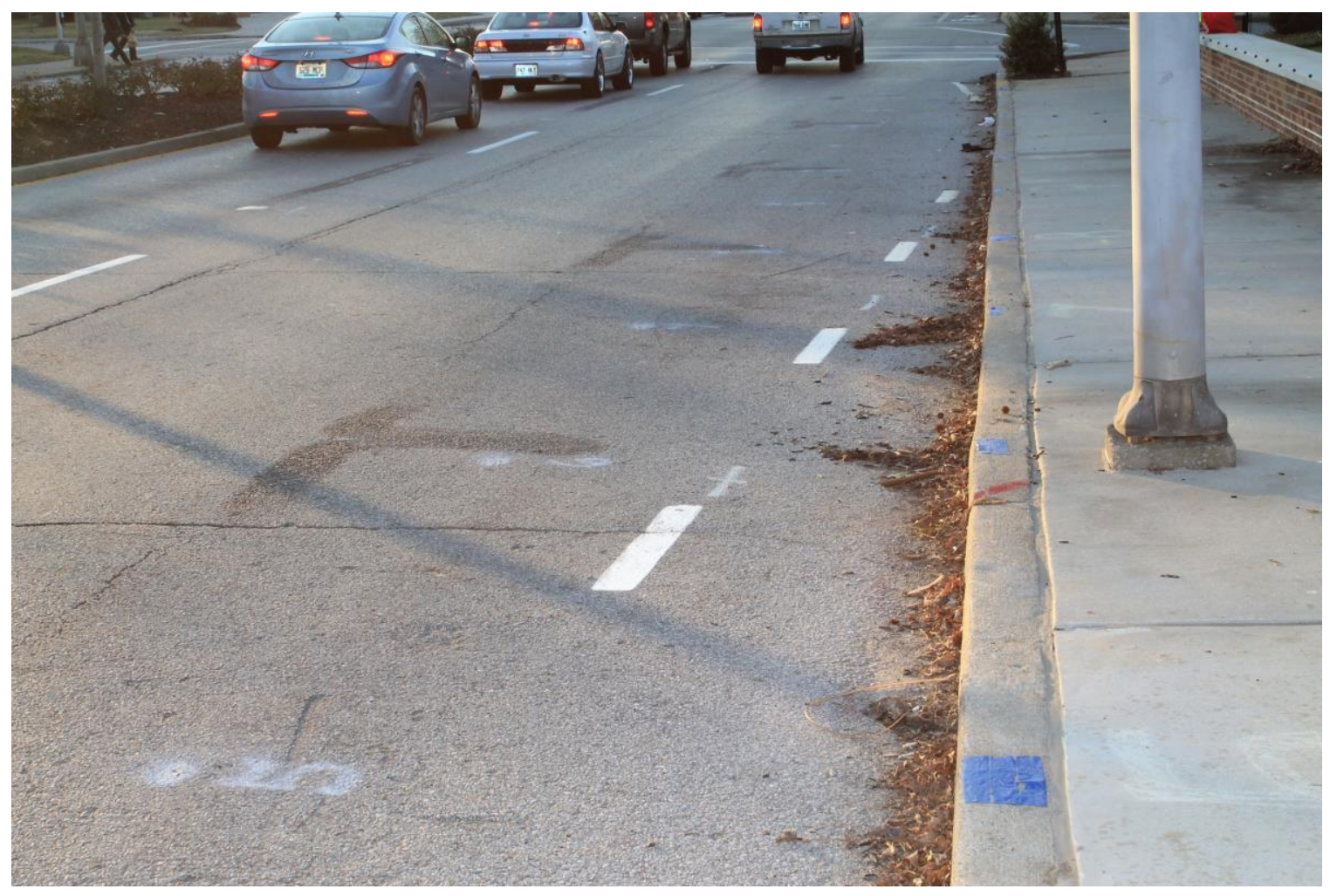

Figure 20: The Second Survey Environment for the Chosen Intersection with Marked Point as a Virtual Line

Figure 20 shows the circumstance of the second survey. 16 points are drawn on the road as a virtual line. The main purpose of the second survey is to observe the position of right-turning motor vehicles as they cross the virtual line. 


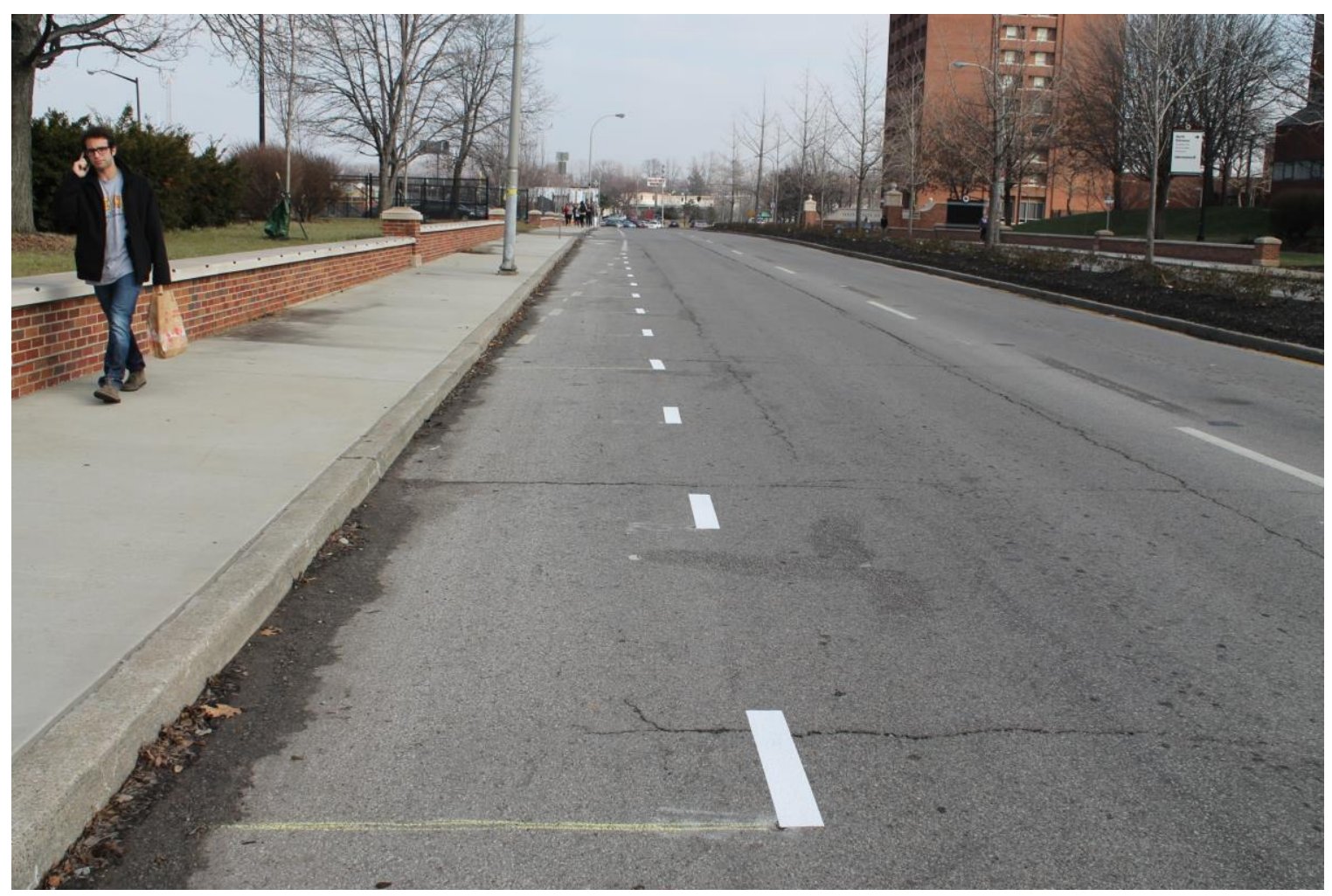

Figure 21: The Third Survey Environment for the Chosen Intersection with a New Striped Line

Figure 21 shows the circumstance of the third survey. A new and clear striped line was painted showing the limit of the bicycle lane. This new striped line changed this new countermeasure back in to the traditional bicycle lane shown in Figure 6. The main purpose of the third survey is to observe the position of right-turning motor vehicles as they cross the striped line. 


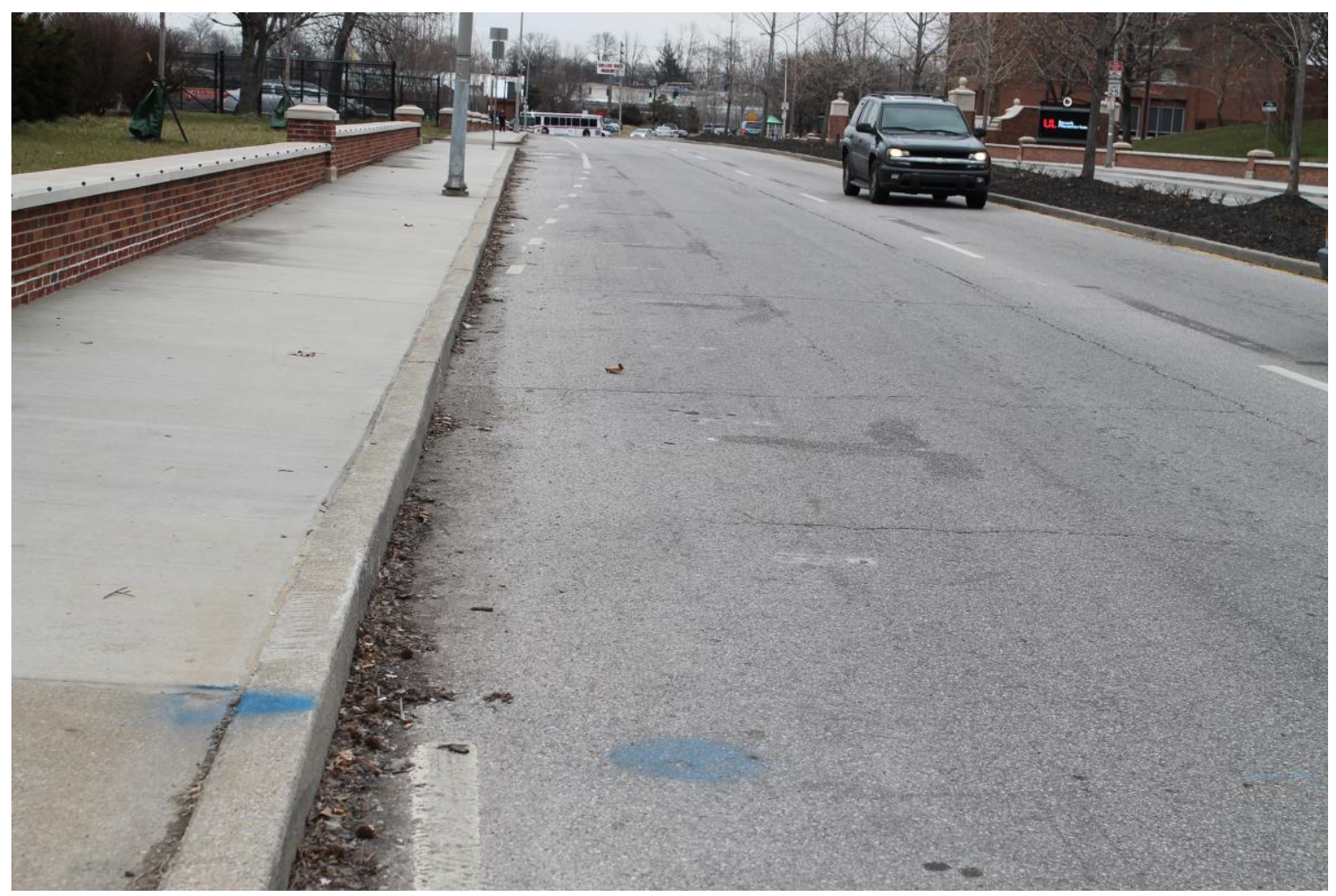

Figure 22: The Fourth Survey Environment for the Chosen Intersection

Figure 22 shows the circumstance of the fourth survey. The striped line used in the third survey has been removed. The main purpose of the fourth survey is to observe the position of right-turning motor vehicles where they began their right-turning maneuver in the absence of the striped line. 


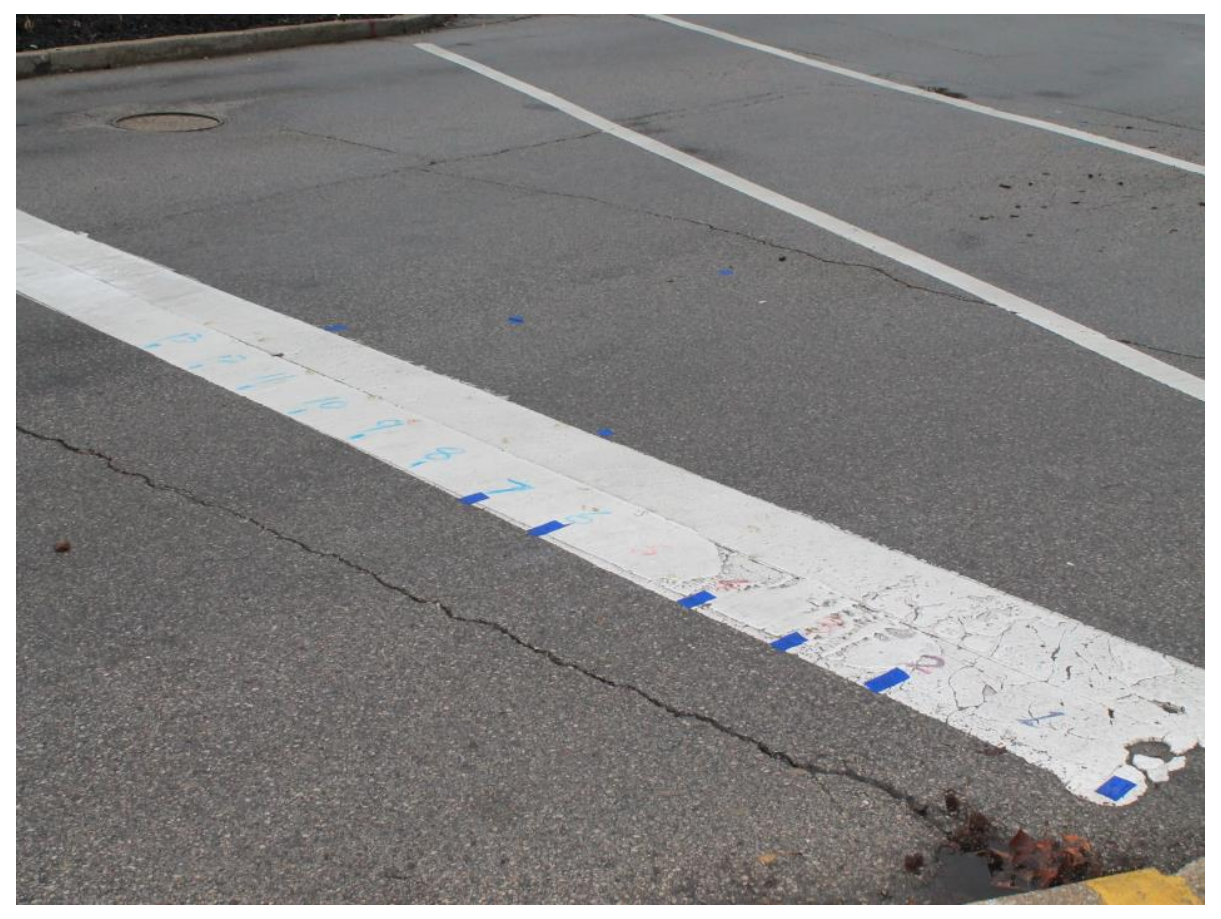

Figure 23: The Measurement of the Distance from Curb

Figure 23 shows another important factor collected in these four surveysDistances from Curb, which measures the distance from the curb of the chosen intersection when motor vehicles cross the stop bar for the right-turning movement.

Besides the two position data sets collected in these four surveys, other information related to drivers and bicyclists are also included:

- Motor Vehicle Type

- Driver's Age

- Using Right Lamp before Turning Right

- Using Traffic Signal before Turning Right 


\section{CHAPTER VI}

\section{RESEARCH RESULTS}

\section{A. Research Results for Bicyclists-related Crashes Data in Louisville, KY}

\section{Introduction}

Kentucky Collision Analysis for the Public is developed and maintained by Kentucky State Police to give the public the ability to analyze data related to collisions occurring in the state of Kentucky. This repository contains information gathered from collision reports submitted by Kentucky law enforcement agencies concerned with crashes between motor vehicles, bicycles and pedestrians in the whole state of Kentucky. For the purpose of this research, bicycle related crashes from January 01, 2003 to December 31, 2012 were studied.

2. Result of Analysis for Bicyclists-related Crashes in Louisville from 2003 to 2012

\section{a) When Crashes Happened}

\section{By Year}

The sum of studied bicycle-related crashes in Louisville is shown in Table 6 . Between 2003 and 2012, there was an average of 155 bicycle-motor vehicle crashes per year. The peak occurred in 2011 with 181 crashes and the lows 
were in 2009 and 2012 with 142 crashes.

\section{Table 6}

Bicycle-related Crashes Happened in Louisville from 2003 to 2012 by Year

\begin{tabular}{|c|c|c|}
\hline Year & Count & Percent \\
\hline 2003 & 166 & $10.7 \%$ \\
\hline 2004 & 154 & $10.0 \%$ \\
\hline 2005 & 151 & $9.8 \%$ \\
\hline 2006 & 160 & $10.3 \%$ \\
\hline 2007 & 153 & $9.9 \%$ \\
\hline 2008 & 148 & $9.6 \%$ \\
\hline 2009 & 142 & $9.2 \%$ \\
\hline 2010 & 149 & $9.6 \%$ \\
\hline 2011 & 181 & $11.7 \%$ \\
\hline 2012 & 142 & $9.2 \%$ \\
\hline Total & 1546 & $100 \%$ \\
\hline
\end{tabular}

(Data Source: Kentucky Collision Analysis for the Public, http://crashinformationky.org)

\section{By Month}

Crashes by month adhere closely to local climate conditions and bicycle traffic patterns in Louisville. According to the data shown in Table 7, bicycle- 
related crashes were least prevalent in the winter, increased in the spring, at peak in the summer and decreased in the autumn. Less than 3 percent of annual crashes occur in January, while over 13 percent occur in August. Mild weather months from April-October account for 80 percent of annual crashes.

Table 7

Bicycle-related Crashes Happened in Louisville from 2003 to 2012 by Month

\begin{tabular}{|c|c|c|c|c|c|c|c|c|c|c|c|c|}
\hline Month & $\mathbf{2 0 0}$ & $\mathbf{2 0 0}$ & $\mathbf{2 0 0}$ & $\mathbf{2 0 0}$ & $\mathbf{2 0 0}$ & $\mathbf{2 0 0}$ & $\mathbf{2 0 0}$ & $\mathbf{2 0 1}$ & $\mathbf{2 0 1}$ & $\mathbf{2 0 1}$ & Total & Percent \\
\hline January & $\mathbf{3}$ & $\mathbf{4}$ & $\mathbf{5}$ & $\mathbf{6}$ & $\mathbf{7}$ & $\mathbf{8}$ & $\mathbf{9}$ & $\mathbf{0}$ & $\mathbf{1}$ & $\mathbf{2}$ & & \\
\hline February & 5 & 5 & 3 & 4 & 4 & 3 & 7 & 5 & 5 & 6 & 47 & $3.0 \%$ \\
\hline March & 10 & 5 & 3 & 4 & 6 & 6 & 6 & 10 & 10 & 11 & 71 & $4.6 \%$ \\
\hline April & 14 & 20 & 16 & 16 & 17 & 12 & 5 & 11 & 19 & 11 & 141 & $9.1 \%$ \\
\hline May & 10 & 14 & 17 & 13 & 23 & 11 & 13 & 15 & 17 & 18 & 151 & $9.8 \%$ \\
\hline June & 28 & 20 & 24 & 18 & 18 & 27 & 19 & 19 & 21 & 14 & 208 & $13.5 \%$ \\
\hline July & 22 & 20 & 20 & 23 & 10 & 21 & 17 & 15 & 21 & 21 & 190 & $12.3 \%$ \\
\hline August & 24 & 21 & 17 & 24 & 28 & 20 & 20 & 16 & 21 & 20 & 211 & $13.6 \%$ \\
\hline September & 21 & 26 & 20 & 15 & 22 & 16 & 20 & 19 & 16 & 18 & 193 & $12.5 \%$ \\
\hline October & 15 & 11 & 18 & 16 & 11 & 17 & 11 & 21 & 15 & 10 & 145 & $9.4 \%$ \\
\hline November & 13 & 7 & 9 & 9 & 6 & 9 & 9 & 6 & 20 & 2 & 90 & $5.8 \%$ \\
\hline December & 2 & 4 & 3 & 6 & 5 & 1 & 10 & 9 & 11 & 5 & 56 & $3.6 \%$ \\
\hline Total & 166 & 154 & 151 & 160 & 153 & 148 & 142 & 149 & 181 & 142 & 1546 & $100.0 \%$ \\
\hline
\end{tabular}

(Data Source: Kentucky Collision Analysis for the Public,

http://crashinformationky.org) 


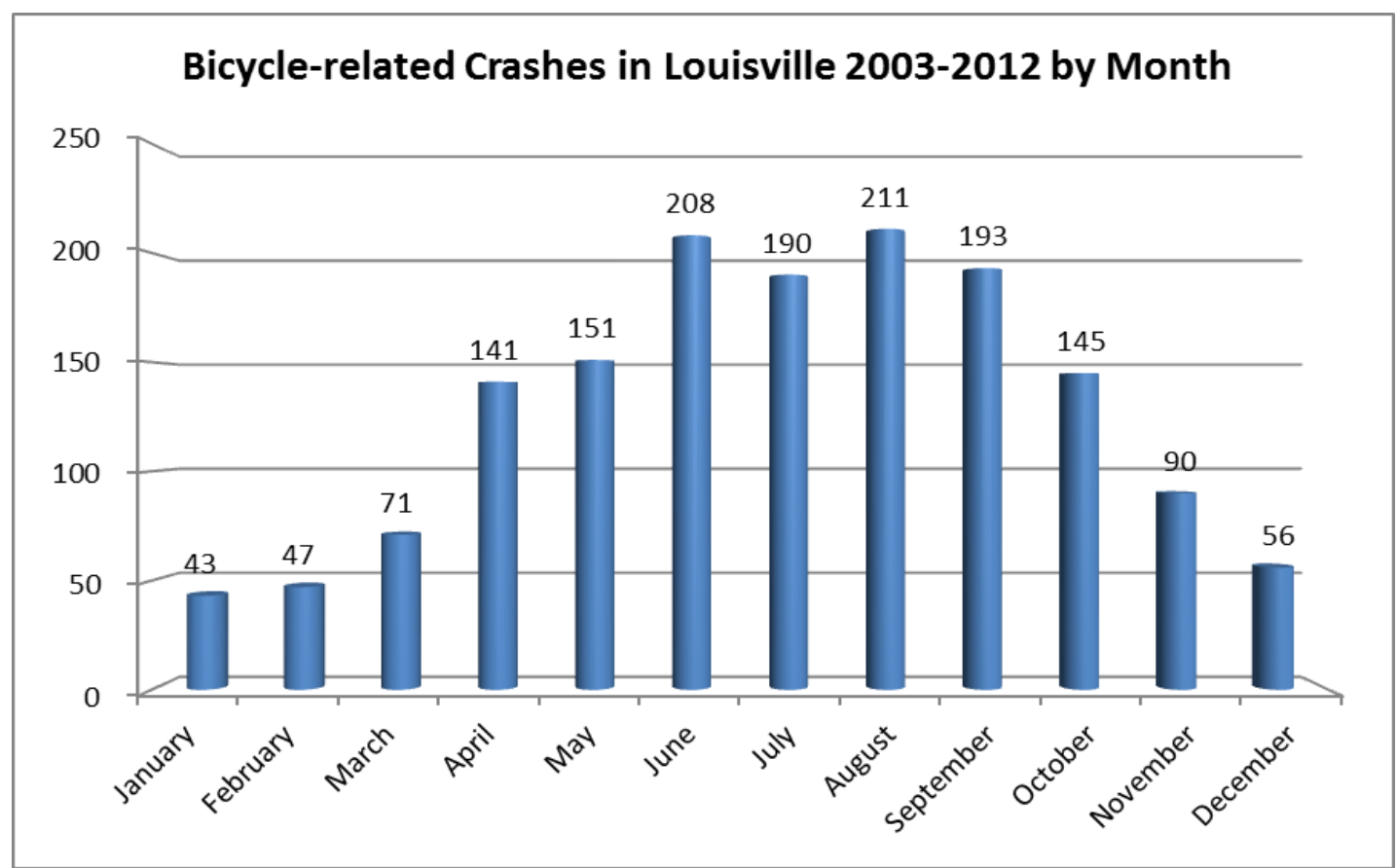

Figure24: Bicycle-related Crashes Happened in Louisville from 2003 to 2012 by Month (Data Source: Kentucky Collision Analysis for the Public, http://crashinformationky.org)

\section{By Day}

According to the data shown in Table 8, crashes were more prevalent on weekdays than weekends. The most common day was Thursday with 16.4 percent of crashes, and the lowest is Sunday with 10.2 percent.

\section{Table 8}

Bicycle-related Crashes Happened in Louisville from 2003 to 2012 by Day of Week 


\begin{tabular}{|c|c|c|c|c|c|c|c|c|c|c|c|c|}
\hline Day & $\begin{array}{c}200 \\
3\end{array}$ & $\begin{array}{c}200 \\
4\end{array}$ & $\begin{array}{c}200 \\
5\end{array}$ & $\begin{array}{c}200 \\
6\end{array}$ & $\begin{array}{c}200 \\
7\end{array}$ & $\begin{array}{c}200 \\
8\end{array}$ & $\begin{array}{c}200 \\
9\end{array}$ & $\begin{array}{c}201 \\
0\end{array}$ & $\begin{array}{c}201 \\
1\end{array}$ & $\begin{array}{c}201 \\
2\end{array}$ & Total & Percent \\
\hline Sunday & 17 & 15 & 20 & 15 & 17 & 14 & 18 & 12 & 19 & 10 & 157 & $10.2 \%$ \\
\hline Monday & 21 & 18 & 27 & 18 & 30 & 28 & 21 & 23 & 26 & 20 & 232 & $15.0 \%$ \\
\hline Tuesday & 26 & 23 & 26 & 31 & 24 & 27 & 12 & 18 & 34 & 21 & 242 & $15.7 \%$ \\
\hline Wednesday & 25 & 31 & 20 & 17 & 23 & 23 & 23 & 33 & 22 & 23 & 240 & $15.5 \%$ \\
\hline Thursday & 18 & 22 & 25 & 29 & 20 & 30 & 28 & 25 & 31 & 25 & 253 & $16.4 \%$ \\
\hline Friday & 31 & 19 & 21 & 22 & 20 & 11 & 25 & 23 & 27 & 22 & 221 & $14.3 \%$ \\
\hline Saturday & 28 & 26 & 12 & 28 & 19 & 15 & 15 & 15 & 22 & 21 & 201 & $13.0 \%$ \\
\hline
\end{tabular}

(Data Source: Kentucky Collision Analysis for the Public

http://crashinformationky.org)

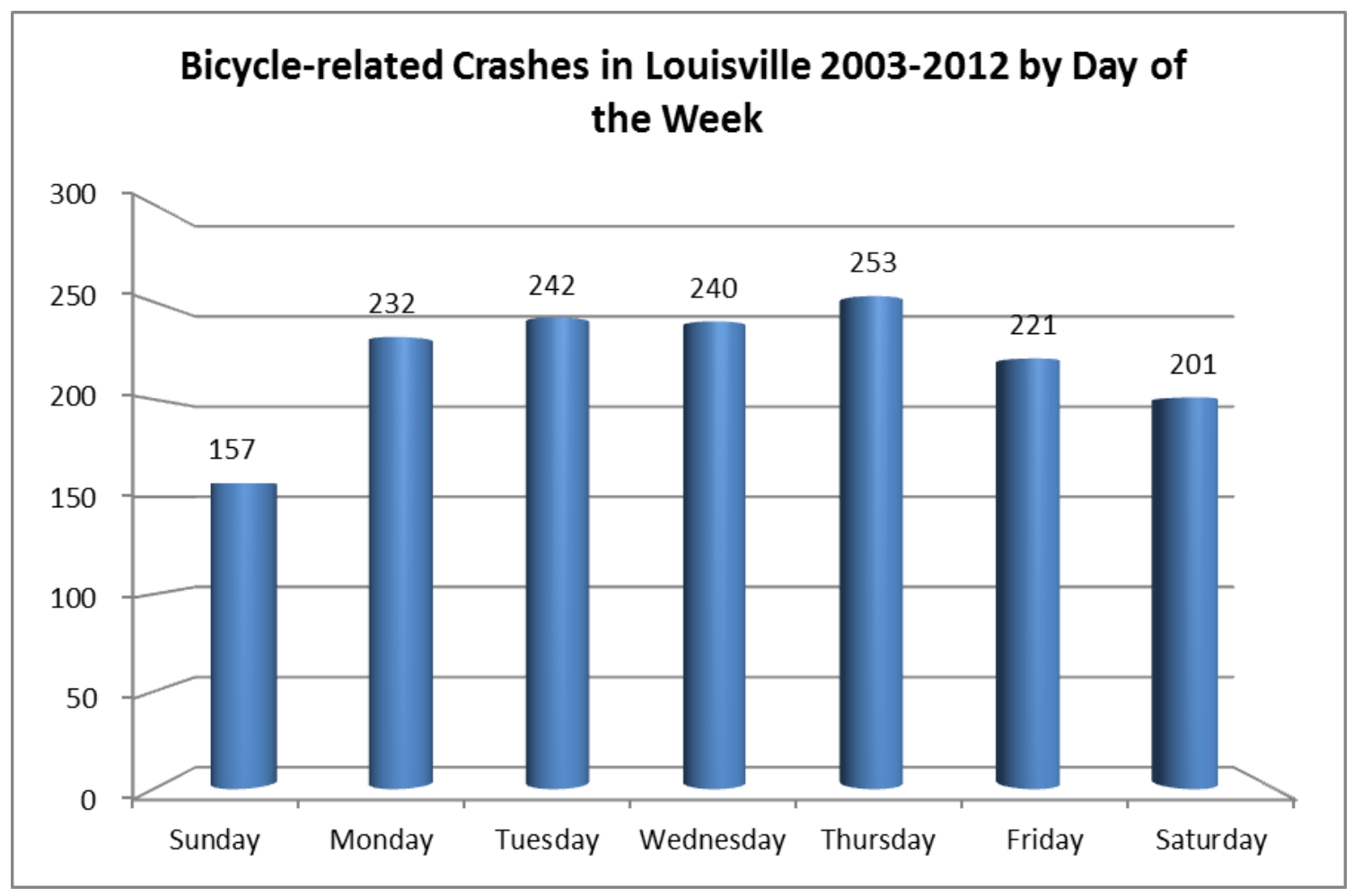

Figure25: Bicycle-related Crashes Happened in Louisville from 2003 to 2012 by Day of Week (Data Source: Kentucky Collision Analysis for the Public, 
http://crashinformationky.org)

\section{By Time of Day}

According to the data shown in Table 9, most crashes occurred during the afternoon peak period between 3:00-6:00 p.m. Crashes increased steadily from each morning, peaked in the late afternoon and dropped off into the evening. The lowest period of crashes was from 3:00 a.m. to 6:00 a.m. These patterns adhere closely to bicyclist traffic patterns and traffic patterns for all modes in Louisville.

\section{Table 9}

Bicycle-related Crashes Happened in Louisville from 2003 to 2012 by Time of Day

\begin{tabular}{|l|c|c|c|c|c|c|c|c|c|c|c|c|}
\hline Time & $\begin{array}{c}\mathbf{2 0 0} \\
\mathbf{3}\end{array}$ & $\begin{array}{c}\mathbf{2 0 0} \\
\mathbf{4}\end{array}$ & $\begin{array}{c}\mathbf{2 0 0} \\
\mathbf{5}\end{array}$ & $\begin{array}{c}\mathbf{2 0 0} \\
\mathbf{6}\end{array}$ & $\begin{array}{c}\mathbf{2 0 0} \\
\mathbf{7}\end{array}$ & $\begin{array}{c}\mathbf{2 0 0} \\
\mathbf{8}\end{array}$ & $\begin{array}{c}\mathbf{2 0 0} \\
\mathbf{9}\end{array}$ & $\begin{array}{c}\mathbf{2 0 1} \\
\mathbf{0}\end{array}$ & $\begin{array}{c}\mathbf{2 0 1} \mathbf{1} \\
\mathbf{2}\end{array}$ & $\begin{array}{c}\mathbf{2 0 1} \\
\mathbf{2}\end{array}$ & Total & Percent \\
\hline $\begin{array}{l}\text { Midnight- } \\
\text { 3:00.m. }\end{array}$ & 7 & 0 & 0 & 5 & 0 & 5 & 3 & 1 & 5 & 6 & 32 & $2.1 \%$ \\
\hline $\begin{array}{l}\text { 3:00-6:00 } \\
\text { a.m. }\end{array}$ & 0 & 0 & 1 & 1 & 0 & 2 & 2 & 2 & 2 & 3 & 13 & $0.8 \%$ \\
\hline $\begin{array}{l}\text { 6:00-9:00 } \\
\text { a.m. }\end{array}$ & 7 & 11 & 10 & 14 & 9 & 13 & 14 & 18 & 12 & 9 & 117 & $7.6 \%$ \\
\hline $\begin{array}{l}\text { 9:00- } \\
\text { Noon }\end{array}$ & 10 & 12 & 17 & 9 & 17 & 13 & 13 & 15 & 20 & 19 & 145 & $9.4 \%$ \\
\hline $\begin{array}{l}\text { Noon- } \\
\text { 3:00 p.m. }\end{array}$ & 24 & 30 & 25 & 25 & 22 & 24 & 29 & 26 & 38 & 22 & 265 & $17.2 \%$ \\
\hline $\begin{array}{l}\text { 3:00-6:00 } \\
\text { p.m. }\end{array}$ & 61 & 41 & 53 & 46 & 47 & 40 & 40 & 42 & 52 & 44 & 466 & $30.3 \%$ \\
\hline 6:00-9:00 & 40 & 44 & 28 & 40 & 34 & 38 & 28 & 32 & 38 & 30 & 352 & $22.9 \%$ \\
\hline
\end{tabular}




\begin{tabular}{|l|c|c|c|c|c|c|c|c|c|c|c|c|}
\hline p.m. & & & & & & & & & & & & \\
\hline $\begin{array}{l}\text { 9:00- } \\
\text { Mitnight }\end{array}$ & 12 & 16 & 16 & 18 & 24 & 13 & 13 & 13 & 14 & 9 & 148 & $9.6 \%$ \\
\hline Total & 161 & 154 & 150 & 158 & 153 & 148 & 142 & 149 & 181 & 142 & 1538 & $100.0 \%$ \\
\hline
\end{tabular}

(Data Source: Kentucky Collision Analysis for the Public

http://crashinformationky.org)

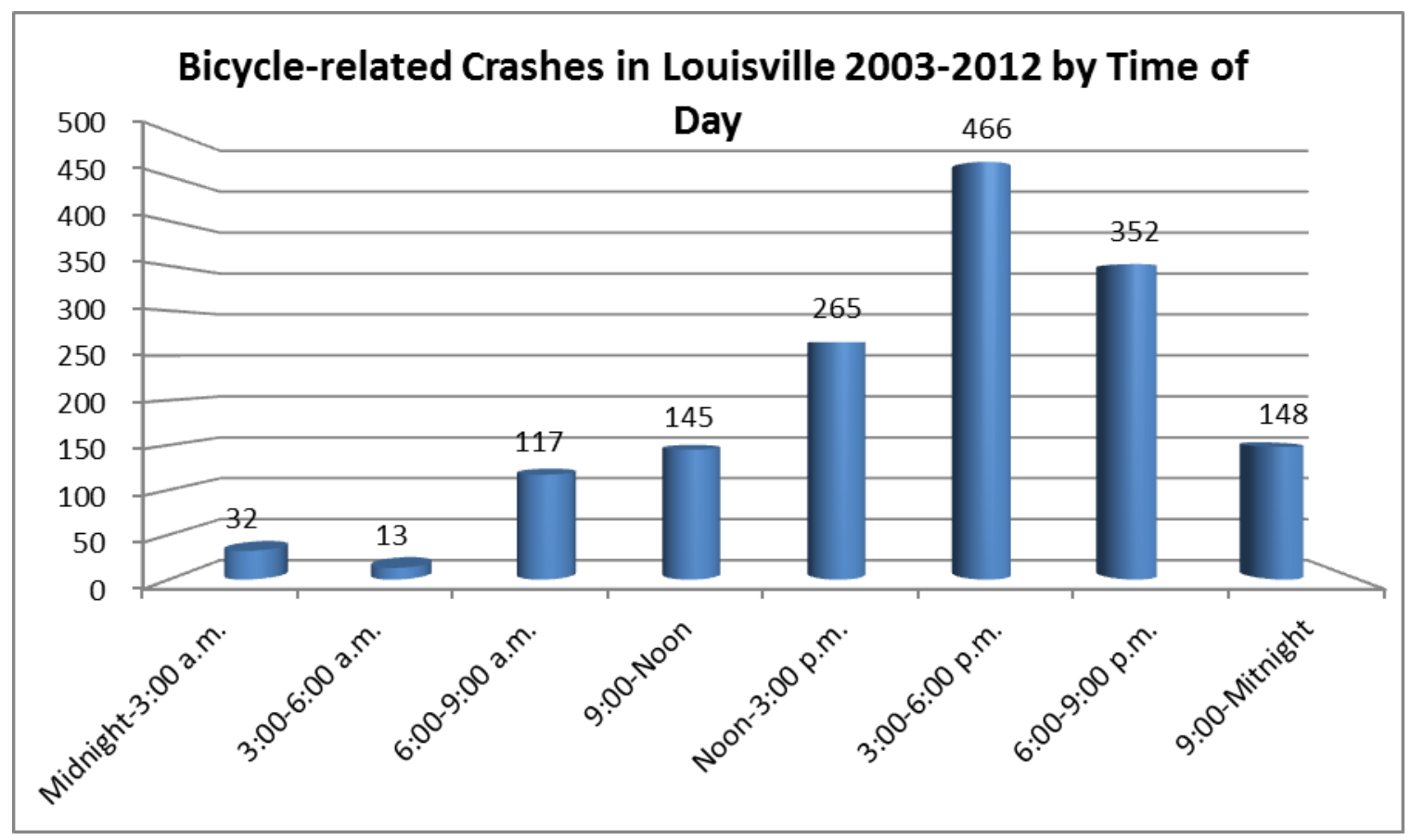

Figure 26: Bicycle-related Crashes Happened in Louisville from 2003 to 2012 by Time of Day (Data Source: Kentucky Collision Analysis for the Public http://crashinformationky.org)

\section{b) Environmental Condition}

\section{Weather}

According to the data in Table 10, environmental conditions were clear 76.5 
percent of the time and cloudy 17.9 percent of the time. It was raining for five percent of all crashes, and snowing, sleet or hail, fog smoke or smog, and unknown for less than 1 percent combined of all crashes.

Table 10

Bicycle-related Crashes Happened in Louisville from 2003 to 2012 by Weather Type

\begin{tabular}{|c|c|c|c|c|c|c|c|c|c|c|c|c|}
\hline Weather & $\begin{array}{c}200 \\
3\end{array}$ & $\begin{array}{c}200 \\
4\end{array}$ & $\begin{array}{c}200 \\
5\end{array}$ & $\begin{array}{c}200 \\
6\end{array}$ & $\begin{array}{c}200 \\
7\end{array}$ & $\begin{array}{c}200 \\
8\end{array}$ & $\begin{array}{c}200 \\
9\end{array}$ & $\begin{array}{c}201 \\
0\end{array}$ & $\begin{array}{c}201 \\
1\end{array}$ & $\begin{array}{c}201 \\
2\end{array}$ & Total & $\begin{array}{c}\text { Perce } \\
\text { nt }\end{array}$ \\
\hline Clear & 125 & 112 & 115 & 114 & 124 & 117 & 107 & 118 & 138 & 112 & 1182 & $76.5 \%$ \\
\hline Cloudy & 34 & 32 & 25 & 29 & 27 & 23 & 28 & 23 & 35 & 21 & 277 & $17.9 \%$ \\
\hline Raining & 6 & 9 & 9 & 16 & 2 & 8 & 6 & 6 & 8 & 7 & 77 & $5.0 \%$ \\
\hline Snowing & 1 & 1 & 0 & 0 & 0 & 0 & 0 & 2 & 0 & 1 & 5 & $0.3 \%$ \\
\hline $\begin{array}{l}\text { Sleet or } \\
\text { Hail }\end{array}$ & 0 & 0 & 0 & 0 & 0 & 0 & 0 & 0 & 0 & 0 & 0 & $0.0 \%$ \\
\hline $\begin{array}{l}\text { Fog, } \\
\text { Smoke or } \\
\text { Smog }\end{array}$ & 0 & 0 & 2 & 0 & 0 & 0 & 0 & 0 & 0 & 0 & 2 & $0.1 \%$ \\
\hline $\begin{array}{l}\text { Unknown } \\
\text { or Other }\end{array}$ & 0 & 0 & 0 & 1 & 0 & 0 & 1 & 0 & 0 & 1 & 3 & $0.2 \%$ \\
\hline Total & 166 & 154 & 151 & 160 & 153 & 148 & 142 & 149 & 181 & 142 & 1546 & $100 \%$ \\
\hline
\end{tabular}

(Data Source: Kentucky Collision Analysis for the Public

http://crashinformationky.org) 


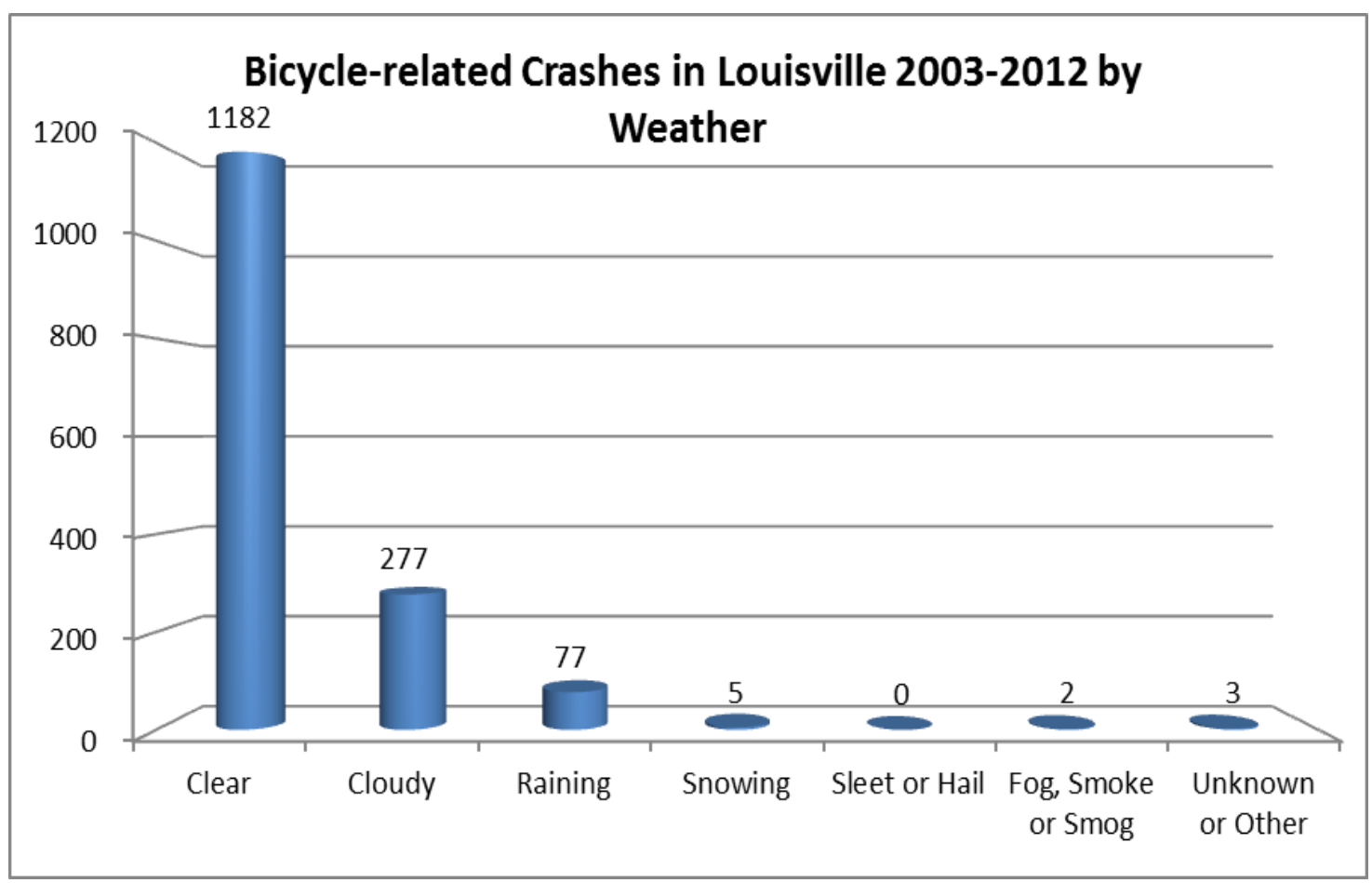

Figure 27: Bicycle-related Crashes Happened in Louisville from 2003 to 2012 by Weather Type (Data Source: Kentucky Collision Analysis for the Public http://crashinformationky.org)

\section{Road Surface Condition}

The road surface condition at the time of crashes was generally favorable. From the data in Table 11, conditions were dry 91.8 percent of the time and wet 7.8 percent of time. Snow, slush or ice were present for 0.3 percent of crashes.

\section{Table 11}

Bicycle-related Crashes Happened in Louisville from 2003 to 2012 by Road Surface Condition 


\begin{tabular}{|l|c|c|c|c|c|c|c|c|c|c|c|c|}
\hline $\begin{array}{l}\text { Road } \\
\text { Surface } \\
\text { Condition }\end{array}$ & $\begin{array}{c}\mathbf{2 0 0} \\
\mathbf{3}\end{array}$ & $\begin{array}{c}\mathbf{2 0 0} \\
\mathbf{4}\end{array}$ & $\begin{array}{c}\mathbf{2 0 0} \\
\mathbf{5}\end{array}$ & $\begin{array}{c}\mathbf{2 0 0} \\
\mathbf{6}\end{array}$ & $\begin{array}{c}\mathbf{2 0 0} \\
\mathbf{7}\end{array}$ & $\begin{array}{c}\mathbf{2 0 0} \\
\mathbf{8}\end{array}$ & $\begin{array}{c}\mathbf{2 0 0} \\
\mathbf{9}\end{array}$ & $\begin{array}{c}\mathbf{2 0 1} \\
\mathbf{0}\end{array}$ & $\begin{array}{c}\mathbf{2 0 1} \\
\mathbf{1}\end{array}$ & $\begin{array}{c}\mathbf{2 0 1} \\
\mathbf{2}\end{array}$ & Total & Percent \\
\hline Dry & 152 & 143 & 134 & 142 & 143 & 139 & 130 & 140 & 165 & 132 & 1420 & $91.8 \%$ \\
\hline Ice & 1 & 0 & 0 & 0 & 1 & 0 & 1 & 0 & 0 & 0 & 3 & $0.2 \%$ \\
\hline Wet & 13 & 10 & 17 & 18 & 9 & 9 & 11 & 9 & 16 & 9 & 121 & $7.8 \%$ \\
\hline $\begin{array}{l}\text { Snow, } \\
\text { Slush }\end{array}$ & 0 & 1 & 0 & 0 & 0 & 0 & 0 & 0 & 0 & 1 & 2 & $0.1 \%$ \\
\hline Total & 166 & 154 & 151 & 160 & 153 & 148 & 142 & 149 & 181 & 142 & 1546 & $100.0 \%$ \\
\hline
\end{tabular}

(Data Source: Kentucky Collision Analysis for the Public

http://crashinformationky.org)

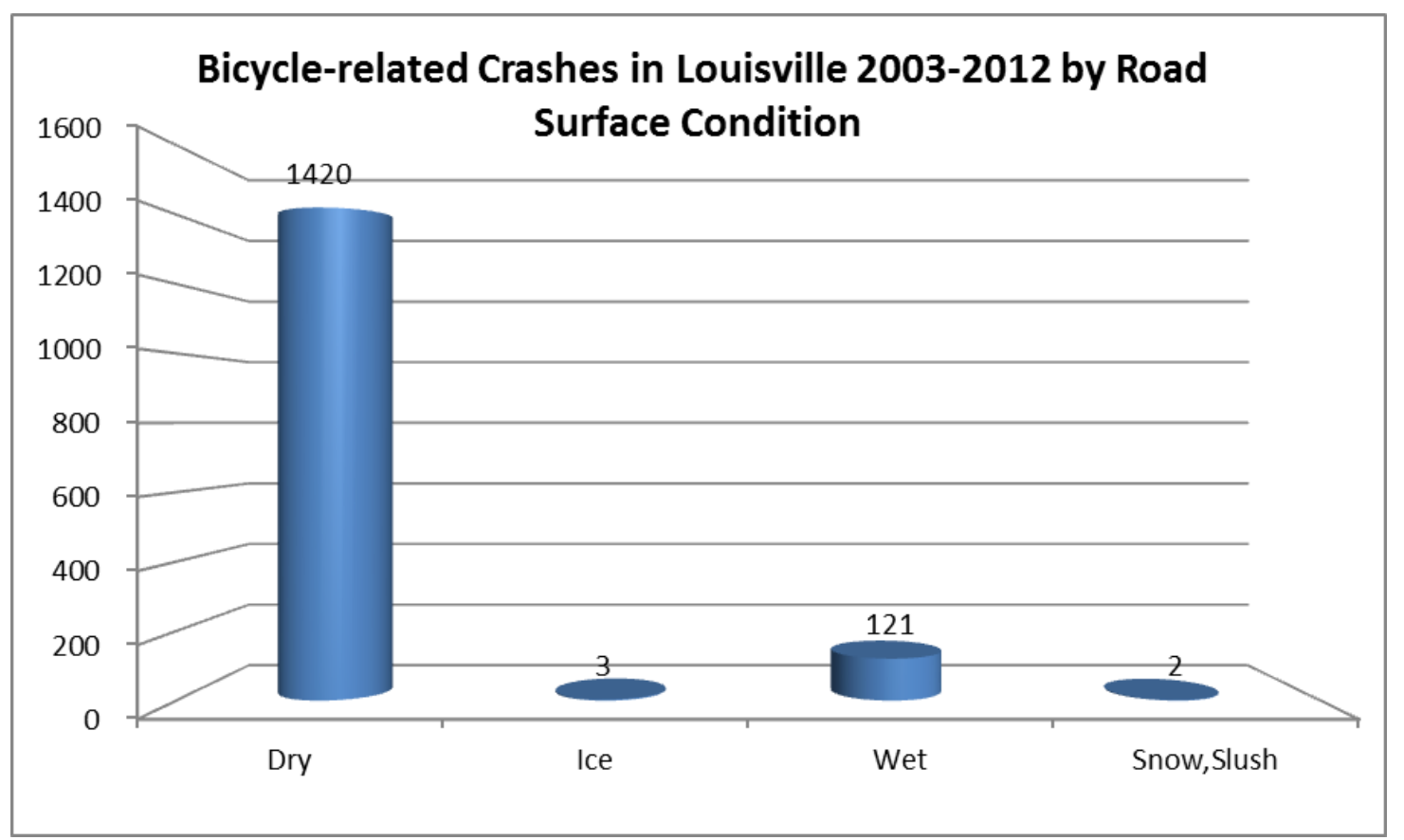

Figure 28: Bicycle-related Crashes Happened in Louisville from 2003 to 2012 by Road Surface Condition (Data Source: Kentucky Collision Analysis for the Public http://crashinformationky.org) 


\section{c) Motor Vehicle Type}

According to Table 12, most motor vehicles involved in bicycle-related crashes were automobiles-90 percent. All other vehicle types each accounted for less than two percent of crashes, except Hit \& Run/ Unknown is 4.6 percent.

\section{Table 12}

Bicycle-related Crashes Happened in Louisville from 2003 to 2012 by Motor Vehicle Type

\begin{tabular}{|l|c|c|}
\hline \multicolumn{1}{|c|}{$\begin{array}{c}\text { Vehicle Type (other } \\
\text { than bicycle) }\end{array}$} & Count & Percent \\
\hline Passenger Car & 969 & $66.0 \%$ \\
\hline $\begin{array}{l}\text { Light Truck/Sports } \\
\text { Utility/Pickup }\end{array}$ & 353 & $24.0 \%$ \\
\hline Hit \& Run/Unknown & 67 & $4.6 \%$ \\
\hline $\begin{array}{l}\text { Emergency Vehicle non } \\
\text { Response }\end{array}$ & 16 & $1.1 \%$ \\
\hline Motorcycle & 15 & $1.0 \%$ \\
\hline Bus & 9 & $0.6 \%$ \\
\hline Truck-Single Unit & 9 & $0.6 \%$ \\
\hline $\begin{array}{l}\text { Other Public Owned } \\
\text { Vehicle }\end{array}$ & 5 & $0.5 \%$ \\
\hline $\begin{array}{l}\text { Motor Scooter or Motor } \\
\text { Bicycle }\end{array}$ & 5 & $0.3 \%$ \\
\hline School Bus & $5 \%$ \\
\hline Truck \& Trailer & $5 \%$ \\
\hline
\end{tabular}




\begin{tabular}{|l|c|c|}
\hline Other & 5 & $0.3 \%$ \\
\hline Taxicab & 2 & $0.1 \%$ \\
\hline Total & 1468 & $100.0 \%$ \\
\hline
\end{tabular}

(Data Source: Kentucky Collision Analysis for the Public http://crashinformationky.org)

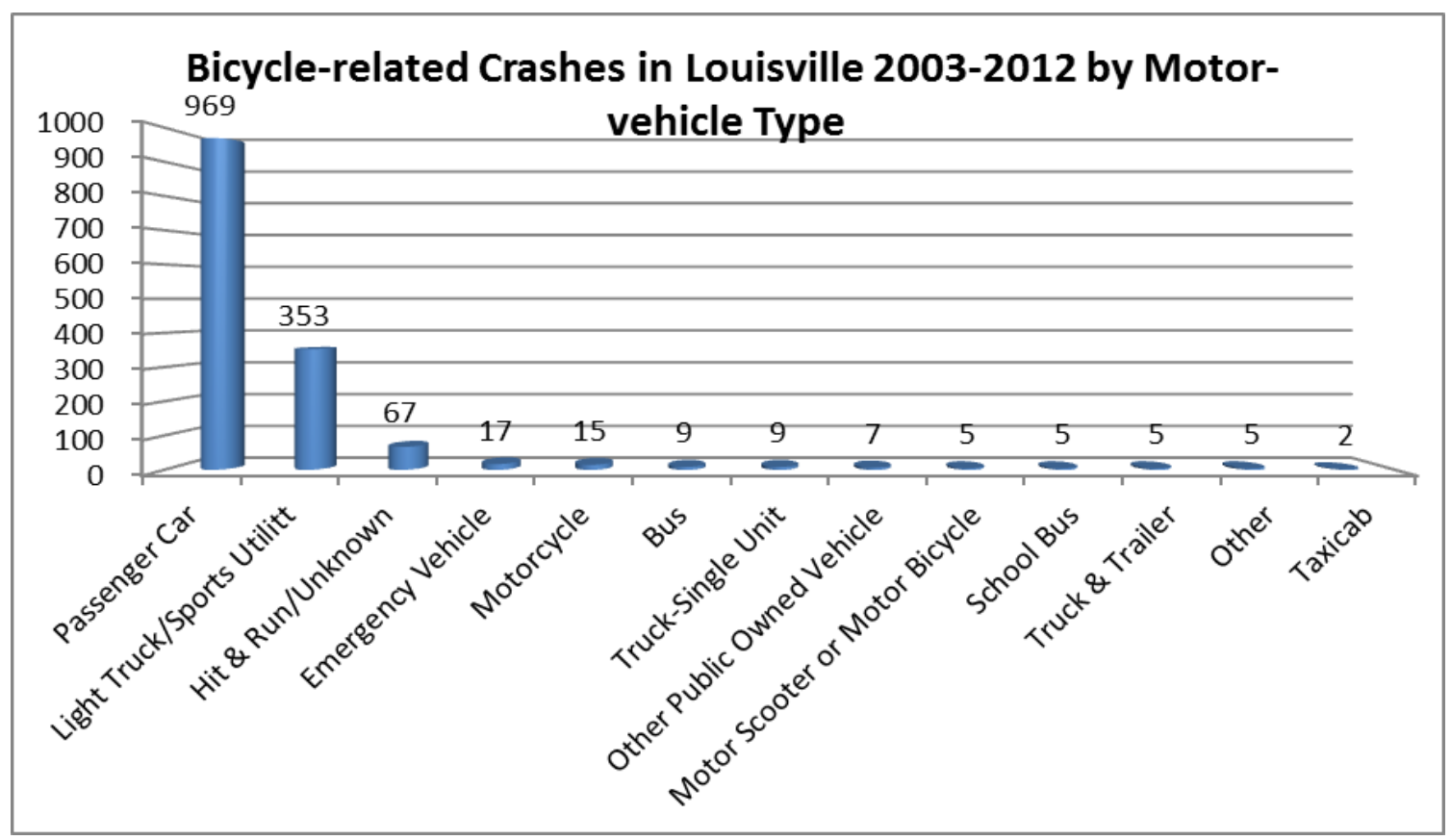

Figure 29: Bicycle-related Crashes Happened in Louisville from 2003 to 2012 by Motor Vehicle Type (Data Source: Kentucky Collision Analysis for the Public http://crashinformationky.org)

\section{d) Bicyclists Age}

According to the data in Table 13, bicyclists in the age group 25-34 made up the highest crash rate in all categories. Young people who were younger than 18 
account for 16.9 percent. Bicyclists older than 65 accounted for less than 5 percent of all crashes.

\section{Table 13}

Bicycle-related Crashes Happened in Louisville from 2003 to 2012 by Bicyclists Age

\begin{tabular}{|c|c|c|c|c|c|c|c|c|c|c|c|c|}
\hline $\begin{array}{l}\text { Bicyclist } \\
\text { Age }\end{array}$ & $\begin{array}{c}200 \\
3\end{array}$ & $\begin{array}{c}200 \\
4\end{array}$ & $\begin{array}{c}200 \\
5\end{array}$ & $\begin{array}{c}200 \\
6\end{array}$ & $\begin{array}{c}200 \\
7\end{array}$ & $\begin{array}{c}200 \\
8\end{array}$ & $\begin{array}{c}200 \\
9\end{array}$ & $\begin{array}{c}201 \\
0\end{array}$ & $\begin{array}{c}201 \\
1\end{array}$ & $\begin{array}{c}201 \\
2\end{array}$ & Total & Percent \\
\hline 4 to 12 & 48 & 34 & 31 & 43 & 33 & 32 & 26 & 19 & 44 & 24 & 334 & $8.9 \%$ \\
\hline 13 to 17 & 39 & 31 & 30 & 36 & 35 & 27 & 28 & 22 & 27 & 27 & 302 & $8.0 \%$ \\
\hline 18 to 24 & 35 & 40 & 47 & 49 & 45 & 46 & 54 & 46 & 68 & 51 & 481 & $12.8 \%$ \\
\hline 25 to 34 & 56 & 36 & 48 & 57 & 50 & 61 & 65 & 72 & 66 & 63 & 574 & $15.2 \%$ \\
\hline 35 to 44 & 52 & 48 & 45 & 60 & 48 & 51 & 44 & 61 & 56 & 47 & 512 & $13.6 \%$ \\
\hline 45 to 54 & 39 & 40 & 51 & 46 & 51 & 55 & 47 & 42 & 78 & 46 & 495 & $13.2 \%$ \\
\hline 55 to 64 & 21 & 28 & 24 & 33 & 31 & 29 & 33 & 38 & 51 & 42 & 330 & $8.8 \%$ \\
\hline $\begin{array}{l}65 \text { and } \\
\text { older }\end{array}$ & 11 & 15 & 16 & 5 & 17 & 19 & 19 & 17 & 28 & 18 & 165 & $4.4 \%$ \\
\hline $\begin{array}{l}\text { Unknown } \\
\text { or Other }\end{array}$ & 97 & 83 & 105 & 59 & 59 & 49 & 17 & 35 & 31 & 36 & 571 & $15.2 \%$ \\
\hline Total & 398 & 355 & 397 & 388 & 369 & 369 & 333 & 352 & 449 & 354 & 3764 & $100.0 \%$ \\
\hline
\end{tabular}

(Data Source: Kentucky Collision Analysis for the Public

http://crashinformationky.org) 


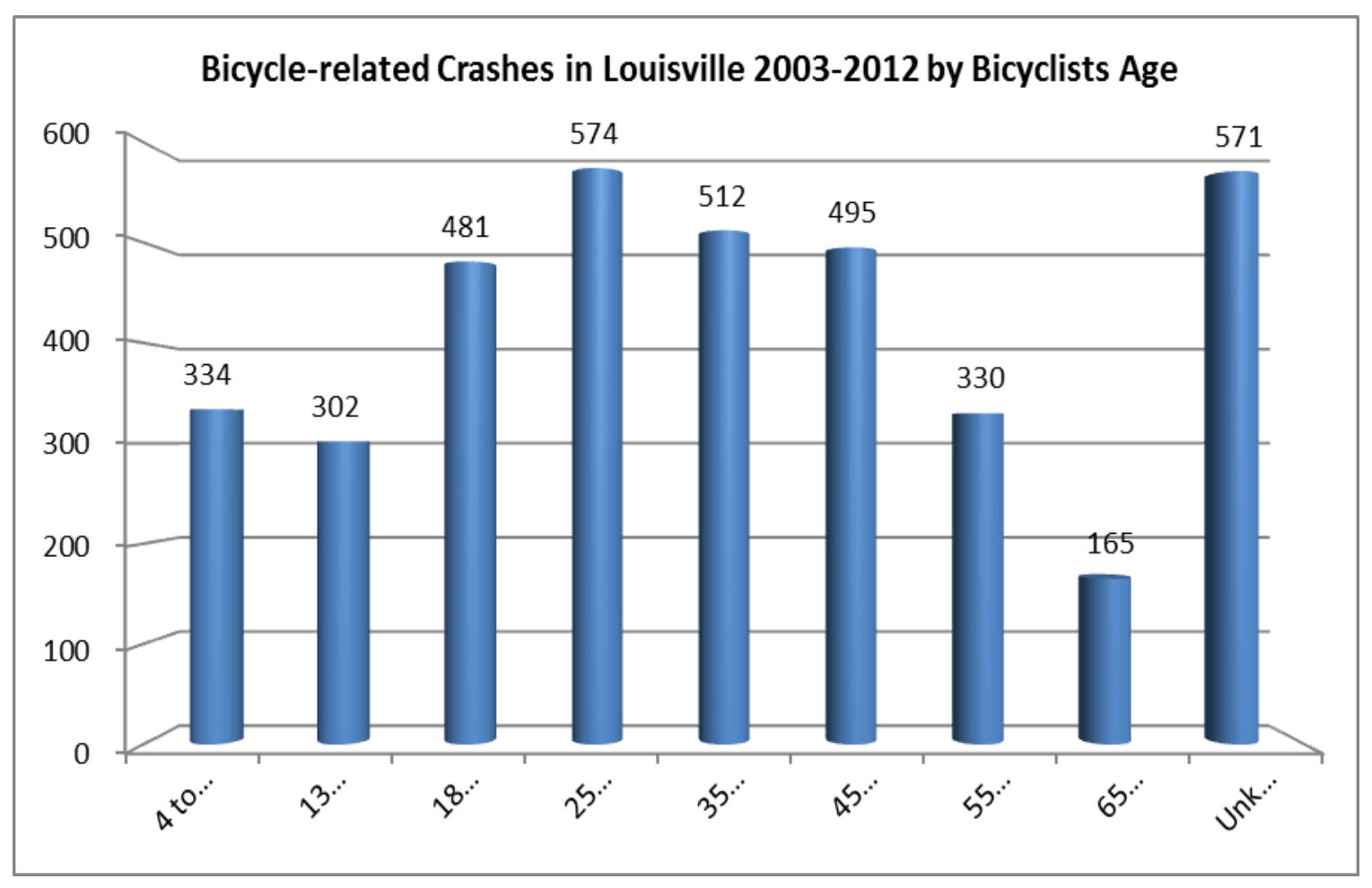

Figure 30: Bicycle-related Crashes Happened in Louisville from 2003 to 2012 by Bicyclists Age (Data Source: Kentucky Collision Analysis for the Public http://crashinformationky.org)

\section{e) Bicyclists' and Drivers' Condition}

\section{Bicyclists' Condition}

According the data in Table 14, of all bicycle-related crashes occurring in Louisville from 2003-2012, the highest known bicyclists' condition was "inattention" which accounted for 20.7 percent. The second highest condition was "failed to yield right-of-way", which accounted for 11.2 percent. Other conditions all made up less than 2 percent. Unfortunately, the category of "none detected" bicyclists and "other" accounted for 51.7 percent and 6.6 percent respectively. 
The total of these two categories was 58.3 percent.

\section{Table 14}

Bicycle-related Crashes Happened in Louisville from 2003 to 2012 by Bicyclists' Condition

\begin{tabular}{|l|c|c|}
\hline \multicolumn{1}{|c|}{ Bicyclists' Condition } & Count & Percent \\
\hline None Detected & 795 & $51.7 \%$ \\
\hline Inattention & 318 & $20.7 \%$ \\
\hline Failed to yield Right-of-way & 173 & $11.2 \%$ \\
\hline Other & 102 & $6.6 \%$ \\
\hline Disregard Traffic Control & 27 & $1.8 \%$ \\
\hline Misjudge Clearance & 24 & $1.6 \%$ \\
\hline Alcohol Involvement & 17 & $1.1 \%$ \\
\hline Exceeded Stated Speed & 12 & $0.8 \%$ \\
\hline Limit & 11 & $0.7 \%$ \\
\hline Distraction & 11 & $0.7 \%$ \\
\hline Not under Proper Control & 8 & $0.5 \%$ \\
\hline Turning Improperly & 7 & $0.5 \%$ \\
\hline Follow Too Close & 7 & $0.5 \%$ \\
\hline Improper Passing & $5 \%$ \\
\hline Too Fast for Conditions & & $0.4 \%$ \\
\hline Weaving in Traffic & & \\
\hline Lost Consciousness/Fainted & & \\
\hline
\end{tabular}




\begin{tabular}{|l|c|c|}
\hline Emotional & 3 & $0.2 \%$ \\
\hline Physical Disability & 2 & $0.1 \%$ \\
\hline Drug Involvement & 1 & $0.1 \%$ \\
\hline Fatigue and Fell Asleep & 1 & $0.1 \%$ \\
\hline Improper Backing & 1 & $0.1 \%$ \\
\hline Overcorrecting/Oversteering & 1 & $0.1 \%$ \\
\hline \multicolumn{1}{|c|}{ Total } & 1539 & $100.0 \%$ \\
\hline
\end{tabular}

(Data Source: Kentucky Collision Analysis for the Public http://crashinformationky.org)

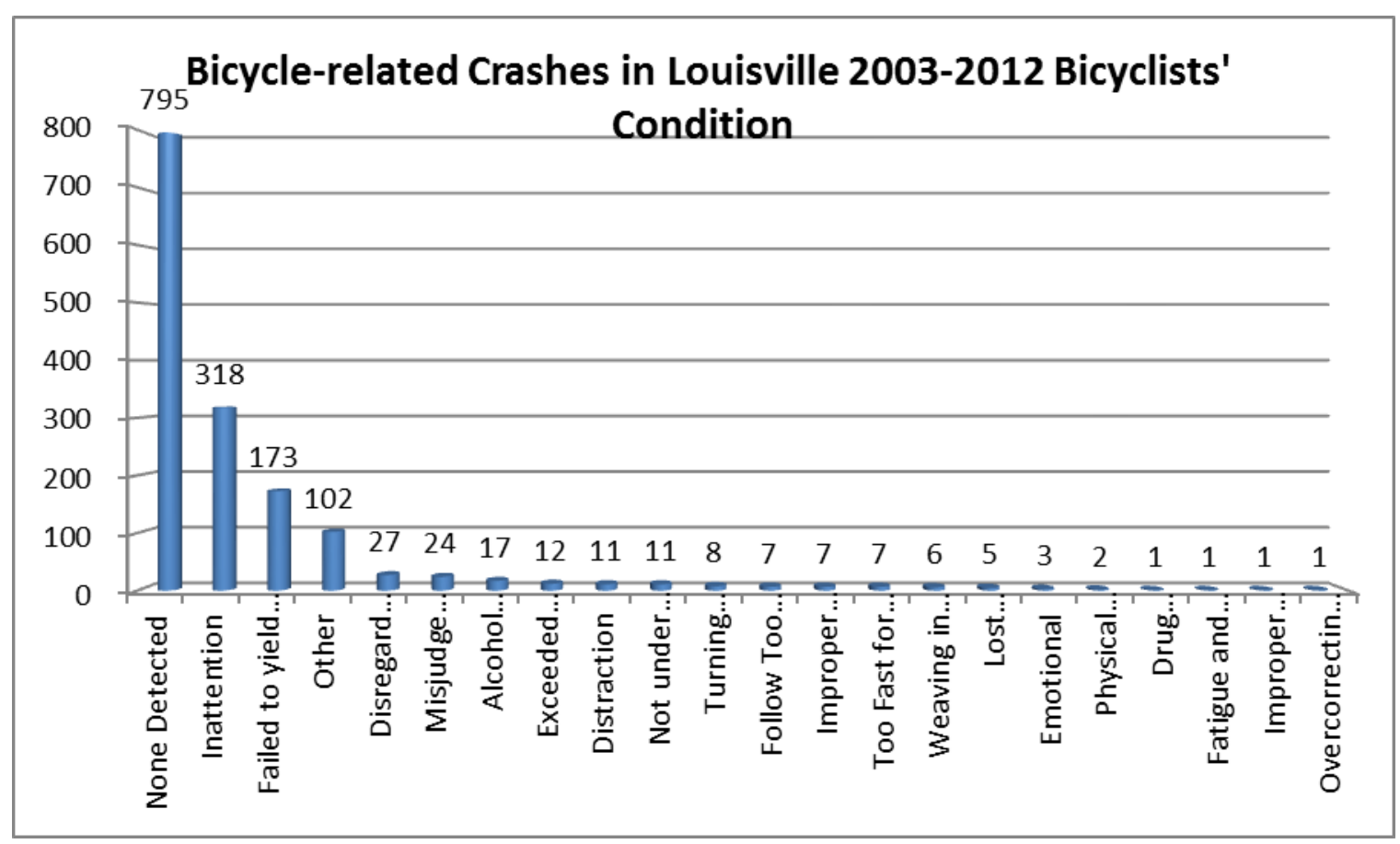

Figure 31: Bicycle-related Crashes Happened in Louisville from 2003 to 2012 by Bicyclists' Condition (Data Source: Kentucky Collision Analysis for the Public http://crashinformationky.org) 


\section{Drivers' Condition}

According to the data in Table 15, the highest known drivers' condition was "inattention", which accounts for 19.4 percent of all crashes; the second highest condition was "failed to yield right-of-way", which accounted for 11.1 percent of all crashes. Other conditions all accounted for less than 2 percent. Unfortunately, the category of "none detected" accounted for 54.1 percent and "other" accounted for 6.1 percent. The total of these two categories was 60.2 percent.

\section{Table 15}

Bicycle-related Crashes Happened in Louisville from 2003 to 2012 by Drivers' Condition

\begin{tabular}{|l|c|c|}
\hline \multicolumn{1}{|c|}{ Drivers' Condition } & Count & Percent \\
\hline None Detected & 822 & $54.1 \%$ \\
\hline Inattention & 295 & $19.4 \%$ \\
\hline Failed to yield Right-of-way & 169 & $11.1 \%$ \\
\hline Other & 92 & $6.1 \%$ \\
\hline Disregard Triffic Control & 25 & $1.6 \%$ \\
\hline Misjudge Clearance & 23 & $1.5 \%$ \\
\hline Alcohol Involvement & 16 & $1.1 \%$ \\
\hline $\begin{array}{l}\text { Exceeded Stated Speed } \\
\text { Limit }\end{array}$ & 11 & $0.7 \%$ \\
\hline Distraction & 10 & $0.7 \%$ \\
\hline
\end{tabular}




\begin{tabular}{|l|c|c|}
\hline Not under Proper Control & 10 & $0.7 \%$ \\
\hline Turning Improperly & 8 & $0.5 \%$ \\
\hline Follow Too Close & 7 & $0.5 \%$ \\
\hline Improper Passing & 7 & $0.5 \%$ \\
\hline Weaving in Traffic & 6 & $0.4 \%$ \\
\hline Lost Consciousness/Fainted & 5 & $0.3 \%$ \\
\hline Too Fast for Conditions & 5 & $0.3 \%$ \\
\hline Emotional & 2 & $0.1 \%$ \\
\hline Physical Disability & 2 & $0.1 \%$ \\
\hline Cell Phone & 1 & $0.1 \%$ \\
\hline Drug Involvement & 1 & $0.1 \%$ \\
\hline Fatigue and Fell Asleep & 1 & $0.1 \%$ \\
\hline Improper Backing & 1 & $0.1 \%$ \\
\hline Overcorrecting/Oversteering & 1 & $0.1 \%$ \\
\hline Total & 1520 & $100.0 \%$ \\
\hline
\end{tabular}

(Data Source: Kentucky Collision Analysis for the Public http://crashinformationky.org) 


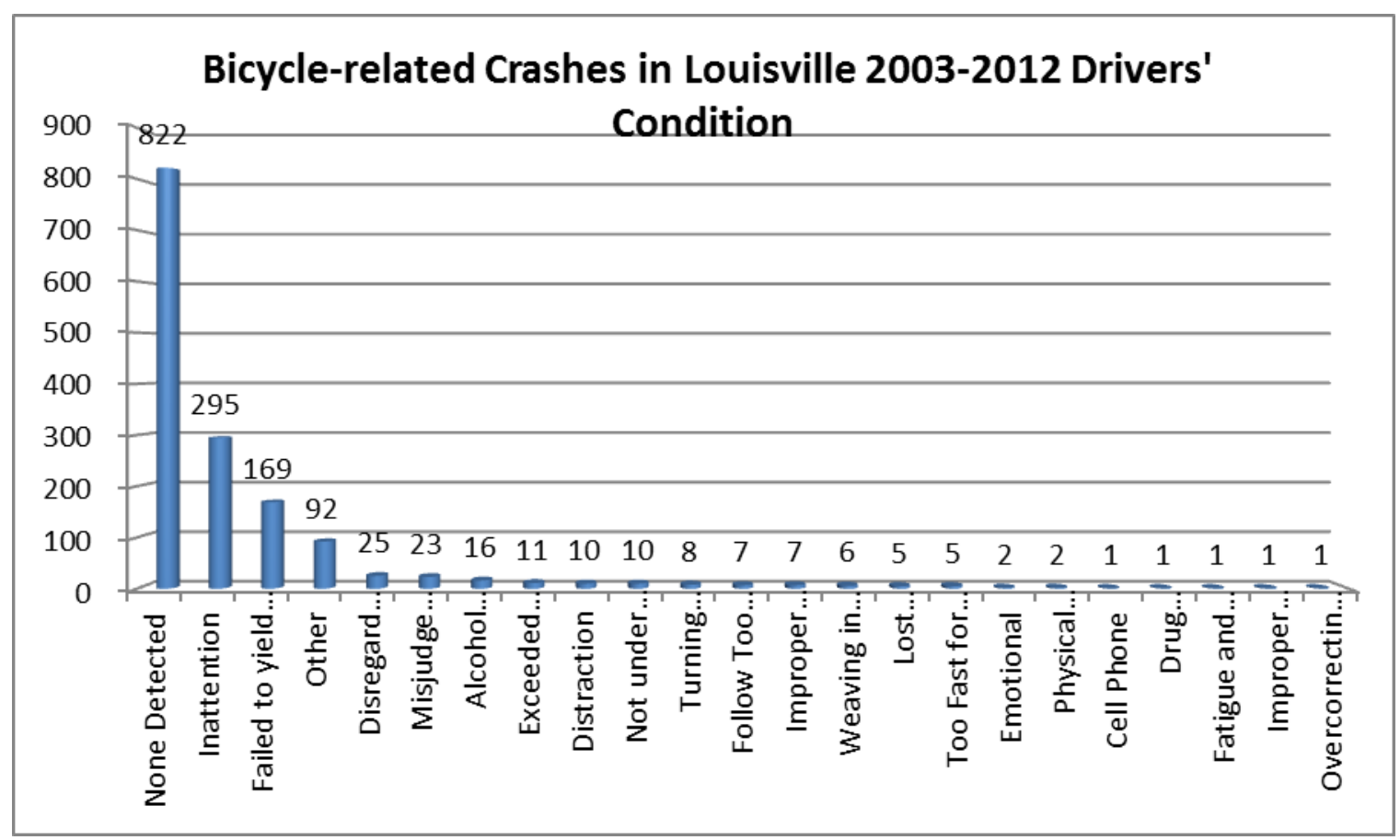

Figure 32: Bicycle-related Crashes Happened in Louisville from 2003 to 2012 by Drivers' Condition (Data Source: Kentucky Collision Analysis for the Public http://crashinformationky.org)

\section{f) Contributing Factors}

\section{Drivers' Pre-crash Maneuver}

According to the data in Table 16, the top three drivers' pre-crash maneuvers were "going straight head" which accounted for 49.2 percent of all crashes, "making left turn" which accounted for 16.3 percent of all crashes and "making right turn" which accounted for 14.3 percent of all crashes. The total of these three categories was 79.8 percent of all crashes. 
Table 16

Bicycle-related Crashes Happened in Louisville from 2003 to 2012 by Drivers' Pre-crash Maneuver

\begin{tabular}{|l|c|c|}
\hline \multicolumn{1}{|c|}{$\begin{array}{c}\text { Motorist Pre-Crash } \\
\text { Maneuver }\end{array}$} & Count & Percent \\
\hline Going Straight Ahead & 724 & $49.2 \%$ \\
\hline Making Left Turn & 240 & $16.3 \%$ \\
\hline Making Right Turn & 211 & $14.3 \%$ \\
\hline Starting in Traffic & 53 & $3.6 \%$ \\
\hline Slowing or Stopped & 51 & $3.5 \%$ \\
\hline Parked & 48 & $3.3 \%$ \\
\hline Other & 32 & $2.2 \%$ \\
\hline Stopping in Traffic & 26 & $1.8 \%$ \\
\hline Backing & 21 & $1.4 \%$ \\
\hline Unknown & 19 & $1.3 \%$ \\
\hline Changing Lanes & 13 & $0.9 \%$ \\
\hline Starting from Parking & 11 & $0.7 \%$ \\
\hline Overtaking & 6 & $0.4 \%$ \\
\hline Leaving Traffic Lane & 5 & $0.3 \%$ \\
\hline Merging & 3 & $0.3 \%$ \\
\hline Entering Parked Position & 3 & $0.2 \%$ \\
\hline Making U Turn & & \\
\hline Avoiding Object in Roadway & 3 & \\
\hline
\end{tabular}




\begin{tabular}{|l|c|c|}
\hline Wrong Way & 1 & $0.1 \%$ \\
\hline Total & 1473 & $100.0 \%$ \\
\hline
\end{tabular}

(Data Source: Kentucky Collision Analysis for the Public

http://crashinformationky.org)

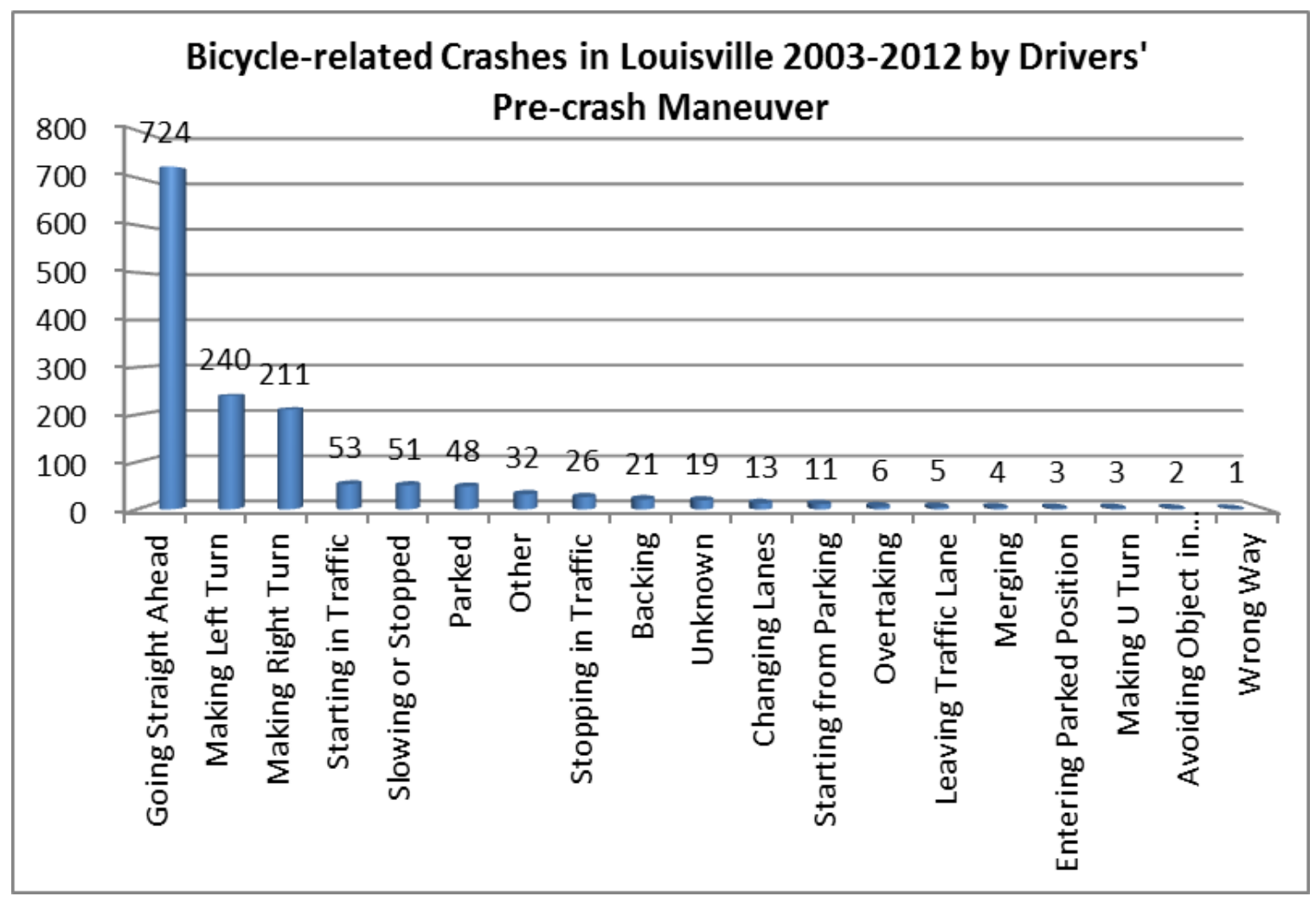

Figure 33: Bicycle-related Crashes Happened in Louisville from 2003 to 2012 by Drivers' Pre-crash Maneuver (Data Source: Kentucky Collision Analysis for the Public http://crashinformationky.org)

\section{Manner of Collision}

According to the data in Table 17, the highest manner of collision between bicycles and motor vehicles was "Angle" which accounted for 38.5 percent of all 
crashes. However, in the data provided by Kentucky Collision Analysis for the Public, there was no detailed information about which kind of angle bicycles and motor vehicles collided with each other.

\section{Table 17}

Bicycle-related Crashes Happened in Louisville from 2003 to 2012 by Manner of Crash

\begin{tabular}{|l|c|c|}
\hline Manner of Collision & Count & Percent \\
\hline Unknown & 649 & $44.6 \%$ \\
\hline Angle & 560 & $38.5 \%$ \\
\hline Sideswipe-same direction & 88 & $6.0 \%$ \\
\hline Head on & 60 & $4.1 \%$ \\
\hline Rear End & 42 & $2.9 \%$ \\
\hline Opposing Left Turn & 24 & $1.6 \%$ \\
\hline $\begin{array}{l}\text { Sideswipe-opposite } \\
\text { Direction }\end{array}$ & 19 & $1.3 \%$ \\
\hline Backing & 13 & $0.9 \%$ \\
\hline Total & 1455 & $100.0 \%$ \\
\hline
\end{tabular}

(Data Source: Kentucky Collision Analysis for the Public

http://crashinformationky.org) 


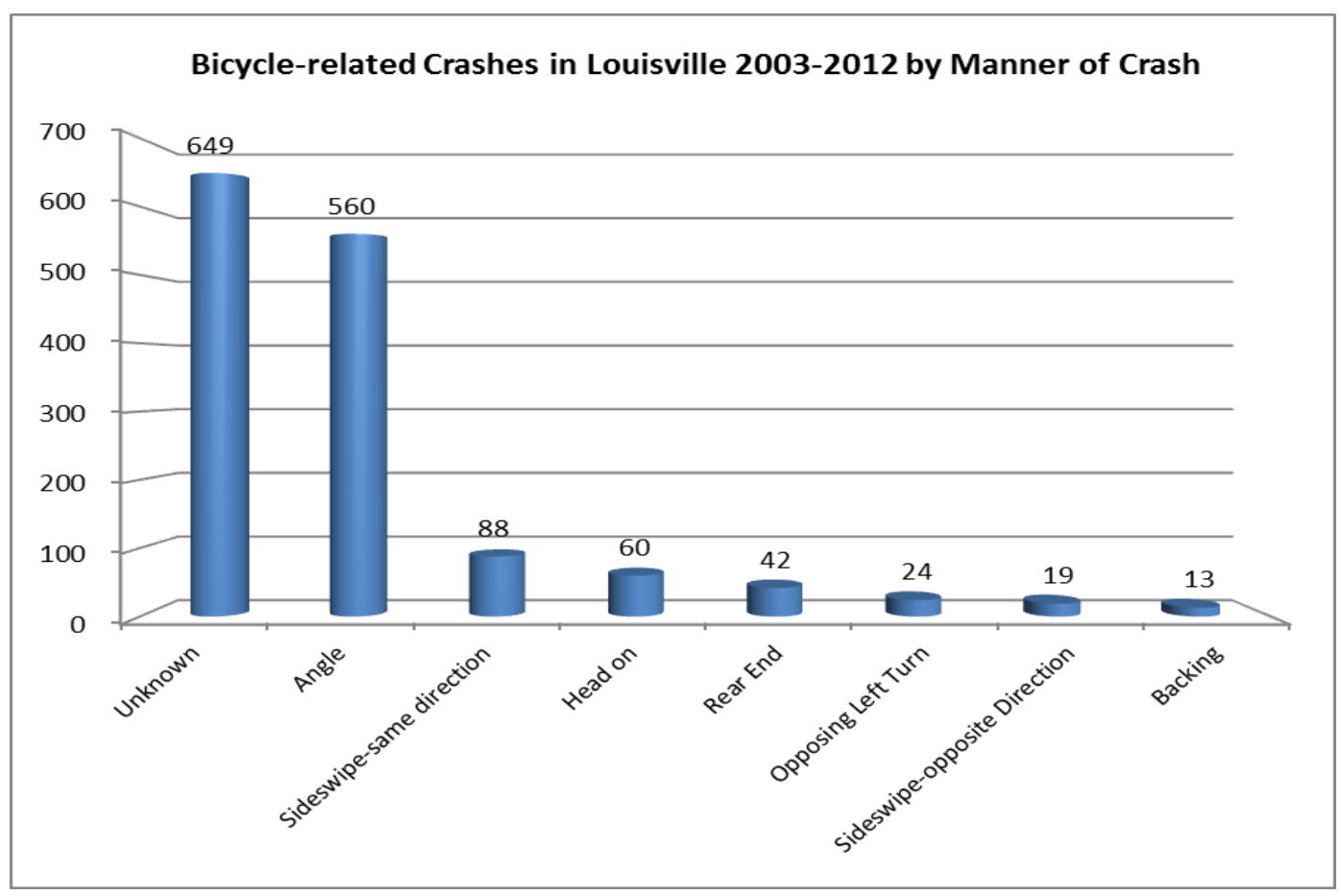

Figure 34: Bicycle-related Crashes Happened in Louisville from 2003 to 2012 by Manner of Crash (Data Source: Kentucky Collision Analysis for the Public http://crashinformationky.org)

\section{Summary}

In summary, several important conclusions can be deduced:

1) Bicycle-related crashes were most prevalent in the summer months, on weekdays and in the afternoon peak period.

2) Weather conditions at the time of the crashes were generally clear.

3) Motorists were often inattentive, or were failing to yield the right-of-way to bicyclists. 
4) Bicyclists were also often inattentive or were failing to yield the right-ofway to motor vehicles.

5) The most common category of crash between bicycles and motor vehicles in Louisville was collision by angle.

Since the highest and the second highest categories of drivers' and bicyclists' condition were "inattention" and "failed to yield right-of-way" respectively, and "making right turn" which accounted for 14.3 percent of all crashes was the third highest Pre-crash Maneuver, this research will try to find out a new countermeasure to raise bicyclists' and drivers' vigilance, and make clear the right-of-way for both bicyclists and drivers around intersections. This research will focus on the conflicts between through bicycles and right-turning motor vehicle drivers. Further studies are needed to find out the reasons and countermeasures for crashes caused by going straight head and making left turn motor vehicles.

\section{B. Research Results for the Newly-Developed Countermeasure for Bicyclist Safety}

\section{Research Results for the First Survey for the Newly-Developed Countermeasure for Bicyclists Safety}




\section{Survey Method}

Items collected in the first survey are:

> Motor Vehicle Type

$>$ Drivers' Gender

> Drivers' Age

$>$ Using Right Lamp before Turning Right

$>$ Turning Position

$>$ Distance from Curb

$>$ Using Traffic Signal before Turning Right

At the observed intersection, it is forbidden to turn right on red. The item "Using Traffic Signal before Turning Right" aims to observe how many people will make a right turn maneuver when the traffic signal is red, which is a dangerous action. The item "Using Right Lamp before Turning Right" is to collect the data about how many people will signal that they will make a right turn maneuver before they really turn right. This item is very important for this research because the bicycle lane is on the right side of the traffic lane. The item "Turning Position" records the position when motor vehicles begin right turn maneuvers. As is shown in Figure 35 and 36, 17 blue marks were put on the curb at 10 feet intervals from the beginning point of the striped oblique line because there are 180 feet from the beginning point of the striped oblique line to the stop bar of the observed intersection. Big numbers were written beside the blue marks for convenience. The item "Distance from Curb" records the distance from the curb 
when motor vehicles cross the stop bar. As is shown in Figure 37, the stop bar was marked at 1 foot intervals. Numbers were written on the stop bar for convenience.

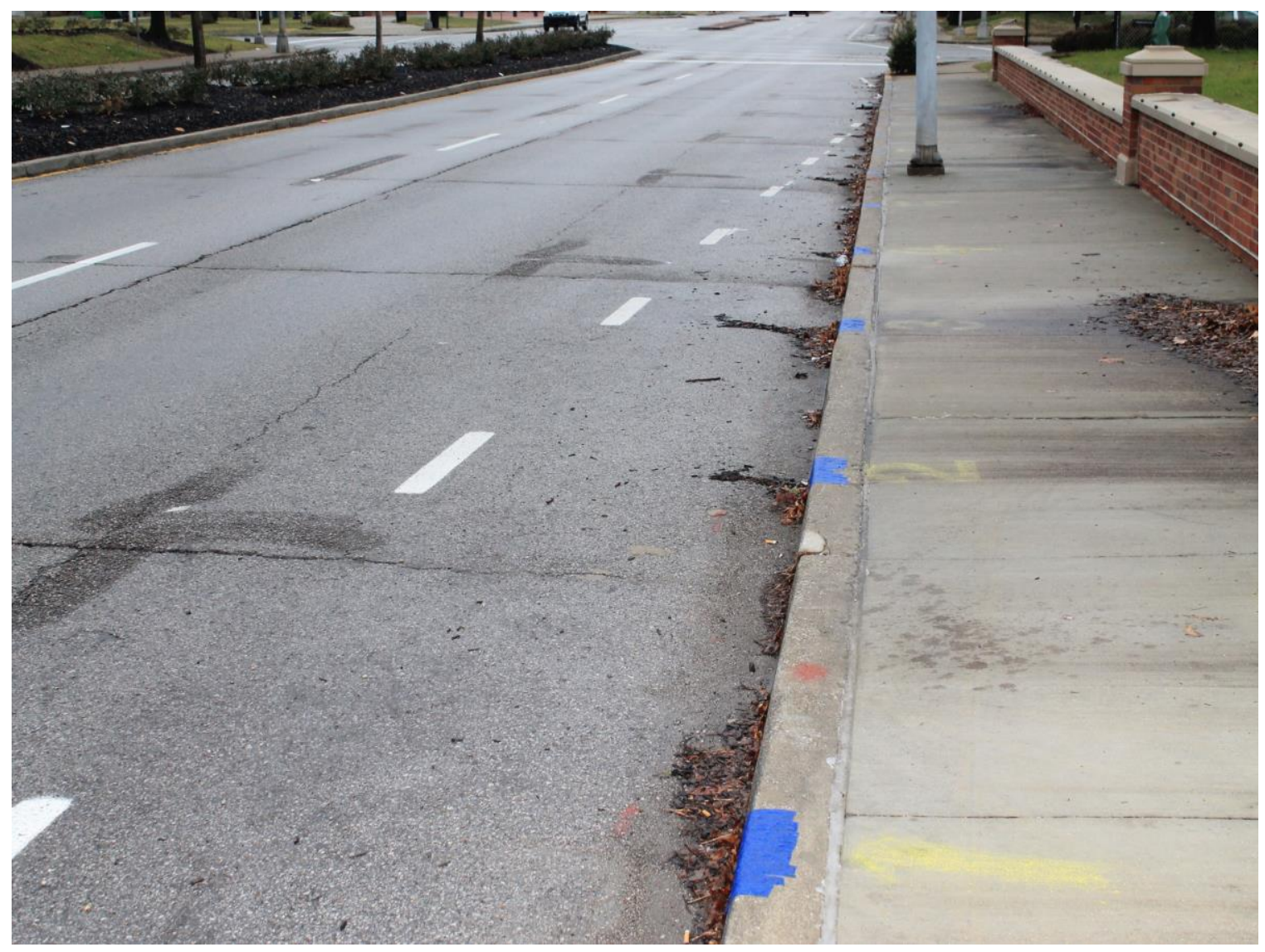

Figure 35: Method for the First Survey of the Newly-Developed Countermeasure for Bicyclists Safety-Turning Position 


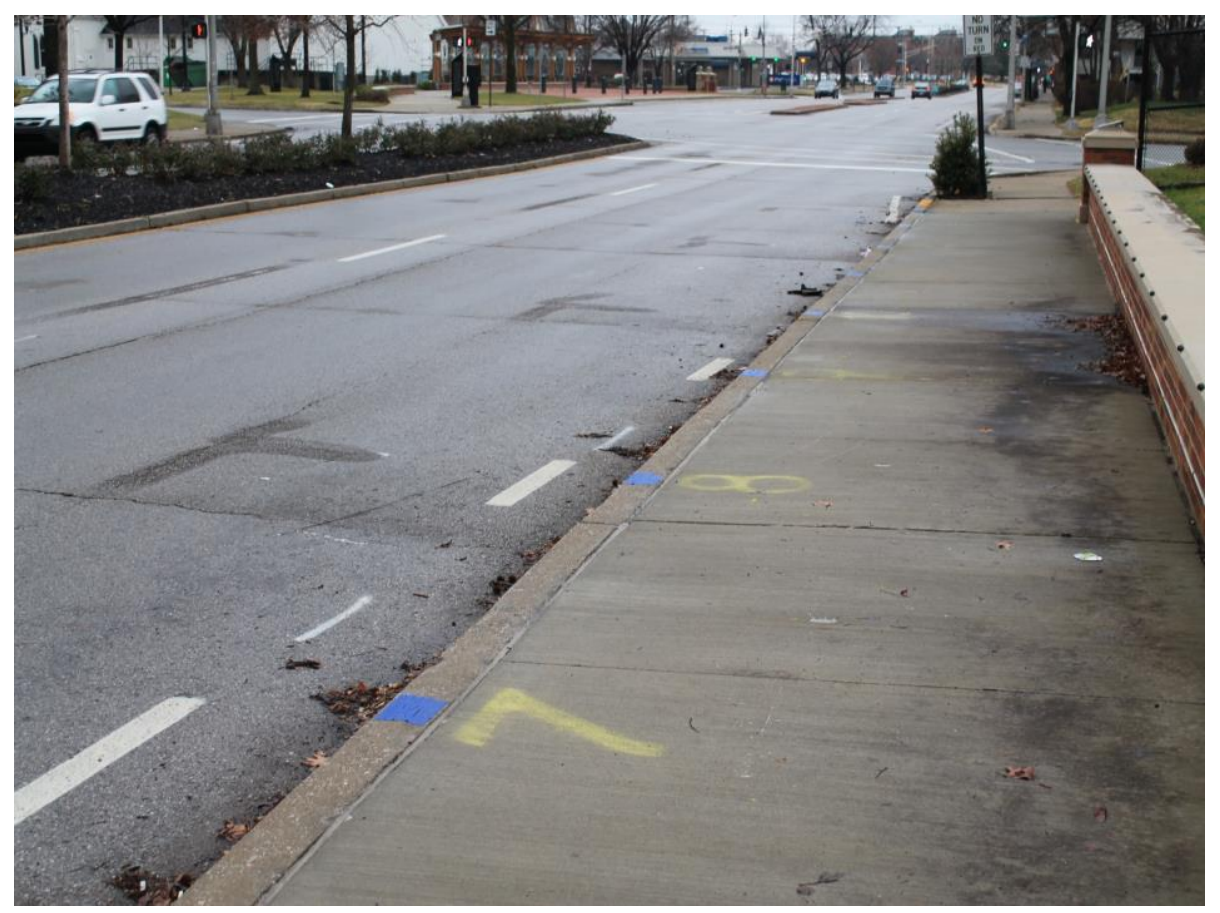

Figure 36: Method for the First Survey of the Newly-Developed Countermeasure for Bicyclists Safety-Turning Position

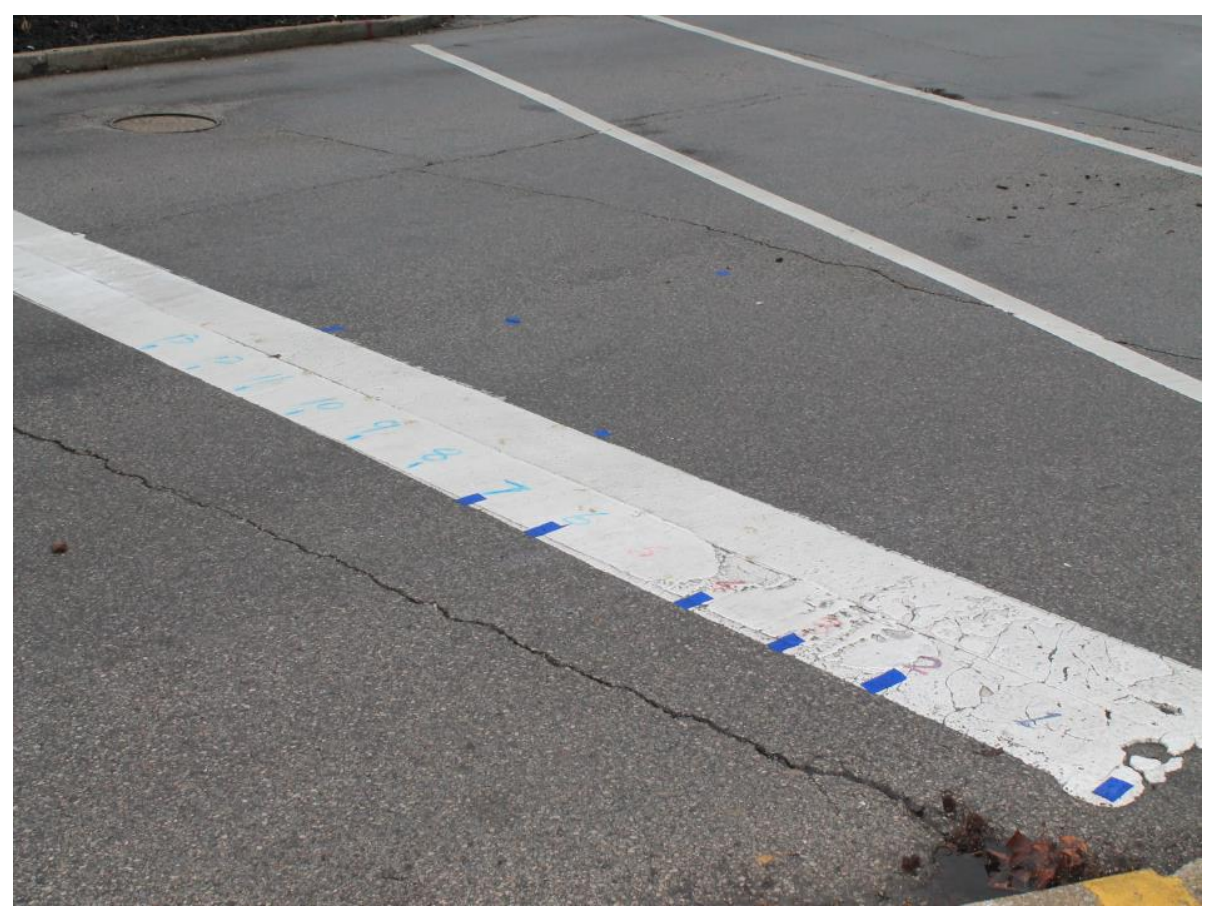


Figure 37: Method for the First Survey of the Newly-Developed Countermeasure for Bicyclists Safety-Distance from Curb

\section{Survey Results}

For the first survey, 405 motor vehicles were observed. The average of "Distance from Curb" is 5.3 feet. The $85 \%$ Distance from Curb is 7 feet. The average of Turning Position from the beginning point of the striped oblique line is 62 feet. The 85\% Turning Position from the Beginning of Oblique line is 100 feet. 91.11 percent of drivers use right turning lamp before they turn right. 7.9 percent of drivers turn right when the traffic signal is red.

Table 18 shows the distribution details of the survey results of distance from curb for the first survey. Figure 37 and 38 show the distribution details of the survey result of distance from curb for the first survey with feet and percentage respectively.

\section{Table 18}

Survey Results for the First Survey-Distance from Curb

\begin{tabular}{|c|c|c|c|}
\hline $\begin{array}{c}\text { Distance from } \\
\text { Curb (feet) }\end{array}$ & Frequency & Percentage & $\begin{array}{c}\text { Accumulation } \\
\text { Percentage }\end{array}$ \\
\hline 1 & 2 & $0.49 \%$ & $0.49 \%$ \\
\hline 1.5 & 3 & $0.74 \%$ & $1.23 \%$ \\
\hline 2 & 6 & $1.48 \%$ & $2.72 \%$ \\
\hline
\end{tabular}




\begin{tabular}{|c|c|c|c|}
\hline 2.5 & 17 & $4.20 \%$ & $6.91 \%$ \\
\hline 3 & 23 & $5.68 \%$ & $12.59 \%$ \\
\hline 3.5 & 28 & $6.91 \%$ & $19.51 \%$ \\
\hline 4 & 46 & $11.36 \%$ & $30.86 \%$ \\
\hline 4.5 & 52 & $12.84 \%$ & $43.70 \%$ \\
\hline 5 & 43 & $10.62 \%$ & $54.32 \%$ \\
\hline 5.5 & 37 & $9.14 \%$ & $63.46 \%$ \\
\hline 6 & 35 & $8.64 \%$ & $72.10 \%$ \\
\hline 6.5 & 30 & $7.41 \%$ & $79.51 \%$ \\
\hline 7 & 29 & $7.16 \%$ & $86.67 \%$ \\
\hline 7.5 & 14 & $3.46 \%$ & $90.12 \%$ \\
\hline 8 & 10 & $2.47 \%$ & $92.59 \%$ \\
\hline 8.5 & 6 & $1.48 \%$ & $94.07 \%$ \\
\hline 9 & 9 & $2.22 \%$ & $96.30 \%$ \\
\hline 9.5 & 3 & $0.74 \%$ & $97.04 \%$ \\
\hline 10 & 7 & $1.73 \%$ & $98.77 \%$ \\
\hline 10.5 & 1 & $0.25 \%$ & $99.01 \%$ \\
\hline 11 & 4 & $0.99 \%$ & $100.00 \%$ \\
\hline Total & 405 & $100.00 \%$ & \\
\hline
\end{tabular}




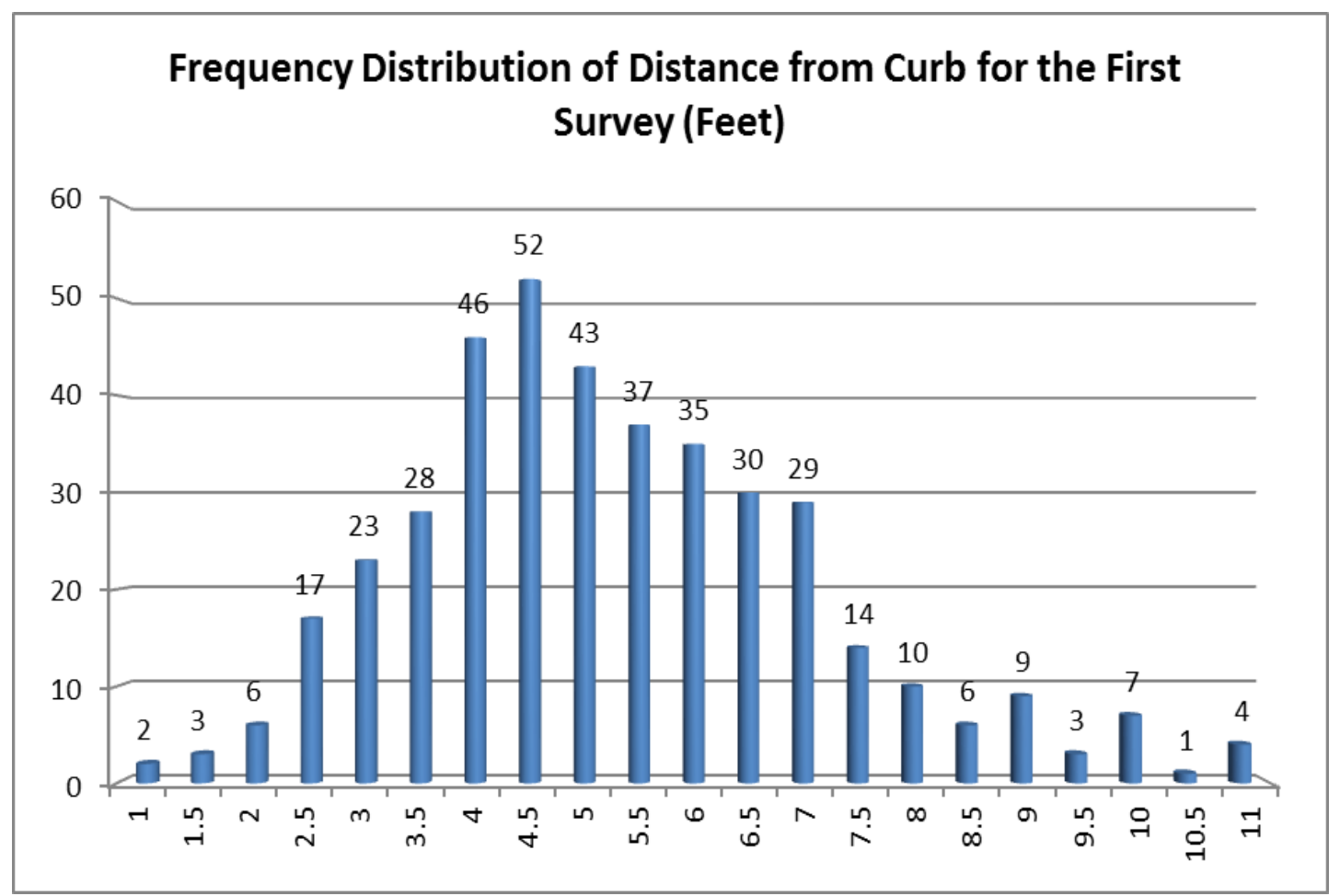

Figure 38: Survey Results for the First Survey-Distance from Curb (feet)

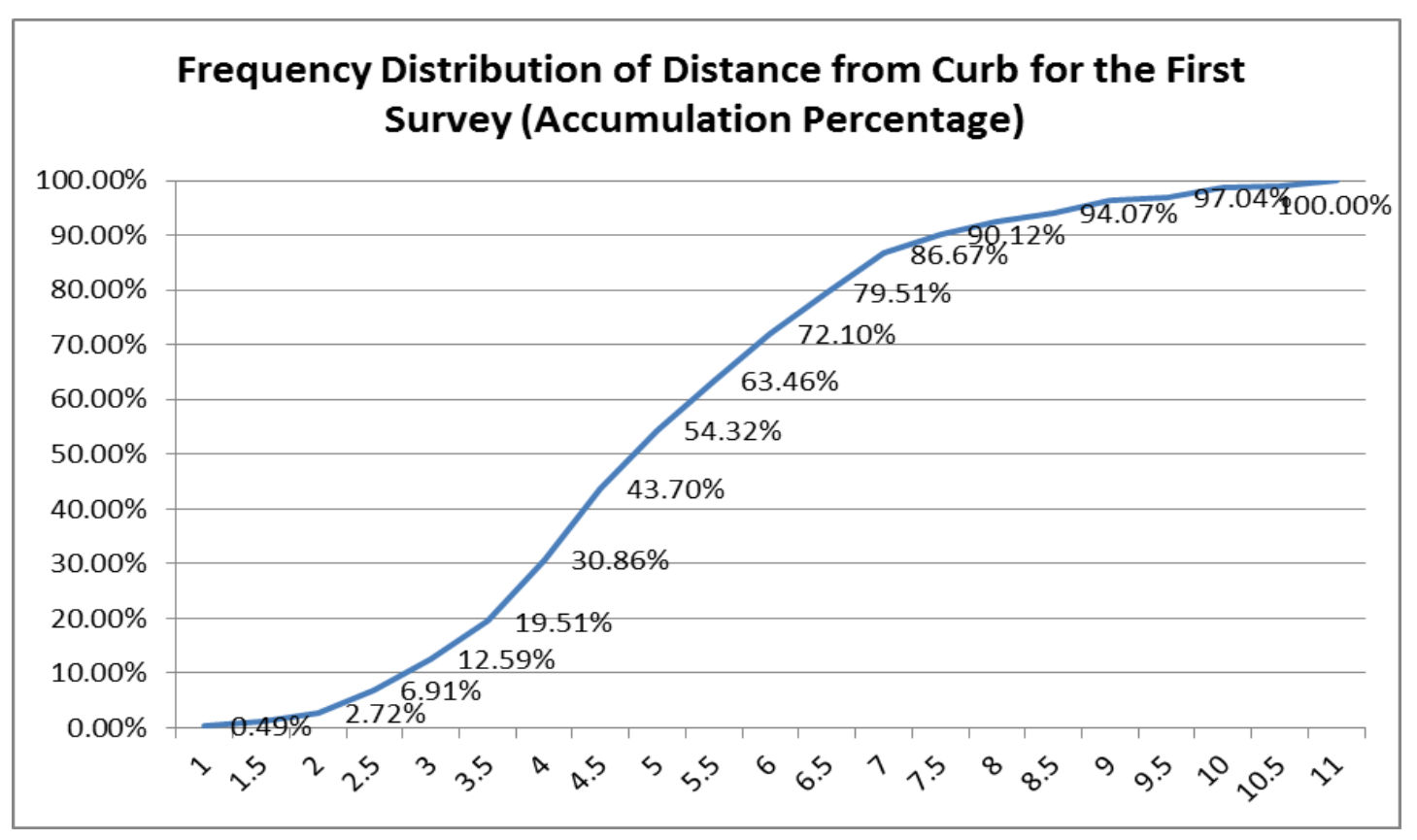

Figure 39: Survey Results for the First Survey-Distance from Curb Accumulation 


\section{Percentage}

Table 19 shows the distribution details of the survey result of turning position for the first survey. Figure 40 and 41 show the distribution details of the survey result of turning position for the first survey with feet and percentage respectively.

Table 19

Survey Results for the First Survey-Turning Position

\begin{tabular}{|c|c|c|c|}
\hline $\begin{array}{c}\text { Turning Position } \\
\text { (feet) }\end{array}$ & Frequency & Percentage & $\begin{array}{c}\text { Accumulation } \\
\text { Percentage }\end{array}$ \\
\hline 10 & 46 & $11.36 \%$ & $11.36 \%$ \\
\hline 20 & 41 & $10.12 \%$ & $21.48 \%$ \\
\hline 30 & 38 & $9.38 \%$ & $30.86 \%$ \\
\hline 40 & 30 & $7.41 \%$ & $38.27 \%$ \\
\hline 50 & 31 & $7.65 \%$ & $45.93 \%$ \\
\hline 60 & 44 & $10.86 \%$ & $56.79 \%$ \\
\hline 70 & 35 & $8.64 \%$ & $65.43 \%$ \\
\hline 80 & 32 & $7.90 \%$ & $73.33 \%$ \\
\hline 90 & 22 & $5.43 \%$ & $78.77 \%$ \\
\hline 100 & 34 & $8.40 \%$ & $87.16 \%$ \\
\hline 110 & 17 & $4.20 \%$ & $91.36 \%$ \\
\hline 120 & 11 & $2.72 \%$ & $94.07 \%$ \\
\hline 130 & 4 & $0.99 \%$ & $95.06 \%$ \\
\hline & & & \\
\hline
\end{tabular}




\begin{tabular}{|c|c|c|c|}
\hline 140 & 7 & $1.73 \%$ & $96.79 \%$ \\
\hline 150 & 7 & $1.73 \%$ & $98.52 \%$ \\
\hline 160 & 3 & $0.74 \%$ & $99.26 \%$ \\
\hline 170 & 3 & $0.74 \%$ & $100.00 \%$ \\
\hline Total & 405 & $100.00 \%$ & \\
\hline
\end{tabular}

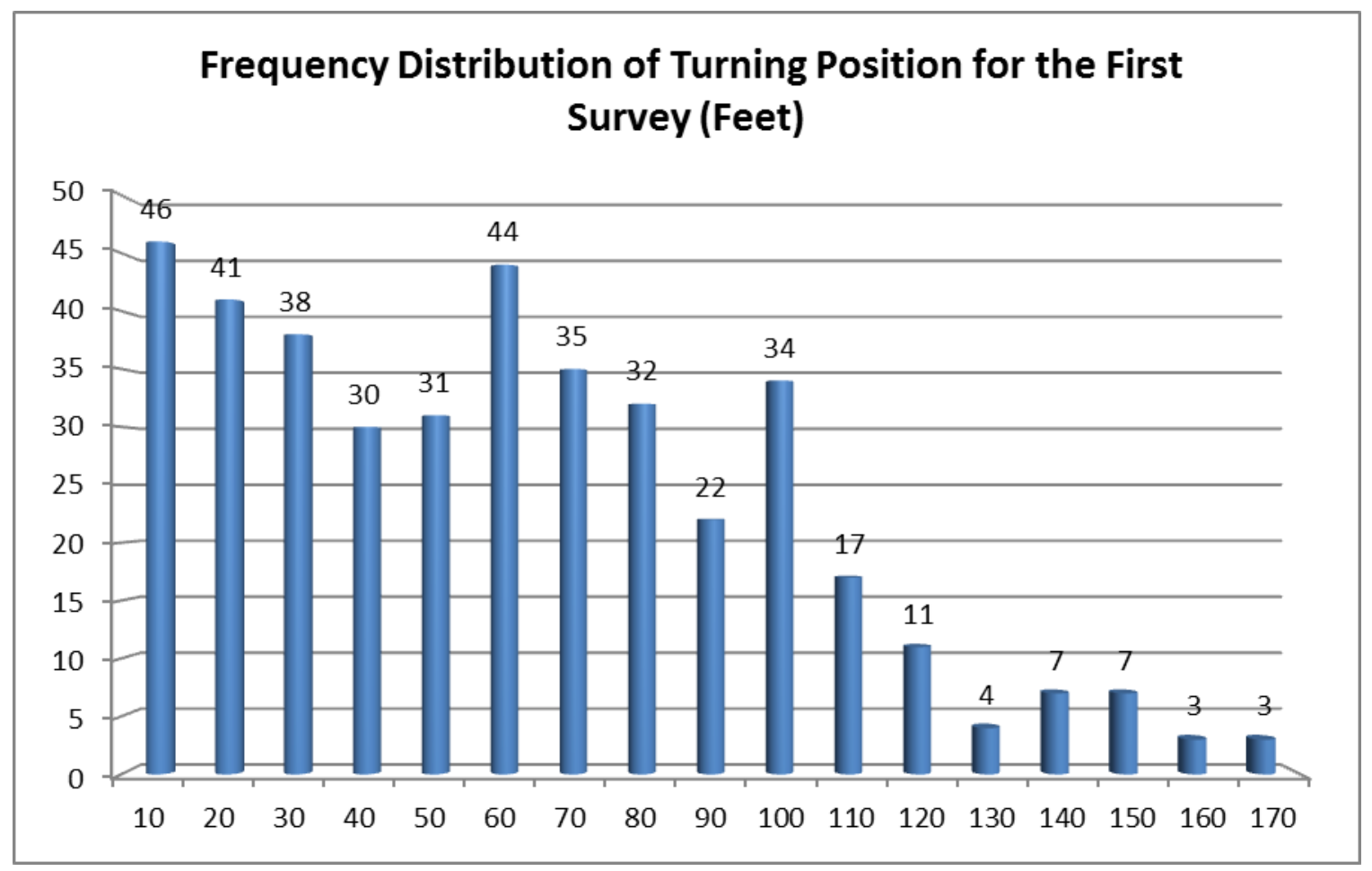

Figure 40: Survey Results for the First Survey-Turning Position (feet) 


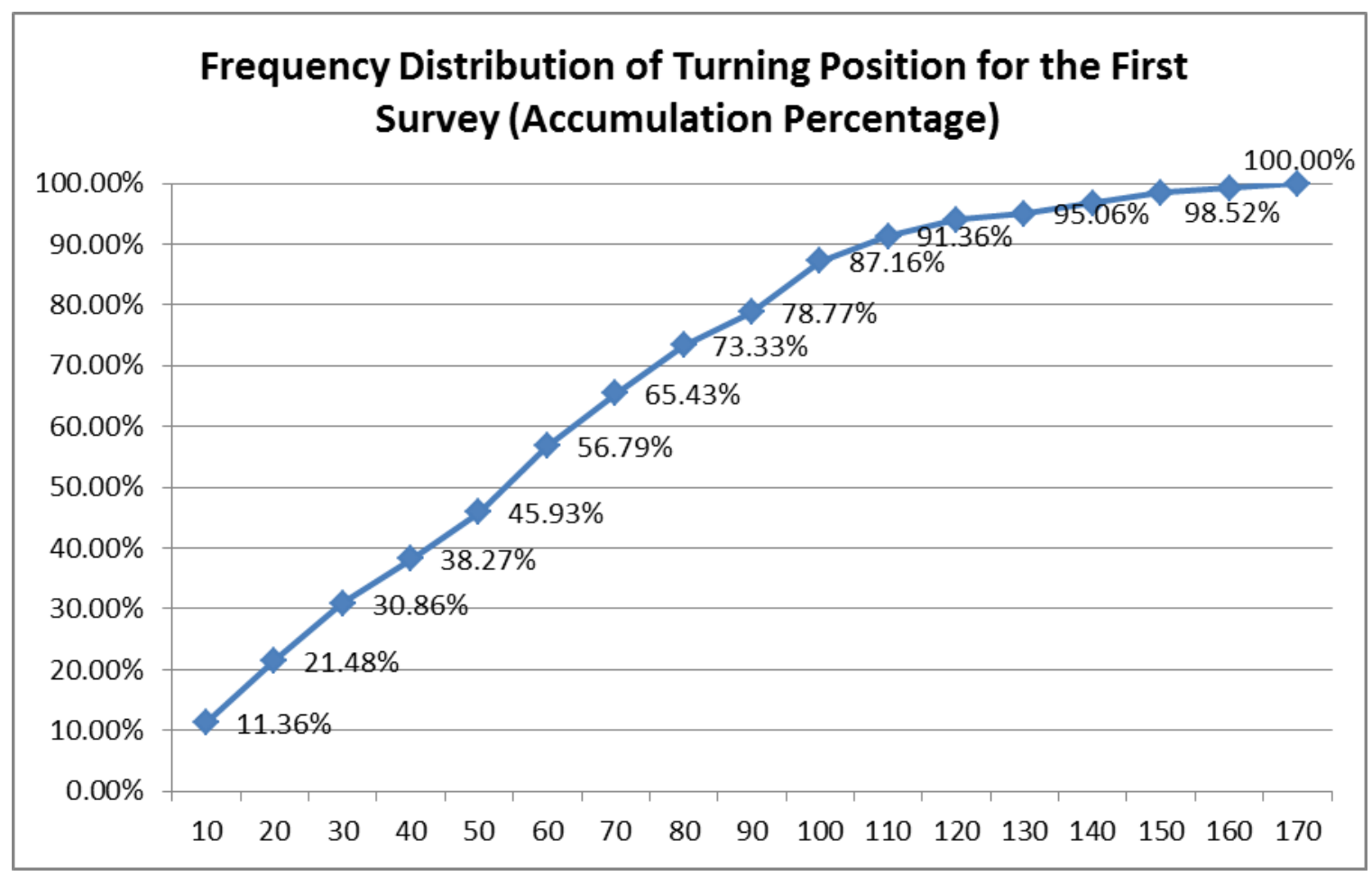

Figure 41: Survey Results for the First Survey-Turning Position Accumulation Percentage

2. Research Results for the Second Survey for the Newly-Developed Countermeasure for Bicyclists Safety

\section{Survey Method}

Items collected in the second survey are:

$>$ Motor Vehicle Type

$>$ Drivers' Gender

$>$ Drivers' Age

> Using Right Lamp before Turning Right 
Crossing the Virtual Line Position

Distance from Curb

Using Traffic Signal before Turning Right

The items of the second survey are same as the first survey, except for the item "Crossing the Virtual Line Position" which records the position when motor vehicles cross the virtual line made by 17 points on the extension line from the beginning point of the striped oblique line. The line is shown in Figure 42 and 43. 17 white points were drawn on the extension line of the bicycle lane at 10 feet intervals from the beginning point of the striped oblique line. Big numbers were written beside the white points for recording convenience. In order to observe the item "Distance from Curb", new and clear points at 1 foot intervals were drawn on the edge of the stop bar which is shown in Figure 44. An example record for the "Distance from Curb" is shown in Figure 45.

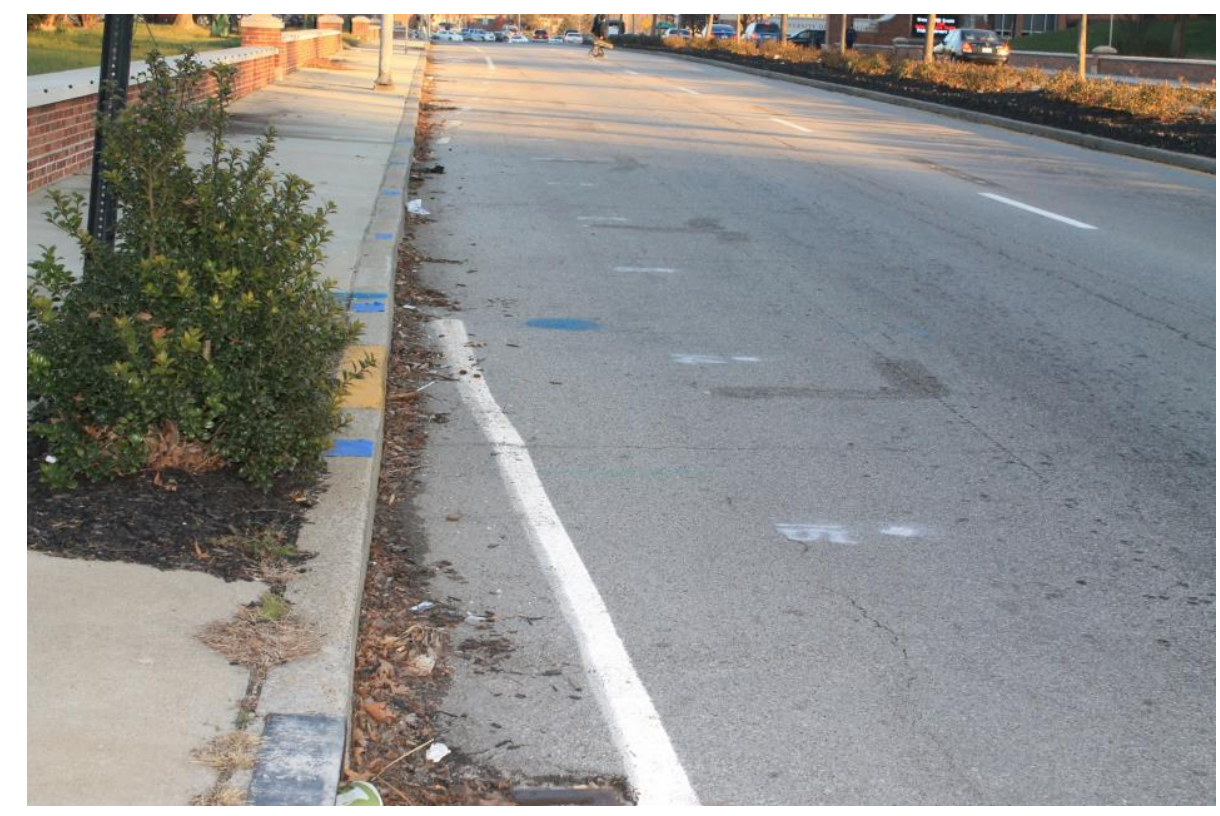


Figure 42: Virtual Line of the Second Survey of the Newly-Developed Countermeasure for Bicyclists Safety-Part 1

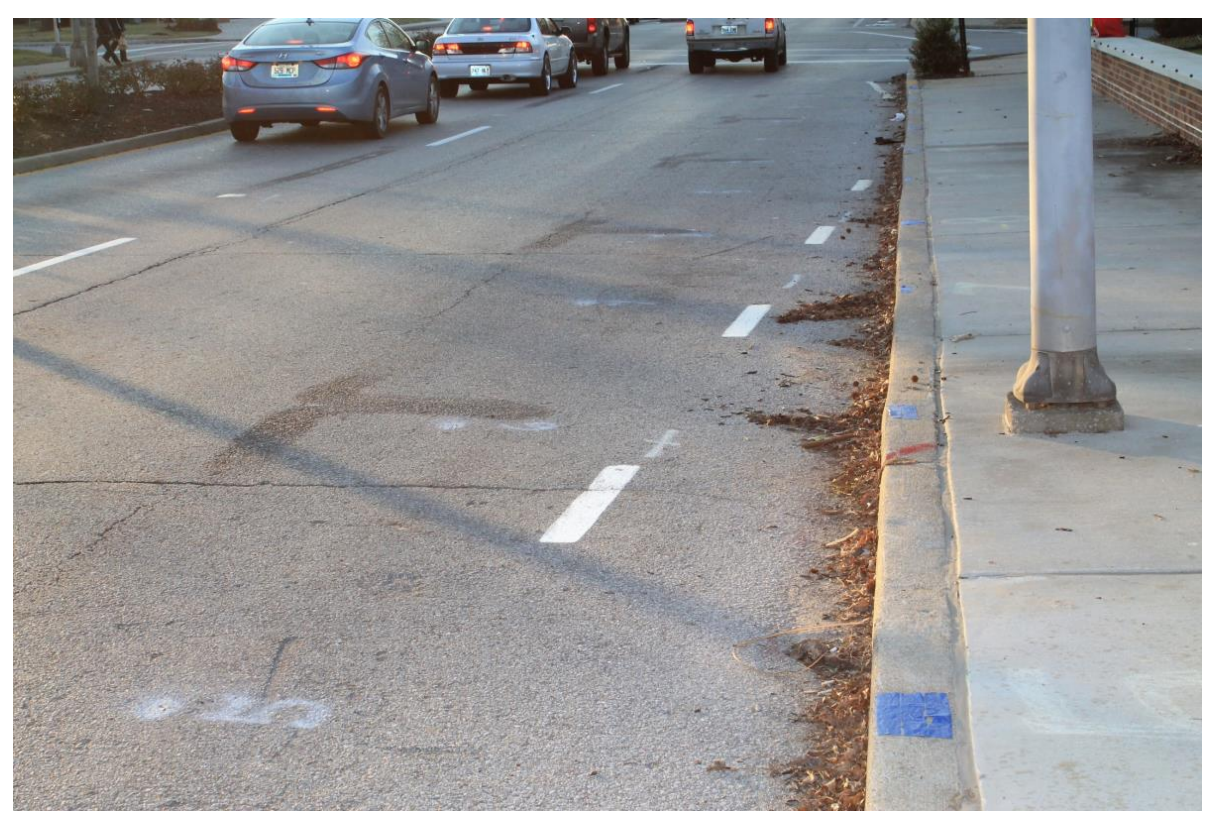

Figure 43: Virtual Line of the Second Survey of the Newly-Developed Countermeasure for Bicyclists Safety-Part 2

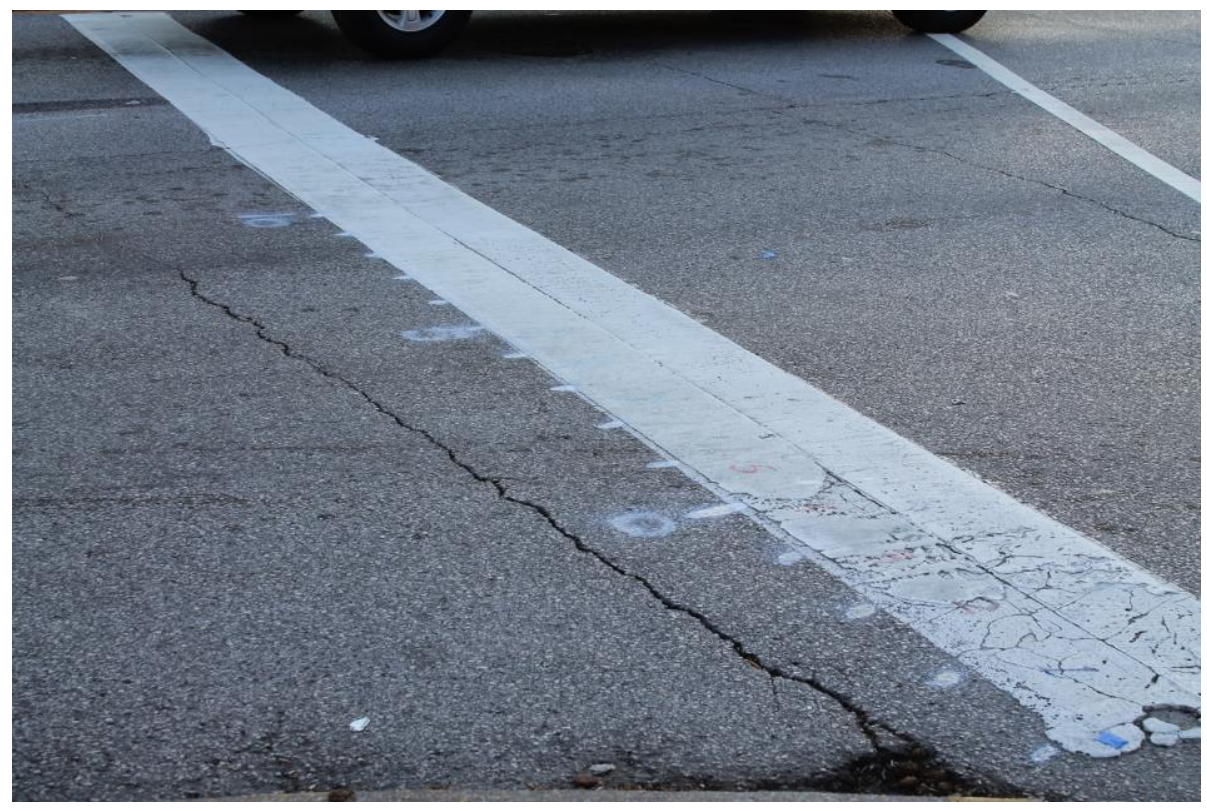


Figure 44: Marks for Distance from Curb for the Second Survey

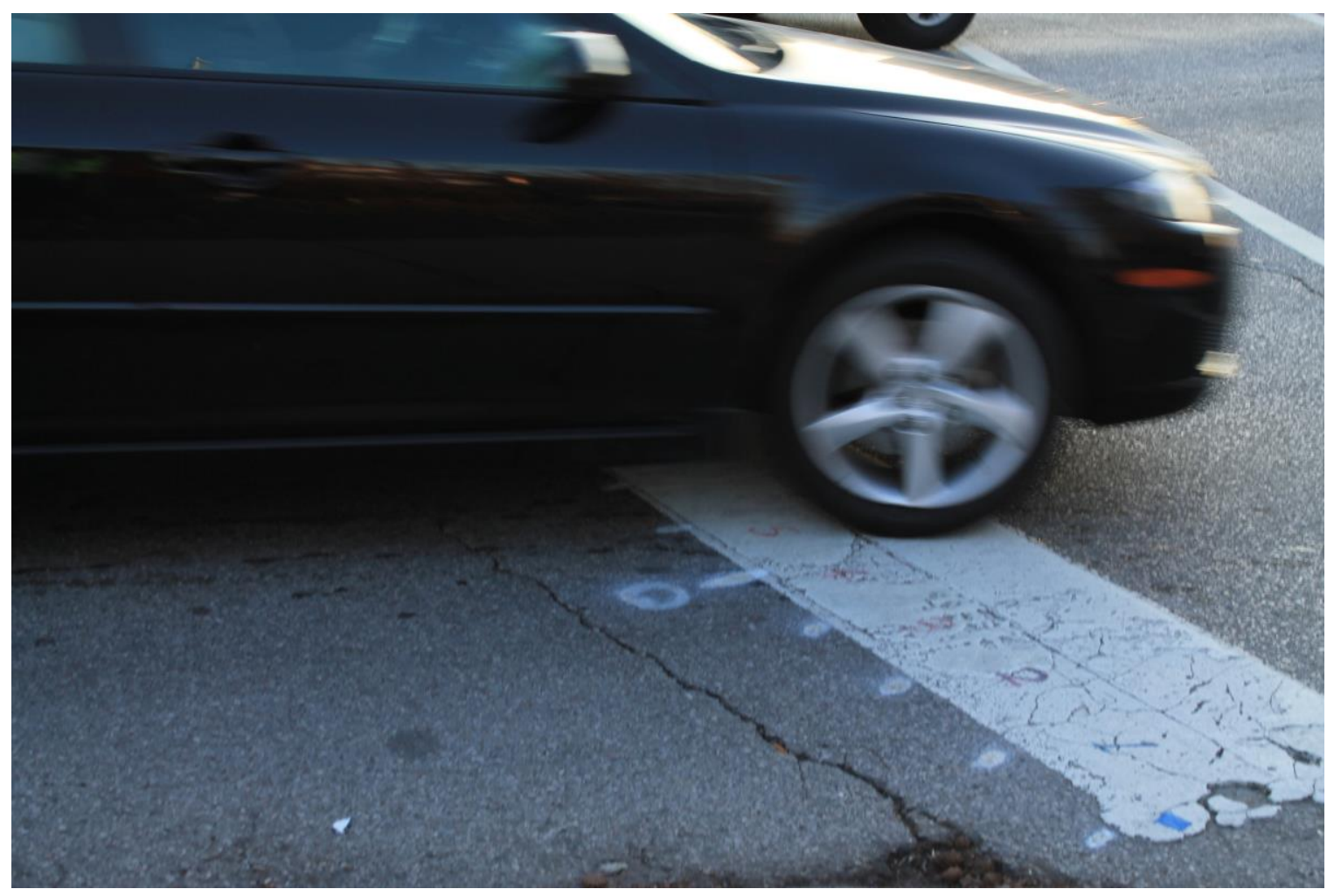

Figure 45: An Example of a Motor Vehicle Crossing the Stop Bar

\section{Survey Results}

For the second survey, 955 motor vehicles were observed. The average of Distance from Curb is 5.1 feet. The $85 \%$ Distance from Curb is 7 feet. The average of Crossing the Virtual Line is 143 feet. The $85 \%$ Crossing the Virtual Line is 160 feet. 90.68 percent of drivers use the right turning lamp before they turn right. 6.2 percent of drivers turn right when traffic signal is red.

Table 20 shows the distribution details of the survey result of distance from 
curb for the second survey. Figure 46 and 47 shows the distribution details of the survey result of distance from curb for the second survey with feet and percentage respectively.

\section{Table 20}

Survey Results for the Second Survey-Distance from Curb

\begin{tabular}{|c|c|c|c|}
\hline $\begin{array}{c}\text { Distance from } \\
\text { Curb (feet) }\end{array}$ & Frequency & Percentage & $\begin{array}{c}\text { Accumulation } \\
\text { Percentage }\end{array}$ \\
\hline 1 & 3 & $0.31 \%$ & $0.31 \%$ \\
\hline 1.5 & 3 & $0.31 \%$ & $0.63 \%$ \\
\hline 2 & 16 & $1.68 \%$ & $2.30 \%$ \\
\hline 2.5 & 23 & $2.41 \%$ & $4.71 \%$ \\
\hline 3 & 80 & $8.38 \%$ & $13.09 \%$ \\
\hline 3.5 & 85 & $8.90 \%$ & $21.99 \%$ \\
\hline 4 & 102 & $10.68 \%$ & $32.67 \%$ \\
\hline 4.5 & 145 & $15.18 \%$ & $47.85 \%$ \\
\hline 5 & 105 & $10.99 \%$ & $58.85 \%$ \\
\hline 5.5 & 74 & $7.75 \%$ & $66.60 \%$ \\
\hline 6 & 92 & $9.63 \%$ & $76.23 \%$ \\
\hline 6.5 & 50 & $5.24 \%$ & $81.47 \%$ \\
\hline 7 & 55 & $5.76 \%$ & $87.23 \%$ \\
\hline 7.5 & 48 & $5.03 \%$ & $92.25 \%$ \\
\hline 8 & 29 & $3.04 \%$ & $95.29 \%$ \\
\hline & & & \\
\hline & & & \\
\hline
\end{tabular}




\begin{tabular}{|c|c|c|c|}
\hline 8.5 & 8 & $0.84 \%$ & $96.13 \%$ \\
\hline 9 & 16 & $1.68 \%$ & $97.80 \%$ \\
\hline 9.5 & 4 & $0.42 \%$ & $98.22 \%$ \\
\hline 10 & 12 & $1.26 \%$ & $99.48 \%$ \\
\hline 10.5 & 1 & $0.10 \%$ & $99.58 \%$ \\
\hline 11 & 4 & $0.42 \%$ & $100.00 \%$ \\
\hline Total & 955 & $100.00 \%$ & \\
\hline
\end{tabular}

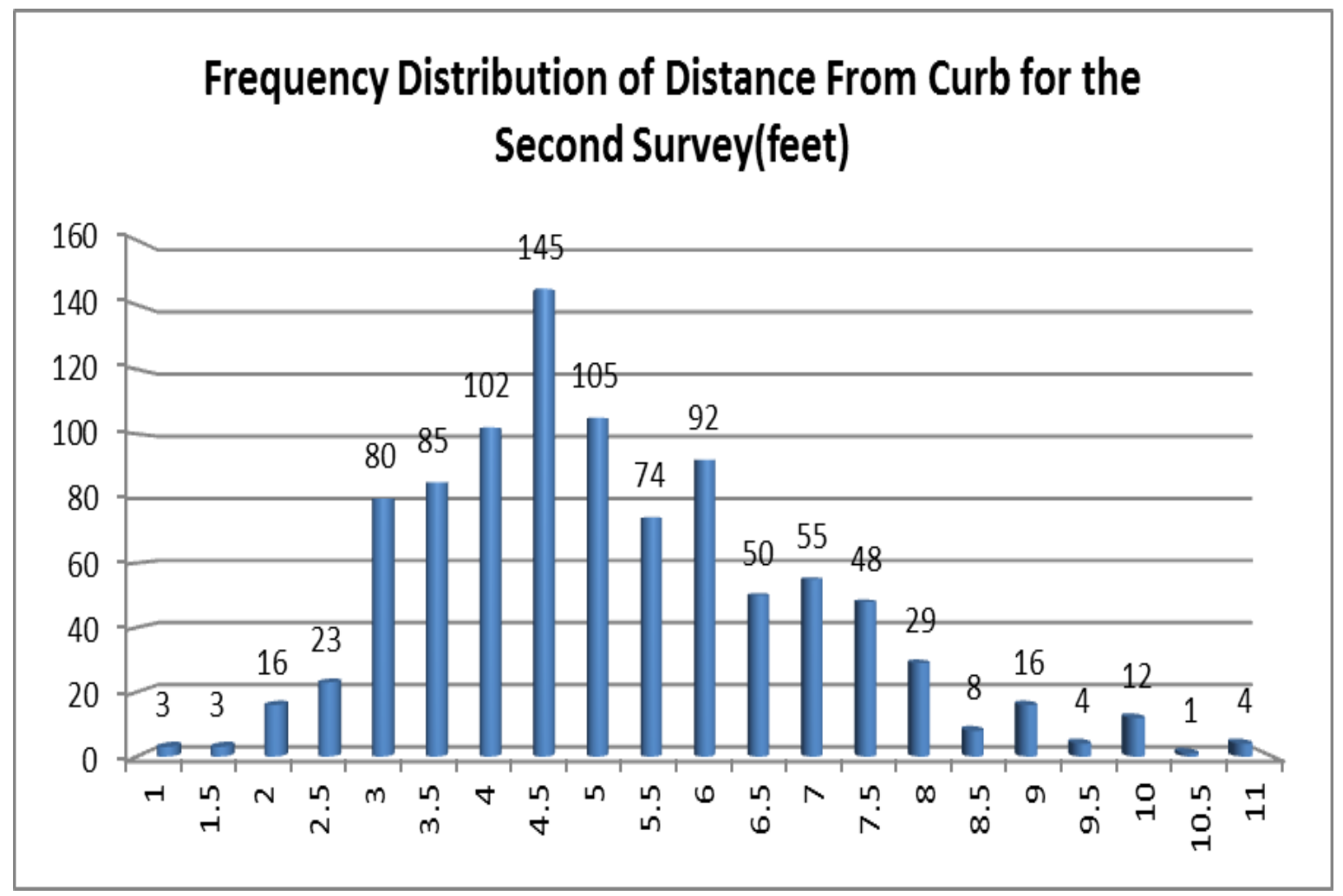

Figure 46: Survey Results for the Second Survey-Distance from Curb (feet) 


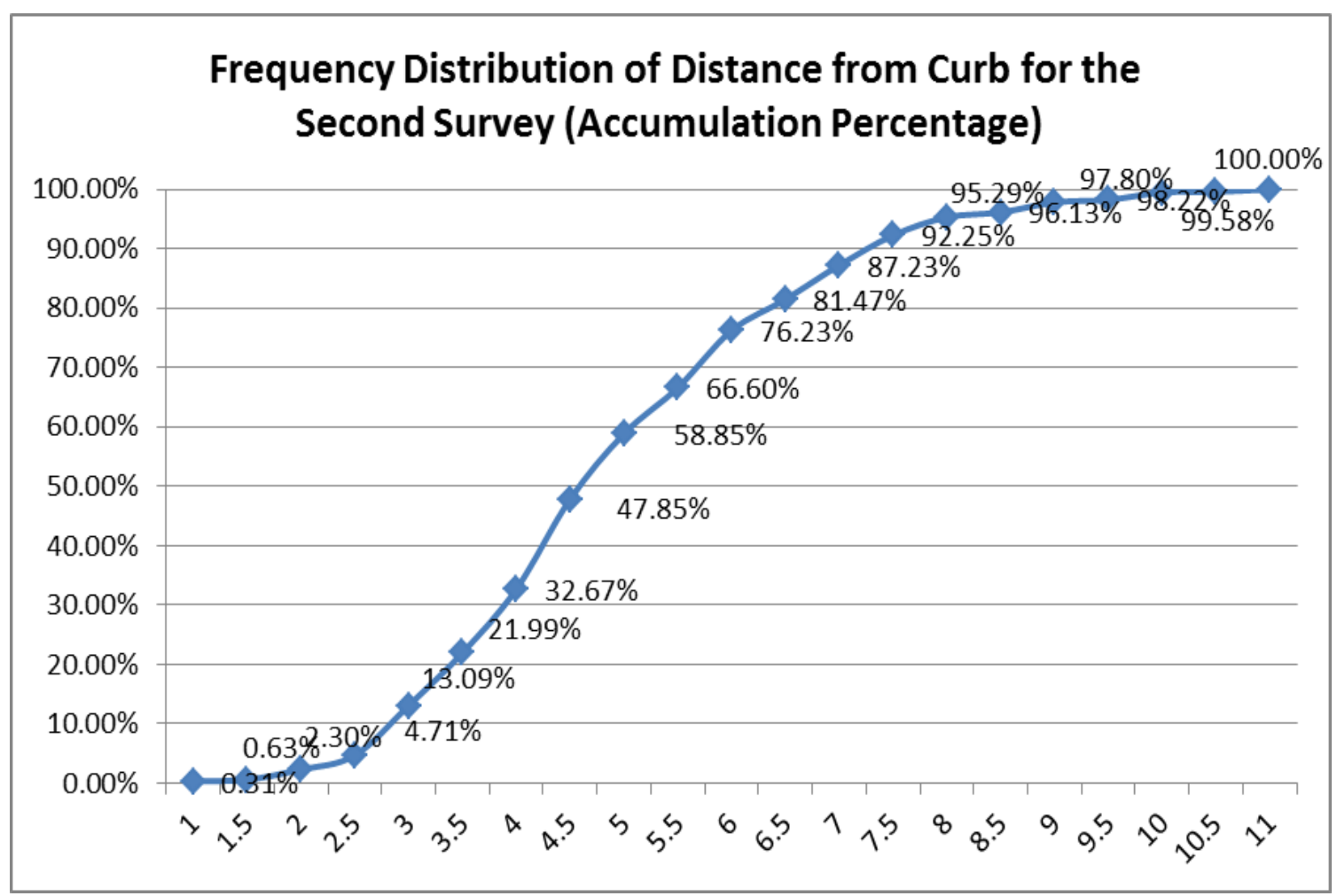

Figure 47: Survey Results for the Second Survey-Distance from Curb Accumulation Percentage

Table 21 shows the distribution details of the survey result of Crossing the Virtual Line Position for the second survey. Figure 48 and 49 shows the distribution details of the survey results of Crossing the Virtual Line Position for the second survey with feet and percentage respectively.

\section{Table 21}

Survey Result for the Second Survey-Crossing the Virtual Line Position

\begin{tabular}{|c|c|c|c|}
\hline $\begin{array}{c}\text { Crossing the } \\
\text { Virtual Line } \\
\text { Position (feet) }\end{array}$ & Frequency & Percentage & $\begin{array}{c}\text { Accumulation } \\
\text { Percentage }\end{array}$ \\
\hline
\end{tabular}




\begin{tabular}{|c|c|c|c|}
\hline 10 & 1 & $0.10 \%$ & $0.10 \%$ \\
\hline 20 & 2 & $0.21 \%$ & $0.31 \%$ \\
\hline 30 & 3 & $0.31 \%$ & $0.63 \%$ \\
\hline 40 & 5 & $0.52 \%$ & $1.15 \%$ \\
\hline 50 & 5 & $0.52 \%$ & $1.68 \%$ \\
\hline 60 & 7 & $0.73 \%$ & $2.41 \%$ \\
\hline 70 & 10 & $1.05 \%$ & $3.46 \%$ \\
\hline 80 & 12 & $1.26 \%$ & $4.71 \%$ \\
\hline 90 & 14 & $1.47 \%$ & $6.18 \%$ \\
\hline 100 & 37 & $3.87 \%$ & $10.05 \%$ \\
\hline 110 & 21 & $2.20 \%$ & $12.25 \%$ \\
\hline 120 & 49 & $5.13 \%$ & $17.38 \%$ \\
\hline 130 & 74 & $7.75 \%$ & $25.13 \%$ \\
\hline 140 & 135 & $14.14 \%$ & $39.27 \%$ \\
\hline 150 & 164 & $17.17 \%$ & $56.44 \%$ \\
\hline 160 & 346 & $36.23 \%$ & $92.67 \%$ \\
\hline 170 & 70 & $7.33 \%$ & $100.00 \%$ \\
\hline Total & 955 & $100.00 \%$ & \\
\hline
\end{tabular}




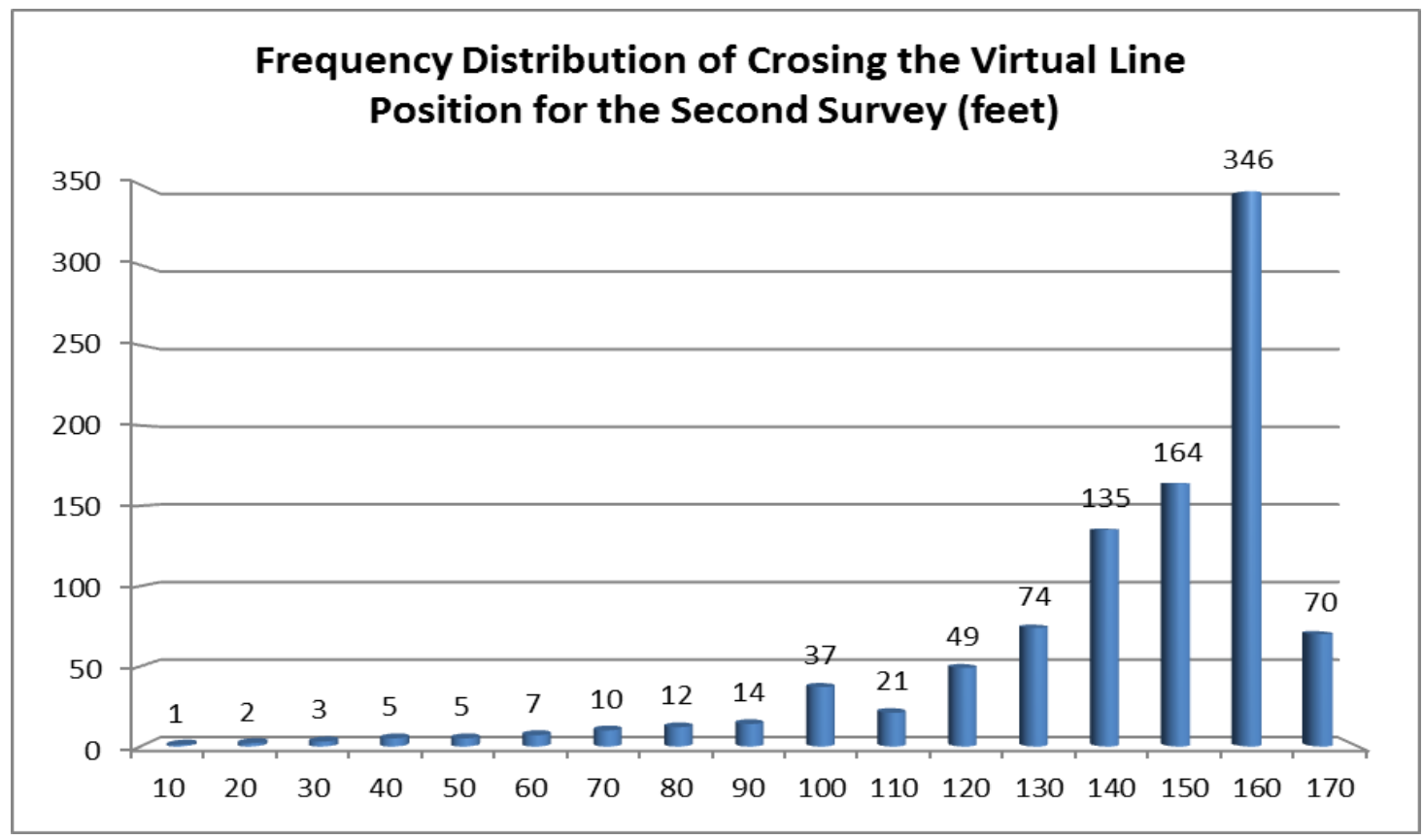

Figure 48: Survey Results for the Second Survey-Crossing the Virtual Line Position (feet)

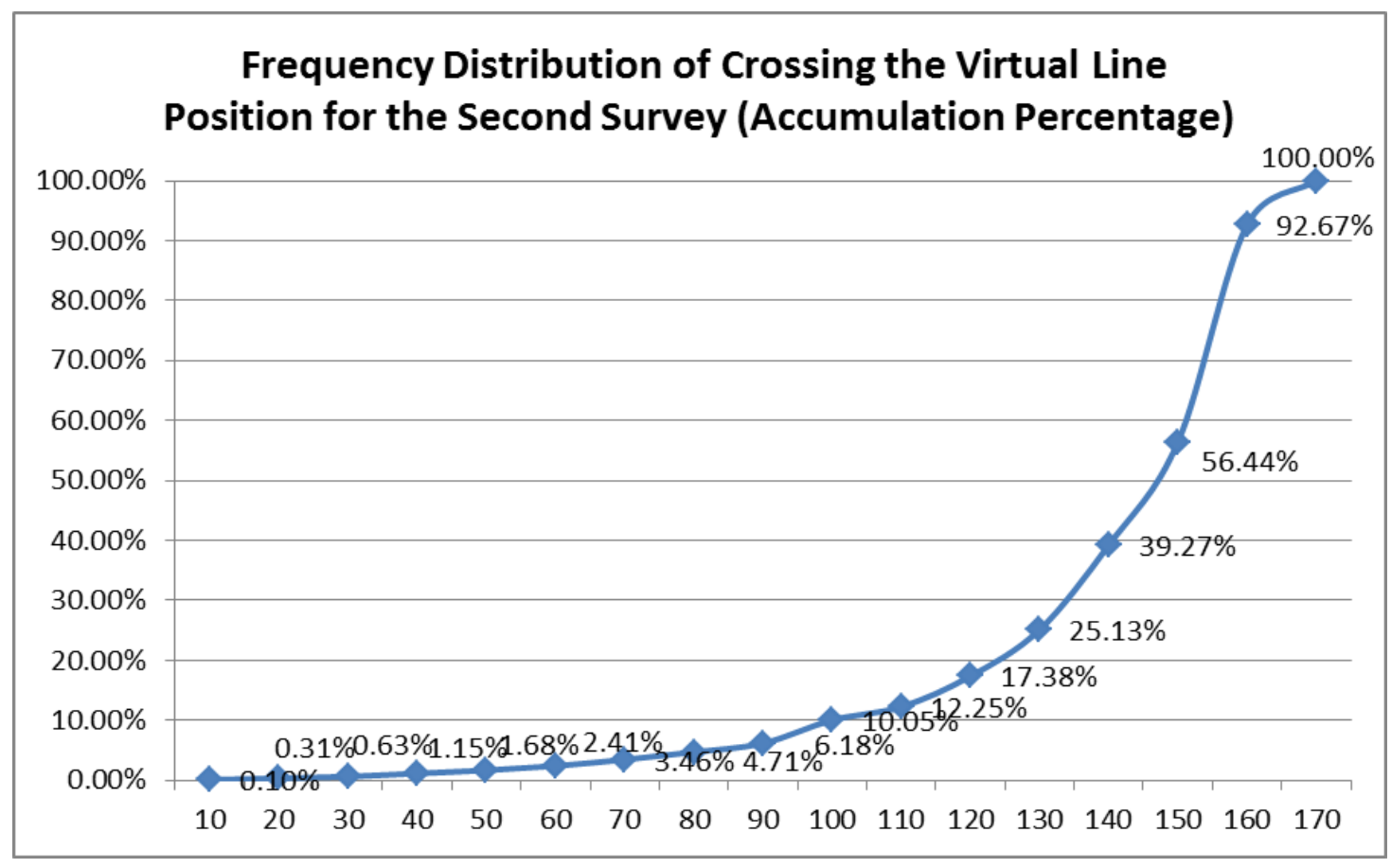


Figure 49: Survey Result for the Second Survey-Crossing the Virtual Line Position Accumulation Percentage

\section{Research Results for the Third Survey for the Newly-Developed Countermeasure for Bicyclists Safety}

\section{Survey Method}

Items collected in the second survey are:

$>$ Motor Vehicle Type

$>$ Drivers' Gender

$>$ Drivers' Age

> Using Right Lamp before Turning Right

$>$ Crossing the Extension Line Position

$>$ Distance from Curb

> Using Traffic Signal before Turning Right

The survey items of the third survey are similar to the first survey and second survey, except the item "Crossing the Extension Line Position", which is shown in Figure 50 and 51 . This extension line starts from the beginning point of the striped oblique line, keeps 5 feet from the sidewalk and ends at the stop bar. Every short white line of this extension is 3 feet at 7 feet intervals. In order to observe the item "Distance from Curb", the method of the second survey still is used, which is shown in Figure 52. 


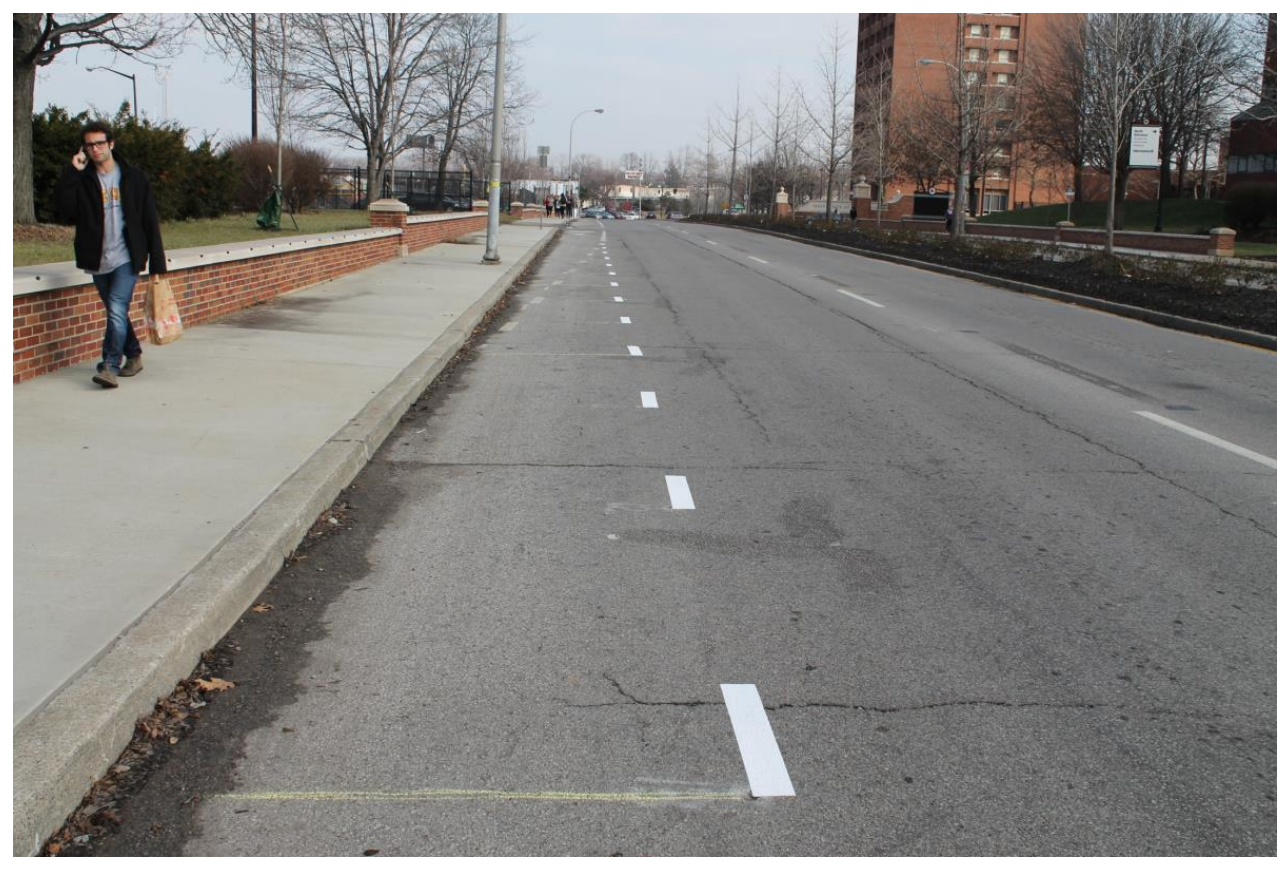

Figure 50: The Extension Line of the Third Survey of the Newly-Developed Countermeasure for Bicyclist Safety-Part 1

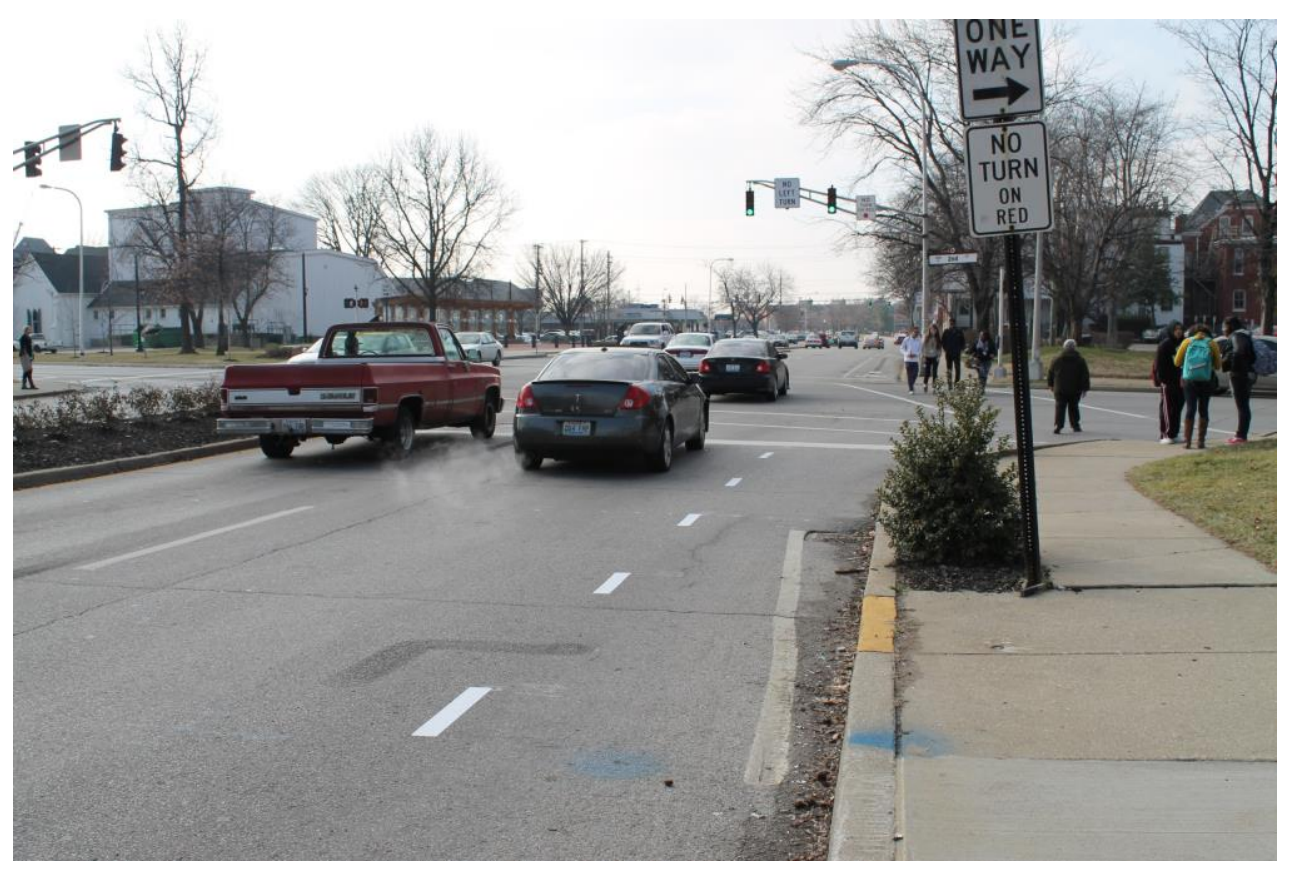

Figure 51: The Extension Line of the Third Survey of the Newly-Developed 
Countermeasure for Bicyclists Safety-Part 2

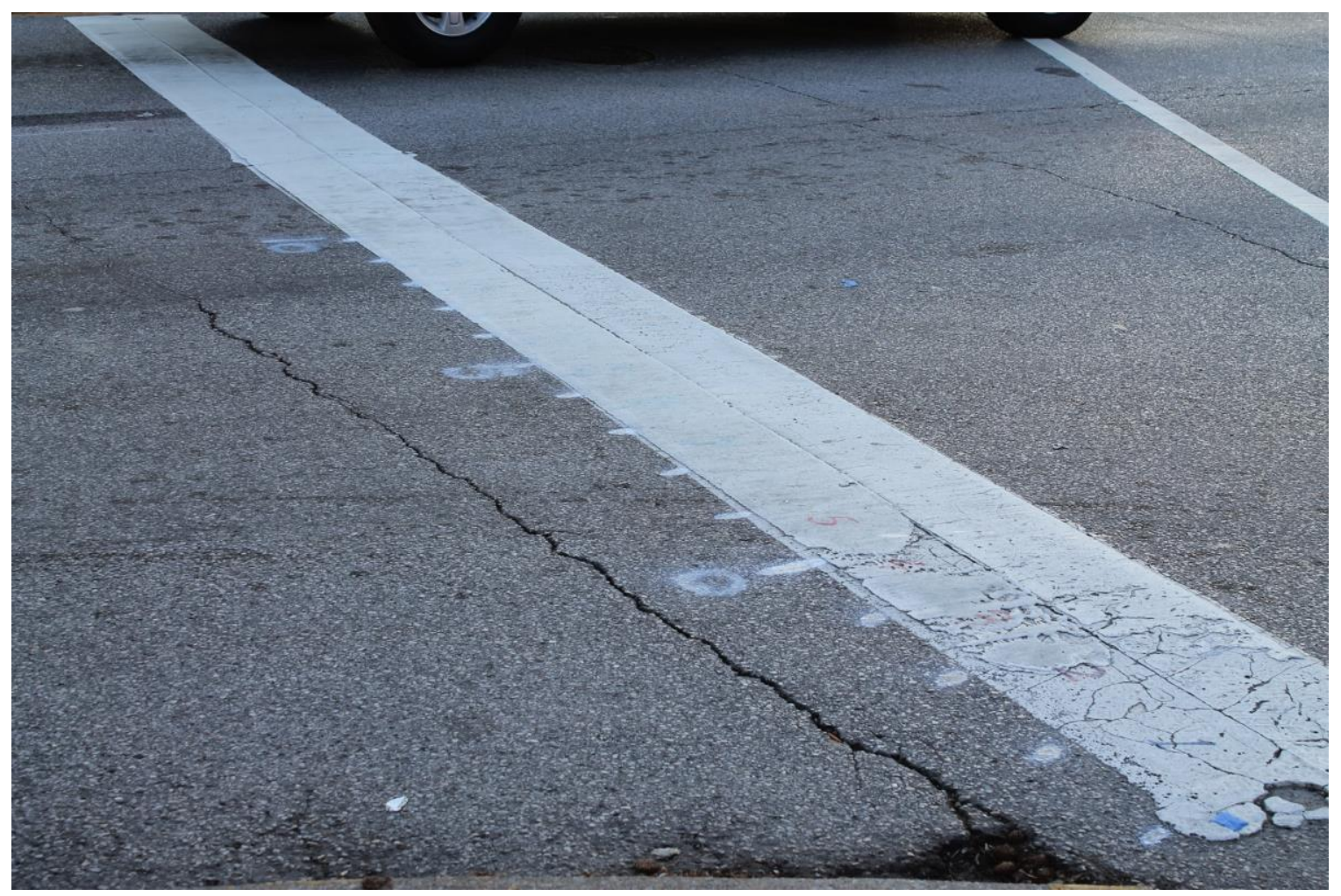

Figure 52: Marks for Distance from Curb for the Third Survey

\section{Survey Results}

For the third survey, 1051 motor vehicles were observed. The average of Distance from Curb is 5.5 feet. The $85 \%$ Distance from Curb is 7 feet. The average of Crossing the Extension Line is 151 feet. The $85 \%$ Crossing the Extension Line is 170 feet. 91.82 percent of drivers use right turning lamp before they turn right. 7.80 percent of drivers turn right when the traffic signal is red.

Table 22 shows the distribution details of the survey result of distance from 
curb for the third survey. Figure 53 and 54 show the distribution details of the survey result of distance from curb for the third survey with feet and accumulation percentage respectively.

Table 22

Survey Results for the Third Survey-Distance from Curb

\begin{tabular}{|c|c|c|c|}
\hline $\begin{array}{c}\text { Distance from } \\
\text { Curb (feet) }\end{array}$ & Frequency & Percentage & $\begin{array}{c}\text { Accumulation } \\
\text { Percentage }\end{array}$ \\
\hline 1 & 5 & $0.48 \%$ & $0.48 \%$ \\
\hline 1.5 & 2 & $0.19 \%$ & $0.67 \%$ \\
\hline 2 & 20 & $1.90 \%$ & $2.57 \%$ \\
\hline 2.5 & 20 & $1.90 \%$ & $4.47 \%$ \\
\hline 3 & 65 & $6.18 \%$ & $10.66 \%$ \\
\hline 3.5 & 84 & $7.99 \%$ & $18.65 \%$ \\
\hline 4 & 108 & $10.28 \%$ & $28.92 \%$ \\
\hline 4.5 & 113 & $10.75 \%$ & $39.68 \%$ \\
\hline 5 & 125 & $11.89 \%$ & $51.57 \%$ \\
\hline 5.5 & 98 & $9.32 \%$ & $60.89 \%$ \\
\hline 6 & 88 & $8.37 \%$ & $69.27 \%$ \\
\hline 6.5 & 61 & $5.80 \%$ & $75.07 \%$ \\
\hline 7 & 56 & $5.33 \%$ & $80.40 \%$ \\
\hline 7.5 & 49 & $4.66 \%$ & $85.06 \%$ \\
\hline 8 & 51 & $4.85 \%$ & $89.91 \%$ \\
\hline
\end{tabular}




\begin{tabular}{|c|c|c|c|}
\hline 8.5 & 24 & $2.28 \%$ & $92.20 \%$ \\
\hline 9 & 30 & $2.85 \%$ & $95.05 \%$ \\
\hline 9.5 & 18 & $1.71 \%$ & $96.76 \%$ \\
\hline 10 & 22 & $2.09 \%$ & $98.86 \%$ \\
\hline 10.5 & 5 & $0.48 \%$ & $99.33 \%$ \\
\hline 11 & 7 & $0.67 \%$ & $100.00 \%$ \\
\hline Total & 1051 & $100.00 \%$ & \\
\hline
\end{tabular}

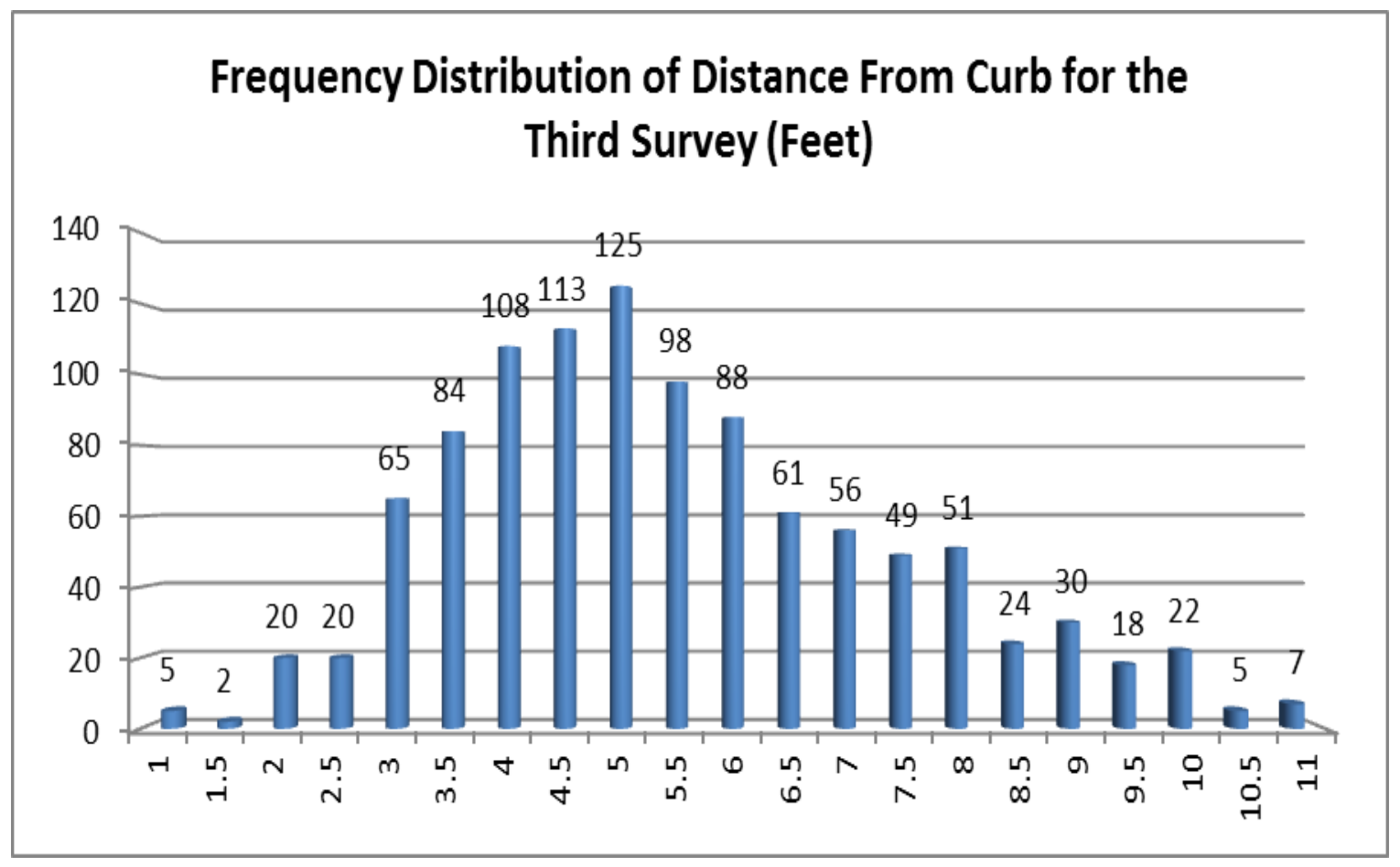

Figure 53: Survey Results for the Third Survey-Distance from Curb (feet) 


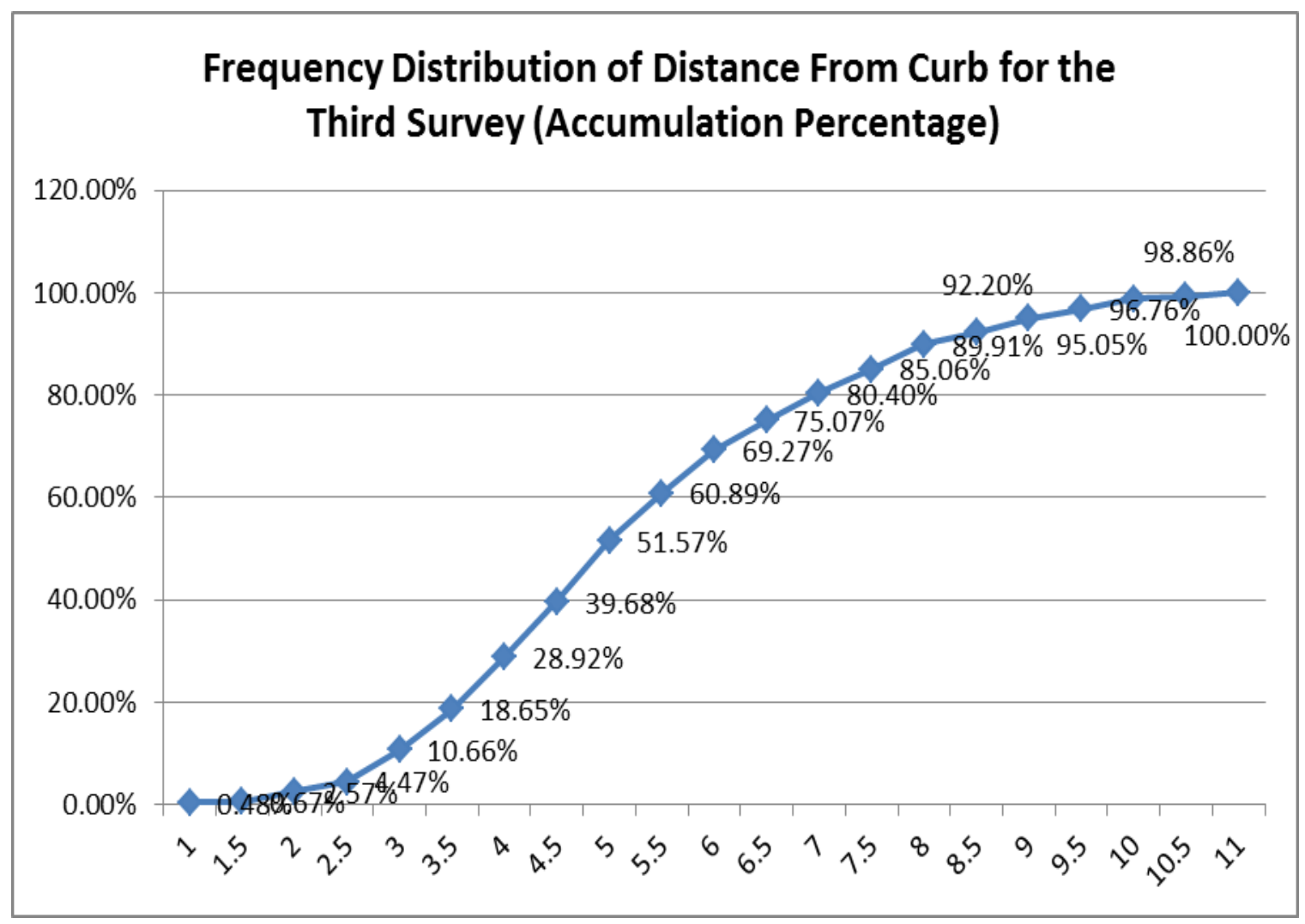

Figure 54: Survey Results for the Third Survey-Distance from Curb Accumulation Percentage

Table 23 shows the distribution details of the survey result of Crossing the Extension Line Position for the third survey. Figure 55 and 56 show the distribution details of the survey results of Crossing the Extension Line Position for the third survey with feet and accumulation percentage respectively.

\section{Table 23}

Survey Result for the Third Survey-Crossing the Extension Line Position 


\begin{tabular}{|c|c|c|c|}
\hline $\begin{array}{l}\text { Crossing the } \\
\text { Extension Line } \\
\text { Position (feet) }\end{array}$ & Frequency & Percentage & $\begin{array}{c}\text { Accumulation } \\
\text { Percentage }\end{array}$ \\
\hline 10 & 2 & $0.19 \%$ & $0.19 \%$ \\
\hline 20 & 3 & $0.29 \%$ & $0.48 \%$ \\
\hline 30 & 2 & $0.19 \%$ & $0.67 \%$ \\
\hline 40 & 3 & $0.29 \%$ & $0.95 \%$ \\
\hline 50 & 4 & $0.38 \%$ & $1.33 \%$ \\
\hline 60 & 5 & $0.48 \%$ & $1.81 \%$ \\
\hline 70 & 9 & $0.86 \%$ & $2.66 \%$ \\
\hline 80 & 2 & $0.19 \%$ & $2.85 \%$ \\
\hline 90 & 13 & $1.24 \%$ & $4.09 \%$ \\
\hline 100 & 7 & $0.67 \%$ & $4.76 \%$ \\
\hline 110 & 13 & $1.24 \%$ & $5.99 \%$ \\
\hline 120 & 10 & $0.95 \%$ & $6.95 \%$ \\
\hline 130 & 37 & $3.52 \%$ & $10.47 \%$ \\
\hline 140 & 96 & $9.13 \%$ & $19.60 \%$ \\
\hline 150 & 241 & $22.93 \%$ & $42.53 \%$ \\
\hline 160 & 417 & $39.68 \%$ & $82.21 \%$ \\
\hline 170 & 187 & $17.79 \%$ & $100 \%$ \\
\hline Total & 1051 & $100.00 \%$ & \\
\hline
\end{tabular}




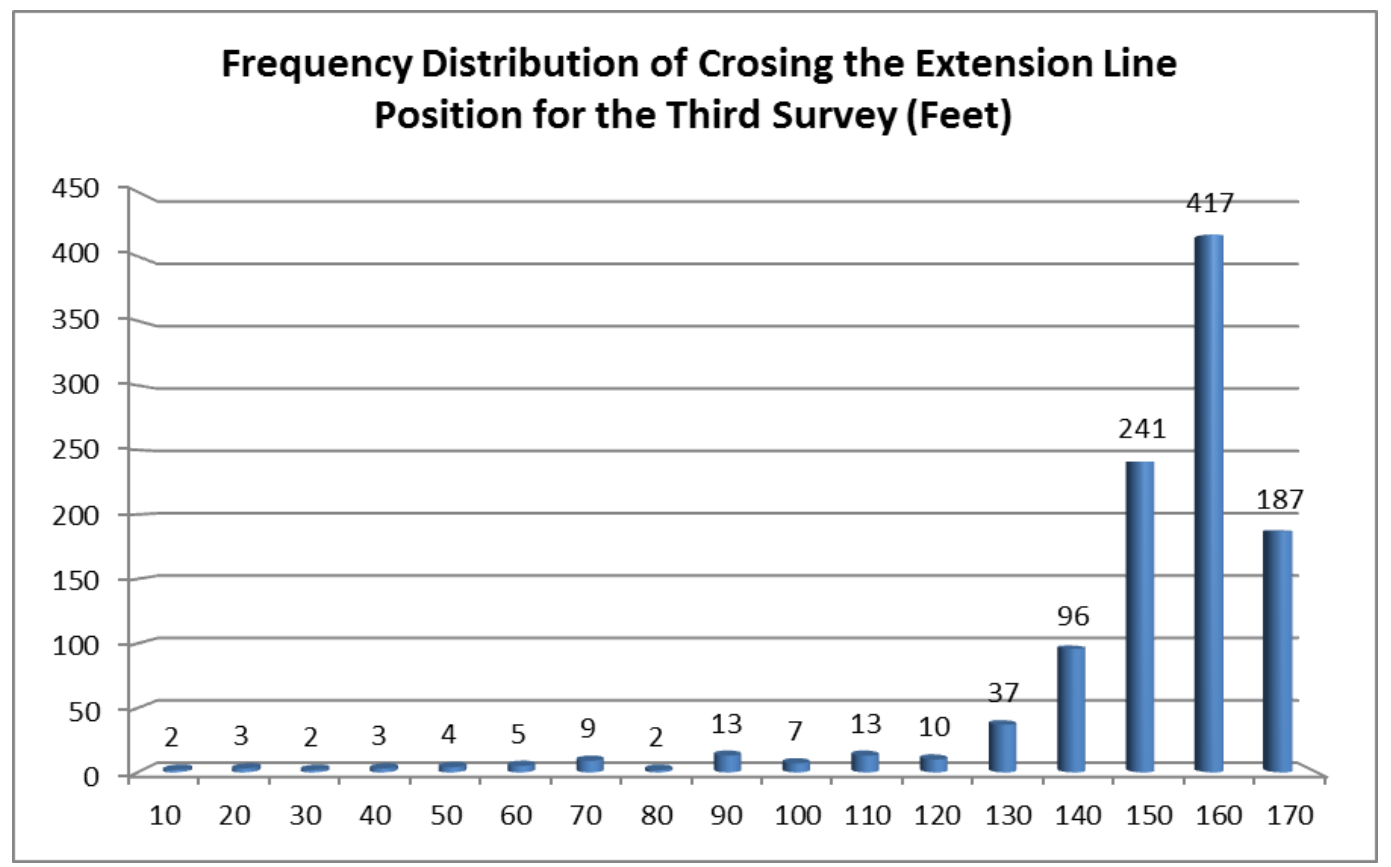

Figure 55: Survey Results for the Third Survey-Crossing the Extension Line Position (feet)

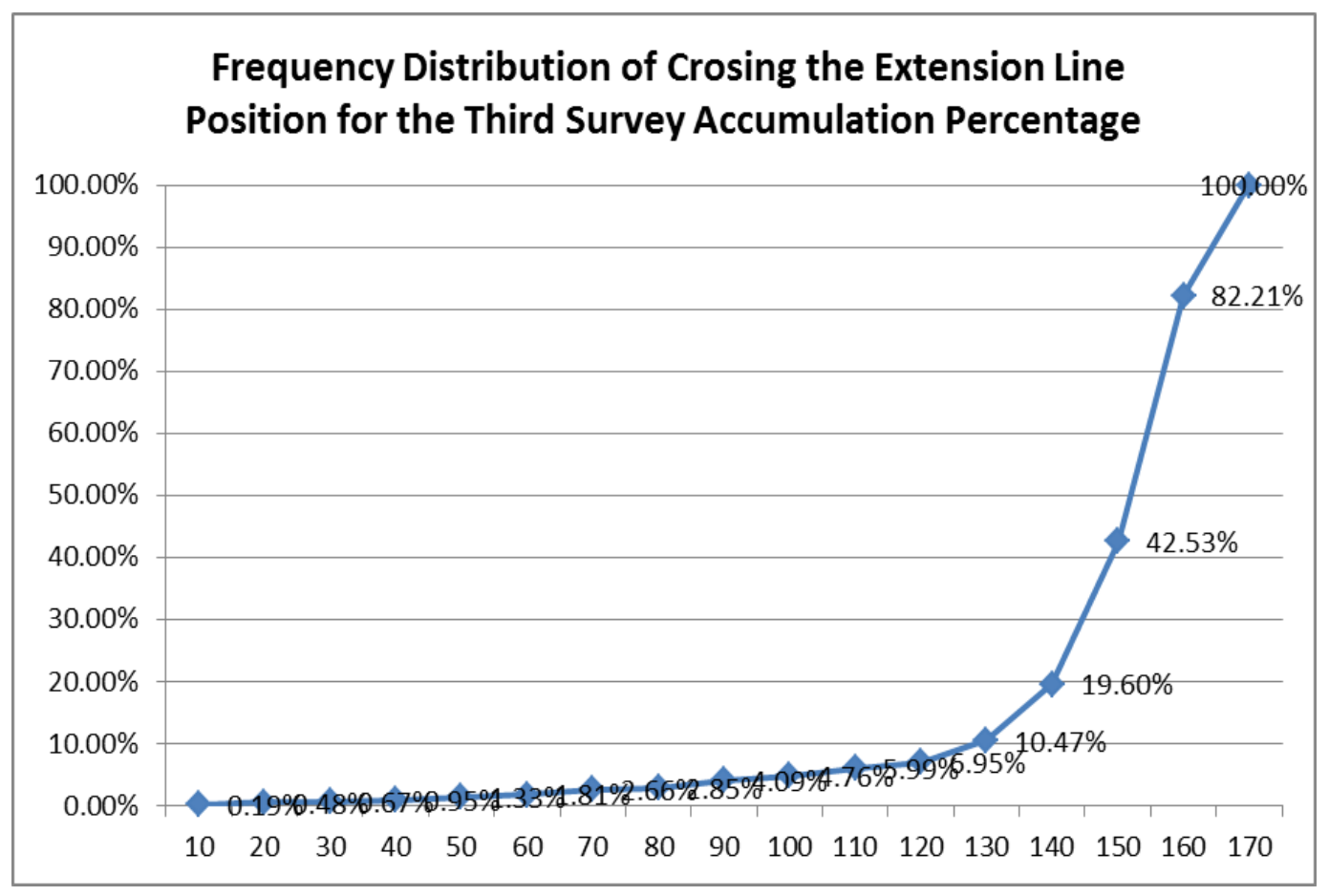


Figure 56: Survey Result for the Third Survey-Crossing the Extension Line Position Accumulation Percentage

\section{Research Results for the Fourth Survey for the Newly-Developed Countermeasure for Bicyclists Safety}

\section{Survey Method}

Items collected in the second survey are:

$>$ Motor Vehicle Type

$>$ Drivers' Gender

$>$ Drivers' Age

> Using Right Lamp before Turning Right

> Turning Position

> Crossing the Trace Line Position

$>$ Distance from Curb

$>$ Using Traffic Signal before Turning Right

The survey items of the fourth survey are similar to the first three surveys, except the item "Crossing the Trace Line Position" which records the position when motor vehicles cross the trace line, which is shown in Figure 57 and 58 and the item "Turning Position", which records the position when motor vehicles begin right turn maneuvers. This trace line is left after the striped line used in the third survey is removed, which starts from the beginning point of the striped oblique 
line and ends at the stop bar. In order to observe the item "Distance from Curb", the method of the second survey still is used, which is shown in Figure 59.

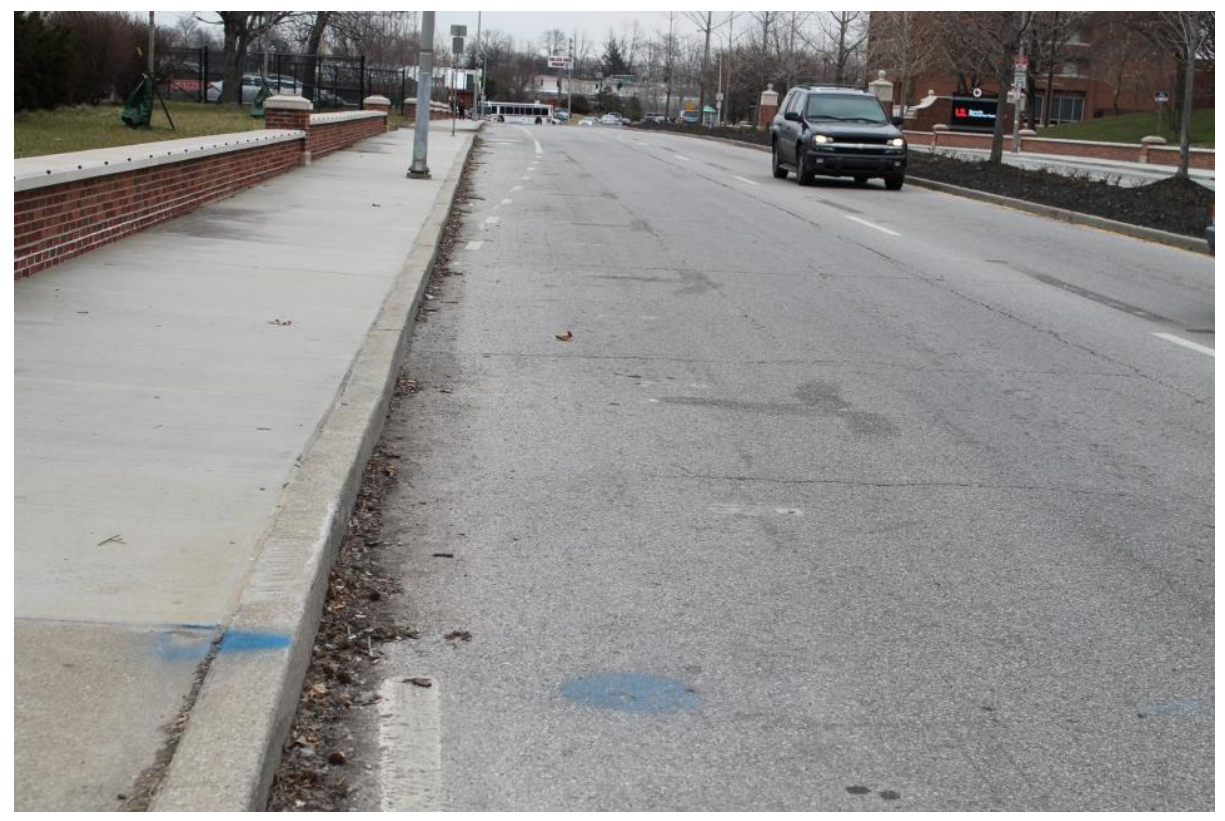

Figure 57: The Trace Line of the Fourth Survey of the Newly-Developed Countermeasure for Bicyclists Safety-Part 1

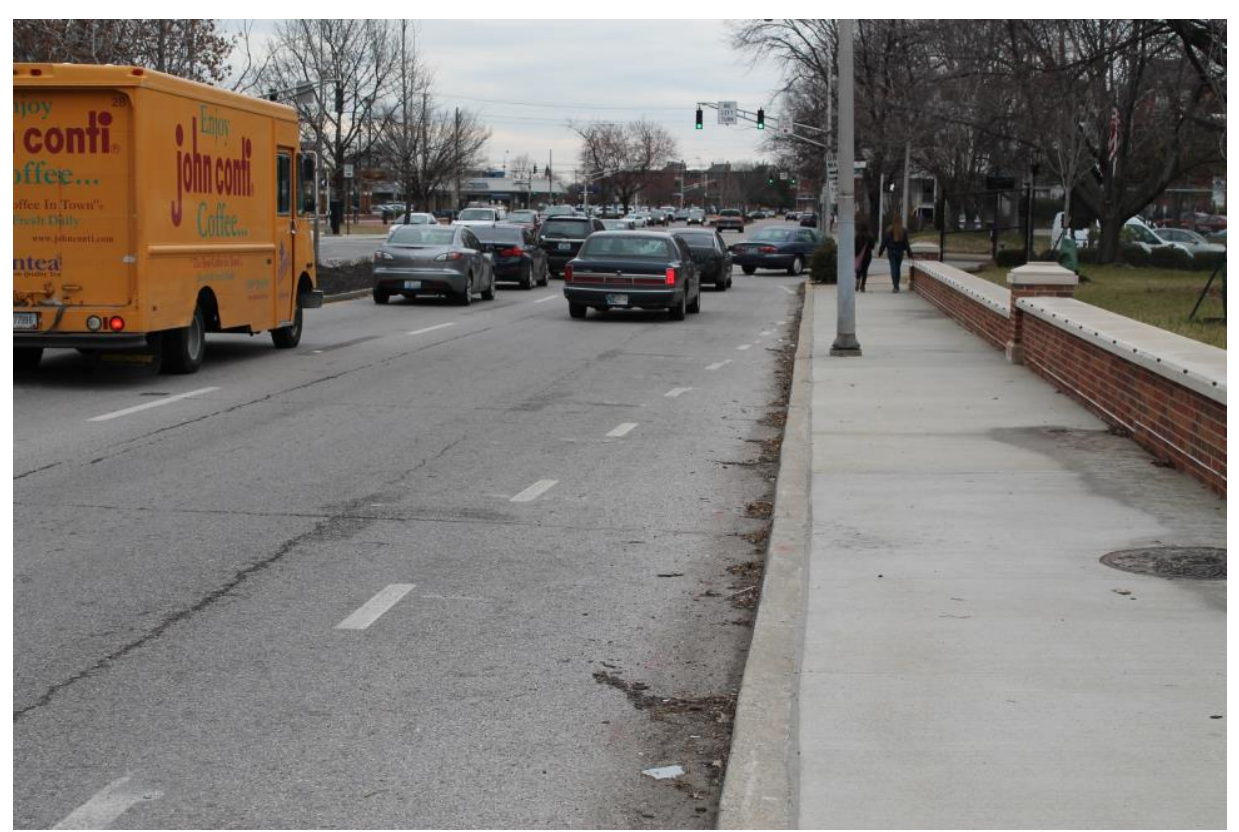


Figure 58: The Trace Line of the Fourth Survey of the Newly-Developed Countermeasure for Bicyclists Safety-Part 2

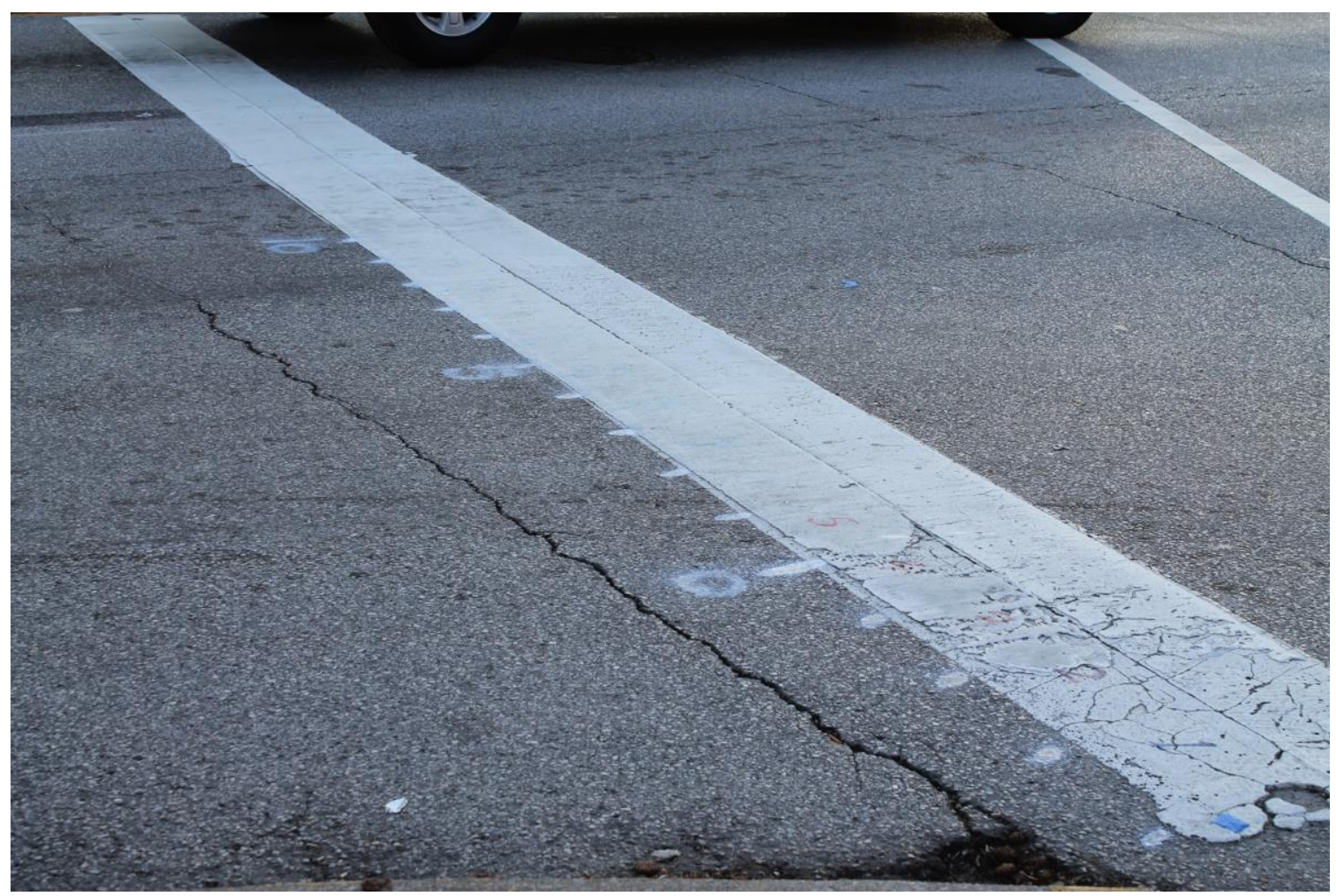

Figure 59: Marks for Distance from Curb for the Fourth Survey

\section{Survey Results}

For the fourth survey, 1032 motor vehicles were observed. The average of Distance from Curb is 5.2 feet. The $85 \%$ Distance from Curb is 7 feet. The average of Turning Position is 67 feet. The $85 \%$ Turning Position is 110 feet. The average of Crossing the Trace Line is 144 feet. The $85 \%$ Crossing the Trace Line is 170 feet. The average of the side driving distance which begins from the position drivers start turning right maneuvers to the position motor vehicles cross 
the trace line is 77 feet. The $85 \%$ side driving distance is 110 feet. 89.83 percent of drivers use right turning lamp before they turn right. 7.47 percent of drivers turn right when traffic signal is red.

Table 24 shows the distribution details of the survey result of distance from curb for the fourth survey. Figure 53 and 54 shows the distribution details of the survey result of distance from curb for the fourth survey with feet and accumulation percentage respectively.

\section{Table 24}

Survey Results for the Fourth Survey-Distance from Curb

\begin{tabular}{|c|c|c|c|}
\hline $\begin{array}{c}\text { Distance from } \\
\text { Curb (feet) }\end{array}$ & Frequency & Percentage & $\begin{array}{c}\text { Accumulation } \\
\text { Percentage }\end{array}$ \\
\hline 1 & 2 & $0.19 \%$ & $0.19 \%$ \\
\hline 1.5 & 1 & $0.10 \%$ & $0.29 \%$ \\
\hline 2 & 16 & $1.55 \%$ & $1.84 \%$ \\
\hline 2.5 & 28 & $2.71 \%$ & $4.55 \%$ \\
\hline 3 & 51 & $4.94 \%$ & $9.50 \%$ \\
\hline 3.5 & 94 & $9.11 \%$ & $18.60 \%$ \\
\hline 4 & 111 & $10.76 \%$ & $29.36 \%$ \\
\hline 4.5 & 141 & $13.66 \%$ & $43.02 \%$ \\
\hline 5 & 116 & $11.24 \%$ & $54.26 \%$ \\
\hline 5.5 & 114 & $11.05 \%$ & $65.31 \%$ \\
\hline
\end{tabular}




\begin{tabular}{|c|c|c|c|}
\hline 6 & 103 & $9.98 \%$ & $75.29 \%$ \\
\hline 6.5 & 87 & $8.43 \%$ & $83.72 \%$ \\
\hline 7 & 58 & $5.62 \%$ & $89.34 \%$ \\
\hline 7.5 & 37 & $3.59 \%$ & $92.93 \%$ \\
\hline 8 & 33 & $3.20 \%$ & $96.12 \%$ \\
\hline 8.5 & 16 & $1.55 \%$ & $97.67 \%$ \\
\hline 9 & 13 & $1.26 \%$ & $98.93 \%$ \\
\hline 9.5 & 4 & $0.39 \%$ & $99.32 \%$ \\
\hline 10 & 4 & $0.39 \%$ & $99.71 \%$ \\
\hline 10.5 & 1 & $0.10 \%$ & $99.81 \%$ \\
\hline 11 & 2 & $0.19 \%$ & $100.00 \%$ \\
\hline Total & 1032 & $100.00 \%$ & \\
\hline
\end{tabular}

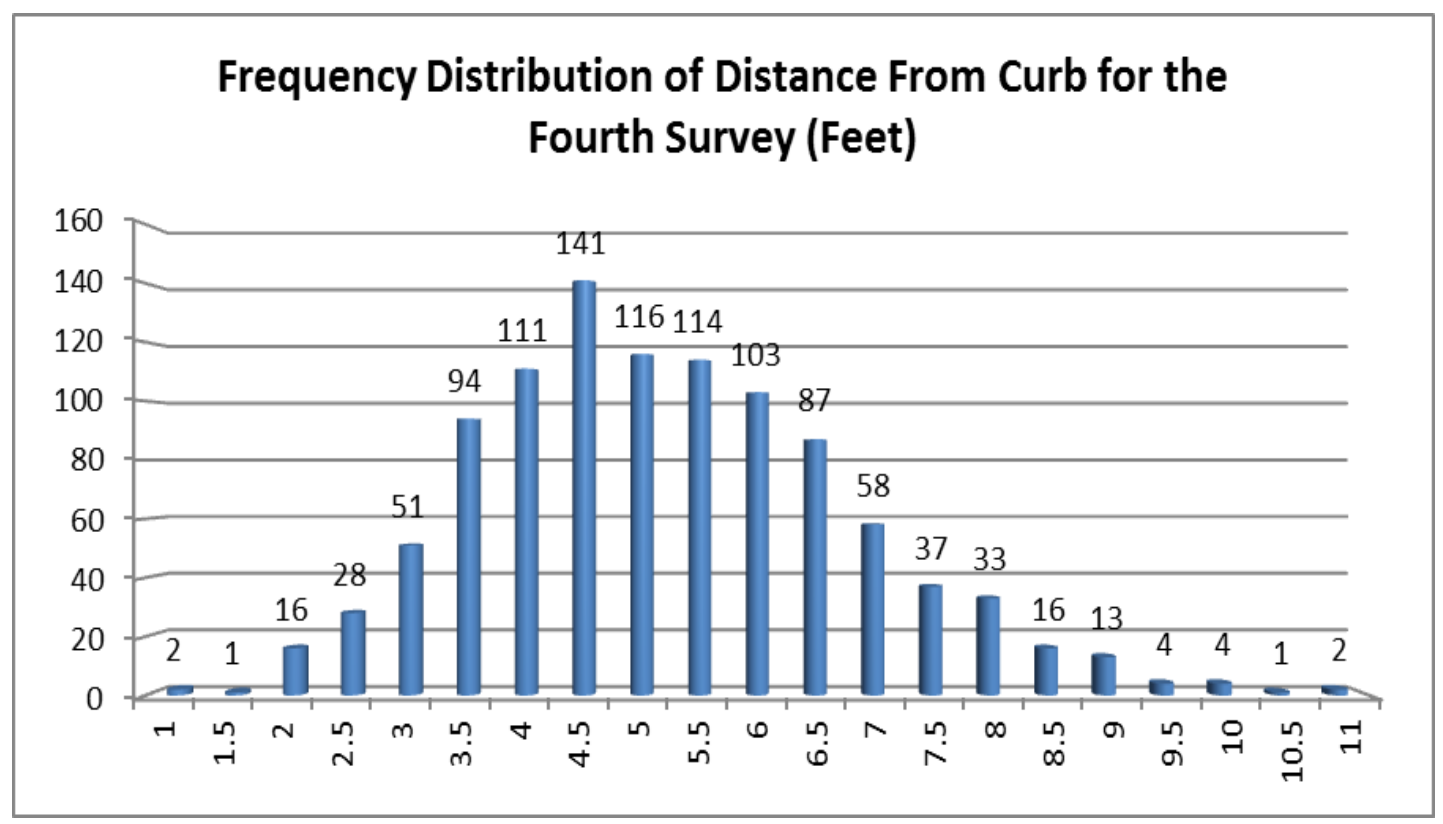

Figure 60: Survey Results for the Fourth Survey-Distance from Curb (feet) 


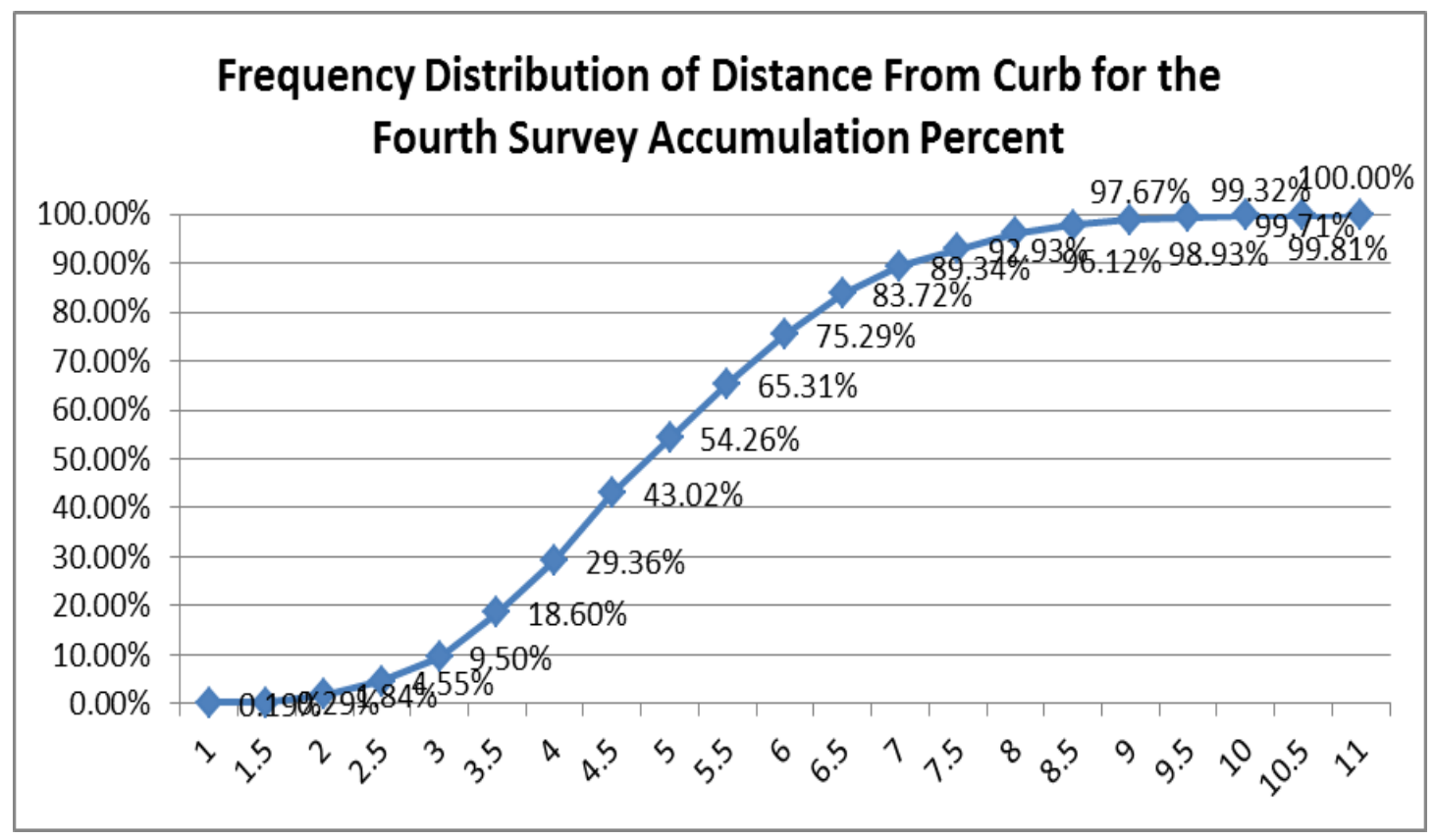

Figure 61: Survey Results for the Fourth Survey-Distance from Curb Accumulation Percentage

Table 25 shows the distribution details of the survey result of Crossing the Trace Line Position for the fourth survey. Figure 62 and 63 shows the distribution details of the survey results of Crossing the Trace Line Position for the fourth survey with feet and accumulation percentage respectively.

\section{Table 25}

Survey Results for the Fourth Survey-Crossing the Trace Line Position

\begin{tabular}{|c|c|c|c|}
\hline $\begin{array}{c}\text { Crossing the } \\
\text { Trace Line } \\
\text { Position (feet) }\end{array}$ & Frequency & Percentage & $\begin{array}{c}\text { Accumulation } \\
\text { Percentage }\end{array}$ \\
\hline
\end{tabular}




\begin{tabular}{|c|c|c|c|}
\hline 10 & 2 & $0.19 \%$ & $0.19 \%$ \\
\hline 20 & 2 & $0.19 \%$ & $0.39 \%$ \\
\hline 30 & 6 & $0.58 \%$ & $0.97 \%$ \\
\hline 40 & 8 & $0.78 \%$ & $1.74 \%$ \\
\hline 50 & 4 & $0.39 \%$ & $2.13 \%$ \\
\hline 60 & 15 & $1.45 \%$ & $3.59 \%$ \\
\hline 70 & 12 & $2.03 \%$ & $5.62 \%$ \\
\hline 80 & 37 & $1.16 \%$ & $6.78 \%$ \\
\hline 90 & 23 & $1.36 \%$ & $8.14 \%$ \\
\hline 100 & 30 & $2.23 \%$ & $11.72 \%$ \\
\hline 110 & 94 & $2.91 \%$ & $13.95 \%$ \\
\hline 120 & 134 & $9.11 \%$ & $25.97 \%$ \\
\hline 130 & 129 & $12.50 \%$ & $38.95 \%$ \\
\hline 140 & 335 & $16.09 \%$ & $67.54 \%$ \\
\hline 150 & 1032 & $100.00 \%$ & $100.00 \%$ \\
\hline 160 & & $32.46 \%$ & \\
\hline 170 & $166 \%$ & & \\
\hline Total & & & \\
\hline
\end{tabular}




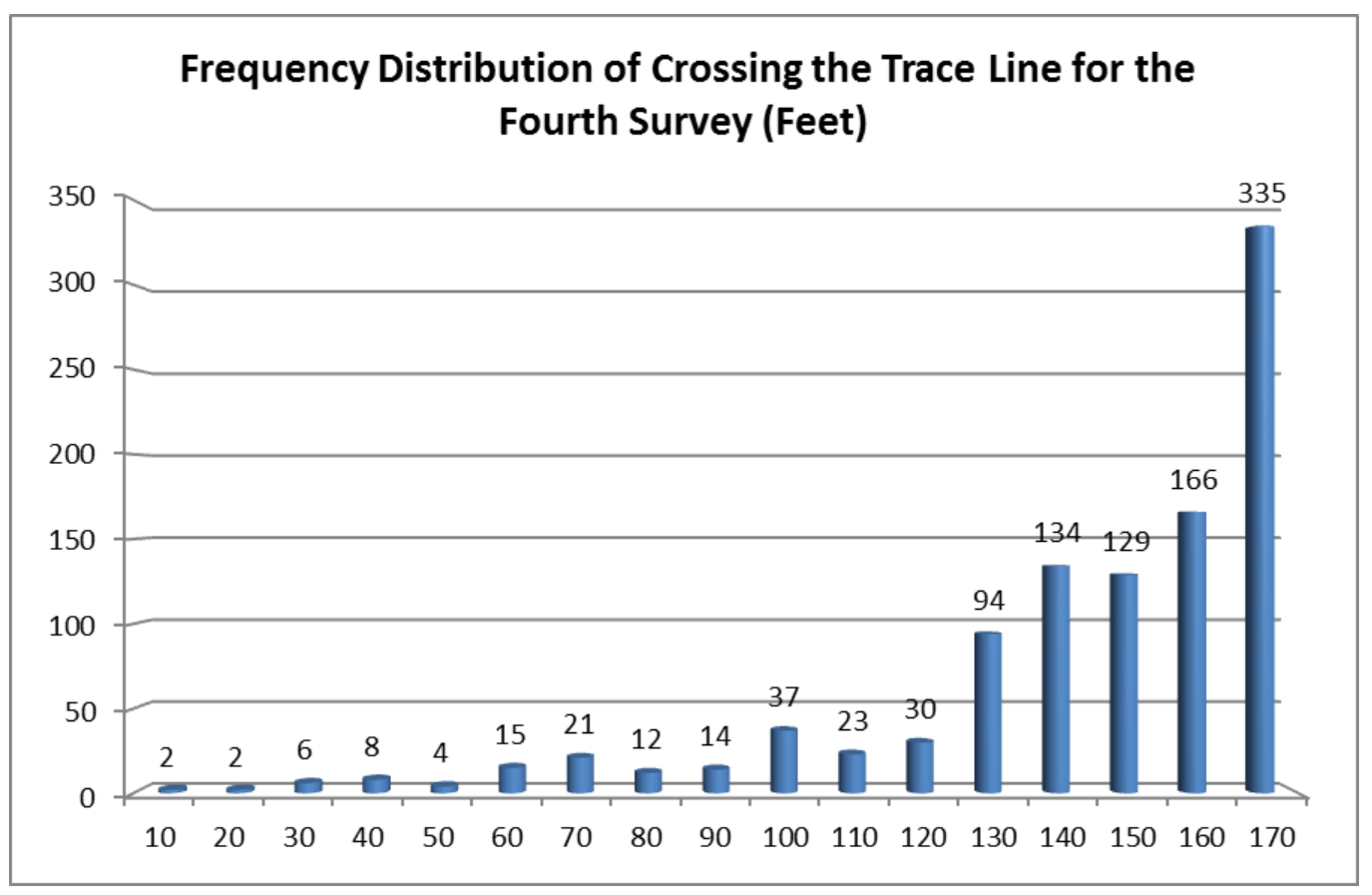

Figure 62: Survey Results for the Fourth Survey-Crossing the Trace Line Position (feet)

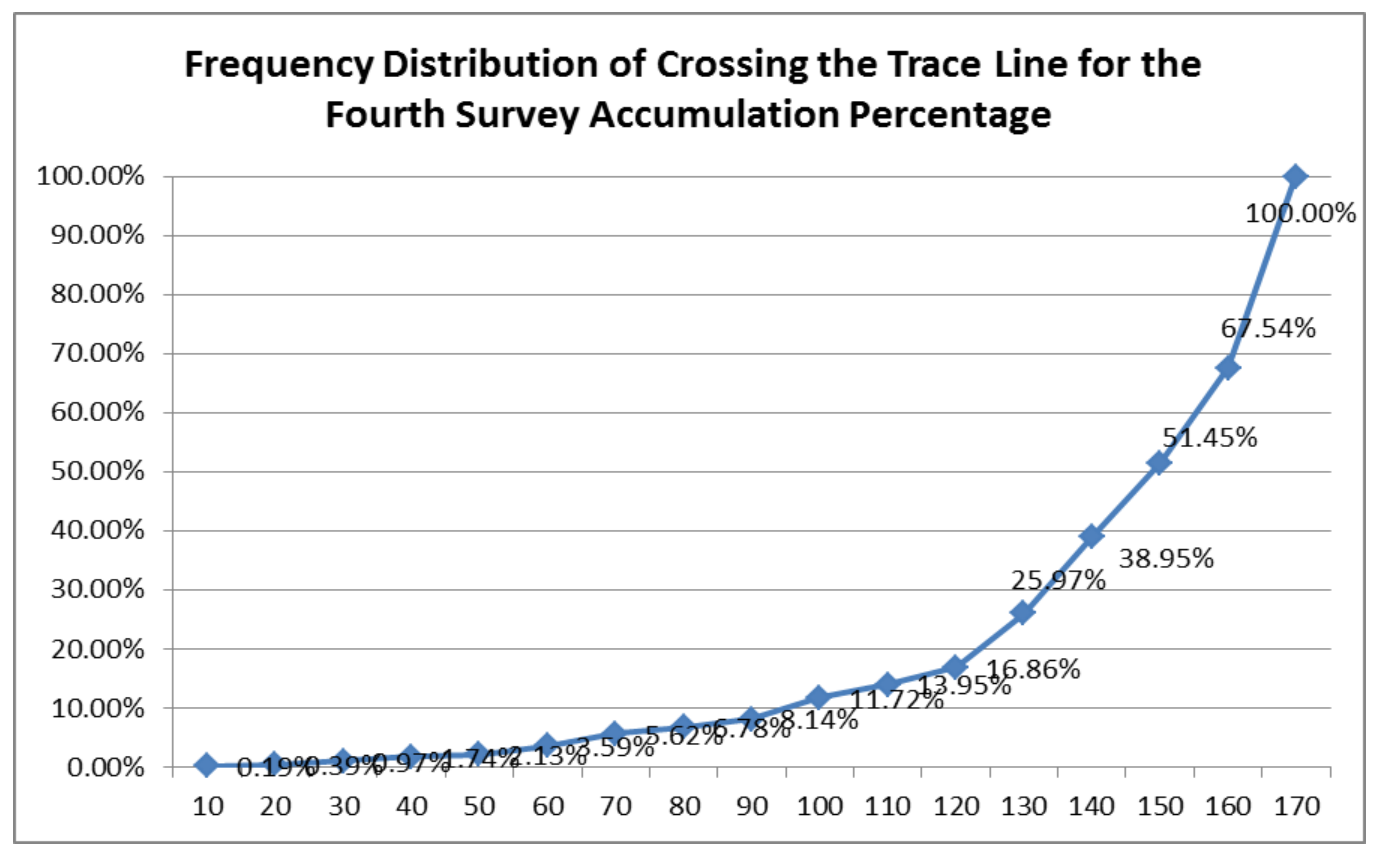

Figure 63: Survey Result for the Fourth Survey-Crossing the Trace Line Position 
Accumulation Percentage

Table 26 shows the distribution details of the survey result of Turning Position for the fourth survey. Figure 64 and 65 shows the distribution details of the survey results of Turning Position for the fourth survey with feet and accumulation percentage respectively.

Table 26

Survey Results for the Fourth Survey-Turning Position

\begin{tabular}{|c|c|c|c|}
\hline $\begin{array}{c}\text { Turning Position } \\
\text { (feet) }\end{array}$ & Frequency & Percentage & $\begin{array}{c}\text { Accumulation } \\
\text { Percentage }\end{array}$ \\
\hline 10 & 94 & $9.11 \%$ & $9.11 \%$ \\
\hline 20 & 91 & $8.82 \%$ & $17.93 \%$ \\
\hline 30 & 89 & $8.62 \%$ & $26.55 \%$ \\
\hline 40 & 94 & $9.11 \%$ & $35.66 \%$ \\
\hline 50 & 60 & $5.81 \%$ & $41.47 \%$ \\
\hline 60 & 65 & $6.30 \%$ & $47.77 \%$ \\
\hline 70 & 117 & $11.34 \%$ & $59.11 \%$ \\
\hline 80 & 60 & $7.75 \%$ & $66.86 \%$ \\
\hline 90 & 95 & $5.91 \%$ & $72.77 \%$ \\
\hline 100 & 63 & $9.21 \%$ & $81.98 \%$ \\
\hline 110 & 41 & $6.10 \%$ & $88.08 \%$ \\
\hline 120 & & $3.97 \%$ & $92.05 \%$ \\
\hline
\end{tabular}




\begin{tabular}{|c|c|c|c|}
\hline 130 & 22 & $2.13 \%$ & $94.19 \%$ \\
\hline 140 & 25 & $2.42 \%$ & $96.61 \%$ \\
\hline 150 & 19 & $1.84 \%$ & $98.45 \%$ \\
\hline 160 & 12 & $1.16 \%$ & $99.61 \%$ \\
\hline 170 & 4 & $0.39 \%$ & $100.00 \%$ \\
\hline Total & 1032 & $100.00 \%$ & \\
\hline
\end{tabular}

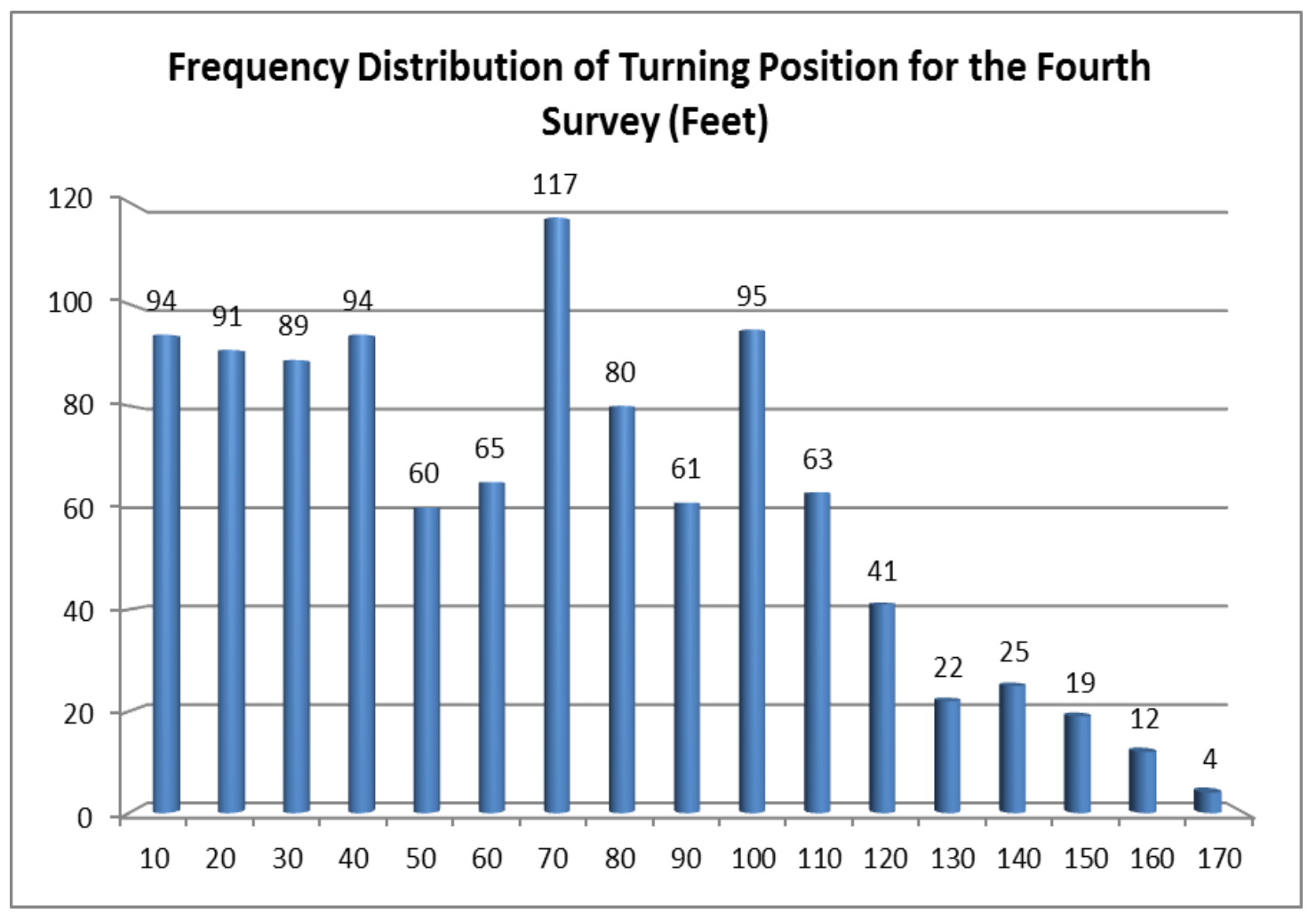

Figure 64: Survey Results for the Fourth Survey-Turning Position (feet) 


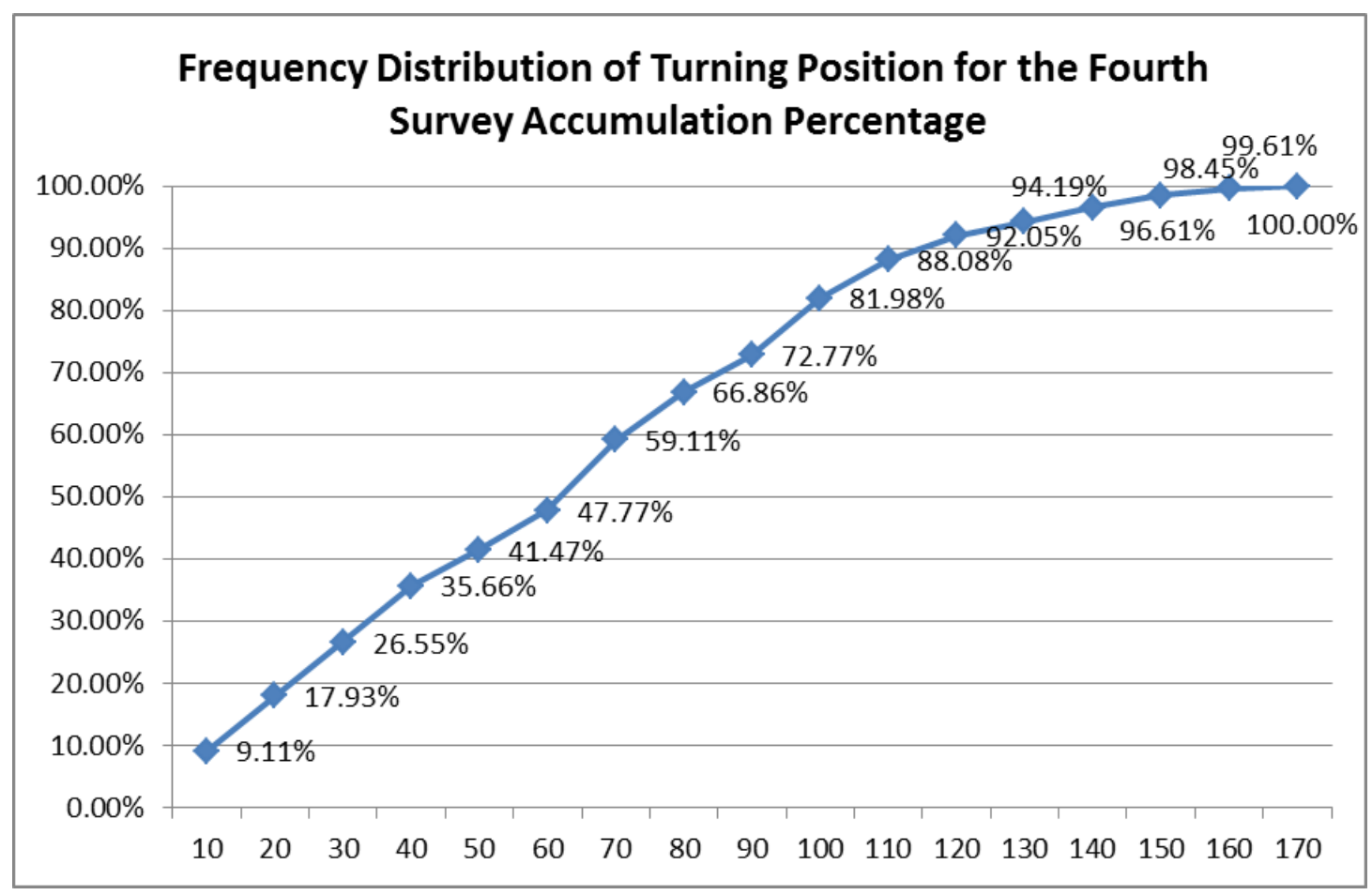

Figure 65: Survey Result for the Fourth Survey-Turning Position Accumulation Percentage

Table 27 shows the distribution details of the survey result of Side Driving Distance for the fourth survey. Figure 66 and 67 shows the distribution details of the survey results of Side Driving Distance for the fourth survey with feet and accumulation percentage respectively.

\section{Table 27}

Survey Results for the Fourth Survey- Side Driving Distance

\begin{tabular}{|c|c|c|c|}
\hline $\begin{array}{c}\text { Side Driving } \\
\text { Distance (feet) }\end{array}$ & Frequency & Percentage & $\begin{array}{c}\text { Accumulation } \\
\text { Percentage }\end{array}$ \\
\hline
\end{tabular}




\begin{tabular}{|c|c|c|c|}
\hline 10 & 26 & $2.52 \%$ & $2.52 \%$ \\
\hline 20 & 32 & $3.10 \%$ & $5.62 \%$ \\
\hline 30 & 41 & $3.97 \%$ & $9.59 \%$ \\
\hline 40 & 35 & $3.39 \%$ & $12.98 \%$ \\
\hline 50 & 65 & $6.30 \%$ & $19.28 \%$ \\
\hline 60 & 117 & $11.34 \%$ & $30.62 \%$ \\
\hline 70 & 152 & $14.73 \%$ & $45.35 \%$ \\
\hline 80 & 144 & $13.95 \%$ & $59.30 \%$ \\
\hline 90 & 120 & $13.66 \%$ & $72.97 \%$ \\
\hline 100 & 72 & $6.98 \%$ & $84.59 \%$ \\
\hline 110 & 42 & $4.07 \%$ & $91.57 \%$ \\
\hline 120 & 26 & $2.52 \%$ & $98.16 \%$ \\
\hline 130 & 8 & $0.78 \%$ & $98.93 \%$ \\
\hline 140 & 1032 & $0.87 \%$ & $99.81 \%$ \\
\hline 150 & & $0.19 \%$ & $100.00 \%$ \\
\hline 160 & & $100.00 \%$ & \\
\hline Total & & & \\
\hline
\end{tabular}




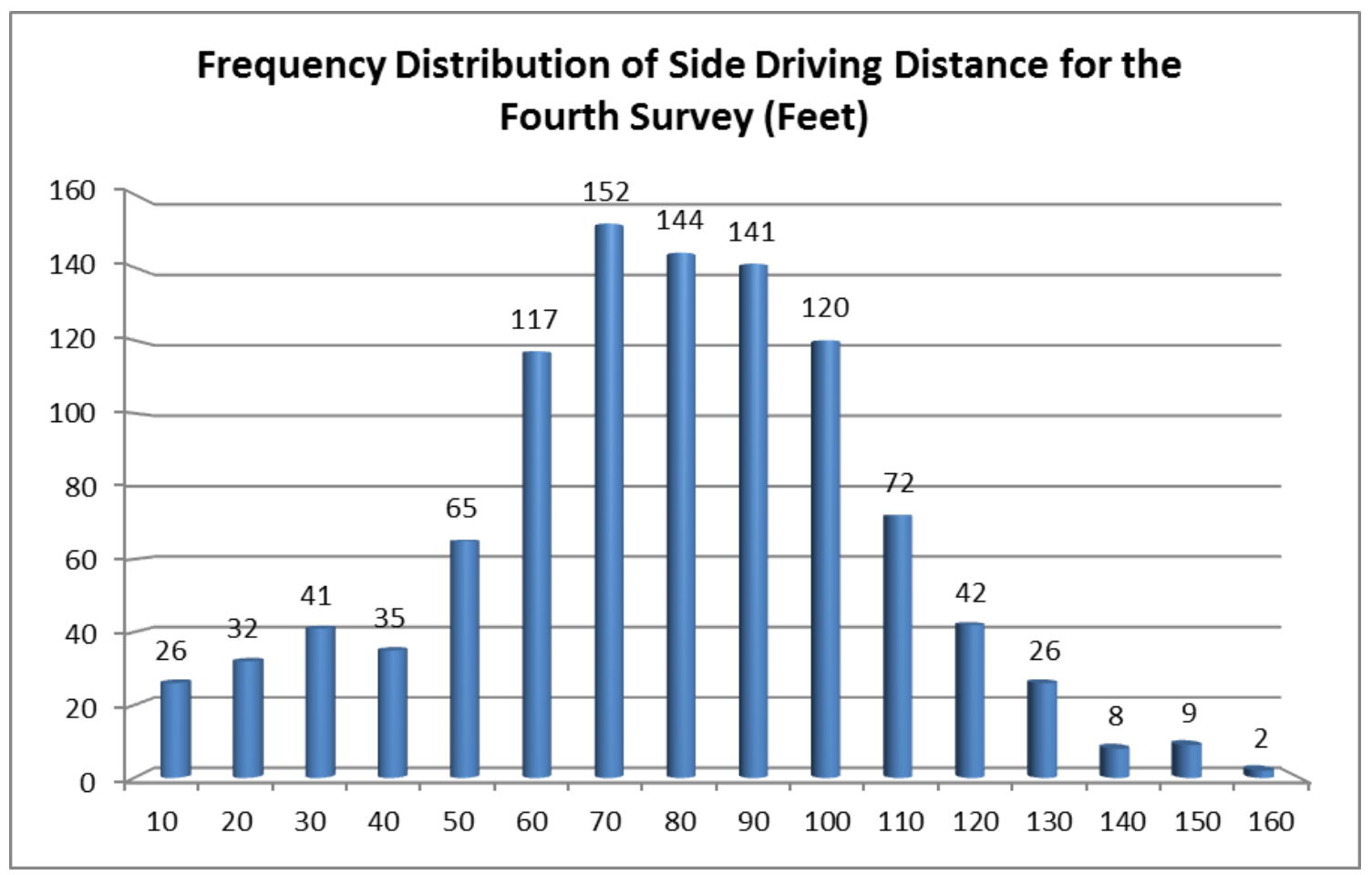

Figure 66: Survey Results for the Fourth Survey- Side Driving Distance (feet)

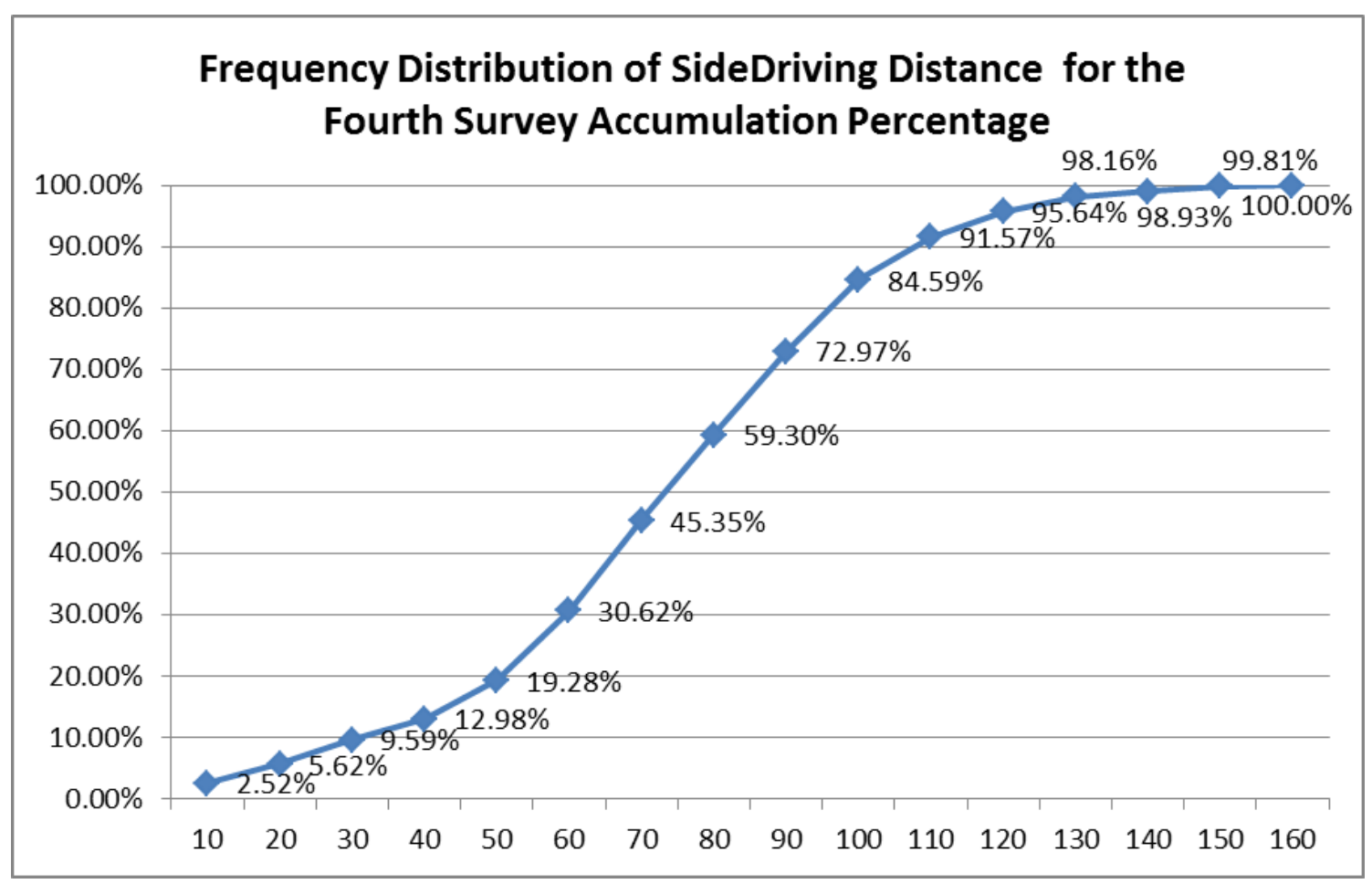


Figure 67: Survey Result for the Fourth Survey- Side Driving Distance Accumulation Percentage.

\section{Analysis for the Drivers' Behavior at the Observed Intersection}

\section{(1) Analysis for the Distance from Curb of the Four Surveys}

According to the analysis for the Distance from the Curb of these three surveys shown in Table 28 and 29, and Figure 68, the distributions of the Distance from the Curb of these four surveys quite match each other. This means drivers adhere to their driving habits when they do right turn maneuvers. Adding or getting rid of the striped extension line can't change drivers' driving habits. The extension outer line of the bicycle lane is 9 feet away from the curving curb at the position the stop bar crosses the bicycle lane and 5 feet away from the straight part of the curb. Usually, bicyclists ride their bicycles 2-3 feet away from the straight part of the curb. Because $85 \%$ of drivers cross the stop bar when they are 7 feet away from the curb, if the drivers or bicyclists lose their attention which is the highest reason for the bicycle-related crashes in Louisville, a bicycle accident will hold high possibility of happening.

\section{Table 28}

Analysis of the Distance from Curb for the Four Surveys

\begin{tabular}{|c|c|c|c|c|}
\hline & $\begin{array}{c}\text { First } \\
\text { Survey }\end{array}$ & $\begin{array}{c}\text { Second } \\
\text { Survey }\end{array}$ & $\begin{array}{c}\text { Third } \\
\text { Survey }\end{array}$ & $\begin{array}{l}\text { Fourth } \\
\text { Survey }\end{array}$ \\
\hline
\end{tabular}




\begin{tabular}{|c|c|c|c|c|}
\hline $\begin{array}{c}\text { Average Distance from } \\
\text { Curb (feet) }\end{array}$ & 5.3 & 5.1 & 5.5 & 5.2 \\
\hline Standard Deviation & 1.889 & 1.749 & 1.968 & 1.606 \\
\hline $\begin{array}{c}85 \% \text { Distance from Curb } \\
\text { (feet) }\end{array}$ & 7 & 7 & 7 & 7 \\
\hline
\end{tabular}

\section{Table 29}

Distribution Analysis of the Distance from Curb for the Four Surveys

\begin{tabular}{|c|c|c|c|c|}
\hline $\begin{array}{c}\text { Distance } \\
\text { from } \\
\text { Curb } \\
\text { (feet) }\end{array}$ & First Survey & $\begin{array}{c}\text { Second Survey } \\
\text { (Percentage) }\end{array}$ & $\begin{array}{c}\text { Third Survey } \\
\text { (Percentage) }\end{array}$ & $\begin{array}{c}\text { Fourth Survey } \\
\text { (Percentage) }\end{array}$ \\
\hline 1 & $0.49 \%$ & $0.31 \%$ & $0.48 \%$ & $0.19 \%$ \\
\hline 1.5 & $0.74 \%$ & $0.31 \%$ & $0.19 \%$ & $0.10 \%$ \\
\hline 2 & $1.48 \%$ & $1.68 \%$ & $1.90 \%$ & $1.55 \%$ \\
\hline 2.5 & $4.20 \%$ & $2.41 \%$ & $1.90 \%$ & $2.71 \%$ \\
\hline 3 & $5.68 \%$ & $8.38 \%$ & $6.18 \%$ & $4.94 \%$ \\
\hline 3.5 & $6.91 \%$ & $8.90 \%$ & $7.99 \%$ & $9.11 \%$ \\
\hline 4 & $11.36 \%$ & $10.68 \%$ & $10.28 \%$ & $10.76 \%$ \\
\hline 4.5 & $12.84 \%$ & $15.18 \%$ & $10.75 \%$ & $13.66 \%$ \\
\hline
\end{tabular}




\begin{tabular}{|c|c|c|c|c|}
\hline 5 & $10.62 \%$ & $10.99 \%$ & $11.89 \%$ & $11.24 \%$ \\
\hline 5.5 & $9.14 \%$ & $7.75 \%$ & $9.32 \%$ & $11.05 \%$ \\
\hline 6 & $8.64 \%$ & $9.63 \%$ & $8.37 \%$ & $9.98 \%$ \\
\hline 6.5 & $7.41 \%$ & $5.24 \%$ & $5.80 \%$ & $8.43 \%$ \\
\hline 7 & $7.16 \%$ & $5.76 \%$ & $5.33 \%$ & $5.62 \%$ \\
\hline 7.5 & $3.46 \%$ & $5.03 \%$ & $4.66 \%$ & $3.59 \%$ \\
\hline 8 & $2.47 \%$ & $3.04 \%$ & $4.85 \%$ & $3.20 \%$ \\
\hline 8.5 & $1.48 \%$ & $0.84 \%$ & $2.28 \%$ & $1.55 \%$ \\
\hline 9 & $2.22 \%$ & $1.68 \%$ & $2.85 \%$ & $1.26 \%$ \\
\hline 9.5 & $0.74 \%$ & $0.42 \%$ & $1.71 \%$ & $0.39 \%$ \\
\hline 10 & $1.73 \%$ & $1.26 \%$ & $2.09 \%$ & $0.39 \%$ \\
\hline 10.5 & $0.25 \%$ & $0.10 \%$ & $0.48 \%$ & $0.10 \%$ \\
\hline 11 & $0.99 \%$ & $0.42 \%$ & $0.67 \%$ & $0.19 \%$ \\
\hline
\end{tabular}




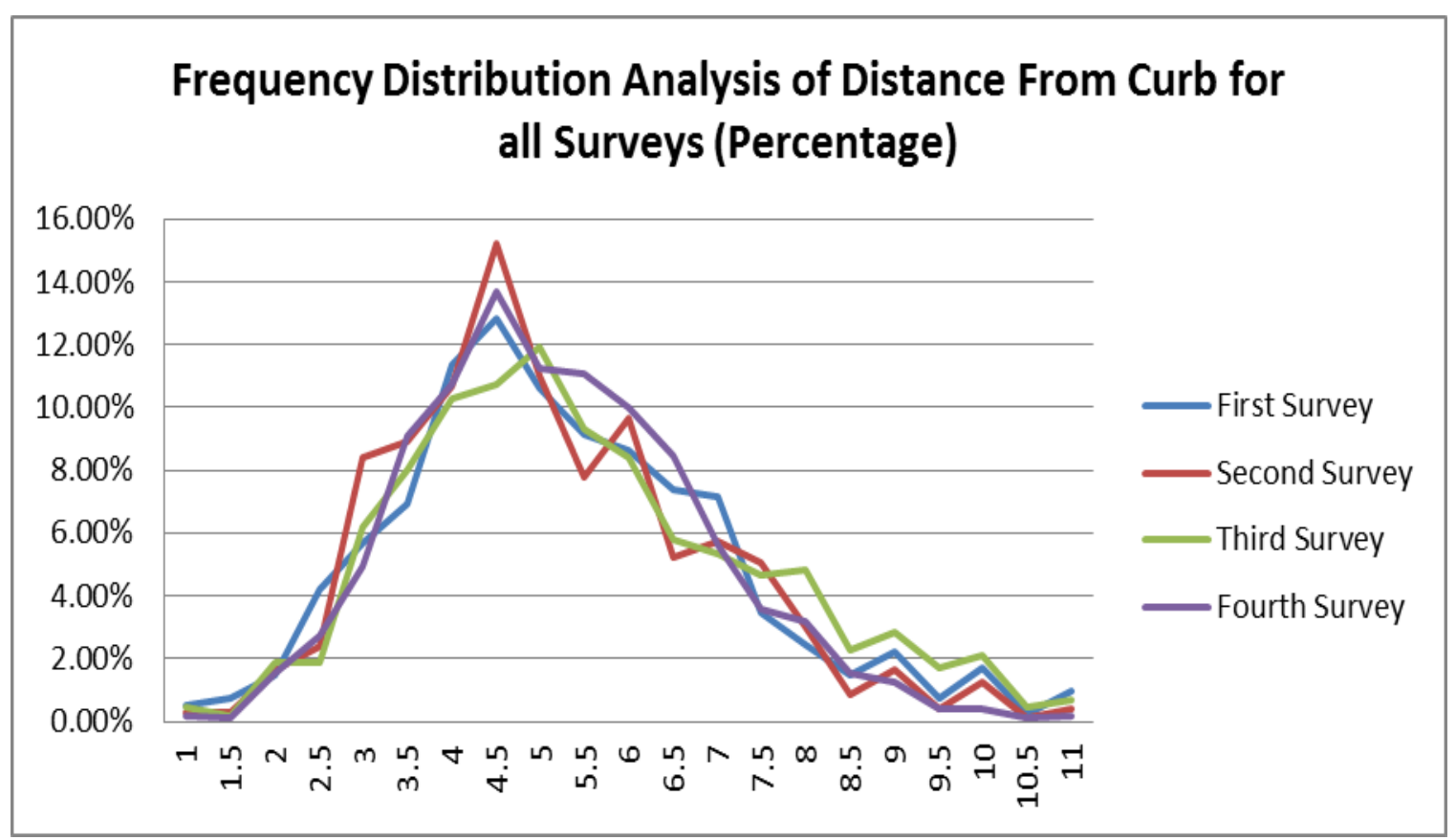

Figure 68: Frequency Distribution Analysis of Distance from Curb for the Four Surveys

\section{(2) Analysis for the Turning Position}

As is shown in Table 30 and 31, and Figure 69, Turning Position data collected in the first survey and the fourth survey match quite well. 38.27 percent of the first survey drivers and 35.66 percent of the fourth survey drivers start their right turn maneuvers before 40 feet away from the beginning points of the striped oblique line. This position is 140 feet away from the stop bar. These drivers can be thought of as following the striped oblique line. About 50 percent of drivers begin turning right maneuvers at the position 60 feet away from the beginning point of the striped oblique line, which is also 120 feet away from the stop bar. $85 \%$ of drivers begin their right turn maneuvers at the position of 100 feet for the 
first survey and 110 feet for the second survey away from the beginning point of the striped oblique line.

Table 30

Analysis of the Turning Position for the First and Four Surveys

\begin{tabular}{|c|c|c|}
\hline & First Survey & Fourth Survey \\
\hline Average Turning Position (feet) & 62 & 67 \\
\hline Standard Deviation & 38.180 & 39.356 \\
\hline 85\%Turning Position (feet) & 100 & 110 \\
\hline
\end{tabular}

\section{Table 31}

Distribution Analysis of the Turning Position for the First and Four SurveysPercentages

\begin{tabular}{|c|c|c|c|c|}
\hline $\begin{array}{c}\text { Turning } \\
\text { Position(feet) }\end{array}$ & First Survey & $\begin{array}{c}\text { First Survey } \\
\text { (Percentage) }\end{array}$ & $\begin{array}{c}\text { Fourth Survey } \\
\text { Percentage) }\end{array}$ & $\begin{array}{c}\text { Fourth Survey } \\
\text { (Accumulation } \\
\text { Percentage) }\end{array}$ \\
\hline 10 & $11.36 \%$ & $11.36 \%$ & $9.11 \%$ & $9.11 \%$ \\
\hline 20 & $10.12 \%$ & $21.48 \%$ & $8.82 \%$ & $17.93 \%$ \\
\hline 30 & $9.38 \%$ & $30.86 \%$ & $8.62 \%$ & $26.55 \%$ \\
\hline
\end{tabular}




\begin{tabular}{|c|c|c|c|c|}
\hline 40 & $7.41 \%$ & $38.27 \%$ & $9.11 \%$ & $35.66 \%$ \\
\hline 50 & $7.65 \%$ & $45.93 \%$ & $5.81 \%$ & $41.47 \%$ \\
\hline 60 & $10.86 \%$ & $56.79 \%$ & $6.30 \%$ & $47.77 \%$ \\
\hline 70 & $8.64 \%$ & $65.43 \%$ & $11.34 \%$ & $59.11 \%$ \\
\hline 80 & $7.90 \%$ & $73.33 \%$ & $7.75 \%$ & $66.86 \%$ \\
\hline 90 & $5.43 \%$ & $78.77 \%$ & $5.91 \%$ & $72.77 \%$ \\
\hline 100 & $8.40 \%$ & $87.16 \% \mathrm{t}$ & $9.21 \%$ & $81.98 \%$ \\
\hline 110 & $4.20 \%$ & $91.36 \%$ & $6.10 \%$ & $88.08 \%$ \\
\hline 120 & $2.72 \%$ & $94.07 \%$ & $3.97 \%$ & $92.05 \%$ \\
\hline 130 & $0.99 \%$ & $95.06 \%$ & $2.13 \%$ & $94.19 \%$ \\
\hline 140 & $1.73 \%$ & $96.79 \%$ & $2.42 \%$ & $96.61 \%$ \\
\hline 150 & $1.73 \%$ & $98.52 \%$ & $1.84 \%$ & $98.45 \%$ \\
\hline 160 & $0.74 \%$ & $99.26 \%$ & $1.16 \%$ & $99.61 \%$ \\
\hline 170 & $0.74 \%$ & $100.0 \%$ & $0.39 \%$ & $100.0 \%$ \\
\hline
\end{tabular}




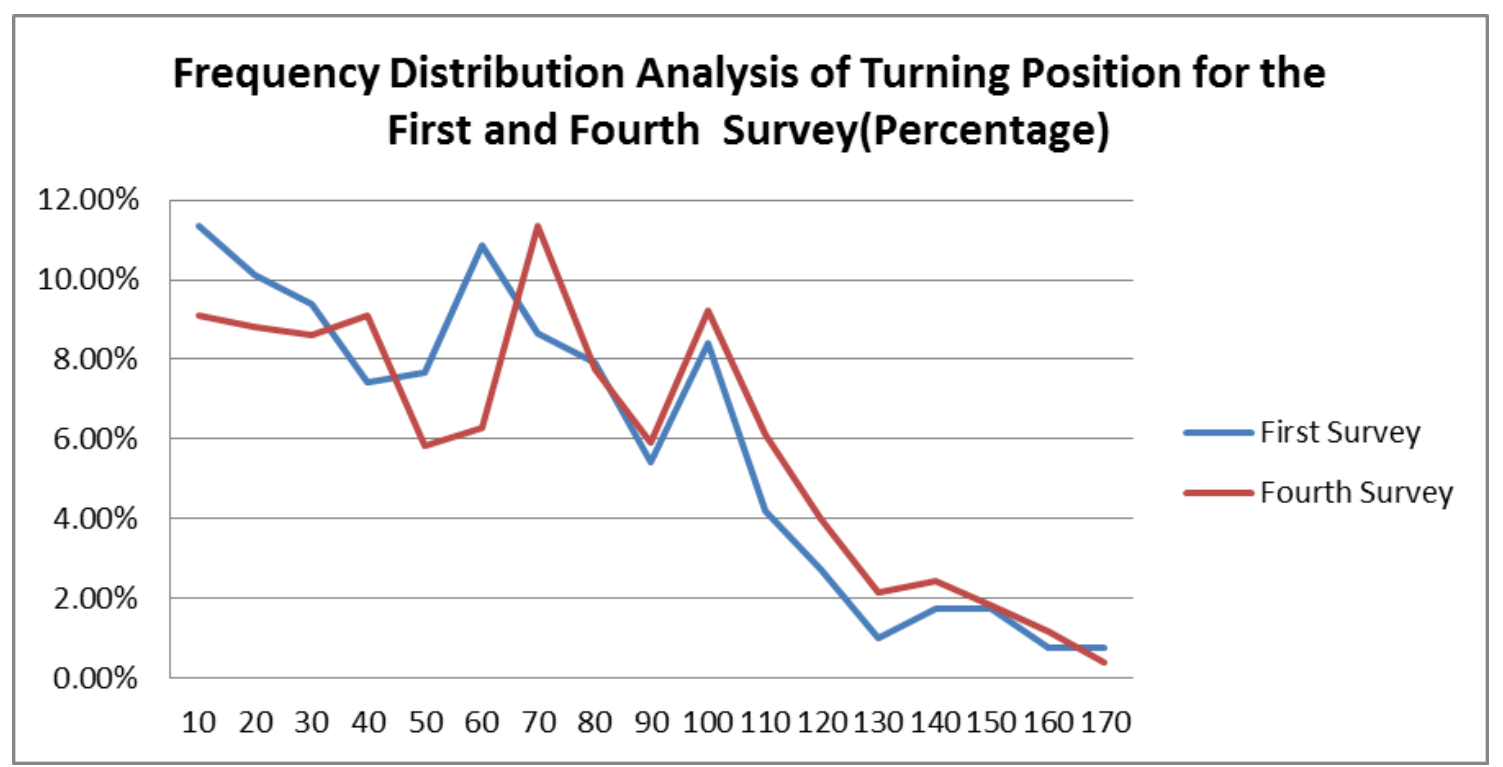

Figure 69: Distribution Analysis of the Turning Position for the First and Four Surveys

\section{(3) Analysis for the Crossing the Virtual Line, Extension line and Trace Line Position}

Even though different names as the virtual line, the extension line and the trace line are used to describe the boundary between the bicycle lane and the traffic lane, the three surveys from the second to the fourth all use the same boundary to describe the position when motor vehicles enter into the researched bicycle lane. The differences are that the virtual line is made up of white spots, the extension line is composed by shot white lines as a kind of formal traffic line, and the trace line is the trace when the extension line was removed. But, different effects come out from Table 32, 33 and 34, and Figure 70. Without the extension line as a formal traffic line, drivers tend to begin their right turn 62 feet 
away from the observed beginning points in the first survey and 67 feet in the fourth survey, and run into the right-of-way of the bicycle lane at the position 142 feet in the second survey and 144 feet in the fourth survey away from the observed beginning point. After the formal traffic line was drawn, which is called the extension line, drivers tend to drive about 10 more feet before they cross the boundary between the bicycle lane and the traffic lane, which is 150 feet away from the beginning point of the oblique line and 30 feet away from the stop bar.

It can be concluded that most drivers tend to run into the right-of-way of the adjacent bicycle lane at the position which is $10-30$ feet away from the stop bar. If the standard arrangement is used, which is shown in Figure 6, more right-turn drivers will conflict with through bicyclists than when the newly-developed countermeasure is put into use. The newly-developed countermeasure can attract about 30-40 percent of drivers running into the right-of-way of the adjacent bicycle lane at the position which is far away from the conflict zone near to the stop bar between bicyclists and drivers. This countermeasure can let bicyclists follow behind right-turning motor vehicles after these motor vehicles merge into the bicycle lane at the position about 70-140 feet away from the stop bar. This will decrease the conflicts between the right-turning motor vehicle and through bicycles and bring a more secure environment for bicyclists.

\section{Table 32}

Statistical Analysis of the Crossing the Line Position for the Second to the Four 
Surveys

\begin{tabular}{|c|c|c|c|}
\hline & Second Survey & Third Survey & $\begin{array}{c}\text { Fourth } \\
\text { Survey }\end{array}$ \\
\hline $\begin{array}{c}\text { Average Crossing the } \\
\text { Boundary (feet) }\end{array}$ & 142 & 151 & 144 \\
\hline Standard Deviation & 26.320 & 22.599 & 30.938 \\
\hline $\begin{array}{c}85 \% \text { Crossing the } \\
\text { Boundary (feet) }\end{array}$ & 160 & 170 & 170 \\
\hline
\end{tabular}

\section{Table 33}

Distribution Analysis of the Crossing the line Position for the Second to the Four Surveys-Percentage

\begin{tabular}{|c|c|c|c|}
\hline $\begin{array}{c}\text { Crossing the } \\
\text { Line(feet) }\end{array}$ & $\begin{array}{c}\text { Second Survey } \\
\text { (Accumulation } \\
\text { Percentage) }\end{array}$ & $\begin{array}{c}\text { Third Survey } \\
\text { (Accumulation } \\
\text { Percentage) }\end{array}$ & $\begin{array}{c}\text { Fourth Survey } \\
\text { (Accumulation } \\
\text { Percentage) }\end{array}$ \\
\hline 10 & $0.10 \%$ & $0.19 \%$ & $0.19 \%$ \\
\hline 20 & $0.21 \%$ & $0.29 \%$ & $0.19 \%$ \\
\hline 30 & $0.31 \%$ & $0.19 \%$ & $0.58 \%$ \\
\hline 40 & $0.52 \%$ & $0.29 \%$ & $0.78 \%$ \\
\hline 50 & $0.52 \%$ & $0.38 \%$ & $0.39 \%$ \\
\hline 60 & $0.73 \%$ & $0.48 \%$ & $1.45 \%$ \\
\hline
\end{tabular}




\begin{tabular}{|c|c|c|c|}
\hline 70 & $1.05 \%$ & $0.86 \%$ & $2.03 \%$ \\
\hline 80 & $1.26 \%$ & $0.19 \%$ & $1.16 p \%$ \\
\hline 90 & $1.47 \%$ & $1.24 \%$ & $1.36 \%$ \\
\hline 100 & $3.87 \%$ & $0.67 \%$ & $3.59 \%$ \\
\hline 110 & $2.20 \%$ & $1.24 \%$ & $2.23 \%$ \\
\hline 120 & $5.13 \%$ & $0.95 \%$ & $2.91 \%$ \\
\hline 130 & $7.75 \%$ & $3.52 \%$ & $9.11 \%$ \\
\hline 140 & $14.14 p \%$ & $9.13 \%$ & $12.98 \%$ \\
\hline 150 & $17.17 \%$ & $22.93 \%$ & $12.50 \%$ \\
\hline 160 & $36.23 \%$ & $39.68 \%$ & $16.09 \%$ \\
\hline 170 & $7.33 \%$ & $17.79 \%$ & $32.46 \%$ \\
\hline
\end{tabular}

\section{Table 34}

Distribution Analysis of the Crossing the line Position for the Second to the Four Surveys- Accumulation Percentage

\begin{tabular}{|c|c|c|c|}
\hline $\begin{array}{c}\text { Crossing the Line } \\
\text { (feet) }\end{array}$ & $\begin{array}{c}\text { Second Survey } \\
\text { (Accumulation } \\
\text { Percentage) }\end{array}$ & $\begin{array}{c}\text { Third Survey } \\
\text { (Accumulation } \\
\text { Percentage) }\end{array}$ & $\begin{array}{c}\text { Fourth Survey } \\
\text { (Accumulation } \\
\text { Percentage) }\end{array}$ \\
\hline
\end{tabular}




\begin{tabular}{|c|c|c|c|}
\hline 10 & $0.10 \%$ & $0.19 \%$ & $0.19 \%$ \\
\hline 20 & $0.31 \%$ & $0.48 \%$ & $0.39 \%$ \\
\hline 30 & $0.63 \%$ & $0.67 \%$ & $0.97 \%$ \\
\hline 40 & $1.15 \%$ & $0.95 \%$ & $1.74 \%$ \\
\hline 50 & $1.68 \%$ & $1.33 \%$ & $2.13 \%$ \\
\hline 60 & $2.41 \%$ & $1.81 \%$ & $3.59 \%$ \\
\hline 70 & $3.46 \%$ & $2.66 \%$ & $5.62 \%$ \\
\hline 80 & $4.71 \%$ & $2.85 \%$ & $6.78 p \%$ \\
\hline 90 & $6.18 \%$ & $4.09 \%$ & $8.14 \%$ \\
\hline 100 & $10.05 \%$ & $4.76 \%$ & $11.72 \%$ \\
\hline 110 & $12.25 \%$ & $5.99 \%$ & $13.95 \%$ \\
\hline 120 & $17.38 \%$ & $6.95 \%$ & $16.86 \%$ \\
\hline 130 & $25.13 \%$ & $10.47 \%$ & $25.97 \%$ \\
\hline 140 & $39.27 \%$ & $19.60 \%$ & $38.95 \%$ \\
\hline 150 & $56.44 \%$ & $42.53 \%$ & $51.45 \%$ \\
\hline 160 & $92.67 \%$ & $82.21 \%$ & $67.54 \%$ \\
\hline
\end{tabular}




\begin{tabular}{|l|l|l|l|}
\hline 170 & $100.00 \%$ & $100.00 \%$ & $100.00 \%$ \\
\hline
\end{tabular}

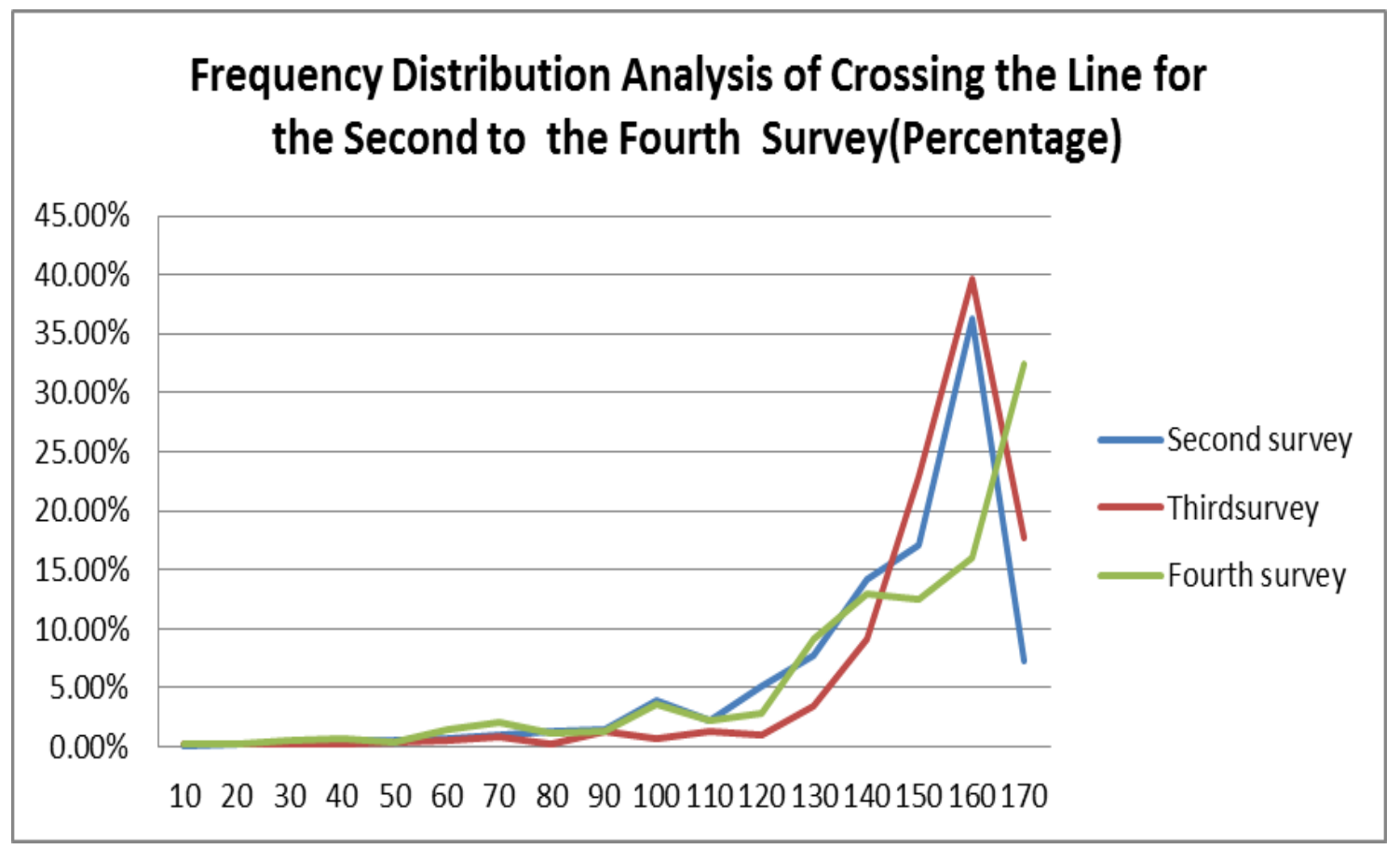

Figure 70: Distribution Analysis of the Crossing the line Position for the Second to the Four Surveys- Percentage

\section{(4) Analysis for the Side Driving Distance of the Fourth Survey}

In this research, side driving distance means the distance between the point where drivers begin right-turn maneuvers to the points where motor vehicles cross the boundary between bicycle lane and traffic lane at the researched intersection. According to the data in Table 26, the average side driving distance is 77 feet, which accounts for 42.78 percent of the whole distance from the beginning point of the oblique line to the stop bar, and the $85 \%$ side driving 
distance is 110 feet, which accounts for 61.11 percent for the same distance. According to the data in Table 34, 12.98 percent of drivers use less than 40 feet for their side driving, which roughly takes about 1-2 seconds if 35 mile/hour and deceleration are used to calculate the side driving time. 46.32 percent of drivers drive 50 to 80 feet to cross the boundary between the bicycle lane and the traffic lane, which roughly takes $2-3$ seconds if 35 mile/hour and deceleration are considered to calculate the side driving time. 36.34 percent of drivers drive 90 to 120 feet to cross the boundary between the bicycle lane and the traffic lane, which roughly takes 3-4 seconds if the same condition of 35 mile/hour is used to calculate the side driving time. Only 4.36 percent of drivers prefer to drive a long distance, which is more than 120 feet along the boundary between the bicycle lane and the traffic lane.

Further analysis for the side driving distance is show in Table 35 and 36 . For drivers who start their right turn maneuvers in the range of $0-40$ feet away from the beginning point of the oblique line, two categories can be used to describe their driving habits. The first category is short side driving distance drivers who prefer to follow the oblique line and quickly enter the right-of-way of the adjacent bicycle lane. About 180 are this kind of driver, which is safe for bicyclists. About another 180 drivers prefer long side driving. They also begin their right-turning maneuvers very early, but prefer driving near to the boundary between the bicycle lane and the traffic lane little by little. They use a long distance and time to enter the right-of-way of the adjacent bicycle lane. If these drivers lose their 
attentions when they enter the right-of-way of the adjacent bicycle lane, crashes between bicycles and motor vehicles will happen. If drivers start their right-turn maneuvers in the range of 0-40 feet away from the beginning point of the oblique line, there are very short distances left for them to make their maneuver. Thus, they have to turn sharply when they cross the boundary between the bicycle lane and the traffic lane near to the stop bar where conflicts between bicycles and motor vehicles usually appear.

\section{Table 35}

Accumulation Percentage Analysis for the Side Driving Distance of the Fourth Survey

\begin{tabular}{|c|c|}
\hline Side Driving Distance (feet) & Percentage \\
\hline $0-40$ & $12.98 \%$ \\
\hline $50-80$ & $46.32 \%$ \\
\hline $90-120$ & $36.34 \%$ \\
\hline $130-180$ & $4.36 \%$ \\
\hline Total & $100.00 \%$ \\
\hline
\end{tabular}

\section{Table 36}

Turing Position Analysis for the Side Driving Distance of the Fourth Survey 


\begin{tabular}{|c|c|c|c|c|}
\hline $\begin{array}{l}\text { Side Driving } \\
\text { Distance }\end{array}$ & $\begin{array}{c}\text { Turning } \\
\text { Position }<=40 \\
\text { feet }\end{array}$ & $\begin{array}{c}40<\text { Turning } \\
\text { Position }<=80 \\
\text { feet }\end{array}$ & $\begin{array}{c}80<\text { Turning } \\
\text { Position }<=12 \\
0 \text { feet }\end{array}$ & $\begin{array}{c}120<\text { Turning } \\
\text { Position }<=18 \\
0 \text { feet }\end{array}$ \\
\hline 0 & 3 & 0 & 0 & 6 \\
\hline 10 & 1 & 0 & 0 & 16 \\
\hline 20 & 6 & 0 & 7 & 19 \\
\hline 30 & 8 & 0 & 10 & 23 \\
\hline 40 & 6 & 2 & 9 & 18 \\
\hline 50 & 20 & 3 & 42 & 0 \\
\hline 60 & 27 & 8 & 82 & 0 \\
\hline 70 & 30 & 45 & 77 & 0 \\
\hline 80 & 34 & 77 & 33 & 0 \\
\hline 90 & 40 & 101 & 0 & 0 \\
\hline 100 & 56 & 64 & 0 & 0 \\
\hline 110 & 55 & 17 & 0 & 0 \\
\hline 120 & 37 & 5 & 0 & 0 \\
\hline 130 & 26 & 0 & 0 & 0 \\
\hline
\end{tabular}




\begin{tabular}{|c|c|c|c|c|}
\hline 140 & 8 & 0 & 0 & 0 \\
\hline 150 & 9 & 0 & 0 & 0 \\
\hline 160 & 2 & 0 & 0 & 0 \\
\hline Total & 368 & 322 & 260 & 82 \\
\hline
\end{tabular}

\section{Summary}

Four surveys were made to study drivers' behavior after a newly-developed countermeasure was put into use. The first survey is the base line of these four surveys, which primarily aims to observe the position where drivers begin their right turn maneuvers and the distance away from the curb when they cross the stop bar. An extension line, which is made by white short lines that are 3 feet long and at 7 feet intervals, was used to change the studied bicycle lane back into a traditional bicycle lane like the bicycle lane shown in Figure 6. The second survey is used to observe where drivers cross the boundary between the bicycle lane and the traffic lane and the distance away from the curb when they cross the stop bar. The third survey is used to observe the position where drivers cross the boundary between the bicycle lane and the traffic lane after a clear formal traffic line is drawn on the boundary. The fourth survey is used to check what will change for the position where drivers cross the boundary after the extension is taken off. The item distance from the curb is also observed. Other items such as 
Using Right Lamp before Turning Right and Using Traffic Signal before Turning Right are also recorded.

After the analysis shown in this chapter, several conclusions can be drawn:

1) Turning-right is one of three highest possibility pre-crash maneuvers in all bicycle-related crashes in Louisville.

2) The motorists are often inattentive, or are failing to yield the right-of-way to bicyclists when bicycle-related crashes happened

3) Bicyclists are also often inattentive, or are failing to yield the right-of-way to motor vehicles when they were hit by other vehicles.

4) The newly-developed countermeasure for bicyclists' safety can't influence the distance from the curb where motor vehicle cross the stop bar. Most drivers prefer 4-6 feet away from the curb when they cross the stop bar.

5) The newly-developed countermeasure for bicyclists' safety can attract about 40 percent of drivers to cross the boundary between the bicycle lane and the traffic lane and enter into the right-of-way of the bicycle lane, which can improve bicyclists' safety.

6) More than 50 percent of drivers need $60-100$ feet to finish the process of entering into the right-of-way of the bicycle lane from the adjacent traffic lane. 


\title{
CHAPTER VII
}

\section{CONCLUSIONS AND RECOMMENDATIONS}

\begin{abstract}
A. Conclusions
According to the research shown above, several conclusions can be drawn:

- Bicycling is a low-cost and practical alternative to motor vehicles, which can bring significant benefits for our communities. Bicycling is the most efficient and accessible form of transportation for those who cannot use other modes of transportation. Bicycling can greatly improve people's health and help decrease obesity rate in the U.S. Bicycling can help control air pollution and ease traffic congestion.
\end{abstract}

- A number of states, regions and local governments have made plans to encourage people to use bicycles as an alternative to motor vehicles.

- The Louisville Metro Bike Master Plan is a long-term action plan to help Louisville reclaim its heritage as a center for bicycling. This plan aims to increase bicycling activity throughout all parts of Louisville by making it a fun, comfortable and accessible mode of travel, and to simultaneously reduce the number of cyclists killed and injured in crashes with motor vehicles.

- Many studies have been done to research the reasons which cause 
crashes between bicyclists and drivers. A large percentage of bicyclistsrelated crashes happen at intersections.

- The most important reason for bicyclists- related crashes is drivers fail to yield when they enter turning movements.

- The federal government has made many laws and regulations, and design standards to help develop bicycle facilities (e.g., Guide to Promoting Bicycling on Federal Lands, Guide for the Development of Bicycle Facilities, and The Manual on Uniform Traffic Control Devices (MUTCD)). Traffic Safety Facts published by the National Highway Traffic Safety Administration every year provides important information for understanding bicyclists-related crashes.

- State and local governments have made numerous studies and reports to determine the specific characteristics of bicyclists-related crashes. These studies determined that the characteristics of bicyclists-related crashes had slight differences from the Traffic Safety Facts of the National Highway Traffic Safety Administration.

- Many solutions have been used to improve safety for bicyclists, such as Colored Bicycle Lane Markings, Colored Bicycle Crossings, and Bike Boxes. Many of them have been used successfully in Europe. Studies also have been made to evaluate the effects of those solutions in the U.S. However, a lot of work is needed to evaluate the effects of those solutions in specific states or communities.

- In order to determine the characteristics of bicyclists-related crashes in 
Louisville, crash data of 10 years (from 2003 to 2012) was collected from the Kentucky Collision Analysis for the Public. Bicycle-related crashes in Louisville are most prevalent in the summer months, on weekdays and in the afternoon peak period in clear weather conditions. Turning-right is one of three highest possibility pre-crash maneuvers in all bicycle-related crashes in Louisville. The most important factor causing bicyclists-related crashes is motorists' inattentiveness, or failing to yield the right-of-way to bicyclists. Bicyclists' inattentiveness or failing to yield the right-of-way is also important for bicyclists-related crashes.

- Surveys were made four times to evaluate the effect of a newly-developed countermeasure for bicyclists' safety. This countermeasure for bicyclists' safety can't influence the distance from the curb where motor vehicle cross the stop bar. Most drivers prefer 4-6 feet away from the curb when they cross the stop bar. This countermeasure for bicyclists' safety can attract about 40 percent of drivers to cross the boundary between the bicycle lane and the traffic lane and enter into the right-of-way of the bicycle lane. More than 50 percent of drivers need 60-100 feet to finish the process of entering into the right-of-way of the bicycle lane from the adjacent traffic lane.

\section{B. Recommendations}

According to the research and conclusions shown above, several 
recommendations are provided:

(1) More specific data should be collected for further study. For example, 51.7 percent of bicyclists' conditions and 54.1 percent of drivers' condition are "non-detected" in Table 14 and Table 15 respectively. 44.6 percent of manner of collision of bicyclist-related crashes are "unknown". The largest manner of collision is "Angle". There is no further information for how bicycles and motor vehicles collide with each other. The database provided by Kentucky State Police just recorded the drivers' pre-crash maneuver and didn't record bicyclists' pre-crash maneuver.

(2) The most significant reason which causes bicyclist-related crashes is inattentiveness and falling to yield right-of-way. Improvements can make the countermeasure more effective, such as use of high contrast colored line and installation of signs denoting the oblique line.

(3) The striped oblique line can also be improved, such as changing the position and length, or changing the angle between this line and the adjacent curb. By doing these improvements, more drivers will be attracted to cross the boundary between the bicycle lane and the adjacent traffic lane earlier than their old driving habits. 


\section{REFFERENCE}

Allen, D., S. Bygrave et al. (2005). Behavior at Cycle Advanced Stop Lines. London, Transport for London: 97

Kim JK, Kim S, Ulfarsson GF, Porrello LA. (2007). Bicyclist Injury Severities in Bicycle-Motor Vehicle Accidents. Accident Analysis\& Prevention, volume 39, Pages 238-251.

California Department of Transportation.(2011). Strategies for Reducing Pedestrian and Bicyclist Injury at the Corridor Level

Carter, D. L., W. W. Hunter, et al. (2006). Pedestrian and Bicyclist Intersection Safety Indices: Final Report. Chapel Hill, N.C., Pedestrian and Bicycle Information Center: 88.

Chao, P., J. S. Matthias, et al. (1978). Bicyclist Behavior at Intersections. Transportation Research Record 683

City of Portland Office of Transportation. (1999). Portland's Blue Bike Lanes: Improved Safety through Enhanced Visibility. Portland, City of Portland

Colorado Department of Transportation. (2007). Analysis of Bicycle-Related and Pedestrian-Related Roadway Crashes, http://www.coloradodot.info 
Cumming, A. (2001). A framework for bicycles at intersections. Safe Cycling, Conference 2000. Brisbane, Queensland, Australia, Queensland, Department of Transportation, State Cycle Unit

Federal Highway Administration the U.S. Department of Transportation, U.S. (2008). Guide to Promoting Bicycling on Federal Lands. FHWA-CFL/TD08-007

Federal Highway Administration of U.S. Department of Transportation. (2012). Manual on Uniform Traffic Control Devices 2009 Revisions

Federal Highway Administration the U.S. Department of Transportation. (1996). Pedestrian and Bicycle Crash Types of the Early 1990s. FHWA-RD-95163

Federal Highway Administration of the U.S. Department of Transportation. (2004). Signalized Intersections: Informational Guide, FHWA-HRT-04-091, Page45

Fernandez de Cieza et al.. A.O. Fernandez de Cieza, J.C. Ortiz Andino, A.R. Archilla, A.M. Gomez, C.G. Gonzalez, S. Mengual, J. Morrall. (1999) Nonmotorized traffic accidents in San Juan, Argentina,Transport, Pages: $19-22$

Garder, P. (1994). Bicycle Accidents in Maine: an Analysis. Transportation Research Board, Pages. 34-41 
Garder P, Leden L, Thedéen T., (1994). Safety Implications of Bicycle Paths at Signalized Intersections. Accid, Anal. Prev, 26 (4), Pages. 429-439

Godefrooij, T. (1997). Segregation or Integration for Bicyclists? The Dutch Approach, The Greening of Urban Transport. R. Tolley. Chichester, England, Wiley: 229

Hunter, W. H. (2000). Evaluation of Innovative Bike-box Application in Eugene, Oregon, Transportation Research Record 1705

Jensen, S. U. (2007). Safety Effects of Blue Cycle Crossings: a before-after Study, Accident Analysis \& Prevention.

Korve, M. J. and D. A. Niemeier, (2002). Benefit-cost Analysis of Added Bicycle Phase at Existing Signalized Intersection, Journal of Transportation Engineering-Asce 128(1): 40-48

Louisville Metro Bike Master Plan Appendix D- Cash Data. (2010). http://www.louisvilleky.gov

Lynn Weigand (2008). Intersection Treatments to Improve Bicycle Access and Safety, Portland State University, Center for Urban Studies, CUS-CTS08-02

Matthew Zoll (2007). Advantages of Bike Lanes, Tucson-Pima County Bicycle Advisory Committee 
Metropolitan Transportation Commission-Planning. (2011). Financing and Coordinating Transportation for the Nice-county San Francisco Bay Area, Bicycles/Pedestrians Safety Toolbox: Engineering, http://www.mtc.ca.gov

Michigan Department of Transportation (2012). Sharing the Road: Optimizing Pedestrian and Bicycle Safety and Vehicle Mobility

National Highway Traffic Safety Administration of the U.S. (2010). Traffic Safety Facts 2010, http://www-nrd.nhtsa.dot.gov/Pubs/811624.pdf)

Opiela, K. S., S. Khasnabis, et al. (1980). Determination of the Characteristics of Bicycle Traffic at Urban Intersections, Transportation Research Record 743

Oregon Department of Transportation. (1992). Oregon transportation plan. Oregon Department of Transportation

D.F. Preusser, W.A. Leaf, K.B. DeBartolo, R.D. Blomberg, M.M. Levy, (1982). The Effect of Right-turn-on-red on Pedestrian and Bicyclist Accidents, J. Saf. Res., 13 (2) (1982), Pages. 44-55

Public Works Department, City of Minneapolis, (2013). Understanding BicyclistMotorist Crashes in Minneapolis, Minnesota: A comprehensive look at crash data from 2000-2010 and solutions for improved bicyclist safety 
Pucher, J., C. Komanoff, et al. (1999). Bicycling Renaissance in North America? Recent Trends and Alternative Policies to Promote Bicycling, Transportation Research Part A: Policy and Practice 33: 625-654

Seattle Department of Transportation, (2013). Bicycle Program: Bike Boxes, http://www.seattle.gov

Stutts, J. C., W. W. Hunter, et al. (1997). Pedestrian-vehicle Crash Types: an Update, Transportation Research Record 1538

R.G. Thom, A.M. Clayton (1992). Low-cost Opportunities for Making Cities Bicycle-friendly Based on a Case Study Analysis of Bicyclist Behavior and Accidents, Transport. Res. Rec., 1372, Pages. 90-101

Twisk, Divera A M van Nes, Nicole, (2012). Understanding Right-Turn Car-Cycle Conflicts at Intersections: Findings from Site-Based and In-Car Observations, Transportation Research Board, ISSN: 0738-6826

Wachtel, A., J. Forester, et al. (1995). Signal Clearance Timing for Bicyclists, Institute of Transportation Engineers Journal 65(3): 38

Wachtel, A. and D. Lewiston. (1994). Risk Factors for Bicycle-Motor Vehicle Collisions at Intersections, Institute of Transportation Engineers Journal 64(9): $30-35$

Wall, G. T., D. G. Davies, et al. (2003). Capacity Implications of Advanced Stop Lines for Bicyclists, London, Transport for London: 48 
Wang, Y. H. and N. L. Nihan (2004). Estimating the Risk of Collisions between Bicycles and Motor Vehicles at Signalized Intersections, Accident Analysis and Prevention 36(3): 313-321

Wheeler, A. (1995). Advanced Stop-lines for Bicyclists-a Simplified Layout, Traffic Engineering and Control 36(5): 283-289

Wolfe, M., J. Fischer, et al. (2006). Bike Scramble Signal at North Interstate and Oregon. Portland, Portland State University

Yinhai Wang and Nancy L. Nihan. (2004). Estimating the Risk of Collisions between Bicycles and Motor Vehicles at Signalized Intersections, Accident Analysis \& Prevention, Volume 36, Issue3, Pages 313-321 


\section{CURRICULUM VITAE}

NAME:

YING ZHANG

PERMANENT ADDRESS: 1805 \#18 Building, Xinjiekouwai St, Xicheng District, Beijing, China (zip code:100082)

CURRENT ADDRESS: $\quad 1703 \mathrm{~S} 4^{\text {th }}$ St apt 05

Louisville, Kentucky, 40208

DOB: $\quad$ March, 09, 1980

EDUCATION \& TRAINING: B.S., Civil Engineering

Beijing Jiaotong University, Beijing, China 1999-2003

M.S. Transportation Planning

Research Institute of Highway, Beijing, China 2004-2007

Ph.D., Civil \& Environmental Engineering

University of Louisville, Kentucky

2010-2013

PROFESSIONAL SOCIETIES: Research Institute of Highway, Beijing, China 2007-2009 